\title{
Conceptualization and Simulation of Runoff Generation from Rainfall for Three Basins in Thurston County, Washington
}

By S. N. Berris

U.S. GEOLOGICAL SURVEY

Water-Resources Investigations Report 94-4038

Prepared in cooperation with

THURSTON COUNTY DEPARTMENT

OF PUBLIC WORKS

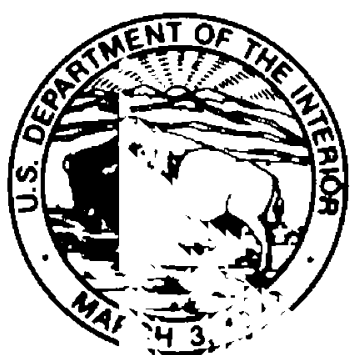




\section{CONTENTS}

Abstract-----1---1

Introduction --

Purpose and scope--

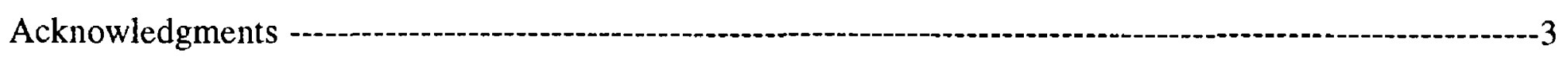

Description of the study area --..-

Conceptual model ---

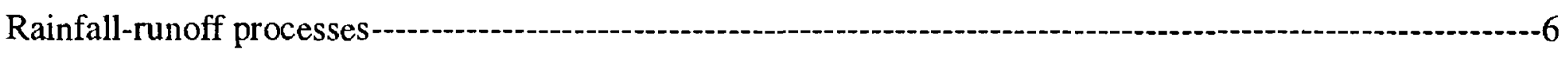

Hortonian overland flow -

Saturation overland flow --

Shallow subsurface flow - -..-.

Ground-water flow --

Conceptual features of runoff generation in the study basins -....... 9

Simulation of runoff generation ---

Description of the computer program - 10

Construction of the simulation models - - 15

Land-segment types--- 15

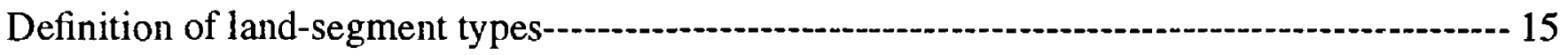

Process-related parameters--.-- 19

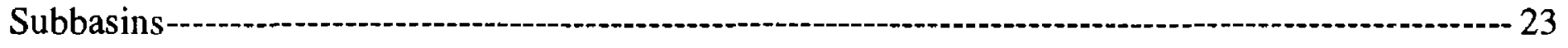

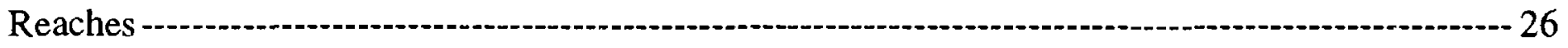

Calibration and evaluation of the simulation models-- 27

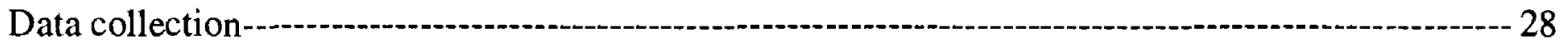

Sources of differences between observed and simulated streamflow

First calibration and evaluation -- 31

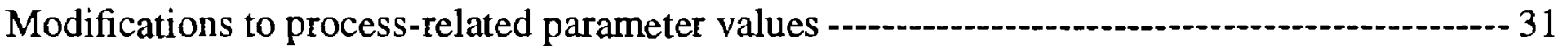

Modifications to subbasins-- 33

Modifications to reaches --- 35

Calibration and evaluation results-- 35

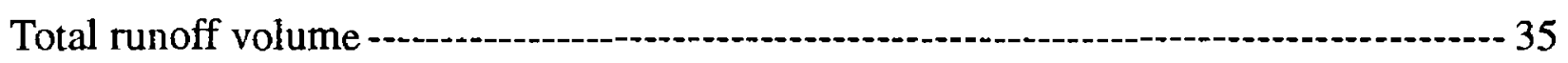

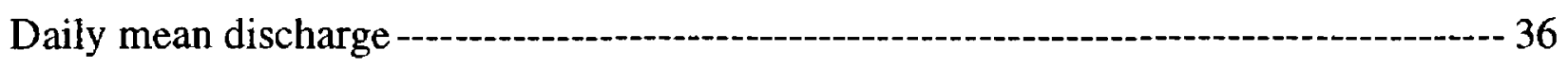

Storm runoff and peak discharge--.--..-.-.-- 36

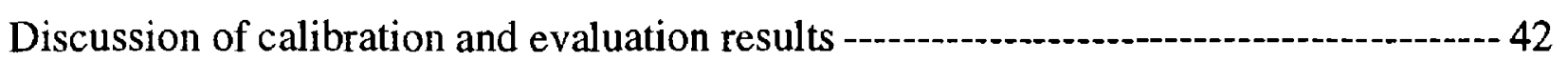

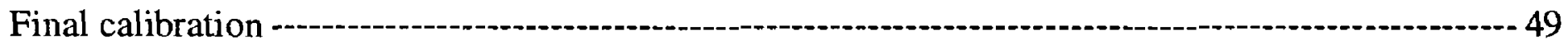

Modifications to process-related parameter values -

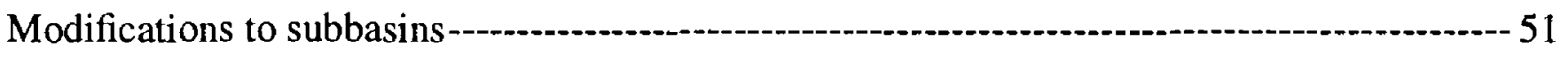

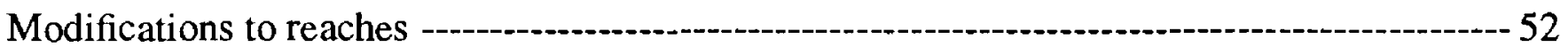

Ground-water controller-a-n- 53

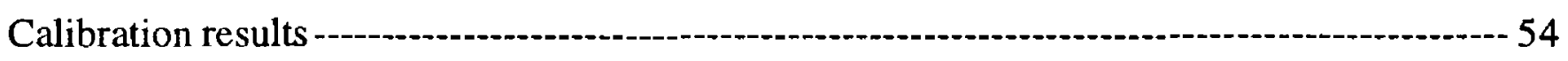

Yearly and seasonal runoff--

Daily mean discharge - -

Storm runoff and peak discharge --- 54

Discussion of calibration results -

Summary -

References cited -- 71 


\section{ILLUSTRATIONS}

1. Map showing location of the study area and basins used for model calibration and evaluation-------.-.---4 2-3. Schematic diagrams showing:

2. Fluxes and storages related to the rainfall-runoff process-- 6

3. Hydrological Simulation Program-FORTRAN flowchart for (a) impervious and (b) pervious land segments --..-.-.- 14

4-8. Maps showing:

4. Distribution of soil-type land segments for Percival Creek, Woodard Creek, and

Woodland Creek Basins-- 17

5. Subbasins in the Percival Creek Basin used in the final simulation model -..................................

6. Subbasins in the Woodard and Woodland Creek Basins used in the final simulation models-.---.-.-.- 25

7. Data-collection network for Woodard and Woodland Creek Basins-a- 29

8. Data-collection network for Percival Creek Basin - 30

9-13. Hydrographs showing observed and simulated daily mean discharges from the first-year calibrated model applied to the period March 1, 1988, through March 15, 1990, for:

9. Station 12078720 in the Percival Creek Basin-- 37

10. Station 12078730 in the Percival Creek Basin--...- 37

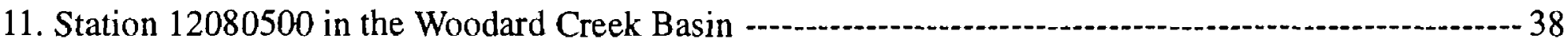

12. Station 12080670 in the Woodland Creek Basin - 38

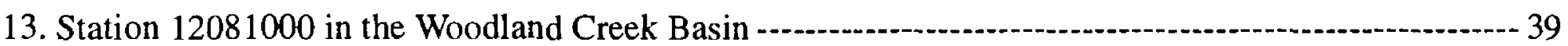

14-23. Hydrographs showing observed and simulated hourly mean discharges from the first-year calibrated model for:

14. Station 12078720 in the Percival Creek Basin, for the storm period December 15, 1988, through January 31, 1989 --...- 43

15. Station 12078720 in the Percival Creek Basin, for the storm period January 5 through $15,1990 \ldots \ldots$..... 43

16. Station 12078730 in the Percival Creek Basin, for the storm period March 15, 1988, through April 15, 1988 --..-.-.- 44

17. Station 12078730 in the Percival Creek Basin, for the storm period January 15, 1990, through February 28, 1990 -...- 44

18. Station 12080500 in the Woodard Creek Basin, for the storm period December 15, 1988, through January $31,1989-$

19. Station 12080500 in the Woodard Creek Basin, for the storm period January 5 through 15, 1990 ---- 45

20. Station 12080670 in the Woodland Creek Basin, for the storm period April 1 through 10, 1988 --.-.-- 46

21. Station 12080670 in the Woodland Creek Basin, for the storm period March 1, 1989, through April 30, 1989 -...-..-.- 46

22. Station 12081000 in the Woodland Creek Basin, for the storm period December 15, 1988, through January 31, 1989 --.-- 47

23. Station 12081000 in the Woodland Creek Basin, for the storm period January 5 through 15,1990 ---- 47

24-28. Hydrographs showing observed and simulated daily mean discharges from the final calibrated model applied to the period March 1, 1988, through March 15, 1990, for:

24. Station 12078720 in the Percival Creek Basin- 59

25. Station 12078730 in the Percival Creek Basin-........- 59

26. Station 12080500 in the Woodard Creek Basin - 60

27. Station 12080670 in the Woodland Creek Basin - 60

28. Station 12081000 in the Woodland Creek Basin - 


\section{ILLUSTRATIONS--Continued}

29-38. Hydrographs showing observed and simulated hourly mean discharges from the final calibrated model for:

29. Station 12078720 in the Percival Creek Basin, for the storm period December 15, 1988, through January 31, 1989

30. Station 12078720 in the Percival Creek Basin, for the storm period January 5 through 15,1991 - ----- 63

31. Station 12078730 in the Percival Creek Basin, for the storm period December 15, 1988, through January 31, 1989 -...- 64

32. Station 12078730 in the Percival Creek Basin, for the storm period January 5 through 15,199 ) ------ 64

33. Station 12080500 in the Woodard Creek Basin, for the storm period December 15, 1988, through January 31, 1989 -.-- 65

34. Station 12080500 in the Woodard Creek Basin, for the storm period January 5 through 15,1990 ---- 65

35. Station 12080670 in the Woodland Creek Basin, for the storm period April 1 through 10, $198 \varepsilon$---.-- 66

36. Station 12080670 in the Woodland Creek Basin, for the storm period March 1, 1989, through April 30, 1989 -.-...-...- 66

37. Station 12081000 in the Woodland Creek Basin, for the storm period December 15, 1988, through January 31, 1989 - 67

38. Station 12081000 in the Woodland Creek Basin, for the storm period January 5 through 15,1090 --- 67

39-41. Schematic diagrams of the hydraulic linkages between subbasins and stream reaches for the final calibrated model for:

39. Percival Creek Basin -.-.....- 73

40. Woodard Creek Basin - 74

41. Woodland Creek Basin-

\section{TABLES}

1. Definitions of process-related parameters used in the study basins in Thurston County, Washington ----- 13

2. Soil series, and the land-segment soil type that represents each soil series in the calibrated rainfall-runoff models --.-- 16

3. Estimated impervious area and effective impervious area for impervious land cover classes represented in the Woodlard Creek, Woodard Creek, and Percival Creek models --.-.-.-.--- 20

4. Designations and characteristics of land-segment types for pervious areas -

5. Areal extent of the land-segment types found in the three study basins and used for model calibration --- 21

6. Initial subbasins (delineated prior to calibration) that were subdivided into new subbasins during first and final calibrations --.-.-.-.- 33

7. Observed and simulated runoff data for the first-year calibrated models during the calibration and evaluation periods -.-.-.-.--on

8. Measures of difference between simulated and observed daily mean discharges of Woodland Creek, Woodard Creek, and Percival Creek for the first-year calibrated models during the calibration period March 1, 1988, through March 29, 1989

9. Measures of difference between simulated and observed daily mean discharges of Woodland Creek, Woodard Creek, and Percival Creek for the first-year calibrated models during the evaluation period March 30, 1989, through March 15, 1990

10. Observed and simulated storm runoff and peak discharge data of Woodland Creek, Woodard Creek, and Percival Creek for the first-year calibrated models 


\section{TABLES--Continued}

11. Process-related parameters used for pervious and impervious land-segment types in the final calibrated models

12. Observed and simulated yearly and seasonal runoff data of Woodland Creek, Woodard Creek, and Percival Creek for the final calibrated models during the calibration period March 1, 1988, through March 15, 1990

13. Observed and simulated yearly and seasonal runoff data of Woodland Creek, Woodard Creek, and Percival Creek for the first-year calibrated models during the period March 1, 1988, through March 15, 1990

14. Measures of difference between simulated and observed daily mean discharges of Woodland Criek, Woodard Creek, and Percival Creek for the final calibrated models during the calibration period March 1, 1988, through March 15, 1990

15. Measures of difference between simulated and observed daily mean discharges of Woodland Creek, Woodard Creek, and Percival Creek for the first-year calibrated models during the period March 1, 1988, through March 15, 1990

16. Observed and simulated storm runoff and peak discharge data of Woodland Creek, Woodard Creek, and Percival Creek for the final calibrated models

17. Input sequence of the Percival Creek model used to run Hydrological Simulation Program-FORTRAN (HSPF)

18. Input sequence of the Woodard Creek model used to run Hydrological Simulation Program-FORTRAN (HSPF) $-97$

19. Input sequence of the Woodland Creek model used to run Hydrological Simulation

Program-FORTRAN (HSPF) 111

\section{CONVERSION FACTORS}

\begin{tabular}{rcl} 
Multiply & By & To obtain \\
\hline inch (in.) & 25.4 & millimeter \\
foot (ft) & 0.3048 & meter \\
mile (mi) & 1.609 & kilometer \\
acre & $4,047$. & square meter \\
square ${\text { mile }\left(\mathrm{mi}^{2}\right)}^{3}$ & 2.590 & cubic milometer \\
cubic foot per second $\left(\mathrm{ft}^{3} / \mathrm{s}\right)$ & 0.028317 & degree Celsius \\
& & \\
degree Fahrenheit $\left({ }^{\circ} \mathrm{F}\right)$ & ${ }^{\circ} \mathrm{C}=5 / 9 \times\left({ }^{\circ} \mathrm{F}-32\right)$ &
\end{tabular}




\title{
Conceptualization and Simulation of Runoff Generation from Rainfall for Three Basins in Thurston County, Washington
}

\author{
By S. N. Berris
}

\begin{abstract}
A study was conducted to conceptualize and simulate the generation of runoff from rainfall in three drainage basins in north-central Thurston County, located at the southern end of the Puget Sound Lowland of western Washington. The drainage basins in the area are complex because the basin properties (such as geology, soils, topography, land covers, and climate) that influence the characteristics of runoff vary from one part of the area to another. The study basins--Percival Creek, Woodard Creek, and Woodland Creek--face urban development that will also affect the characteristics of runoff. A conceptual model was derived to link the physical properties of the three basins to the drainage mechanisms and hydrologic processes that govern runoff generation. The conceptual model provided a qualitative framework for quantifying the generation of runoff in numerical simulation models, called basin models, constructed for each of the study basins. Hydrological Simulation Program-FORTRAN (HSPF) was the hydrologic-simulation program used to construct the basin models. Streamflow data collected at five streamflow-gaging stations over a 2-year period from March 1988 to March 1990 were used for model calibration.
\end{abstract}

The study, conducted in cooperation between the U.S. Geological Survey and the Thurston County Department of Public Works, found that the conceptual model of runoff generation adequately described runoff generation in the three study basins. The seven features included in the conceptual model differentiated the drainage mechanisms of runoff in undisturbed and disturbed areas of the study basins. The main runoff mechanisms of undisturbed areas were identified as shallow subsurfac: flow from hillslopes mantled with glacial till, bedrock, and, to a lesser degree, lacustrine deposits; as ground-wat 2 flow from glacial-outwash deposits; and as saturation overland flow from depressions, stream bottoms, and flat upland areas underlain by glacial till or, less so, lacustrine deposits. Hortonian overland flow was not an important mechanism in undisturbed areas. In disturbed impervious areas, however, Hortonian overland flow was the dominant mechanism. In disturbed pervious areas, Hortonian overland flow also was an important mechanism in combination with some of the other mechanisms. Surface detention and retention storage, interception, and plant transpiration were less characteristic of disturbed areas than of undisturbed areas.

The conceptual model was tested by incorporating its features into basin models built with Hydrological Simlation Program-FORTRAN (HSPF). The simulation results from the basin models generally confirmed the study's conceptual model. Absolute differences botween simulated and observed total runoff volumes fcr the entire calibration period were less than 6 percent; differences for each single water year were less than 8 pe-cent. Seasonal runoff differences also were generally modest. Absolute differences for winter and spring runoff were less than 8 percent for the entire calibration period. Although absolute differences for summer runoffs were as much as 100 percent, the large percentages represented only a small actual difference in the total volume of runoff. The simulations produced mean absolute differences of daily mean discharges equal to or less than 32 percent. However, these differences exceeded an average 25 percent at only one of five stations. Large daily mean dis harges were 
generally the most accurately simulated; mean absolute differences were less than 15 percent. Absolute differences for storm runoff volumes and peak discharges were less than 32 percent and 33 percent, respectively.

In addition to confirming the conceptual model of runoff generation, the simulations for this study showed that the values of most HSPF land-segment parameters obtained from a previous study of other Puget Sound basins also applied to the Thurston County study basins. The exception was the value for the parameter KVARY, which governs ground-water discharge rates in the simulation models. Parts of the study area are underlain by aquifers that responded differently to rainfall than did the aquifers underlying the areas in the earlier study that first determined the parameter value. The value for this parameter will likely vary elsewhere in the Puget Sound Lowland.

It was also found that the conceptual model of runoff generation did not adequately describe the flow paths from land segments to streams. The study showed that both the flow paths between land segments and streams and the hydraulic characteristics of streams varied throughout the study basins.

\section{INTRODUCTION}

Rural, undeveloped land in north-central Thurston County, Wash., faces development into urban and suburban communities that will change the hydrology of the County's drainage basins. Development will cover pervious areas with such impervious surfaces as pavement and buildings, and the added impervious area will decrease the infiltration of rainfall into the soil and ground-water system and increase the flow of water over the ground directly to streams. Additionally, the added impervious surfaces allow more rapid drainage because of reduced depression storage and surface roughness. Runoff will increase, and the increase will not be limited to the immediate area of the development but will extend downslope and downstream. The increased runoff may result in increased soil erosion, increased flood magnitudes and frequencies, and increased degradation of fish habitat.

Adverse changes in runoff can be mitigated by limiting the rate and volume of runoff after development to those existing before development. Such planning requires the determination of what runoff rates and volumes are before development and what they will be afterwards. Streamflow records can help determine predevelopment runoff, although they often are not sufficiently long enough for that task. Post-development runoff, however, can be determined only by use of some type of predictive method. Runoff rates and volumes before and after development can be estimated by a h/drologicsimulation program.

A hydrologic-simulation program can represent how basin properties affect the hydrologic processes involved in generating runoff from rainfall. Such basin properties that affect runoff include basin area, geology, soils, topography, vegetation, land cover, and climate. The hydrologic processes involved in runoff generat on include evapotranspiration, interception, infiltration, percolation, and flow of water over the land and laterally through the earth. Once calibrated, hydrologic-simulation programs can simulate runoff characteristics resulting from future development in a basin by adjusting parameter values that represent land cover and vegetation properties in that basin. Thus, these programs are helpful tc assess how alternative urban-development plans may change runoff characteristics.

A sensible strategy for constructing a hydrologicsimulation program is (1) to qualitatively describe the hydrologic processes that generate runoff from rainfall in a conceptual model and (2) to quantitatively describe the hydrologic processes conceptualized to generate runoff in a numerical model. The conceptual and nimerical models can be evaluated by comparing model-simulated runoff values with observed runoff data. If the numerical model adequately simulates runoff, then it can se've as a useful tool for predicting changes in runoff resulting from changes in basin properties, such as from urban development.

The drainage basins in north-central Thurston County are complex because basin properties vary dramatically from one part of the area to another. Therefore, alternative urban-development plans cannot be examined using simple, empirical runoff relations. To conceptualize and simulate runoff generation in three complex Thurston County drainage basins--Percival Creek, Woodard Creek, and Woodland Creek--the U.S. Geologica' Survey entered into a cooperative agreement with the Thrrston County Department of Public Works, the agency responsible for mitigating adverse changes in runoff that may come from development.

The program chosen for this study was the Hydrological Simulation Program-FORTRAN (HSPF; U.S. Environmental Protection Agency, 1984), on which basin models would be constructed. HSPF can represent the pertinent basin properties, such as soils, sirface cover, and 
topography, that affect the movement and storage of water in the basins. HSPF also simulates hydrologic processes (evapotranspiration, interception, infiltration, percolation, and flow of water over the land and laterally through the earth) by allocating and distributing water to drainage pathways and storage reservoirs according to values of specified parameters. When HSPF-based basin models accurately simulate hydrologic processes, the streamflows simulated by those models match actual streamflows. This study compared simulated streamflow values with streamflow data collected at gaging stations in order to assess how accurately the basin models simulated runoff generation processes.

A previous study conceptualized and simulated the influence of soils, surface cover, and topography on runoff generation in headwater basins in King and Snohomish Counties, about 60 miles northeast of Thurston County (Dinicola, 1990). Because the King and Snohomish County basins and the Thurston County basins have similar soils, surface cover, and topography, the conceptual model formulated for the Thurston County basins incorporated the conceptual model formulated for the King and Snohomish County basins. Thurston County, however, does have large areas covered by soils that are not common in the King and Snohomish County basins. Therefore, parts of the previous study's conceptual model have been modified in this study to accommodate the differences in soils, and these modifications have been incorporated into the simulation of runoff generation in the Thurston County basins.

\section{Purpose and Scope}

This report (1) describes a qualitative conceptual model of how runoff is generated in three Thurston County basins, (2) explains the construction of numerical models that were based on the conceptual model and parameter values formulated for other Puget Sound basins and that were designed to simulate runoff generation in the Thurston County basins, (3) presents both the calibration strategy used in model development and the statistical measures of the final model accuracy, and (4) discusses the significant results regarding the adequacy of the models in describing runoff generation and the inadequacy of the models in describing flow paths from land segments to streams.

The conceptual model of the study basins provides a qualitative framework for quantifying how basin properties govern the movement and storage of water and thereby influence runoff generation. This report explains how the conceptual model was transformed into numerical models (simulation models) constructed with HSPF; how the conceptual model guided assignment of numerical values to HSPF parameters; and how the simulation models were calibrated to simulate runoff in the Percival Creek, Woodard Creek, and Woodland Creek Basins.

Data to operate and calibrate the simulation models were collected between March 1988 and March 1990. Rainfall data (15-minute time step) and potential evapotranspiration (PET) values (daily time step) were used as input time series for operating the models. Stream discharge data (15-minute time step) were compared with simulated streamflow values during model calibration.

\section{Acknowledgments}

Personnel from the Storm and Surface Water Utility and the Thurston Geographical Information Facility of the Thurston County Department of Public Works and from the Environmental Health Division of the Thurston County Health Department have assisted with the design, data collection, and mapping involved in this study. Several Thurston County citizens have allowed gage installations on their property and have recorded data for the study. Their cooperation and assistance is appreciated.

\section{DESCRIPTION OF THE STUDY AREA}

The three study basins lie in north-central Thurston County, in western Washington at the southern end of the Puget Sound Lowland (fig. 1). The Lowland trends north and south between the Cascade Range to the east and the Olympic Mountains to the west, and it is partly occupied by the waters of Puget Sound. This broad, rolling glacialdrift plain has undergone several episodes of glacial deposition. Its surface layers were formed by erosion and deposition during the last glaciation period about 15,000 years ago (Noble and Wallace, 1966) and by the large prehistoric meltwater Lake Russell. The southern limit of glaciation extends slightly south of the study area. Along the southwestern edge of the study area, bedrock ridges of basalt and sandstone known as the Black Hills protrude above the drift plain.

The three study basins cover a total of 40 square miles: Percival Creek, 8 square miles; Woodland Creek, 26 square miles; and Woodard Creek, 6 square miles. All are situated on the drift plain, except for the southwestern edge of the Percival Creek Basin, which extends into the bedrock of the Black Hills. 


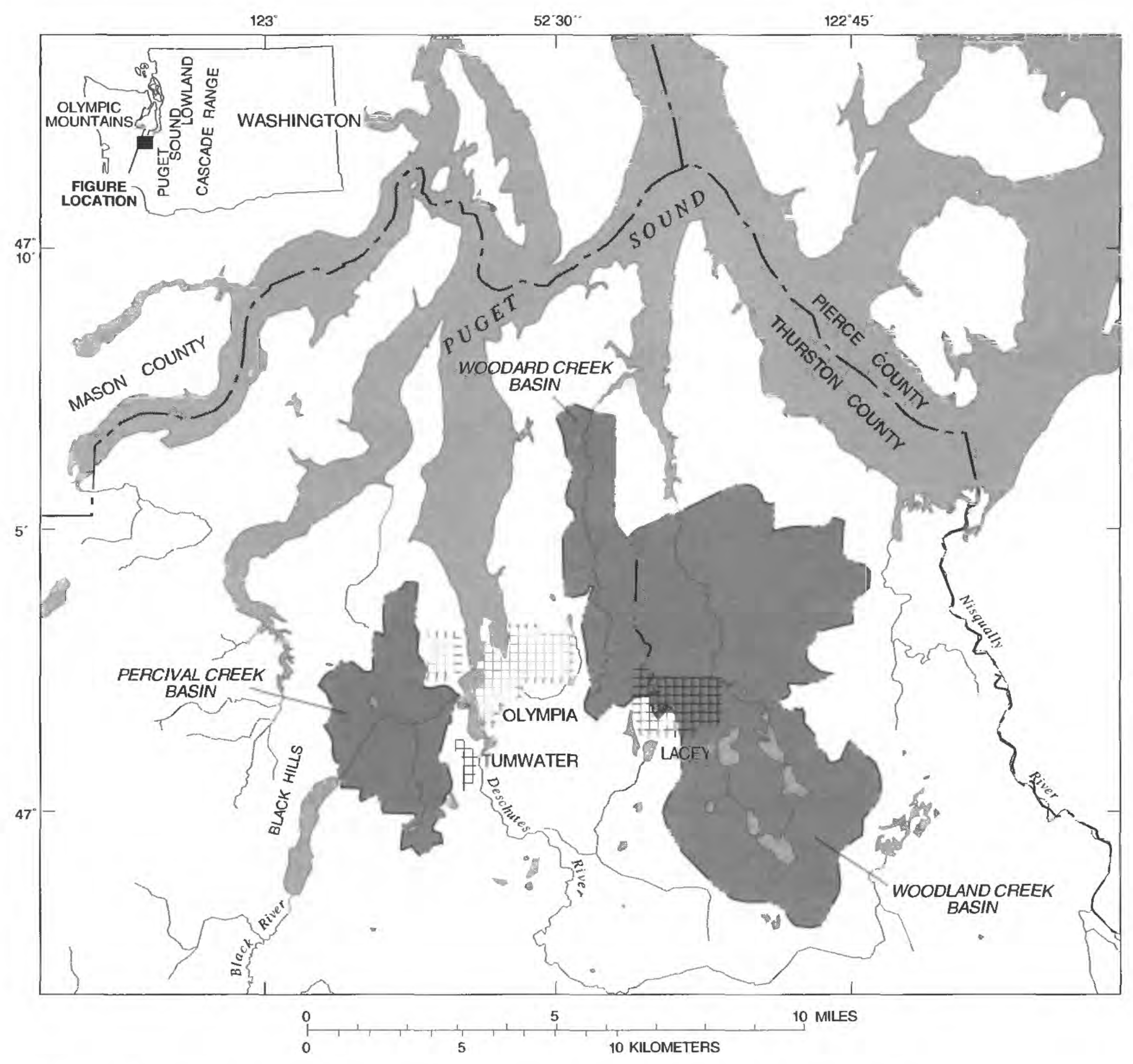

Figure 1.--Location of the study area and basins used for model calibration and evaluation. 
The mid-latitude, west-coast marine climate of the study area produces warm, dry summers and cool, wet winters. The mean annual temperature at Olympia is about $50^{\circ} \mathrm{F}$, and the mean monthly temperatures in January and July are about $37^{\circ} \mathrm{F}$ and $63^{\circ} \mathrm{F}$, respectively. Mean annual precipitation at Olympia is about 51 inches, most of which falls as rain. About 79 percent of this precipitation falls between October and March as long-duration storms of light to moderate intensity (National Oceanic and Atmospheric Administration, 1982).

The landscape of the study basins is complex. It exhibits varied (rather than uniform) topography, land cover, and soils, all of which interact with water from rainfall and influence the generation of runoff.

Two landform types dominate parts of the study basins within the drift plain: (1) rolling, hilly areas of glacial till and stratified, glacial lake-laid sediments and (2) level to mildly undulating areas of glacial outwash. Many depressions in the glacial outwash areas have no outward surface drainage and are referred to as "closed". The southwestern edge of the study area, known as the Black Hills, is not within the drift plain. It consists of moderately to steeply (up to 65 percent) sloping ridges.

Land cover in the drainage basins predominantly consists of forest, grass, water, and impervious areas. Ample rainfall in the wet season supports evergreen forests, and they are widespread throughout the study basins. However, grassy areas, or prairies, lie on soils derived from glacial outwash that drain too quickly to support dense forests. Water commonly covers areas of the study basins: swamps and peat bogs occupy depressions in areas of glacial till and lake-laid sediments, and three large lakes fill depressions in Woodland Creek Basin's southern areas of glacial outwash. Grass and impervious surfaces overlie land converted to urban and residential uses. Impervious cover is found throughout the study area but is most common along an east-west axis midway between the northern and southern parts. The impervious cover, commonly pavement and buildings, prevents nearly all downward drainage, causing water to drain laterally over the surface.

Most soils in the drainage basins derived from deposits of glacial till, glacial outwash, and lake-laid sediments on the drift plain. Soils near the southwestern boundary of Percival Creek Basin derived from the weathered basalt and sandstone of the Black Hills (U.S. Department of Agriculture, 1990).
Soils derived from glacial till, common in the northern peninsular regions, are made up of a locse 2- to 4-foot layer of ablation till on top of a dense 3- to 45-foot layer of basal till. The loose ablation till consists of a highly permeable gravelly silt loam derived from sediments that settled from the surface of melting ice. Basal till consists of a strongly compacted material of low permeability, commonly known as hardpan. Derived from sediments compacted by the pressure of ice, basal till retards the downward movement of water and causes vinter and spring periods of saturated soils and summer periods of only moderate moisture retention.

Soils derived from glacial outwash are common in the southern and east-central parts of Wood and and Woodard Creek Basins and in the south-central part of Percival Creek Basin. Outwash soils, formed from sediments deposited by heavily laden glacici-meltwater streams, consist of poorly sorted, unconsoli fated deposits of coarse sand and gravel at least 10 to 20 feet thick. These loose, gravelly loam soils are highly permeable and tend to drain quickly.

Soils derived from stratified, glacial lake-laid (lacustrine) sediments are found in the northern poninsular regions of the Woodland and Woodard Creek Basins. These soils consist of silty loams, averaging 2 feet in thickness, that overlie fine-textured clays ard silty clays 2 to 10 feet thick. The fine-textured substratum slows downward drainage, causing periods of satc rated soil conditions during winter. The moderately fine-textured upper layer of silty loam helps these soils retain moisture during the summer.

Soils derived from Black Hills rock consist mainly of a 4-foot-thick mantle of gravelly, moderately permeable silt loams overlying basalt or sandstone bedrock. Poorly drained soils derived from a variety of sources are found locally in depressions and low areas along drainageways throughout the study area. The soils in these places are often saturated because the water table is at or near the surface for most of the year.

\section{CONCEPTUAL MODEL}

A conceptual model can provide a qualitative description of how the underlying hydrologic system works. The conceptual model derived for t'e Thurston County study area was drawn partly from the description of the study area, and partly from past reserrch and observations of rainfall-runoff processes. The conceptual 
model provided a framework for understanding runoff generation and for constructing numerical simulation models for the study basins.

The following review of rainfall-runoff processes in the study basins is included to provide background information on the specific conceptual model determined for this study. Fluxes and storages related to the rainfallrunoff processes are shown in schematic form in figure 2.

\section{Rainfall-Runoff Processes}

Rainfall over the basins reaches the canopy of trees and shrubs or falls directly onto the surface of the ground. Water intercepted by the canopy remains stored on leaves and branches for later evaporation. Wher the canopy can hold no more (when its interception capa:ity is met), additional rainfall will drip off the branches and leaves or flow down the stems to the ground surface, where it joins rainfall that has fallen directly there.

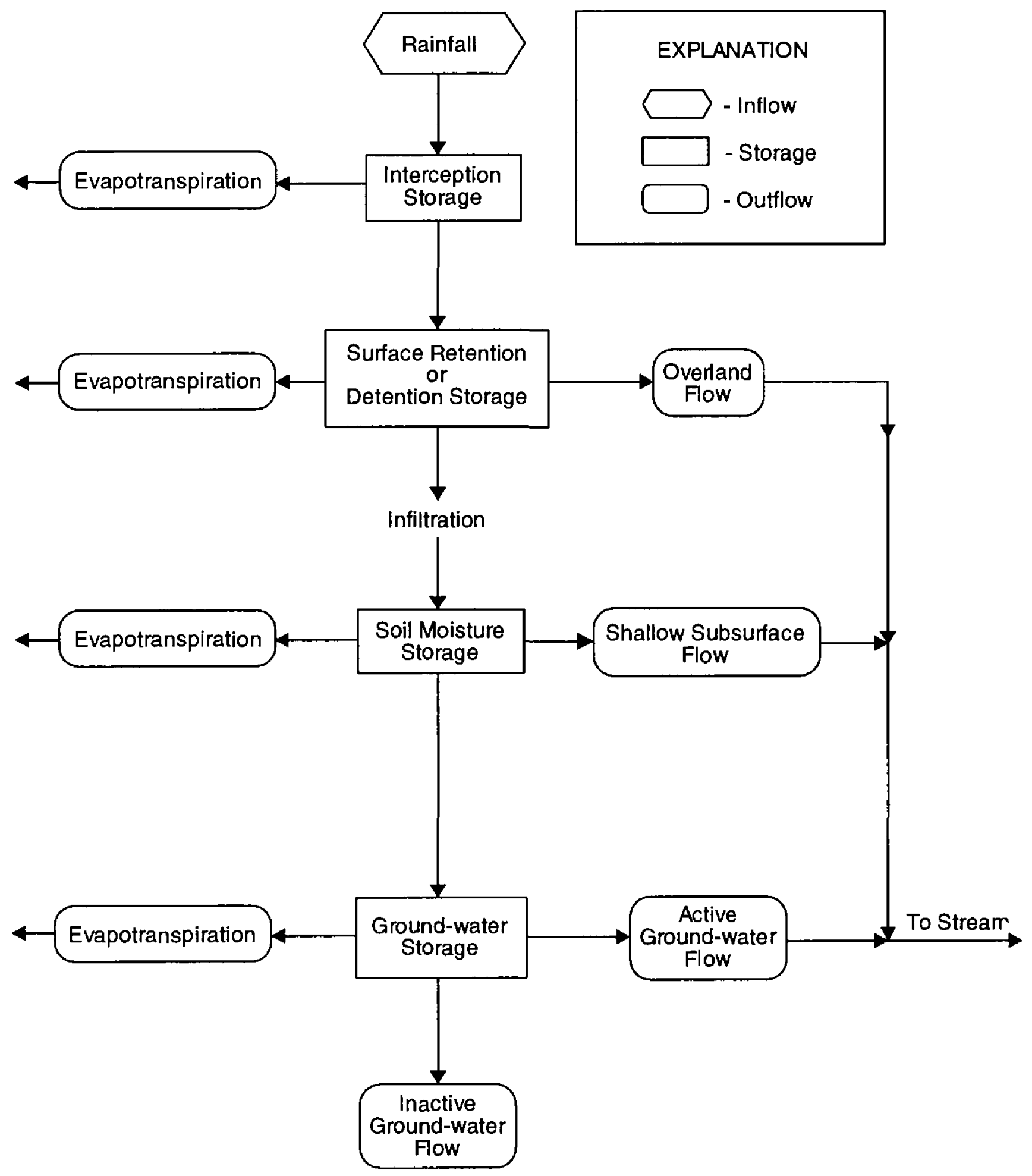

Figure 2.--Fluxes and storages related to the rainfall-runoff process. 
On the ground surface, water may collect in small surface depressions or infiltrate into the soil. Water is stored in small surface depressions as either retention storage or detention storage. Only evaporation can remove water in retention storage. If the depressions that retain water are filled with water (if, in other words, the retention storage capacity of the surface is met), then additional water falling on the surface will flow over the tops of these depressions as overland flow. Water in detention storage is only temporarily stored before it will move downgradient either by overland flow or by infiltration into the ground.

Water can flow downgradient on the surface of the ground as overland flow. Overland flow occurs in two distinct situations: (1) when the rainfall intensity exceeds the soil's infiltration capacity and moves over the surface as Hortonian overland flow or (2) when the water table rises to the surface of the ground, thereby saturating the soil and causing the overland flow called saturation overland flow. Runoff rates of overland flow, which depend on slope, are generally quick, peaking quickly after rainfall intensity peaks and declining quickly after rainfall intensity slackens.

Water that infiltrates into the soil moves into what is called soil moisture storage. This stored water can later undergo evaporation or transpiration, or it can move laterally or downward through the soil. If it accumulates in the soil above a drainage-impeding horizon, it may flow laterally just above the horizon as shallow subsurface flow, often referred to as interflow. Such horizons occur in the study basins at the top of compacted basal till, compacted glacial-lake sediments, and bedrock. Rates of subsurface flow depend on slope, but they are usually fairly quick, though slower and more attenuated than overland flow (Viessman and others, 1977; and Dunne and Black, 1970).

Water in the soil that recharges the ground-water system may be available for transpiration, or it may flow downgradient as ground-water flow. Ground-water flow that seeps out of the ground to a surface-water channel is called active ground-water flow; ground-water flow that does not reach a surface-water channel is called inactive ground-water flow. Ground-water flow is generally much slower and more attenuated than shallow subsurface flow or overland flow (Viessman and others, 1977).

Overland flow, shallow subsurface flow, and groundwater flow, the three runoff pathways, often interact, and all may occur simultaneously in a basin. Overland flow, for example, may infiltrate and become shallow subsurface or ground-water flow when land cover, such as forest litter, limits the velocity of overland flow and provides storage for later infiltration. As another example, when rain falls on a soil that slowly drains by shallow subsurface or ground-water flow, prolonged infil ration may fill the soil's storage capacity. If the soil profile is saturated to the surface, then the infiltration rate is reduced to zero, and saturation overland flow will occur.

Rainfall allocated to the three drainage pathways may contribute to streamflow either by seeping or by flowing into channels in the drainage network. In the drainage network, it moves downgradient toward a basin mouth. The water is now measurable as streamflo'v, or runoff. Determining streamflow rates, also called discharge, involves considering the volume of water in a channel and such hydraulic properties of a channel as t'ie slope, the channel shape, and the channel roughness.

There are, thus, three drainage pathways for the four generally accepted drainage mechanisms: an overland flow pathway for either the Hortonian overland flow or the saturation overland flow mechanism; a sha'low subsurface flow pathway for the shallow subsurface flow mechanism; and a ground-water flow pathway for the ground-water flow mechanism (Pearce and others, 1986; Dunne and Leopold, 1978). (It is inconvenient, but the same name can designate both the pathway and the mechanism.) These four mechanisms are the intermediaries between basin properties and runoff responses. That is, by means of the four drainage mechanisms, certain tasin properties are consistently related to certain runoff resnonses. The conceptual model associates basin properties with runoff responses by these four drainage mechanisms. More detailed descriptions of the four mechanisms with specific regard to the study basins are presented be'ow.

\section{Hortonian Overland Flow}

Hortonian overland flow occurs wher the rainfall rate exceeds the infiltration rate of a soil. The upper soil becomes saturated before lower parts do, s'ırface depressions fill with water, and runoff begins. The rate of runoff peaks soon after the rainfall rate peaks and then declines quickly after the rainfall rate subsides belo'w the infiltration rate of the soil. This mechanism rarel'r occurs in undisturbed, forested areas with ample forest litter and natural soil structure. The litter detains even heavy rainfall so that it has time to percolate into the soil profile.

Hortonian overland flow is an unlikely drainage mechanism in the undisturbed, forested pa-ts of the Thurston County study basins, where the rainfall rate seldom exceeds the soil's infiltration capac'ty. The 2-year, 
1-hour rainfall rate in the study basins is about 0.5 inch per hour. (The 2-year, 1-hour rainfall rate is the average rate of rainfall over a 1-hour interval that is exceeded only once every 2 years.) The 100 -year, 1 -hour rainfall rate is about 1.1 inches per hour (U.S. Department of Commerce, 1973). These rates are lower than the saturated hydraulic conductivities of soils in most of the study area, which vary between 2 and 6 inches per hour (U.S. Department of Agriculture, 1990). The saturated hydraulic conductivity of a soil is its minimum infiltration rate (Skaggs and Khaleel, 1982; Steinbrenner and Gessel, 1955). In some places, study area soils have lower saturated hydraulic conductivities of 0.6 to 2 inches per hour, but rainfall rates reach or exceed 0.6 inch per hour only once in about 15 years. Thus, Hortonian overland flow seldom occurs because most undisturbed forest soils in the study area can detain rainwater from storms in the forest litter and store it in depressions for later percolation into the soil (Burges, 1989).

When urban development transforms natural land surfaces, it can change the types and relative effects of the mechanisms that generate runoff. The largest changes occur when an impervious surface, a pavement or a building, for instance, covers a formerly pervious surface and reduces the amount of area over which infiltration can take place. Hortonian overland flow then becomes a dominant mechanism, producing larger volumes of runoff at faster rates than would take place on pervious areas. Impervious areas directly connected to drainage networks cover about a tenth of the study basins.

Urban development activities can also affect runoff processes on pervious parcels within a developed area. Compacting the soil and clearing away vegetation and forest litter can increase runoff rates and volumes. Clearing and grading land eliminates surface depressions that provide retention storage. Adding imported, fine-textured topsoils to lawns and gardens, parks, and golf courses reduces soil porosity in the upper soil. Replacing deeprooted trees with shallow-rooted vegetation disturbs soil structure. Because all of these activities diminish the soil's capacity to infiltrate water, they promote Hortonian overland flow.

Disturbing pervious areas also makes more water available for runoff. More water drains from adjacent rooftops and similar surfaces, and less water is intercepted as rainfall by plant surfaces. Less water is removed by transpiration of soil moisture.

\section{Saturation Qverland Flow}

When rain falls on saturated soil and cannot infiltrate, saturation overland flow is generated. This condition develops in areas like stream bottoms, depressions, and many other flat or low-lying areas where soils are poorly drained and easily saturated during wet periods. Rainfall infiltration or shallow subsurface flow ard ground-water flow from adjacent hillslopes raise the water tables and saturate the low-lying soils. Once these snils are saturated, further rainfall will generate flow over the soil surface. These poorly drained areas, essentially asting like impervious areas, produce quick, sharp runoff responses. Although both saturation overland flow and Hortonian overland flow take place over the soil su-face, the conditions that initiate them are different. In contrast to saturation overland flow, Hortonian overland fow occurs when the texture and structure of the upper soil layers inhibit infiltration.

Saturation overland flow can be an important mechanism in two distinct settings in the study area. The first setting comprises areas of flat to mildly undulating soils, usually in uplands, derived from glacial till or lacustrine sediments. In these areas, which make up about 8 percent of the study area, direct precipitation is the main contributor of water to saturation overland flow, though incoming shallow subsurface and ground-water flow from surrounding hillslopes may also contribute. Because these soils usually can hold at least 12 inches of wator before they are saturated, they may need priming from a prolonged wet period before saturation overland flow begins after the summer dry season. During a wet period such as late winter or early spring, the soils, already primed, may need only a single storm to initiate saturation overland flow.

The second setting for saturation overland flow consists of topographic depressions and areas adjacent to streams or other drainage courses. In these areas, which make up about 7 percent of the study area, the water table may be near or above land surface throughout the year. Shallow subsurface flow, ground-water fow, and direct precipitation may all contribute substant al quantities of water to saturation overland flow when these areas are saturated. Because the soils are commonly saturated throughout the year and the water tables are high, these areas generate runoff more frequently and more copiously than the upland areas with till and lacust -ine-sediment deposits. 


\section{Shallow Subsurface Flow}

Shallow subsurface flow is common where moderately to highly permeable soil layers lie over a substratum of low permeability, such as compact glacial till or bedrock. Shallow subsurface flow is generated when rainfall rapidly infiltrates the upper layers of the soil and accumulates above a substratum of low permeability that impedes vertical drainage. The accumulated water will flow laterally downhill through the permeable soil until a break in slope, a topographic convergence, or an incised channel allows the water to seep, or exfiltrate, to the surface.

The rate of shallow subsurface flow is directly related to the slope. If the slope is mild or flat, shallow subsurface flow will only slowly move through the soil matrix. In these flat or mildly sloping soils, water can accumulate above the drainage-impeding substratum and saturate the soil matrix to the surface to generate saturation overland flow. Runoff rates from shallow subsurface flow are usually fairly quick, but these rates are slower and more attenuated than runoff rates from overland flow (Viessman and others, 1977; and Dunne and Black, 1970).

Shallow subsurface flow is a predominant drainage mechanism on hillslopes in both undisturbed and developed areas of the study basins where soils derived from glacial till or lacustrine deposits or where shallow soils lie over bedrock. The upper horizon of these soils, typically 2 to 4 feet thick, has a saturated hydraulic conductivity greater than 0.6 inch per hour; the substratum has a hydraulic conductivity of less than 0.06 inch per hour (U.S. Department of Agriculture, 1990). These soils cover about 22 percent of the study area.

\section{Ground-Water Flow}

Runoff from ground-water flow is generated when water percolates through the soil matrix until it reaches the ground-water system and then flows toward surface channels or, in the study area, toward Puget Sound. Groundwater flow is a large component of total runoff in areas where soils are derived from glacial-outwash deposits. These soils, which cover about half the study area, are extremely permeable, having saturated hydraulic conductivities greater than 2 inches per hour, so rainfall infiltrates rapidly to recharge ground-water reservoirs. Because these soils are rarely saturated, water typically is not diverted from ground-water recharge by overland flow under any slope condition. Runoff rates from a storm by ground-water flow generally are much slower and more attenuated than by shallow subsurface or o"erland flow-usually on the scale of days rather than hours in small basins (Viessman and others, 1977). The slope of the water table, which usually follows topograshy, influences the rate of ground-water flow (Heath, 1983): the steeper the slope, the faster the flow rate. In the gl acial-outwash deposits of the study area, however, both topography and water table slopes are fairly mild.

\section{Conceptual Features of Runoff Generation in the Study Basins}

The drainage mechanisms and hydrologic processes discussed above are the basis for the concentual model of runoff generation in the Thurston County study area. The following seven features of the model are the same as those applied by Dinicola (1990) to headwater basins in King and Snohomish Counties, except that in this study the second and third features have been modified to include runoff generation from shallow soi's underlain by bedrock or fine-grained lacustrine deposits The first four features apply to undisturbed forested arear.

(1) Classic Hortonian overland flow is not an important mechanism in most, if not all, of these undisturbed areas.

(2) Saturation overland flow is the predominant mechanism in depressions, stream bottoms, and flat upland areas mantled by glacial till. It is a secondary mechanism in flat upland areas underla'n by finegrained lacustrine deposits. Runoff is generated more rapidly and more often from the depres sions and stream bottoms than from the flat uplands. In the flat uplands, runoff is generated only during prolonged wet periods.

(3) Shallow subsurface flow, sometimes combined with seepage, is the predominant drainage mechanism on hillslopes mantled with glacial till, bedrock, or, to a lesser degree, fine-grained lacustrine deposits. Within the soil profile, water does not move readily, but once it seeps to the surface, it may become a large part of storm runoff. The rate of runoff from subsurface flow is proportional to the angle of the hillslope.

(4) Ground-water flow is the predominant mechanism on glacial-outwash deposits. Runoff rates from this mechanism are slow and attenuated. 
The final three features apply to disturbed nonforested areas. The fifth and sixth features pertain to mechanisms that generate runoff, and the seventh feature pertains to additional hydrologic processes affected by disturbances of natural, pervious areas.

(5) Rapid Hortonian overland flow is the sole drainage mechanism on impervious areas.

(6) Hortonian overland flow, in combination with other runoff mechanisms, is a viable drainage mechanism in disturbed pervious areas where development changes the soil structure and texture and increases the moisture supply from nearby impervious surfaces.

(7) Pervious parcels within disturbed areas have decreased surface detention, decreased detention storage, decreased rainfall interception, and decreased plant transpiration.

\section{SIMULATION OF RUNOFF GENERATION}

Three basin models using Hydrological Simulation Program-FORTRAN, one for each study basin, were constructed to approximate the conceptual model numerically and to simulate the runoff generation. The following sections describe (1) how the HSPF program simulates runoff generation, (2) how the basin models were constructed, and (3) how the basin models were calibrated to observed streamflow.

\section{Description of the Computer Program}

HSPF was used for the basin simulation models because this program had been effective in simulating runoff generation for headwater basins with similar properties elsewhere in the Puget Sound Lowland (Dinicola, 1990). The following features of HSPF make it suitable to simulate rainfall-runoff processes in the Thurston County study basins.

(1) HSPF can represent the hydrologic processes, including the four drainage mechanisms, described by the conceptual model.

(2) HSPF can simulate the generation of runoff continuously over time, including periods of storm runoff and low flows, and account for antecedent soil moisture conditions.
(3) HSPF can simulate the hydraulics of natural and man-made drainage networks.

HSPF approximates the conceptual model in a numerical representation of the hydrologic system that can distribute and track water that falls as rair. This numerical representation of the system includes numerous waterdrainage pathways and water-storage reservoirs of a basin. In this system, overland flow, shallow sut surface flow, and ground-water flow are considered the pathways that drain to channels, whereas ground-water recharge to deep aquifers and evapotranspiration (ET) are considered pathways that do not drain to local channels. Water-storage reservoirs in this system include interception storage, retention storage, detention storage, soil-moisture storage, and ground-water storage. After distributing rainfall to initial starting points in the system, HSPF coml ines the parts of it that contribute to runoff and simulates inflow to each channel of a drainage network. Simulated channel inflow is then routed as streamflow through the drainage network by a modified kinematic wave mathemati:al routine that is a component of HSPF. The drainage netvork may include any man-made or natural flow-conveyance system, but hydraulic properties of individual channels must be held constant. HSPF cannot accommodate su 2 h hydraulic conditions as backwater and pressurized flow.

HSPF uses numerical values of model parameters to represent land and hydraulic properties of specific land parcels and channel reaches in a drainage basin during runoff simulations. The following discussion (1) introduces the concepts of "process-related" and "fixed" parameters; (2) describes the division of drainage basins into land segments, subbasins, and channel reaches; and (3) describes how HSPF simulates runoff' generation and delivery.

HSPF represents the land and hydraulic properties of drainage basins by "process-related" parameters and by "fixed" parameters. Process-related para'neters represent properties that govern the movement or storage of water once it reaches the land or vegetation surface, but before it reaches a channel in the drainage network. Processrelated parameters include the quantity of rainfall intercepted by vegetation; the quantity of wat 2 r perched on the land surface or absorbed in the forest litter; the quantity of water stored in the soil matrix; the soil infiltration rate; the evapotranspiration rate; and the rates at which overland flow, shallow subsurface flow, and groun-water flow drain to channels in the drainage networl. Measuring the physical properties to be represented by process-related parameters is rarely easy. Numerical val tes for the parameters of the Thurston County study bas'ns initially were 
selected from a previous modeling study (Dinicola, 1990) or estimated from available physiographic information. The parameter values then were evaluated and, when necessary, refined during model calibration.

Fixed parameters represent the hydraulic properties of the drainage network and other measurable drainage basin properties, such as the amount of area covered by the respective soil types, land covers, and slopes. These are the parameters commonly modified during engineering and planning applications of the calibrated model to predict runoff responses to alternate urban development scenarios for a drainage basin. The hydraulic properties, which include channel shape, channel roughness, channel slope, and channel length, determine the relation of discharge to the volume of water stored in a channel. Water volume in storage and corresponding discharge are the fixed parameters that define how water is routed through a channel. For this study, field reconnaissance and maps provided the information about hydraulic properties that determined parameter values used for channel routing. The parameter values for the areas of different classifications of such basin properties as soil, land cover, and slope also came from information provided on maps.

A drainage basin can be divided into three components for runoff simulation by HSPF: land segments, subbasins, and channel reaches. This division allows both (1) the assignment of parameter values to discrete land parcels and channel reaches and (2) the assignment of runoff to specific destinations.

HSPF requires that the surface of each drainage basin be divided into land segments. A land segment is a parcel of land with distinctive but fairly uniform meteorologic, physical (soil, land cover, and slope), and hydrologic traits. On the basis of its traits, each individual land segment is classified as one of the land-segment types. The classification of basin properties and the division of the land surface into land-segment types is called the segmentation scheme. Individual land segments with the same package of traits belong to the same land-segment type. Each land-segment type is assigned its own set of processrelated parameters. The distinctive set of parameters for each land-segment type belongs to all land segments classified to that type. This arrangement enables the program to simulate distinct hydrologic responses to rainfall and potential evapotranspiration for distinctive basin areas.

While providing enough land-segment types to account for all physical properties that exert notable influence on runoff in the study basins, this study has restricted the number of land-segment types to reduce the number of parameters requiring calibration. The HSP program does not require that all land segments of the same type be contiguous. It only requires (1) that the parameters represent the hydrologic properties of all land segments within each land-segment type and (2) that the total area of each land segment within a given type be known. Tr us, relatively few land-segment types represent the complex areal mosaic of soils, land covers, and slopes in each modeled basin.

HSPF allows division of drainage basins into subbasins so that a simulation model can more closely control the delivery of runoff to specific destinations. A simulation model typically delivers runoff genera ${ }^{+}$ed in a subbasin to the channel draining that subbasin This typical delivery scheme, however, is not mandatory. Sometimes, for example, a subbasin may be closed; that is, it may lack connection to a surface-drainage network. In such cases, HSPF allows a simulation model to deliver water elsewhere, for instance, to inactive ground wat 2 . Another example occurs when different outflows from land segments in a given subbasin are delivered to channels in different subbasins. Overland flow and shallow subsurface flow from a land segment in a subbasin may be delivered to the channel draining that subbasin, but ground-water flow may be delivered to a channel farther downstream in a different subbasin.

HSPF can route streamflow along chennels of a drainage network to the outlet of a drainage basin. Using the routing capability requires that the linked network of stream channels, drainage pipes, and perennial lakes, ponds, and wetlands be divided into segments called reaches. A reach must have relatively uniform hydraulic properties and must drain or connect subbasins. A reach sometimes may lose water when it seeps from a channel or lake bottom or when it discharges from one or more outlets outside the reach's subbasin. Reach segmentation was somewhat generalized in the study basins to simulate only the essential hydraulic properties that affect streamflow rates in a drainage network. It was not necessary to simulate flow through every pipe, ditch, pond, and channel in the study basins.

The previous discussion introduced th e concept of process-related and fixed parameters and described the division of drainage basins. The following discussion describes how HSPF simulates runoff by uning processrelated and fixed parameter values to repre?ent land and hydraulic properties of land segments, subbasins, and reaches. For a detailed description of runoff simulation by HSPF, refer to the HSPF user's manual, pages 158-176 for 
pervious land segments, pages 209-212 for impervious land segments, and pages 221-240 for reaches (U.S. Environmental Protection Agency, 1984).

HSPF bases the allocation, travel rates, and destinations of water from incident precipitation on the processrelated parameters assigned to land segments where the precipitation falls. Table 1 defines the HSPF processrelated parameters of the three basin models used in this study. In basing allocation, travel rates, and destinations on land-segment type parameters, HSPF distinguishes between impervious and pervious land segments.

HSPF allocates precipitation falling on impervious land segments either to surface retention or detention storage, or to overland flow (fig. 3a). The process-related parameter RETSC defines retention storage capacity and removes this retained water from the quantity available for overland flow. Only evaporation removes water from this reservoir. When the retention storage is full, further rainfall moves to surface detention storage, where it is detained temporarily until it moves to a channel as overland flow. The process-related parameters LSUR, NSUR, and SLSUR all influence the rate of overland flow.

Precipitation falling on pervious land segments is intercepted by the vegetal canopy, or it reaches the surface of the ground (fig. 3b). The process-related parameter CEPSC defines the quantity of water intercepted by the canopy, and this water in interception storage is later removed by evapotranspiration. When the interception storage capacity is met, further precipitation is allocated to the surface of the ground.

Water that reaches the surface of the ground is directed by HSPF either to direct infiltration or to potential runoff. This initial allocation is affected by multiple influences: the supply rate of water, the current soil moisture storage, and the physical properties of the soil as represented by the process-related parameters INFILT, INFILD, INFEXP, and LZSN. In general, low supply rates, low soil moisture storage volumes, and high INFILT values will result in large quantities of direct infiltration. Conversely, high supply rates, high soil moisture storage volumes, and low INFILT values will favor potential runoff. A portion of the potential runoff may still infiltrate as delayed infiltration, as will be discussed later in this section.

Water that infiltrates (directly or delayed) is stored in the unsaturated lower zone of the soil as lower zone storage, or it enters the ground-water system. The capacity of lower zone storage is defined by the process-related parameter LZSN. Water stored in the lower zone can only be removed by evapotranspiration, and the rate of evapotranspiration is determined by the process-related parameter LZETP. As water stored in the low/er zone increases, more infiltrated water enters either active ground-water storage or inactive ground-water storage. The parameter DEEPFR defines the proportion of water entering inactive ground-water storage, where stored water is not available for runoff. Water allotted to active ground-water storage, on the other hand, is available either for evapotranspiration or for ground-water flow toward channels. Evapotranspiration is determined by the parameter AGWETP, and the rate of ground-water flow toward a channel is influenced by the parameters AGWRC and KVARY. Additionally, ground-water flow toward a channel is subject to evapotranspiration as determined by the parameter BASETP.

Rainfall reaching the ground but nct routed by HSPF to direct infiltration becomes potential n'noff. HSPF makes this potential runoff available to three storages: upper zone storage, surface detention stcrage, and interflow storage. The parameter UZSN allo sates a share of the potential runoff to be stored in surface depressions and the upper, organic soil layers as upper zo ne storage. HSPF may, in turn, assign water in upper zone storage either to evapotranspiration or to delayed infiltrat ion toward either lower zone storage or ground-water storage. Delayed infiltration depends on the relative volumes of water in upper zone storage and lower zone stora ze, and on the influence of the parameter INFILT. In ge eral, if the upper zone storage is wetter than the lower zore storage, HSPF will assign water to delayed infiltration. If, conversely, the lower zone storage is wetter than the upfer zone storage, then HSPF will send more water to surface detention storage and, subsequently, to overland flow toward channels. The rate of overland flow from pervious land segments, as from impervious segments, is influenced by the parameters LSUR, NSUR, and SLSUR. Finally, the parameters INTFW and LZSN determine the share of potential runoff for interflow storage, which may frovide outflow as shallow subsurface flow toward channels. The parameter IRC influences the rate of subsurface flo" $\%$.

HSPF does not distinguish betweer Hortonian and saturation overland flows. The user, however, can assign parameter values that will appropriately simulate these two flow mechanisms. To simulate saturation overland flow, for example, the user can adjust the parameter value for INFEXP, the exponent in the infiltrat on equation. A high INFEXP value will dramatically derrease infiltration capacity when there is a relatively small increase in soil moisture storage (represented in HSPF by lower zone storage). This adjustment, which makes low'er zone storage 
Active ground-water evapotranspiration (ET); accounts for the fraction of available PET that can be met from active ground-water storage. It simulates ET from deep-rooted plants. Active ground water is that portior of ground-water storage that can discharge to a surface channel. No units.

AGWRC

Active-ground-water recession coefficient; governs the changing rate at which active ground water drains from the land over time. Units: 1/day.

BASETP Baseflow ET; accounts for the fraction of available potential evapotranspiration (PET) that can be ret as baseflow from ground water to the surface channel. It simulates ET from riparian vegetation. No units.

CEPSC Interception-storage capacity of plants. Units: inches.

DEEPFR Fraction of deep ground water; governs the fraction of ground water that becomes inactive ground water and does not discharge at the surface inside the modeled basin. No units.

INFEXP Infiltration equation exponent; governs the decrease of infiltration rate with increasing soil moisture in the unsaturated lower zone. No units.

INFILD Ratio of maximum to mean infiltration rate; accounts for differences in the infiltration rate caused by variations within a given land-segment type. No units.

INFILT Soil infiltration capacity index; governs the ability of water to directly infiltrate soil and become soil moisture in the unsaturated lower zone. Water stored in the lower zone is available for evapotranspiration or recharge to ground-water storage. For HSPF, the water that does not directly infiltrate to the unsaturated lower zone is available for overland flow, shallow subsurface flow, or later direct infiltration. Units: inches/hour.

INTFW Interflow index; governs the quantity of water that becomes shallow subsurface flow to a surface channel. No units.

IRC Interflow recession coefficient; governs the changing rate at which subsurface flow drains from the land over time. Units: 1/day.

KVARY

Active-ground-water outflow modifier; governs the amount of influence that ground-water inflow has on ground-water outflow. Units: 1/inch.

LSUR Surface length of the average overland flow plane. Units: feet.

LZETP Lower-zone evapotranspiration (ET); represents the density of deep-rooted vegetation that conveys water from the unsaturated lower zone upward to the atmosphere. No units.

LZSN Lower-zone nominal storage; accounts for the capacity of soil-moisture storage in the unsaturated lc wer zone. Units: inches.

NSUR Surface roughness (Manning's " $n$ " value); the average overland flow plane. No units.

RETSC Retention-storage capacity of impervious surfaces. Units: inches.

SLSUR Surface slope of the average overland flow plane. No units.

UZSN Upper-zone nominal storage; accounts for storage capacity in depressions and surface layers of a per'ious area. Units: inches. 

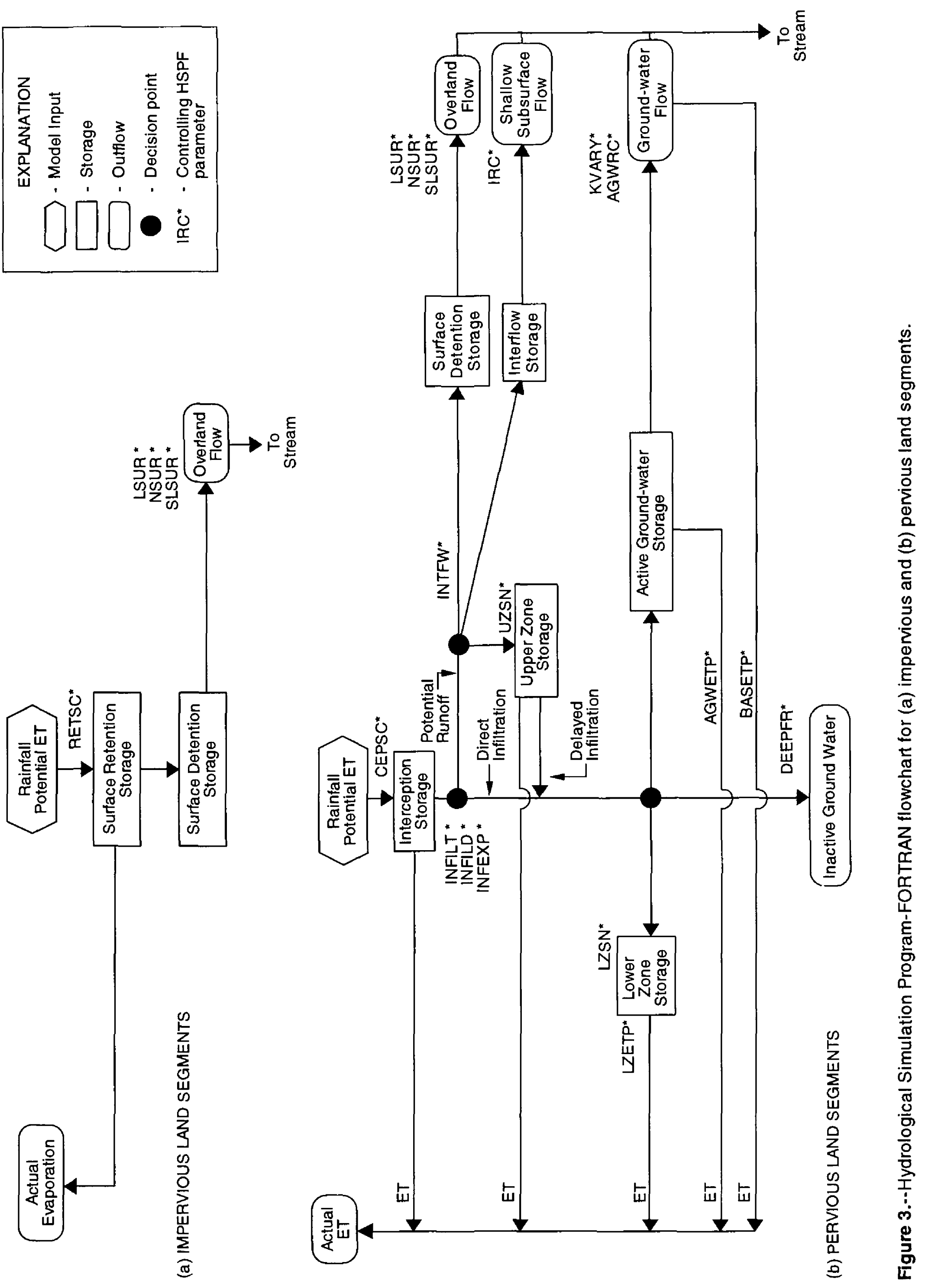
act as a surrogate for the depth of the water table, simulates saturation overland flow. Infiltration will be larger when soils are dry and negligible when soils are wet.

The HSPF-based simulation models determine for each subbasin the volume of water draining in a given time to a surface channel reach or to inactive ground water. A subbasin may contain some or all of the landsegment types in a drainage basin. The quantity of incident precipitation that is time-allocated along each drainage path is multiplied by the surface area of the associated land-segment type (a fixed parameter) to determine the volume of water draining from a land-segment type per unit of time either to a surface reach or to inactive ground water. The total volume of water entering from a subbasin into a reach or into inactive ground water over a given time interval is the sum of the volumes produced from all of the land-segment types in the subbasin during the interval. In turn, the total volume of water stored in a reach in a given time is the sum of all the volumes draining into the reach from all connected subbasins and the initial volume stored in the reach, minus the volume discharged from the reach during this time. The total volume of water in the reach determines the outlet discharge as specified by fixed parameters.

\section{Construction of the Simulation Models}

Numerical simulation models for the three study basins were constructed by incorporating the previously described conceptual model into the HSPF program. Constructing the HSPF-based simulation models required division of the study area into land-segment types, subbasins, and stream reaches.

Division of each basin into land-segment types enabled each basin model to simulate the runoff generation conceptualized for the distinct physical properties of the basin. Each land-segment type had distinct, uniform physical properties that, in the conceptual model, were associated with certain hydrologic processes and runoff responses. Process-related parameters were assigned to each land-segment type to simulate these processes and responses.

Division of each basin into subbasins enabled each model to provide the necessary hydraulic linkage from specifically located land-segment types to specific channel segments or to inactive ground water. The surface area of each land-segment type within a subbasin was used to determine the volume of runoff from each type, and these runoff volumes were assigned to specific d»stinations, usually to stream reaches draining the subt asin.

Division of each study basin's drainage network into channel segments, called reaches, enabled each basin model to route streamflow along the reaches of the drainage network to the drainage basin outlet. Each reach received runoff volumes from the land-segment types in its own associated subbasin and also from all connected upstream reaches. A more detailed description of how the study area was divided into land-segment ty'pes, subbasins, and reaches is presented below.

\section{Land-Segment Types}

The HSPF program separates operations of rainfallrunoff simulation into modules called bloc's. The PERLND block computes water budgets for pervious land-segment types, and the IMPLND block computes water budgets for impervious land-segment types. These blocks contain the process-related paramet 2 rs for their respective pervious and impervious types.

Simulating runoff generation from ea:h landsegment type in the study basins involved two tasks during model construction: (1) defining the land-segment types in the study area and (2) assigning values to the processrelated parameters for each type. The land-segment type definitions were based on three basin properties: soil type, land cover, and slope. The parameter values numerically represented physical properties that govern the movement or storage of water between the vegetal carspy or ground and the channels in the drainage network.

\section{Definition of Land-Segment T:pes}

The first phase of model construction divided each study basin into 17 land-segment types, 16 that represent pervious areas (called PERLNDS in HSPF) and 1 that denotes impervious areas (IMPLNDS). Th e PERLNDS were differentiated on the basis of soil type (outwash, till, Kitsap, saturated), land cover (forest, nonforest, crop), and slope (flat, moderate, steep).

Soil types in the pervious parts of the study area came from combining the soil series shown on Soil Conservation Service Soil Survey maps (U.S. Department of Agriculture, 1990) into four general categories--outwash, till, Kitsap (contains two soil series derived from lacustrine deposits), and saturated soils--on the basis of 
physical and hydrologic response characteristics (table 2 ). The distribution of soil types in the study basins appears on figure 4 .

Table 2.--Soil series, and the landsegment soil type that represents each soil series in the calibrated rainfall-runoff models (U.S. Department of Agriculture, 1990)

\begin{tabular}{|c|c|}
\hline $\begin{array}{l}\text { Land-segment } \\
\text { soil type }\end{array}$ & $\begin{array}{c}\text { Thurston County } \\
\text { soil series }\end{array}$ \\
\hline \multirow[t]{9}{*}{ Outwash } & Cagey \\
\hline & Chehalis \\
\hline & Everett \\
\hline & Giles \\
\hline & Indianola \\
\hline & Nisqually \\
\hline & Spana \\
\hline & Spanaway \\
\hline & Yelm \\
\hline \multirow[t]{2}{*}{ Kitsap } & Hoogdal \\
\hline & Skipopa \\
\hline \multirow[t]{9}{*}{ Till } & Alderwood \\
\hline & Delphi \\
\hline & $\begin{array}{l}\text { Dystric } \\
\text { Xerochrypts }\end{array}$ \\
\hline & Kapowsin \\
\hline & McKenna \\
\hline & Melbourne \\
\hline & Olympia \\
\hline & $\begin{array}{l}\text { Rainier-Rock } \\
\text { Complex }\end{array}$ \\
\hline & Schneider \\
\hline \multirow[t]{8}{*}{ Saturated } & Bellingham \\
\hline & Everson \\
\hline & Hydraquents \\
\hline & Mukilteo \\
\hline & Norma \\
\hline & Semiahoo \\
\hline & Shalcar \\
\hline & Tisch \\
\hline
\end{tabular}

Land-segment types based on outwash soil types (hereafter called outwash segment types) represent areas covered by soils formed in glacial outwash deposits and by other well-drained soils. This study divided outwash segment types into three land-cover classes: forest, nonforest, and crops. As described in the conceptual model, runoff comes mostly from ground water in forested and disturbed areas of outwash, but disturbed areas, with nonforested or crop land covers, also may generate some Hortonian overland flow during intense rainstorms. Disturbed, pervious areas were divided into nonforested and crop land covers to represent greater evapotranspiration (ET) for crop land cover than for nonforested land cover. The crop land cover occurs only in areas of outwash soils. Outwash segment types were not divided into slope classes because slopes in areas of glacial-outwash deposits are flat to moderate and do not vary widely through the basins. Dinicola (1990) found that slope has little affect on the runoff characteristics of outwash and other well-drained soils.

Till segment types represent areas wh ere soils cover a layer of compacted glacial till or bedrock. Till areas mostly produce runoff from shallow subsurface flow in both forested and nonforested locations. However, till segment types covered by disturbed, nonfcrested areas commonly produce Hortonian overland flcw during storms. This study subdivided till segmen ${ }^{+}$types according to two land cover classes: forested or nonforested. Slope also affects the subsurface and overland flow characteristics of till segment types. For examyle, till soil types with flat slopes often generate runoff from saturation overland flow when soils become saturated during extended wet periods. Thus, both forested and nonforested till segment types were further subdivided according to their slope: flat, moderate, or steep.

Kitsap segment types, not designated for basins previously investigated by Dinicola (1990), represent areas with soils derived from fine-grained lacustrine deposits. Kitsap segment types, like the till segment types, represent soils underlain by a substratum of low permeability. Kitsap soils, however, have greater soil-moisture storage capacities and, because of more interstitial pore space than till soils, they have slightly greater rates of vertical drainage through the substratum. Thus, subsurface flow is slightly less important, and ground-water flow is slightly more important in Kitsap segment types tran in till segment types. In nonforested Kitsap segment types, as in till segment types, intense storms may produce Hortonian overland flow. In Kitsap segment types w: th flat slopes, saturation overland flow is an important mechanism. Accordingly, Kitsap segment types also were subdivided according to their land cover and slope. 


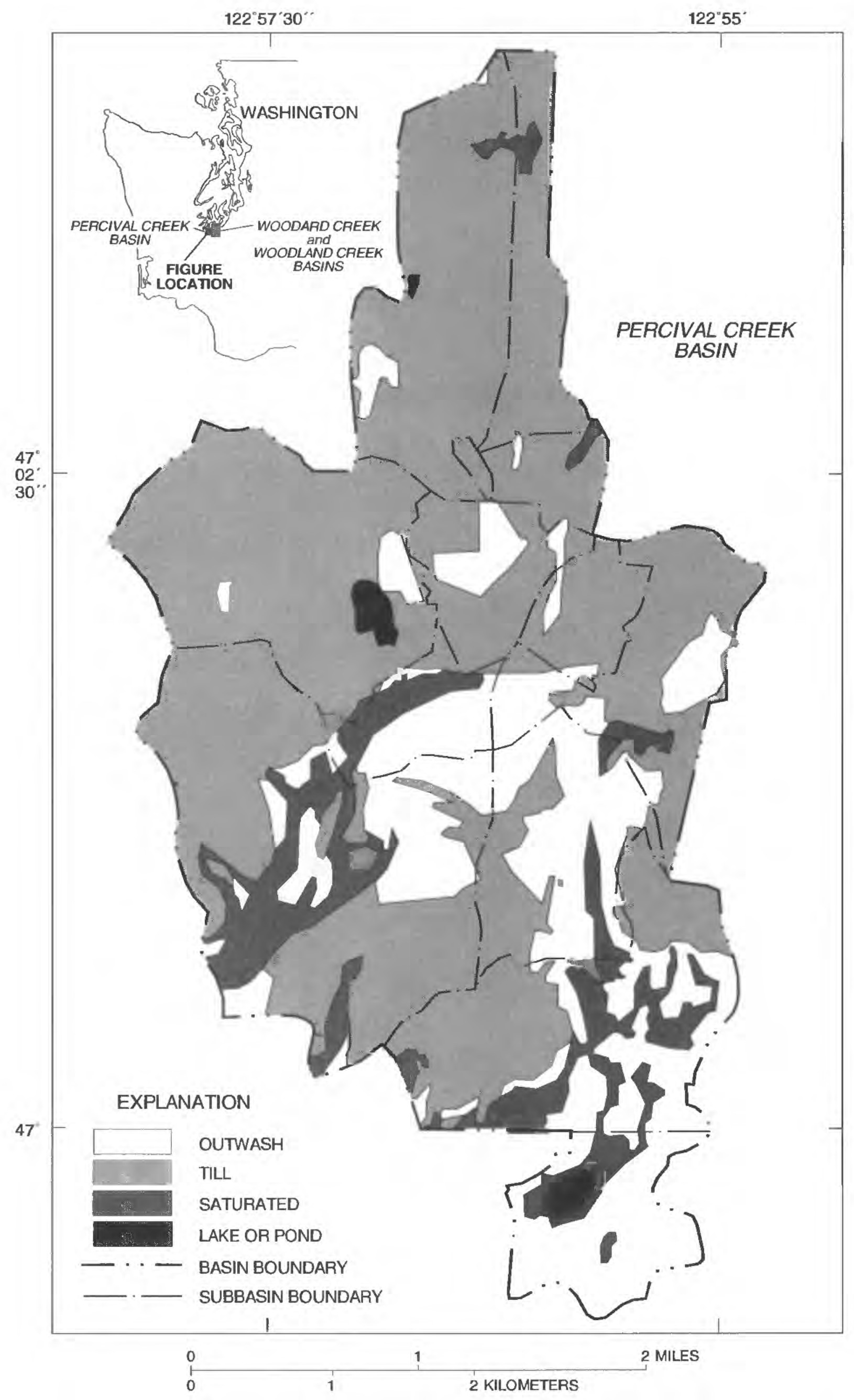

Figure 4.--Distribution of soil-type land segments for Percival Creek, Woodard Creek, and Woodland Creek Basins. 


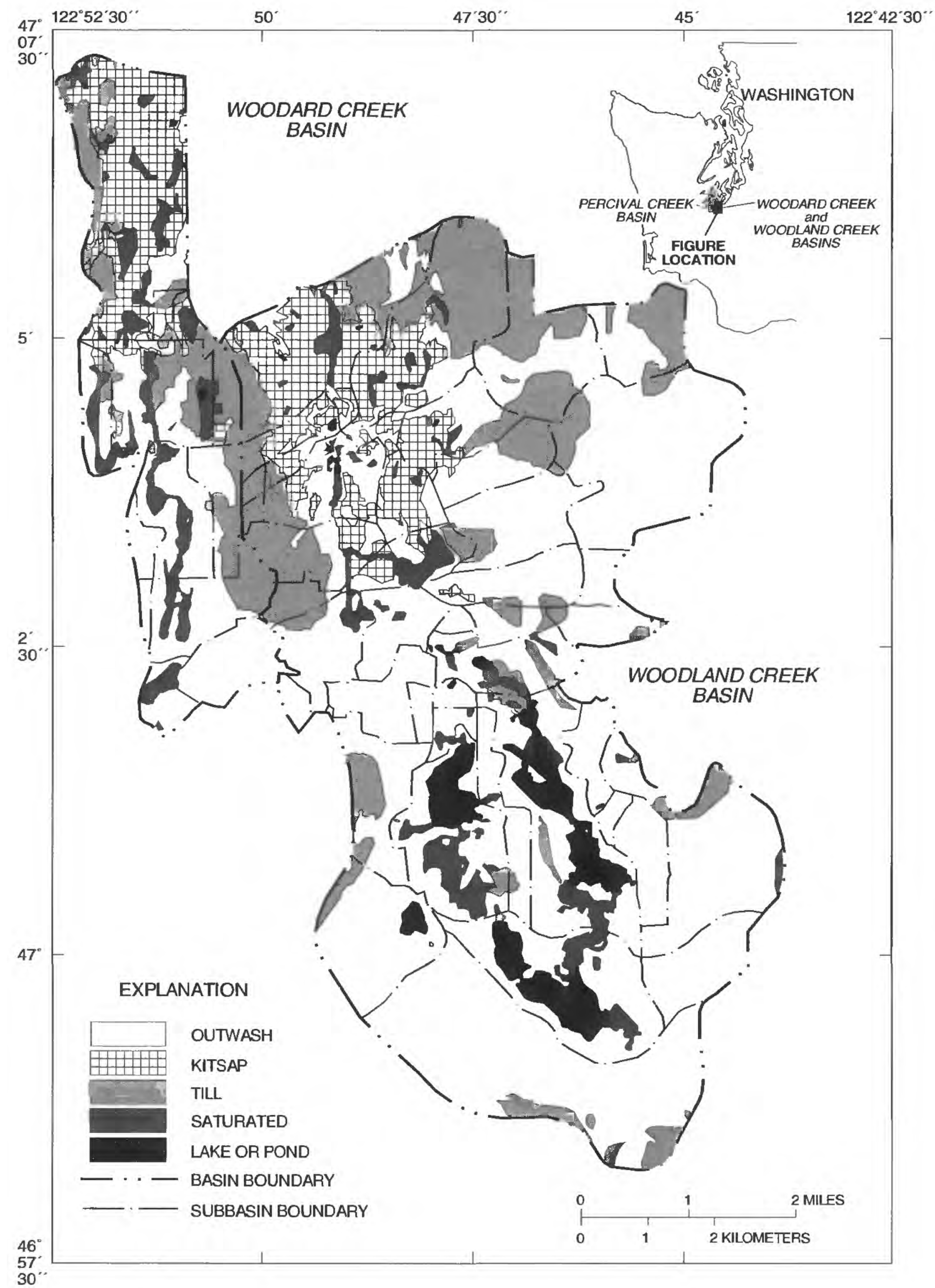

Figure 4.--Continued. 
The saturated segment type represents topographic depressions and stream bottoms that are poorly drained and seasonally inundated. This segment type mainly generates runoff from saturation overland flow. Because this segment type represents undeveloped, flat-sloped areas, it was not subdivided according to land cover and slope. The undeveloped land cover of this flat-sloped segment type is generally a mixture of wetland forests, shrubs, and meadow grasses.

The classes of land cover in pervious parts of the study area--forest, nonforest, or crops--were determined and mapped from interpretation of aerial photographs. Forest land cover denotes undisturbed and forested areas. Nonforested land cover refers to land segments that are disturbed and nonforested, such as grass lawns, pastures, and gravel pits. Crop land cover, not designated for basins previously investigated by Dinicola (1990), refers to agricultural areas that undergo tillage and intensive crop production. Crop land cover shows up only in areas of outwash soil types. For each class of land cover, distinct values for the process-related parameters represent the interception storage, infiltration rate, depression storage, and evapotranspiration.

This study assigned till and Kitsap land segments to one of three slope classes--flat ( 0 to 3 percent), moderate ( 3 to 15 percent), and steep (greater than 15 percent)--on the basis of Soil Survey maps from the Soil Conservation Service (U.S. Department of Agriculture, 1990). Topographic maps were used to verify the classifications.

Determining the areal extent of effective impervious areas in the basins was more difficult than determining the extent of pervious areas. Effective impervious areas generate runoff that drains directly from impervious surfaces to channels. However, most impervious areas are not completely effective because a portion of the runoff drains to adjacent pervious land segments rather than directly to channels (rooftops that drain to lawns are a common example). The extent of effective impervious areas in the study basins was estimated by first measuring from aerial photographs the area of six classes of land use that contained impervious land cover: sparse, moderate, suburban, and high-density residential, and medium and heavy commercial-industrial. The total area for each of the six classes was then adjusted, using previously defined percentages, to estimate the area within each class covered solely by impervious surfaces (Alley and Veenhuis, 1983; Dinicola, 1990). Finally, the estimate of impervious area was further adjusted by applying another set of previously defined percentages to estimate the effective impervious area of each land cover class (Alley and Veenhuis, 1983;
Dinicola, 1990; U.S. Department of Agriculture, 1986). Definitions of the impervious land-cover classes and the estimated percentages of impervious and effective impervious areas for each class appear in table 3.

Because all noneffective impervious areas (those impervious areas that do not drain directly to channels) were assumed to drain to adjacent pervious land, the study assigned noneffective impervious areas tc the same soil type and slope class as those of the adjacent pervious segments. The land cover of noneffective impervious areas within sparse residential areas was classified into the same forest or nonforest land cover type as the adjacent land segment. Noneffective impervious areas in the other five impervious classes were always classified as nonforest land cover.

Table 4 lists the designations and characteristics of land-segment types for pervious areas. Table 5 shows the area of each land-segment type contributing to each of the five stream-gaging stations. Contributing areas are those areas that supply runoff to stream reaches and are distinguished from noncontributing areas, which are closed subbasins that do not drain to stream reaches. Table 5 expresses contributing areas as percentages of total contributing areas upstream of stations.

\section{Process-Related Parameters}

Each land-segment type was charactorized as having a rainfall-runoff response distinct from those of other land-segment types. During model construction, distinctive numerical values were assigned to the process-related parameters of each land-segment type to represent these responses.

For 10 of the 17 land-segment types in this study, the initial values of process-related parameters were the values used earlier by Dinicola (1990) for basins elsewhere in the Puget Sound Lowland. These 10 land-segment types were outwash segment types $O F$ and $O G$; till segment types TFF, TFM, TFS, TGF, TGM, and TIJS; saturated segment type SAT; and effective impervio"s area segment type EIA. One outwash land-segment typ w with crop land cover $(\mathrm{OC})$ and six land-segment types with Kitsap soils (KFF, KFM, KFS, KGS, KGM, and KGS) were not present in the basins of the earlier study. For the outwash-crop land-segment type (OC), the initial processrelated parameter values were those previously determined for outwash-nonforest land-segment types (OG), except that one parameter value was adjusted to increase evapotranspiration. For the Kitsap land-segment types, the 
Table 3.--Estimated impervious area and effective impervious area for impervious land cover classes represented in the Woodland Creek, Woodard Creek, and Percival Creek models

\begin{tabular}{|c|c|c|c|c|}
\hline $\begin{array}{l}\text { Impervious land- } \\
\text { cover class }\end{array}$ & $\begin{array}{l}\text { Definition/ } \\
\text { examples }\end{array}$ & $\begin{array}{l}\text { Estimated } \\
\text { percentage of } \\
\text { impervious area }\end{array}$ & $\begin{array}{l}\text { Estimated } \\
\text { percentage of } \\
\text { effective } \\
\text { impervious area }\end{array}$ & $\begin{array}{l}\text { Reduced estimated } \\
\text { percentag: of } \\
\text { effective } \\
\text { impervio' } \% \text { area }^{1}\end{array}$ \\
\hline Sparse residential & 1 unit per $2-5$ acres & 10 & 4 & 0 \\
\hline Moderate residential & $1-3$ units per acre & 20 & 10 & 0 \\
\hline Suburban residential & $4-8$ units per acre & 35 & 23 & 0 \\
\hline High density residential & Apartments, and mobile home parks & 60 & 48 & 24 \\
\hline $\begin{array}{l}\text { Medium commercial/ } \\
\text { light industrial }\end{array}$ & $\begin{array}{l}\text { Office parks and low density } \\
\text { industrial }\end{array}$ & 60 & 48 & 24 \\
\hline $\begin{array}{l}\text { Heavy commercial/ } \\
\text { industrial }\end{array}$ & $\begin{array}{l}\text { Shopping centers, dense strip } \\
\text { development, urban cores, } \\
\text { and heavily industrialized areas }\end{array}$ & 90 & 86 & 58 \\
\hline
\end{tabular}

${ }^{1}$ This column applies to the final calibrated models for Woodland Creek subbasins WL2, WL9, WL13, and WL14; and Woodard Creek subbasins WD1, WD2, and WD3.

Table 4.--Designations and characteristics of land-segment types for pervious areas $[\cdots$, no data $]$

\begin{tabular}{|c|c|c|c|}
\hline \multirow{2}{*}{$\frac{\text { Designations }}{\text { Land-segment type }^{1}}$} & \multicolumn{3}{|c|}{ Characteristics } \\
\hline & Soil type & Land-cover type & Slope type \\
\hline $\mathrm{OF}$ & Outwash & Forest & - \\
\hline OG & Outwash & $\begin{array}{l}\text { Nonforest } \\
\text { (mostly "grass") }\end{array}$ & -- \\
\hline $\mathrm{OC}$ & Outwash & Crop & -- \\
\hline TFF & Till & Forest & Flat \\
\hline TFM & Till & Forest & Moderate \\
\hline TFS & Till & Forest & Steep \\
\hline TGF & Till & Nonforest & Flat \\
\hline TGM & Till & Nonforest & Moderate \\
\hline TGS & Till & Nonforest & Steep \\
\hline KFF & Kitsap & Forest & Flat \\
\hline KFM & Kitsap & Forest & Moderate \\
\hline KFS & Kitsap & Forest & Steep \\
\hline KGF & Kitsap & Nonforest & Flat \\
\hline KGM & Kitsap & Nonforest & Moderate \\
\hline KGS & Kitsap & Nonforest & Steep \\
\hline SAT & Saturated & .- & -- \\
\hline
\end{tabular}

\footnotetext{
${ }^{1}$ Land-segment type definitions: OF, outwash soils, forest cover, all slopes; OG, outwash soils, nonforest cover, all slo res; OC, outwash soils, crops, all slopes; TFF, till soils, forest cover, flat slopes; TFM, till soils, forest cover, moderate slopes; TFS, till soi!s, forest cover, steep slopes; TGF, till soils, nonforest cover, flat slopes; TGM, till soils, nonforest cover, moderate slopes; TGS, till soils, nonforest cover, steep slopes; KFF, Kitsap soils, forest cover, flat slopes; KFM, Kitsap soils, forest cover, moderate slopes; KFS, Kitsap soils, forest cover, steep slopes; KGF, Kitsap soils, nonforest cover, flat slopes; KGM, Kitsap soils, nonforest cover, moderate slopes; KGS, Kitsap soils, nonforest cover, steep slopes; SAT, saturated soils, all covers, all slopes.
} 


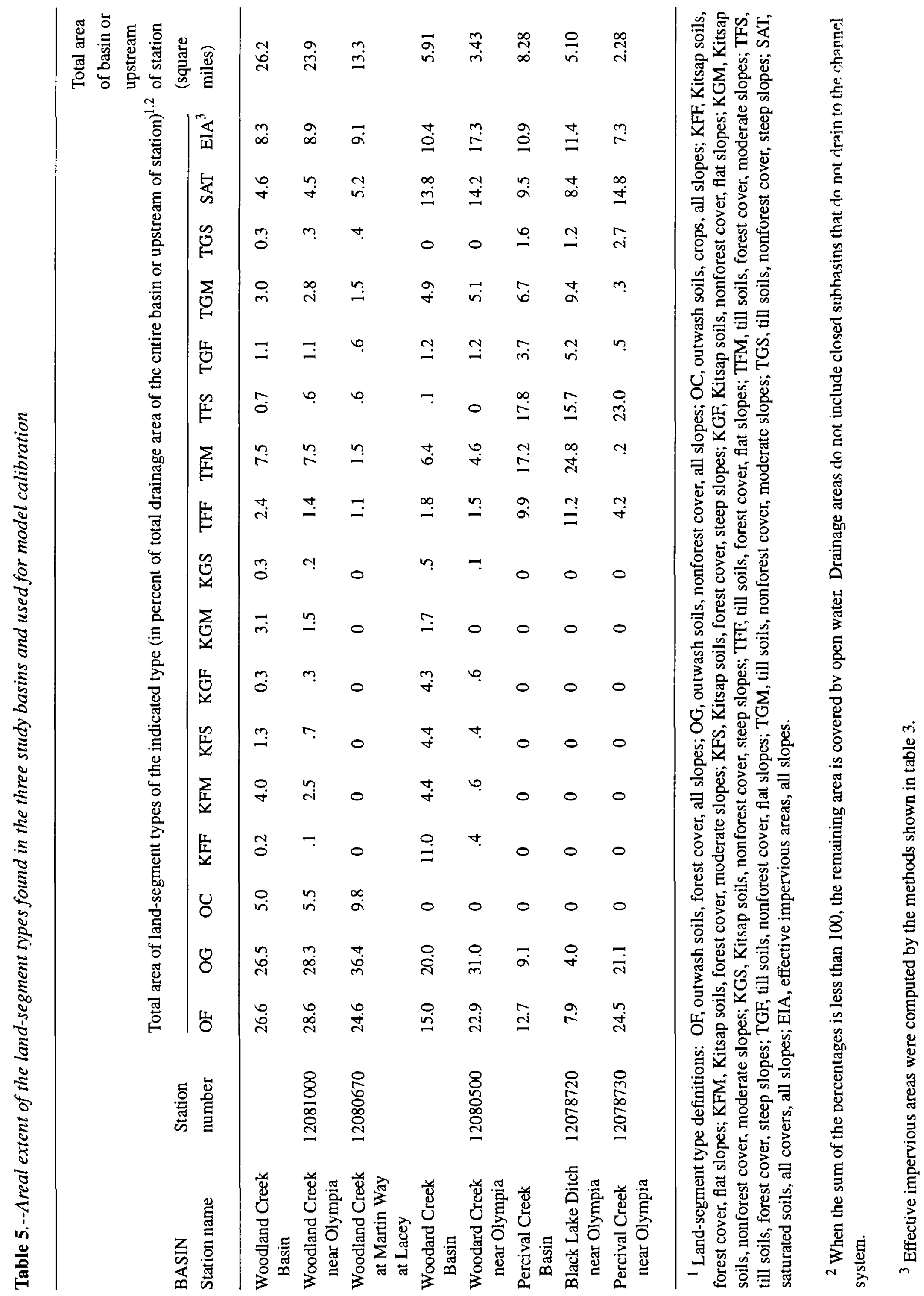


initial parameter values were those previously determined for till land-segment types, except that two parameter values were adjusted to increase soil moisture capacities and vertical drainage rates.

Only a few of the 18 process-related HSPF parameters described in table 1 strongly controlled the simulation of runoff generation for each land-segment type. Numerical values for these parameters followed the principles discussed below, which come from the conceptual model of runoff generation in the study basins. It was through the assigned parameter values that the features of the conceptual model were incorporated into the numerical simulation models.

In areas of outwash soil types, ground-water flow was the principal drainage mechanism. Therefore, high values were assigned to the soil-infiltration capacity index, INFILT, and low values to the interflow index, INTFW, to simulate rapid infiltration of precipitation and subsequent recharge to ground water. Because Hortonian overland flow was a viable mechanism for disturbed areas, the soilinfiltration capacity index, INFILT, was reduced for outwash-nonforest and outwash-crop segment types. This allowed Hortonian overland flow during extreme storms. Simulated interception storage and evapotranspiration were also reduced for the outwash-nonforest and outwash-crop segment types by lowering the interception storage-capacity index, CEPSC, and the lower-zone ET index, LZETP. A higher lower-zone ET index, LZETP, was assigned to the crop segment to make simulated ET greater than that for the nonforested segment types.

In areas of till soil types, including soils underlain by bedrock, shallow subsurface flow was a chief drainage mechanism. In undisturbed till segment types with moderate to steep slopes, low values were assigned to the soilinfiltration capacity index, INFILT, and high values to the interflow index, INTFW, to simulate shallow subsurface flow. The low INFILT value simulated impeded vertical drainage through the compacted till to the unsaturated lower zone and ground-water storage; and the high INTFW value simulated large amounts of shallow subsurface flow over the compacted till. Simulated shallow subsurface response was accelerated for undisturbed till segment types with steep slopes by lowering the interflow recession coefficient, IRC. To increase the amount of simulated shallow subsurface flow from undisturbed till segment types with steep slopes, the INTFW values were made higher than for moderate-sloped till segment types. To increase subsurface drainage even further for steepsloped, undisturbed till segment types, the values of INFEXP, the infiltration equation exponent, were lowered.
Simulated runoff generated from til' segment types with flat slopes was similar to but slower than that from those segment types on hillslopes during small storms. Because the rate of shallow subsurface flow was proportional to the angle of hillslopes, flat areas of till segment types can produce saturation overland flow, especially during large storms. In these segment types. restricted vertical and lateral drainage caused high water tables perched above the compacted till to saturate the s il profiles fully during large storms. These flat till segment types were assigned relatively higher INFEXP values (to simulate slow vertical drainage), lower INTFW values (to simulate reduced shallow subsurface flow), and higher IRC values (to simulate slow subsurface flow respon -9 ) than the respective values assigned to till segment types with moderate to steep slopes.

Segment types representing disturbed till hillslopes (defined by moderate to steep slope and ronforest land cover) generated more Hortonian overlard flow than segment types for undisturbed till hillslopes. Thus, parameter values for the soil infiltration-capacity index, INFILT, were lowered to simulate reduced vertical drainage, and values for the upper-zone nominal storag? index, UZSN, were lowered to simulate decreased retention and detention of surface runoff. The interception storage-capacity index, CEPSC, and the lower-zone ET in lex, LZETP, were also lowered to simulate reduced int srception storage and evapotranspiration, two changes that follow the conversion of forest land cover to grass or pasture.

In areas of fine-grained lacustrine diposits designated as Kitsap segment types, as in area of till segment types, shallow subsurface flow was an important drainage mechanism on moderate or steep hillslopes, and saturation overland flow was a viable mechanism in flat areas. However, both vertical drainage through the substratum and soil moisture storage capacities were slig'tly greater in areas of Kitsap segment types than in areas of till segment types. Accordingly, for Kitsap segment to'pes, the study used values for process-related parameters that were similar to those for till segment types, except that INFILT values were increased slightly to allow for more simulated infiltration and LZSN values were raised to simulate greater soil-moisture storage capacities. Other processrelated parameter values remained the same as those for till segment types.

Saturated soil types--poorly draining soils in topographical depressions and stream bottoms--produce saturation overland flow when these soils are saturated during wet periods of the year. Therefore, parameter values were assigned to generate substantial overland flow in saturated 
segment types during wet periods, but to inhibit runoff during the dry season. Large INFILT values were assigned so that simulated infiltration would be large when these soils had a soil-moisture deficit in the dry season. Large values were also used for UZSN, the upper-zone nominal storage index, to simulate a large quantity of water stored in the deep upper organic horizon as retention and detention storage before overland flow was generated. Furthermore, large values for INFEXP, the infiltration equation exponent, simulated rapid saturation of these soils because of rising water tables and poor drainage during wet periods; and large values for AGWETP, the active ground-water ET index, and for LZETP, the lower-zone ET index, represented substantial evapotranspiration from these soils.

\section{Subbasins}

Construction of simulation models also involved dividing each study basin into subbasins in order to route runoff from specifically located land-segment types to specific reaches. The hydraulic linkages from any of the 17 land-segment types possible in a subbasin to a specific stream reach or to inactive ground water are assigned in the NETWORK block of HSPF. Additionally, runoff in the form of streamflow from upstream reaches to downstream reaches was designated in the NETWORK block.

In the simulation models constructed for this study, subbasins were delineated along the topographic divides that separate surface runoff into respective basins or subbasins and along the divisions of the surface-drainage network into reaches. Most subbasins were assigned to drain through their reaches, but to account for the areas that do not drain to surface reaches, some closed subbasins were delineated where rainfall moves only to evapotranspiration or to recharge ground water.

In the final simulation models, Woodland Creek Basin was divided into 44 subbasins, Woodard Creek Basin into 12 subbasins, and Percival Creek Basin into 13 subbasins, for a total of 69 subbasins (figs. 5 and 6). There were 16 closed subbasins in Woodland Creek Basin, 6 in Woodard Creek Basin, and none in Percival Creek Basin.

For the pre-calibration models, all overland flow, shallow subsurface flow, and ground-water flow generated in most model subbasins discharged to the reach and through the mouth of the subbasins in which they originated. For closed subbasins, ground water discharged in the nearest stream reach draining an adjacent lowerelevation subbasin.

Not all runoff, however, necessarily discharges out of the surface-water outlets of the subbasins in which it originates. Some subbasins may have, for example, a reach that consists of a man-made drainage ditch or storm-sewer system. If these drainage systems run above the water table or shallow subsurface flow pathway or if they consist of impervious pipe or concrete, ground-water flow or shallow subsurface flow may bypass subbasin reaches as it flows downgradient. During model construction, it was specified in the NETWORK block that all runoff generated in these subbasins would discharge to the reaches and through the mouths of these originating subbasins. Later, though, during model calibration, these specifications were changed for some subbasins, and, additionally, new subbasins were defined. These types of modifications allowed more accurate definitions of runoff contributions from land segments to stream reaches. These types of modifications will be further discussed in the subsections, "Modifications to Subbasins" in the sections, "First Calibration and Evaluation" and "Final Calibration."

During model calibration, ground-water flow, shallow subsurface flow, or overland flow generated in a given subbasin was sometimes specified to drain to a reach located at a lower elevation in another subbasin. This specification was intended to simulate such situations as ground water flowing from a closed subbasin or groundwater flow or shallow subsurface flow bypassing manmade ditches or storm sewer systems. If several short, small tributary channels only sporadically drain an actual subbasin from several outlets, the NETWORK block was constructed to represent the situation by specifying that overland flow discharged to a lower-elevation reach in an adjacent subbasin.

In the natural hydrologic system of a basin, runoff drains by way of actual flow paths through or over all land intervening on the way to the surface drainage network. HSPF, however, does not simulate the actual pathway of water through all the land segments to the stream reach. Instead, it assumes that runoff from a land segment drains directly to a reach. The reach may be the most nearby reach, or it may be a reach in another subbasin. HSPF does not explicitly simulate water moving through the many individual flow paths in land segments, and this simplification helps keep basin models relatively efficient and simple. 


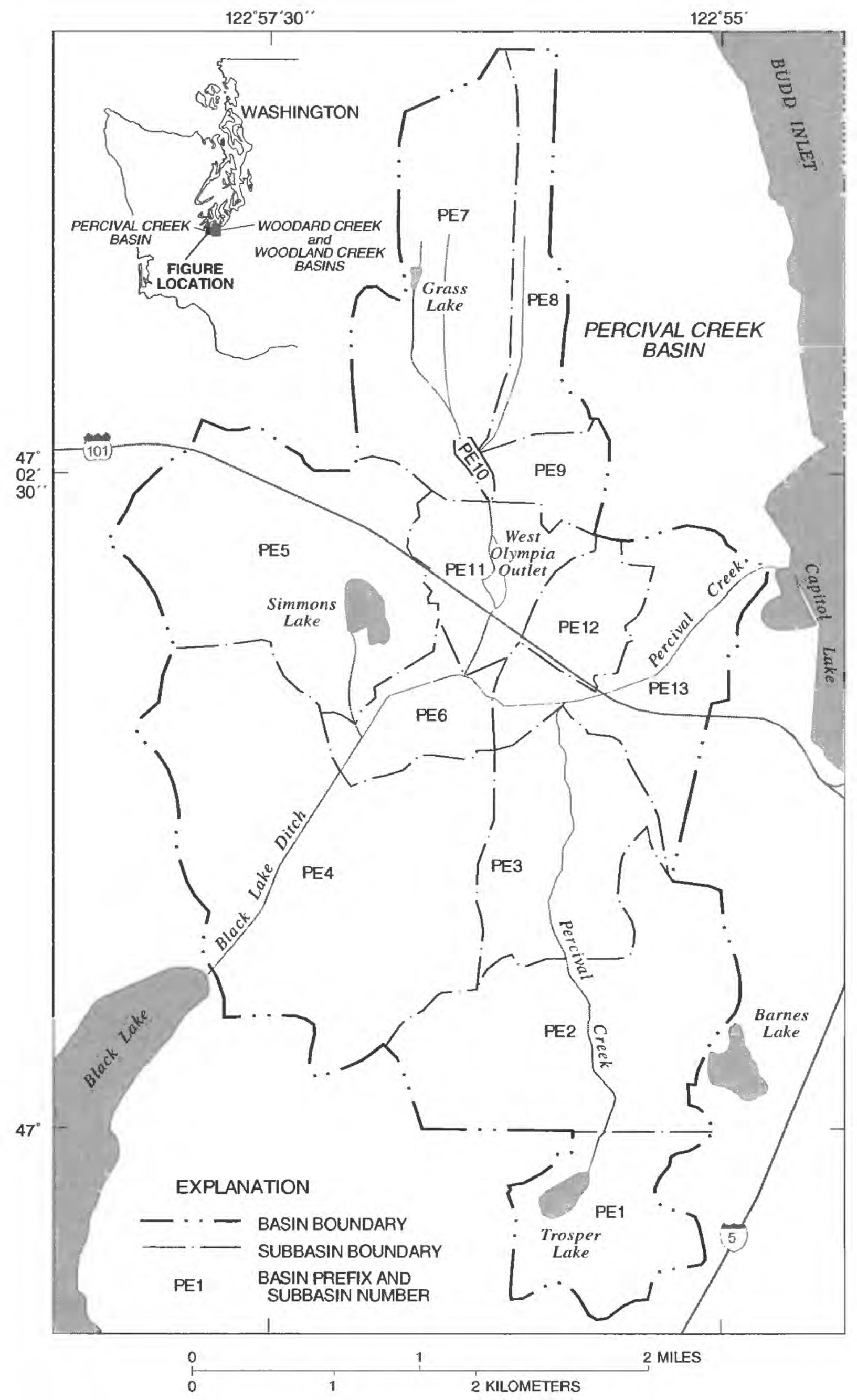

Figure 5.--Subbasins in the Percival Creek Basin used in the final simulation model. 


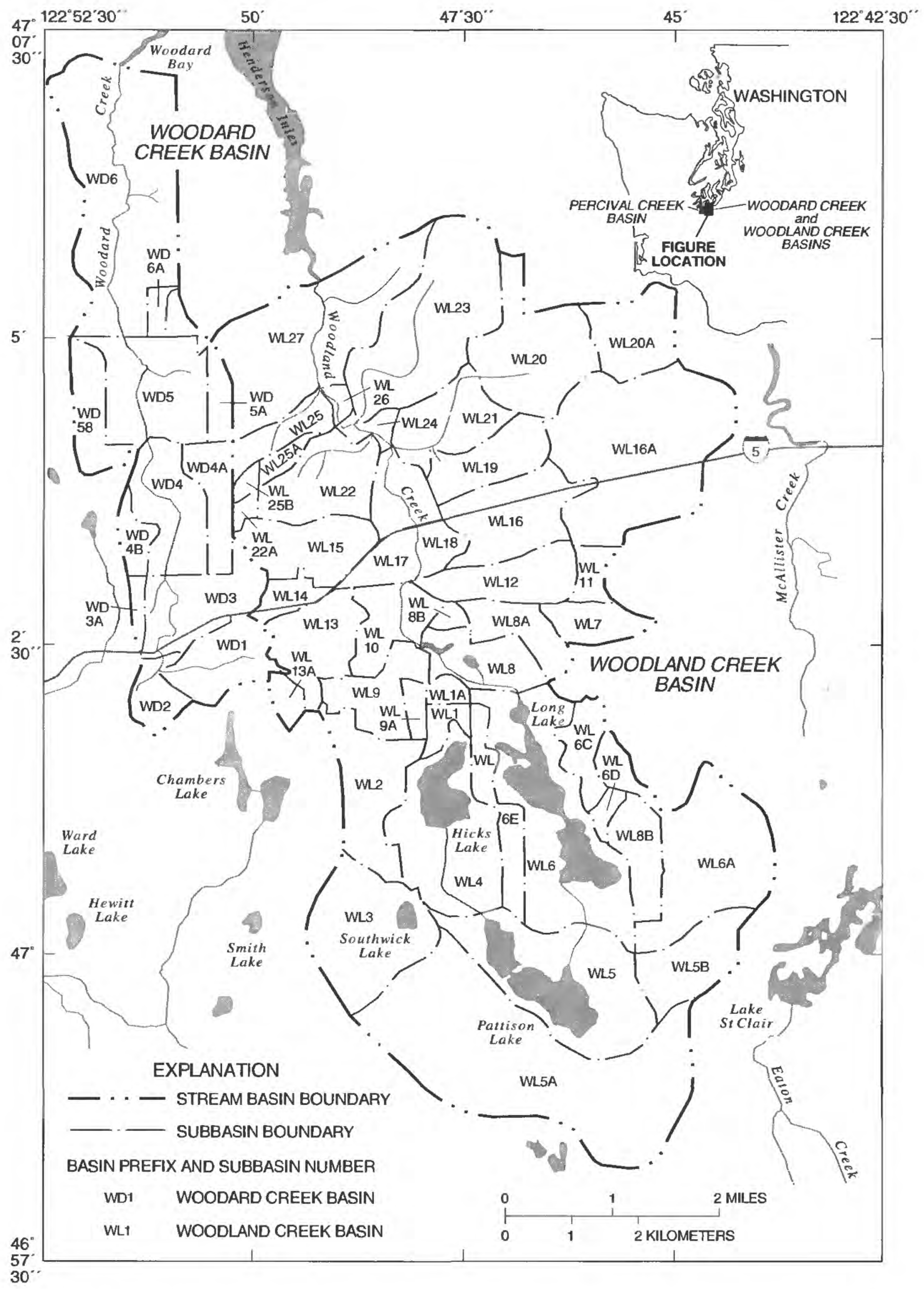

Figure 6.--Subbasins in the Woodard and Woodland Creek Basins used in the final simulation. 
Because HSPF simplifies the delivery of runoff from land-segment types to subbasin reaches, simulated travel times may be shorter than actual travel times. Nevertheless, these differences in time-of-travel were not found to be significant for overland flows and ground-water flows in the small subbasins of the study and were minimized for shallow subsurface flow.

The difference in travel times between simulated and actual overland flow was negligible because actual overland flow moves relatively quickly to reaches. The travel time difference also was not significant for ground-water flow. Although the study defined subbasin boundaries on surface-water divides, these divides probably do not always coincide with ground-water divides for mildly sloping areas. For mildly sloping areas where hydraulic conductivities of the underlying ground-water system were high, some ground-water flow was assigned, during calibration, to lower elevation, downgradient reaches outside originating subbasins. It is likely that rainfall causes ground water in these areas to respond uniformly as a large system underlying several subbasins. The effect of rainfall on these subbasins, including closed subbasins and other subbasins where ground water may not discharge to nearby channels, is to raise the water table, to increase its gradient, and to increase ground-water flow throughout the ground-water system. As the gradient of the water table increases, ground-water flow moves downgradient and displaces lower elevation ground water located near a downgradient channel at increasing rates, and the displacement in turn increases ground-water discharge to that channel. Thus, recharge to an aquifer lying under an upgradient closed subbasin can displace downgradient ground water to a lower-elevation channel. The HSPF simulation of direct drainage to a channel reach that bypasses intervening land segments is a reasonable approximation of ground-water displacement, and the time-of-travel differences should not be significant.

Travel-time differences may noticeably affect the simulation of shallow subsurface flow because actual shallow subsurface flow is much slower than overland flow, and, unlike ground-water flow, it does not respond to precipitation uniformly under several subbasins. To minimize travel-time differences, the study generally did not assign shallow subsurface flow to drain to reaches in adjacent subbasins but instead confined the flow to reaches within its own originating subbasin. When the simulation had to assign shallow subsurface flow to an adjacent subbasin, the study required that the originating subbasin be small (less than 150 acres) so that the drainage path would be short and the actual travel time brief.

\section{Reaches}

The last phase of model construction involved dividing the drainage network into segments, or reaches, each with relatively uniform hydraulic characteristics. The reaches were used either to drain or to connect subbasins. Each reach had its own contributing subbasin area, and each received runoff discharge from the land segments within the subbasin and from all connected upstream reaches. Each reach consisted of stream channels, stormdrainage pipes, lakes, ponds, or wetlands. In the final basin models, Percival Creek was divided into 13 reaches, Woodard Creek into 6 reaches, and Woodland Creek into 22 reaches, for a total of 41 reaches.

\section{The RCHRES (reach-reservoir) block of HSPF} routes streamflow along connected reaches of a drainage network to the outlet of a drainage basin. Streamflow routing is based on the hydraulic characteristics of the stream reaches, and those characteristics are defined by fixed parameters in the flow tables, or F-tables, of the RCHRES block. F-tables represent the relation of surface-water discharge at the downstream end of a reach to surface-water volume temporarily stored in the reach. HSPF uses this stored volume of water to simulate the discharge from a reach during a given time interval. F-tables also can specify losses from channel or lake seepage.

The initial volume-discharge relations for reaches were determined from measurements or estimates of hydraulic properties during field reconnaissance and from measurements of some channel properties directly from maps. Reconnaissance data collected in a previous investigation (Bortleson and others, 1976) provided information on lake properties in Woodland Creek Basin. This information was used to determine the volume-discharge relations for Hicks Lake in subbasin WL4, Pattison Lake in subbasin WL5, and Long Lake in subbasin WL6. Field reconnaissance yielded measurements or estimates of channel cross sections, channel roughness, culvert lengths, culvert slopes, culvert roughness, culvert cross sections, and culvert entrance shapes. Map data provided information on channel lengths and slopes, and on storm-drainage pipe cross sections, slopes, and lengths. Because HSPF simulates stream discharges at the downstream end of reaches, field reconnaissance usually took place at or near these downstream ends. However, hydraulic properties sometimes were observed at several locations within a reach because cross sections measured during field reconnaissance had to represent the reach as a whole. The hydraulic information was collected so that depthdischarge relations could be estimated from Manning's equation for open channels or from the energy equation for 
culverts. For a given depth and discharge, cross-sectional areas were multiplied by channel length to determine the volume of water stored in the reach. Each F-table represented a general average for the entire reach rather than a specific relation for every single channel, pipe, lake, pond, or wetland within the reach.

The relative sensitivity of a reach, or the degree to which a change in the stored volume of a reach changes its discharge, is represented in the F-tables. For example, an F-table for a reach consisting of a lake would have a large range of storage volumes corresponding to a small range of discharge at the outlet. Thus, for a large storm, a large change in storage volume will correspond to only a small change in discharge at the lake outlet. Discharge from this reach would be relatively insensitive to changes in storage volume. Pattison Lake (subbasin WL5) and Long Lake (subbasin WL6) in the Woodland Creek Basin are examples of insensitive reaches.

\section{Calibration and Evaluation of the Simulation Models}

After the study area was divided into land-segment types, subbasins, and reaches and after initial values were assigned to HSPF parameters, the simulation models were calibrated and evaluated. The underlying goal of model calibration and evaluation was to appraise the conceptual model of runoff generation in the Woodland, Woodard, and Percival Creek Basins. If the initial simulation models constructed using the same general approach and parameter values determined by Dinicola (1990) (along with using the first approximation of parameter values for the land-segment types not found in that previous study) had resulted in adequate simulations of streamfiow, then model calibration would not have been needed. Favorable results would have implied that the conceptual model and the quantitative expression of the conceptual model (the numerical models) were adequate for the Thurston County study basins. Thus, the conceptualizations and parameters for land-segment types in basins in King and Snohomish Counties in the central Puget Sound Lowland also would have applied to those land-segment types in basins in Thurston County in the southern Puget Sound Lowland. However, because the initial simulation models did not adequately simulate observed streamflow, the simulation models required calibration and further evaluation.

The immediate goal of calibrating the basin models was to minimize differences between observed and simulated streamflows at stream-gage sites. This procedure involved testing and, when necessary, adjusting the values of process-related and fixed parameters. The need for adjustments was signalled by significant differences between simulated and observed hydrographs and volumes. The nature and extent of adjustments was guided by supplemental information on drainage networks, soils, geology, and ground water.

The goal of evaluating the basin models was to test how well the calibrated models could simulate streamflows for periods other than those used during the calibration process. If the calibrated models were truly representative of the runoff generation process, then the differences between observed and simulated streamflows for both the calibration and the evaluation periods should have been similar in magnitude. If the differences were significantly larger for the evaluation period, then it could have been concluded that the calibrated models were not adequately representing the runoff generation processes.

The original study plan for this investigation was designed so that the first year of observed data would be used for model calibration and the second year would be used for evaluation. The results of this "split-sample" approach are presented in the section of this report entitled "First Calibration and Evaluation." As described in that section, some measures of simulation differences for the evaluation period were much larger in magnitude than those differences reported for the calibration period. It was decided that improvements could be made to the first calibration if observed data from the evaluation period were used to refine the calibration.

The section of this report entitled "Final Calibration" presents the results of calibrating the basin models with 2 years of observed data. These final basin models were not evaluated with additional streamflow data as part of this investigation because the entire observed record was used for calibration, but some important features were added to the basin models as a result of the 2-year calibration effort.

Calibration and evaluation were based on streamflow (stream discharge and volume) because it is an easily measured basinwide response to precipitation. However, identifying the individual hydrologic processes that generate this response is difficult, and the process-related parameters that govern the simulation of these processes are difficult to measure independently. Nevertheless, calibrating basin models to observed streamflow data is a practical method of comparing runoff theory and observations. 
The following sections describe (1) the observed data used for model calibration and evaluation; (2) the sources of difference between observed and simulated streamflows; (3) the adjustments and refinements to model parameters for both the first calibration and evaluation effort, and the final calibration effort; and (4) the calibration and evaluation results. The sections discussing calibration and evaluation results include an evaluation of differences between observed and simulated streamflows for (1) the first-year calibrated models calibrated to a little more than 1 year of observed streamflow and evaluated with a second year of observed streamflows and for (2) the final calibrated models calibrated to a little more than 2 years of observed streamflows.

\section{Data Collection}

The streamflow data for model calibration and evaluation were collected during the period March 1, 1988, through March 15, 1990, at 15-minute intervals from six continuous-record streamflow gages--two gages in Woodland Creek Basin, one in Woodard Creek Basin, and three in Percival Creek Basin (figs. 7 and 8). Because the upstream boundary of Percival Creek Basin was defined as the northern outlet of Black Lake, lake outflow data obtained at gage 12078705 (Black Lake Ditch at Lake Outlet near Tumwater) were not used for model calibration but were used to define the upstream inflows for streamflow simulation with the Percival Creek model. Calibration for this part of the Percival Creek model was carried out at the downstream gaging station 12078720 (Black Lake Ditch near Olympia). The contributing areas to the five other gages used for calibration ranged from 2.3 to 23.9 square miles. For the same period, instantaneous peak flows were estimated a few times each year at two crest-stage gage sites in the basins; stage was measured periodically at five lake and stream sites; and occasional measurements of discharge were obtained at a number of sites scattered throughout the basins.

The basin models simulated runoff generation and streamflows for each entire basin even though each basin contained substantial area between the farthest downstream gaging station and the basin mouths. These areas are called "ungaged areas." Gaging stations were not installed farther downstream toward the basin mouths because either (1) access was not available or (2) locations with hydraulic conditions suitable for collection of streamflow data were not available. Ungaged areas cover 11 percent of the Percival Creek Basin (579 acres), 42 percent of the Woodard Creek Basin (1,584 acres), and 9 percent of the Woodland Creek Basin (1,480 acres). The basin models were not calibrated to observed streamflows in the ungaged areas, and model results for these areas are not presented in this report. It is likely that streamflow simulations will be less accurate in the ungaged areas than in the gaged areas.

Simulation of stream discharge and runoff volumes required input time series for observed rainfall and estimated potential evapotranspiration. Rainfall accumulation data were collected continuously at 15 -minute intervals from March 1, 1988, through March 15, 1990, at four sites in the three basins (figs. 7 and 8). Pan-evaporation data were obtained from the National Weather Service Class A evaporation pan near Puyallup, Wash., about 30 miles northeast of the study area, for the periods March through October 1988 and May through September 1989. A coefficient of 0.75 applied to pan data yielded potential evapotranspiration (PET) (Farnsworth and Thompson, 1982). PET data for the periods November 1988 through April 1989 and October 1989 through March 1990 were estimated from a version of the Jensen-Haise equations (Bauer and Vaccaro, 1986), which required temperature data from the National Weather Service station at Olympia Airport.

The data-collection period represented a variety of hydrologic conditions. Although there were variations of rainfall throughout the study area, rainfall was generally slightly below average (mean annual precipitation is about 51 inches in the Olympia area) from March 1, 1988, through February 28,1989 , and slightly above average from March 1, 1989, through February 28, 1990. A large range of streamflows was present during the datacollection period--from the low streamflows in the summer of 1988 to the high streamflows in the winter of 1990. An extremely large series of storms between January 4 and 9,1990 , dropped 8 to 10 inches of rain in 6 days, more intense rain than at any other time in the study period. These storms provided the opportunity to calibrate the models to extremely high streamflows.

\section{Sources of Differences Between Observed and Simulated Streamflow}

There is commonly a difference between modelsimulated streamflow and observed streamflow. Two reasons usually account for the difference: (1) the basic data to drive or calibrate the model are inadequate or inaccurate; or (2) the models inadequately represent runoff processes. 


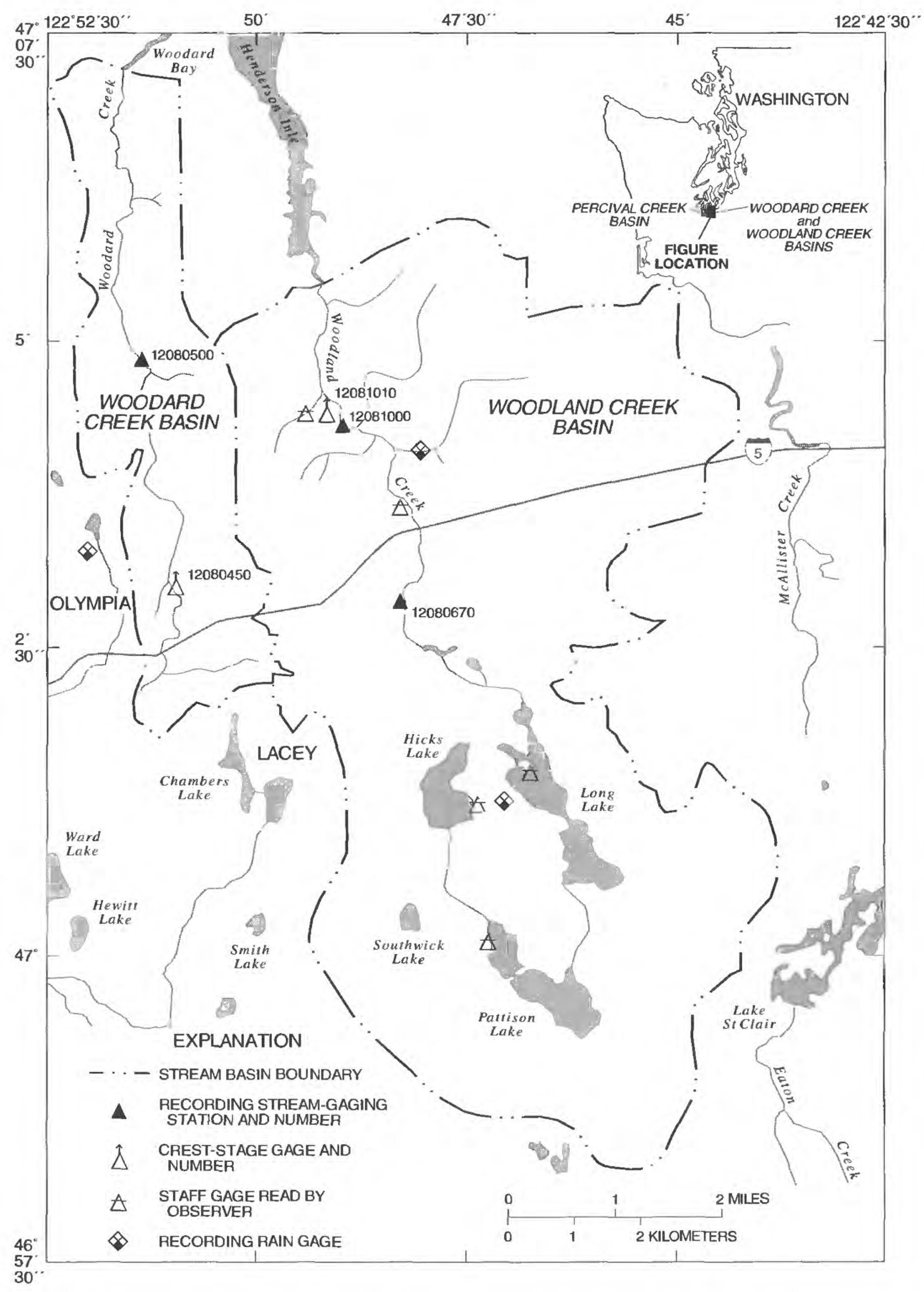

Figure 7.--Data-collection network for Woodard and Woodland Creek Basins. 

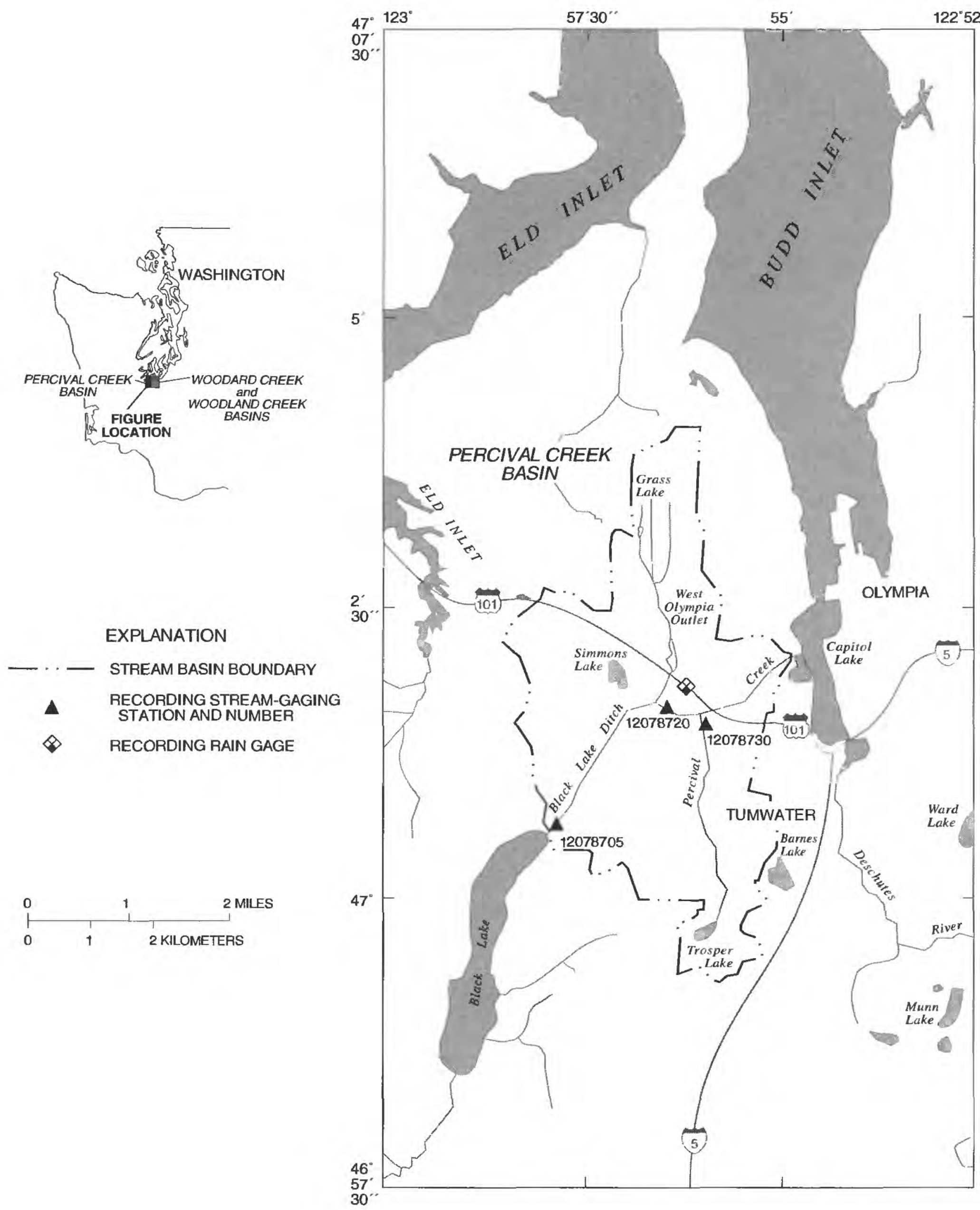

Figure 8.--Data-collection network for Percival Creek Basin. 
Rainfall data may not always be adequate or accurate. Although precipitation from the frontal storms that commonly generate runoff in the Puget Sound region was assumed to be homogeneous throughout the area, the data from this study's rain gages, spaced about one per 10 square miles, show that rainfall varied significantly from one gage to another. Thus, precipitation may not have been adequately represented for each subbasin. Another problem was that the rain gages were not constructed to measure snowfall or snowmelt accurately. Although snow is not common in the study area, Olympia Airport recorded about 7 inches of snow in January 1988, 14 inches in February 1989, 9 inches in March 1989, 2 inches in January 1990, and 27 inches in February 1990. Finally, rain-gage malfunctions, although not significant, resulted in periods of missing record that contributed some inaccuracy. Rainfall for periods of missing record had to be estimated from nearby gages because model runs required continuous rainfall records with no gaps. The precipitation measurement and distribution problems described above may subsequently result in inaccurate streamflow simulations in the study basins.

Daily PET rates also may contribute inaccuracy to simulated streamflow. PET rates were not directly measured in the study area. Therefore, daily PET rates in the study area were derived from pan-evaporation records for Puyallup, Wash., and from temperature data at Olympia Airport. Although the data used to derive the daily PET rates were collected near the study basins, these derived rates may vary from the actual PET rates in the study's drainage basins. Thus, PET rates may not be adequately represented in the drainage basins.

Differences between simulated and observed streamflows may also result from inaccuracy in the observed streamflow data. The most common source of inaccuracy in observed streamflow data was the inconsistent quality of records from some stations. Although locations for stream-gaging stations were chosen specifically for model calibration and evaluation, unstable channels at some locations caused variable stage-discharge relations. Discharge was measured at these locations frequently to improve the accuracy of these relations, but even so, the accuracy of stage-discharge records at certain gaging stations was rated "fair". A fair rating means that 95 percent of the observed daily streamflows are accurate only to within 15 percent of true values. Moreover, missing periods of stream-flow records resulted from malfunctioning streamgage stations, usually because of freezing. Streamflow records for these missing periods were estimated from the hydrographs of nearby unaffected gages.
Differences between simulated and observed streamflows also arise from uncertain representations of hydrologic processes by HSPF and by uncertain parameter values in the basin models. The HSPF pro,gram can represent most of the many complex physical processes that affect runoff generation, but like all current rainfall-runoff models, it simplifies the natural system, and this simplification sometimes produces differences between simulated and observed streamflows. Because values for the model parameters that are used in the representation of processes could not be directly and precisely measured, they were determined or adjusted by calibration to ob erved streamflows. Parameter values were in accord with reliable information on soils, geology, ground wate-. and channe1 networks, but there is some uncertainty about how accurately and fully parameter values represent all the features controlling the hydrologic processes at work throughout the study basins. Later sections of this report will discuss evaluations of these discrepancies.

\section{First Calibration and Evaluation}

As mentioned previously, the simulation models initially constructed using the general approach and parameter values determined by Dinicola (1990) did not adequately simulate streamflow without further calibration. These initial models were thus calibrated to observed streamflow data in the surface drainages of Woodard Creek, Woodland Creek, and Percival Cree ${ }^{1}$. downstream from Black Lake between March 1, 1988, and March 29, 1989. The calibration process involved modifying (1) a process-related parameter in the PERLND block, (2) surface- and ground-water contributions to sutbasin drainage networks in the NETWORK block, and (3) volumedischarge relations of reaches in the F-tables of the RCHRES block. An attempt was made to evaluate these calibrated models, also referred to as the first-year calibrated models, by comparing simulated streamflows with observed streamflows for the period March 30, 1989, through March 15, 1990.

\section{Modifications to Process-Related Parameter Values}

Process-related parameter values are commonly modified during calibration to minimize differences between observed and simulated streamflor's at streamflow-gaging stations. The following discussion describes, in a general manner, the poor simulation re rilts from the initially constructed models, the explanation why the 
values of process-related parameters were sometimes not modified to improve the poor simulations, and the modification of one process-related parameter value, KVARY.

Initial simulation results (after model construction) were considered to be poor from the Woodland and Woodard Creek models and from the Percival Creek model representing the part of Percival Creek Basin upstream from Black Lake Ditch near Olympia, Wash. (station 12078720). The simulation results were considered to be poor for two reasons listed below.

(1) Simulated runoff volumes, daily mean discharges, peak discharges, and high runoff volumes from storms generally exceeded observed data. Such results are called "over-simulation," and converse results are called "under-simulation" in this report.

(2) Timing and magnitude of simulated ground-water discharge did not coincide with observed seasonal baseflows.

There are two possible reasons for over-simulating runoff volume at the gaging stations: the under-simulation of actual evapotranspiration (AET) and the over-simulation of runoff contributions to a reach from land segments in a subbasin. The potential evapotranspiration data input to the three basin models averaged about 24 inches per year for the 2-year calibration period. The simulated AET averaged about 17 inches per year for the three basins during that same period. It is likely that AET did not satisfy the PET demand during the dry summer months when soil-moisture levels were low. Additionally, simulated AET values are consistent with AET values simulated for basins in King and Snohomish Counties (R.S. Dinicola, U.S. Geological Survey, written commun., 1992). Therefore, the simulated values of AET are reasonable, leaving the over-simulation of runoff contributions from land segments to reaches as a likely source of errors.

Adjusting process-related parameter values is a common calibration technique to reduce runoff contributions to stream reaches. However, except for KVARY, adjustment of process-related parameter values did not consistently improve the over-simulation of runoff at four of the five gaging stations used for calibration. Most adjustments produced variable results, depending on the season and location of the gaging stations.

Results from runoff simulations, using the original parameter values chosen during model construction, at the fifth gaging station were generally satisfactory, except that simulated ground-water baseflows were lower than measured baseflows. The fifth gaging station, Percival Creek station 12078730, collected streamflow data from a relatively simple basin. This part of the Percival Creek Basin is relatively simple because, except in the headwater subbasin (PE1), Percival Creek lies in a valley between moderately to steeply sloped hills that cl sarly define the subbasin boundaries. All ground-water flow, shallow subsurface flow, and overland flow generate $\mathrm{d}$ in this part of Percival Creek Basin was simulated to conntribute to streamflows without over-simulating observed streamflow. Thus, for this relatively simple part of Percival Creek Basin, the process-related parameter values adequately represented the hydrologic responses of land segments to rainfall. It is also probable that the parameter values also adequately represented the hydrologic responses of land segments to rainfall for the other basins because most of the same land-segment types were present throughout all of the basins. However, the process-related parameters do not direct outflow from land segments (g־ound-water flow, shallow subsurface flow, and overland flow) to reaches. The NETWORK block is used to direct these outflows. In the initially constructed models, outflows from land segments were directed to reaches in the sarre subbasins or, in the case of closed subbasins, to reaches in adjacent downstream subbasins. Thus, in the initially constructed models, oversimulation of runoff contributions from land segments to reaches occurred where outflows contribute to inactive ground water or to reaches in other subbasins.

The deep fraction (DEEPFR) pararneter can be used to assign outflows from land-segment tyวes to inactive ground water. However, this parameter governs outflows from all land segments in a given type regardless of the location of that land segment. This para neter was not adjusted in the basin models because contributions from land segments to inactive ground water varied with location. Thus, the only practical method of adjusting contributions of outflows to reaches or inactive ground water was to adjust the routing of outflows in the NETWORK block of the HSPF program. This is discussed in the following section, "Modifications to Sut basins."

The value of only one process-related parameter was modified in the PERLND block during $\mathrm{frst}$ calibration. The parameter KVARY (the active ground-water outflow modifier) was reduced for all land-segment types in the initial Woodland and Woodard Creek Besin models to improve the timing and magnitude of simulated groundwater discharge. This value was changet because during winter and spring wet periods, simulated streamflows decreased more gradually than observed streamflows after storm-driven hydrograph peaks, with the recession limb of the simulated hydrograph having a flatter slope than the 
recession limb of the observed hydrograph. Simulated baseflows during these winter and spring wet periods were higher than observed baseflows, but simulated baseflows during summer low-flow periods were lower than observed streamflows. Reducing the value for KVARY improved streamflow simulations by decreasing simulated ground-water flow contributions to reaches during winter and spring wet periods and by increasing these contributions during the summer dry period. The other processrelated parameter values did not need adjustment in first calibration.

\section{Modifications to Subbasins}

Several modifications related to the delineation of subbasins and the drainage from subbasins were made during first calibration. Additional subbasins were delineated; contributions of ground-water flow, shallow subsurface flow, and overland flow to stream reaches in some subbasins were changed; and the percentage estimates of effective impervious area for each partially impervious land cover class in some subbasins were revised.

Additional subbasins were delineated using two methods: (1) subdividing existing subbasins into two or more subbasins and (2) adding new subbasins from outside the previously defined basin boundaries. The need to subdivide subbasins into two or more subbasins was recognized when simulated streamflows exceeded streamflows observed in several Woodland and Woodard Creek subbasins. Subsequent field reconnaissance indicated that surface-water runoff from large parts of these subbasins did not drain to the reaches within the subbasins and that it was questionable whether all shallow subsurface flow and ground-water flow drained to the reaches. Therefore, some existing subbasins were subdivided to allow more accurate definition of the hydraulic linkages between the land segments and reaches (table 6). The refinement of these linkages in the NETWORK blocks of the basin models resulted in more accurate simulations.

The need to add new subbasin area from outside the previously determined basin boundaries was recognized when simulated ground-water baseflows were lower than measured baseflows at the Percival Creek stream gage at Mottman Road near Olympia. A new subbasin (PE1A) of 180 acres was added to the initial Percival Creek model. This new subbasin functioned to add ground-water flow contributions to Percival Creek from outside the basin.
Table 6.--Initial subbasins (delineated prior to calibration) that were subdivided into new subbasins during first and final calibrations

\begin{tabular}{|c|c|c|c|}
\hline Basin & $\begin{array}{l}\text { Initial } \\
\text { sub- } \\
\text { basins }\end{array}$ & $\begin{array}{l}\text { New } \\
\text { subbasins } \\
\text { for the } \\
\text { first-year } \\
\text { calibrated } \\
\text { models }\end{array}$ & $\begin{array}{l}\text { New } \\
\text { subbasins } \\
\text { for the } \\
\text { final cal- } \\
\text { ibrated } \\
\text { models }\end{array}$ \\
\hline \multirow[t]{9}{*}{$\begin{array}{l}\text { Woodland } \\
\text { Creek }\end{array}$} & WL5 & $\begin{array}{l}\text { WL5A } \\
\text { WL5B }\end{array}$ & $\begin{array}{l}\text { WL5A } \\
\text { WL5B }\end{array}$ \\
\hline & WL6 & $\begin{array}{l}\text { WL6A } \\
\text { WL6B } \\
\text { WL6C } \\
\text { WL6D } \\
\text { WL46 } \\
\text { WL46A }\end{array}$ & $\begin{array}{l}\text { WL6A } \\
\text { WL6B } \\
\text { WL6C } \\
\text { WL6D } \\
\text { WL6E }\end{array}$ \\
\hline & WL8 & $\begin{array}{l}\text { WL1A } \\
\text { WL8A } \\
\text { WL8B }\end{array}$ & $\begin{array}{l}\text { WL1A } \\
\text { WL8A } \\
\text { WL8B }\end{array}$ \\
\hline & WL9 & WL9A & WL9A \\
\hline & WL13 & WL13A & WLI3A \\
\hline & WL16 & WLI6A & WLI6A \\
\hline & WL20 & WL20A & WL20A \\
\hline & WL22 & WL22B & WL22A \\
\hline & WL25 & $\begin{array}{l}\text { WL22A } \\
\text { WL25A }\end{array}$ & $\begin{array}{l}\text { WL25A } \\
\text { WL25B }\end{array}$ \\
\hline \multirow[t]{4}{*}{$\begin{array}{l}\text { Woodard } \\
\text { Creek }\end{array}$} & $\begin{array}{l}\text { WD2 } \\
\text { and } \\
\text { WD3 }\end{array}$ & WD3A & $\begin{array}{l}\text { WD2 } \\
\text { WD3 } \\
\text { WD3A }\end{array}$ \\
\hline & WD4 & $\begin{array}{l}\text { WD4A } \\
\text { WD4B } \\
\text { WD4C }\end{array}$ & $\begin{array}{l}\text { WD4A } \\
\text { WD4B }\end{array}$ \\
\hline & WD5 & $\begin{array}{l}\text { WD5A } \\
\text { WD5B }\end{array}$ & $\begin{array}{l}\text { WD5A } \\
\text { WD5B }\end{array}$ \\
\hline & WD6 & WD6A & WD6A \\
\hline
\end{tabular}

\footnotetext{
'WD2 and WD3 were considered one subbasin in the initial Woodard Creek model and the first-year calibrated Woodard Creek model.
} 
The boundary of headwater subbasin PE1 was poorly defined because of the flat topography of the outwash plain in that area, and the apparent surface-water divide in the area did not seem to coincide with the ground-water divide. Thus, ground water under PE1 is likely part of a larger ground-water system that can respond to precipitation falling outside the basin. Although the precise location of the boundaries of PE1A was unknown, total size of the new subbasin was determined by calibration to observed baseflows.

Simulated streamflows commonly exceeded observed streamflows, and the frequent disparity indicated some ground-water flow, shallow subsurface flow, or overland flow from some subbasins did not drain into the reaches that discharge at the mouths of the originating subbasins (subbasin reaches). The flow mechanisms presumably bypassed subbasin mouths for the following reasons:

(1) Ground-water recharge in extensive outwash areas drained to regional rather than local aquifers;

(2) Ground-water and shallow subsurface flows never surfaced in a basin because the reach draining a subbasin, or sections of the reach, was higher than the ground-water table;

(3) Contributions of runoff to the drainage networks were modified by complex ground-water/surface-water interactions at lakes; and

(4) Contributions of subsurface flow and overland flow were decreased in areas with man-made conveyance systems, infiltration facilities, dry wells, or hummocky areas with many closed depressions.

Specifications in the NETWORK block of the calibrated models were revised so that estimated parts of ground-water, shallow subsurface, and overland flow would not discharge at the mouth of certain subbasins. Some simulated runoff was specified to discharge into the subbasin reach, and the remainder of runoff was specified to either discharge at a downgradient reach in a nearby subbasin or recharge to inactive ground water. For example, a part of the ground-water flow from a series of Woodland Creek subbasins (WL1 A, 8A, 8B, 9, 9A, 10, 12, $13,13 \mathrm{~A}, 14,16$, and $16 \mathrm{~A}$ ) was assigned to contribute to a complex system of springs in subbasin WL17 of the Woodland Creek Basin. The quantity of ground-water contributions to the springs was estimated from stream discharge measurements of Woodland Creek immediately upstream and downstream of the springs, and at the springs.

Another subbasin-related modification made during first calibration was for subbasins where outwash land segments lay immediately downhill from till segments. Observed runoff responses from such areas were dampened and attenuated--more typical of outwash rather than till segments. The NETWORK block in the basin models was revised to treat such uphill till segments as though they were outwash segments, a modification designed to represent the drainage of runoff from a ti 1 segment to the first downhill outwash segment. This adjıstment assumed that the overland flow and shallow subsu face flow generated on an uphill till segment would become recharge once they reached a downhill outwash segmen*.. On the basis of streamflow information, the proportion of land segments having till and outwash soil types was refined for Woodard Creek subbasin WD3 and for Woodland Creek subbasins WL13, 14, 15, 16, 16A, 17, 19, 20, and 21 .

Errors in the initial estimates of effective impervious area were suspected when, in some highl'? urbanized subbasins in outwash areas of Woodland and Woodard Creek Basins, simulated discharge peaks resulting from storms were higher and quicker than the observed peaks and simulated runoff volumes after storms were greater than observed volumes. Hence, contributions of runoff from impervious areas in these urbanized subt asins were adjusted in the NETWORK block. The drainage systems in these areas are mostly grass-lined swa'es rather than curb-and-gutter systems, and grass-lined swales can store and infiltrate large quantities of runoff generated from impervious areas. On the basis of calibration to observed streamflow, the estimated percent effectiveness was decreased for the six classes of impervious land cover (table 3) in Woodland Creek subbasins W'L9, 13, and 14 and Woodard Creek subbasin WD1. These were the decreases:

Sparse residential--from 4 percent to 0 percent;

Moderate residential--from 10 percent to 0 percent;

Suburban residential--from 23 percent to 0 percent;

High-density residential--from 48 perc snt to 24 percent;

Medium commercial/low-density indu:trial--from 48 to 24 percent;

Heavy commercial/heavy industrial--from 86 to 58 percent. 


\section{Modifications to Reaches}

The F-tables in the RCHRES block of the initial models were modified to refine volume-discharge relations and to account for documented reach losses. The volume-discharge relations were refined when the simulated magnitude and timing of storm hydrographs did not closely match those of observed hydrographs. These refinements, based on information from field surveys and reconnaissance and from maps, usually involved smallscale adjustments of the volume or corresponding discharge for a given depth of water in a stream reach. However, defining the volume-discharge relations at the outlets of large lakes in the Woodland Creek Basin was difficult, and the calibration of volume-discharge relations in these cases involved larger adjustments.

Losses of water due to infiltration into bed materials was simulated by adding a second discharge column in the volume-discharge relation of certain F-tables. Visual observations of streamflows often detected reach losses, which were verified by streamflow measurements where possible. Seepage runs, which are serial, nearly concurrent discharge measurements along the length of a stream to determine losses and gains, were performed on Woodland Creek, the only creek where such channel-bed losses were thought to be significant. Reach losses were especially common in subbasins with lakes or with large areas of outwash soil where ground-water levels have a significant influence on surface-water processes.

\section{Calibration and Evaluation Results}

After all of the discussed modifications were completed, the calibrated models simulated the first year of observed streamflow data, from March 1, 1988, through March 29, 1989, reasonably well at most of the streamflow-gaging stations. These first-year calit rated models then were evaluated by simulating a second year of streamflow data collected between March 30, 1989, and March 15, 1990. Most of the models simu'ated this second year of observed streamflow data less accurately than the first year of data. A statistical analysis of differences in simulating total runoff volumes, daily mean discharges, and storm runoff and peak discharges is ou+lined in the following sections.

Total runoff volume.--Observed and simulated runoff volumes from five of the six gaging stations were compared for both the calibration and the evaluation periods. Data from a sixth gaging station not used for calibration, 12078705, were used to define streamflows entering Percival Creek Basin from Black Lake. Observed and simulated values of total runoff volume for the first-year calibrated models are compared in table 7 for both the calibration and evaluation periods.

For the calibration period, the absolut: values of differences between observed and simulated total runoff ranged from 1.7 to 12.8 percent, the largest difference being for Woodland Creek station 12081000 . For the

Table 7.--Observed and simulated runoff data for the first-year calibrated models during the calibration and evaluation periods

[Observed, observed value; Simulated, simulated value; Difference, simulated-observed; Percent difference, $100 \mathrm{x}$ (simu'atedobserved/observed)]

\begin{tabular}{lccccc}
\hline $\begin{array}{l}\text { Station name/ } \\
\text { station number }\end{array}$ & $\begin{array}{l}\text { Simulation } \\
\text { period }^{1}\end{array}$ & $\begin{array}{l}\text { Observed } \\
\text { (inches) }\end{array}$ & $\begin{array}{c}\text { Simulated } \\
\text { (inches) }\end{array}$ & $\begin{array}{c}\text { Difference } \\
\text { (inches) }\end{array}$ & $\begin{array}{c}\text { Percent } \\
\text { differance }\end{array}$ \\
\hline Black Lake Ditch near & $\mathrm{C}$ & 93.41 & 97.26 & 3.85 & 4.1 \\
Olympia/12078720 & $\mathrm{E}$ & 96.21 & 103.25 & 7.04 & 7.3 \\
Percival Creek near & $\mathrm{C}$ & 46.15 & 47.38 & 1.23 & 2.7 \\
Olympia/12078730 & $\mathrm{E}$ & 45.89 & 47.07 & 1.18 & 2.6 \\
Woodard Creek near & $\mathrm{C}$ & 25.92 & 25.49 & -.43 & -1.7 \\
Olympia/12080500 & $\mathrm{E}$ & 28.93 & 28.47 & -.46 & -1.6 \\
Woodland Creek at & $\mathrm{C}$ & 2.32 & 2.26 & -.06 & -2.6 \\
Martin Way at Lacey/ & $\mathrm{E}$ & 5.42 & 4.06 & -1.36 & -25.1 \\
12080670 & & & & & \\
Woodland Creek near & $\mathrm{C}$ & 10.82 & 12.21 & 1.39 & 12.8 \\
Olympia/1 2081000 & $\mathrm{E}$ & 12.79 & 14.41 & 1.62 & 12.7 \\
\hline
\end{tabular}

${ }^{1}$ Simulation period C, calibration period from March 1, 1988, through March 29, 1989.

Simulation period E, evaluation period from March 30, 1989, through March 15, 1990. 
evaluation period, percent differences for four of the five stations were similar to those for the calibration period. For the fifth station, Woodland Creek station 12080670 , the percent difference increased from 2.6 percent to 25.1 percent in absolute value. Differences greater than 10 percent for both the calibration and evaluation periods for the Woodland Creek model suggest that this first-year model was not adequately simulating some important processes.

Daily mean discharge.--The accuracy of the models in simulating daily mean discharges was assessed by comparing observed and simulated hydrographs from the five streamflow-gaging stations for the calibration and the evaluation periods (figs. 9-13) and by computing statistical measures of difference between observed and simulated values of daily mean discharges for the total flow record and for low, medium, and high flows. Tables 8 and 9 show these statistical measures of difference for the calibration period and the evaluation period respectively. The differences, usually largest at the upstream Woodland Creek station (12080670), were generally larger for the evaluation period. Differences were particularly large for the period after a large January 1990 storm.

Three statistical measures of difference were useful in evaluating the success of the simulations: the mean absolute difference, the bias, and the root-mean-square difference. The mean absolute difference is the average of differences between observed and simulated daily mean discharges without regard to whether the differences were positive or negative. The bias is the arithmetic average of the actual differences. A large positive bias usually means that a model is overestimating streamflow, and a large negative bias means that it is underestimating streamflow. The root-mean-square is the standard deviation of the differences. Assuming a normal distribution of differences, two-thirds of all the difference are less than or equal to this value. The statistical measures of difference also are expressed in terms of percent relative to the observed values. A mean absolute difference of 25 percent, for instance, means that the simulated daily mean discharges differ, on average, 25 percent from their corresponding observed values. (See footnote 3 of table 9 for a formal definition.)

Mean absolute differences for the daily mean discharge record for all flow regimes ranged from 13.2 to 36.5 percent during the first calibration period and from 13.7 to 79.1 percent during the evaluation period. For the calibration period, mean absolute differences for the total flow record were less than 17 percent for four of the five stations, but the difference was 36.5 percent for the fifth station, Woodland Creek station 12080670 . The large difference at this station was primarily due to the 60.7 percent difference for low flows. Note that a small difference in cubic feet per second--only a little mo*e than 0.5 cubic foot per second here--can translate into large percent difference. For the evaluation period, the largest absolute differences between observed and simulated daily mean discharges--79.1 percent for total flows--were from the same Woodland Creek station (12080670). Differences for the other stations were less than 30 percent.

Most of the measures of differences increased for the evaluation period. Mean absolute differences for all flow regimes, for example, increased from 165 to 27.7 percent for Woodard Creek station 12080500 and increased from 36.5 to 79.1 percent for Woodland Creek station 12080670. Mean absolute differences fcr low flows increased from 26.2 to 42.6 percent for Yoodard Creek station 12080500 , from 60.7 to 161 percent for Woodland Creek station 12080670 , and from 8.1 to 19.3 percent for Woodland Creek station 12081000. Mern absolute differences for medium flows increased from 28.6 to 53.1 percent for Woodland Creek station 12080670; and for high flows, the differences increased from 11.5 to 21.8 percent for Woodard Creek station 12080500.

Despite the increased statistical measures of difference, most hydrographs of observed and simulated daily mean discharges usually matched fairly well for the evaluation period (figs. 9-13). An exception was the hydrographs from Woodland Creek station 12080670, which show that the model underestimated flow's in the spring of 1989 and the winter of 1990 (fig. 12). O her exceptions were the hydrographs in figures $9,11,12$, and 13 , which show that the models overestimated daily mean discharge at four of the five stream-gaging stations for the large storm of January 8-9, 1990.

Storm runoff and peak discharge.--Periods of storm-runoff when hydrographs displayed large, distinct peaks provided additional opportunities to judge the performance of the basin models. Figures 14 through 23 show hydrographs for observed and simulated discharges during selected storm periods, and table 10 compares observed and simulated storm-runoff volumes and peak discharges. Only one storm period was assessed for Woodland Creek station 12080670 in the calibration period because the annual hydrograph plainly indicates the influence of a dominant ground-water component rather than responses from individual storms (f g. 12). Differences between simulated and observed storm runoff volumes (for the duration of high water resulting from storms) during the first calibration period ranged from 1.6 to 50.0 percent in absolute value, though only 1 of 16 


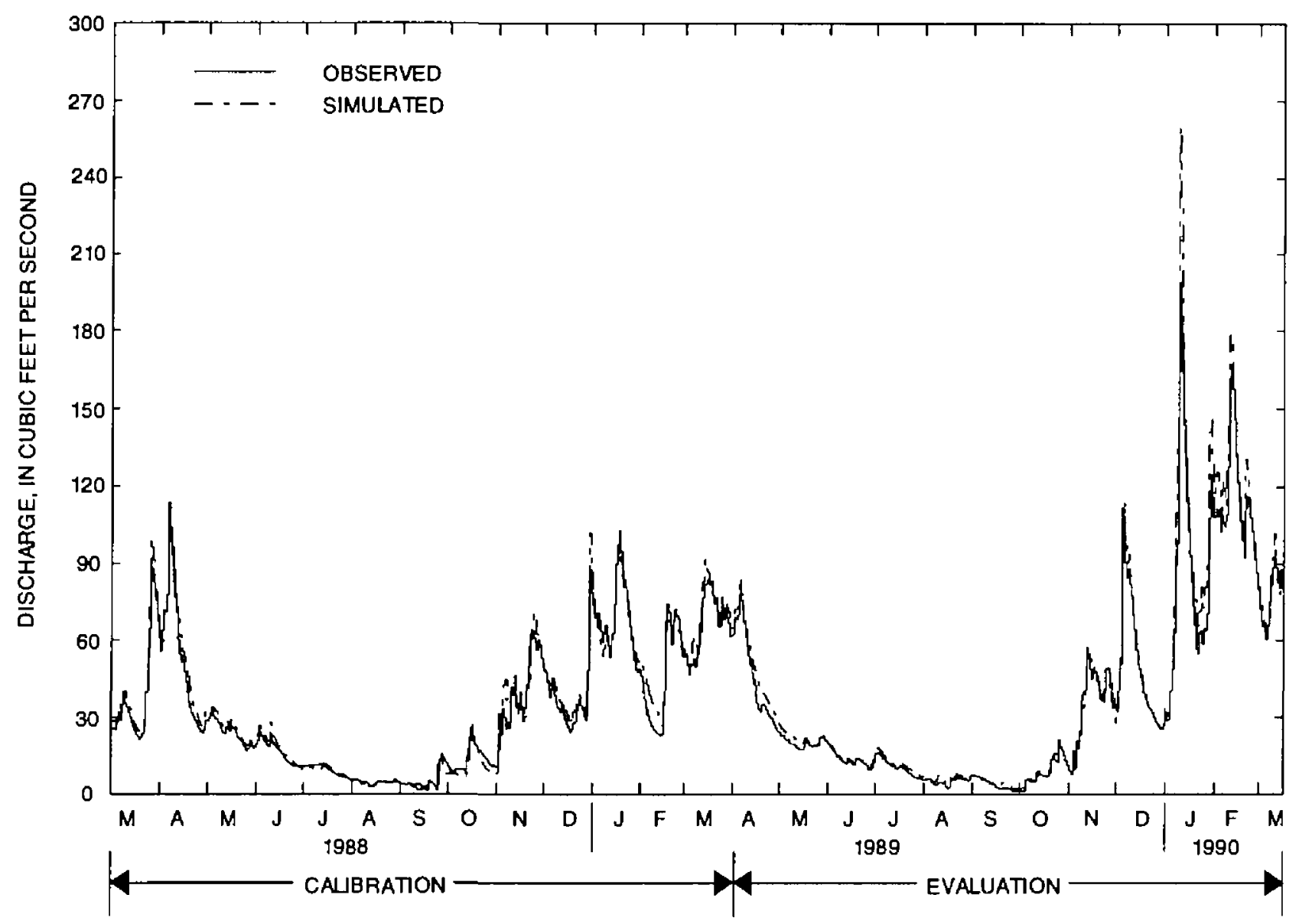

Figure 9.--Observed and simulated daily mean discharges for Black Lake Ditch near Olympia, Washington (station 12078720), in the Percival Creek Basin. Simulated discharges are from the first-year calibrated model applied to the period March 1, 1988, through March 15, 1990.

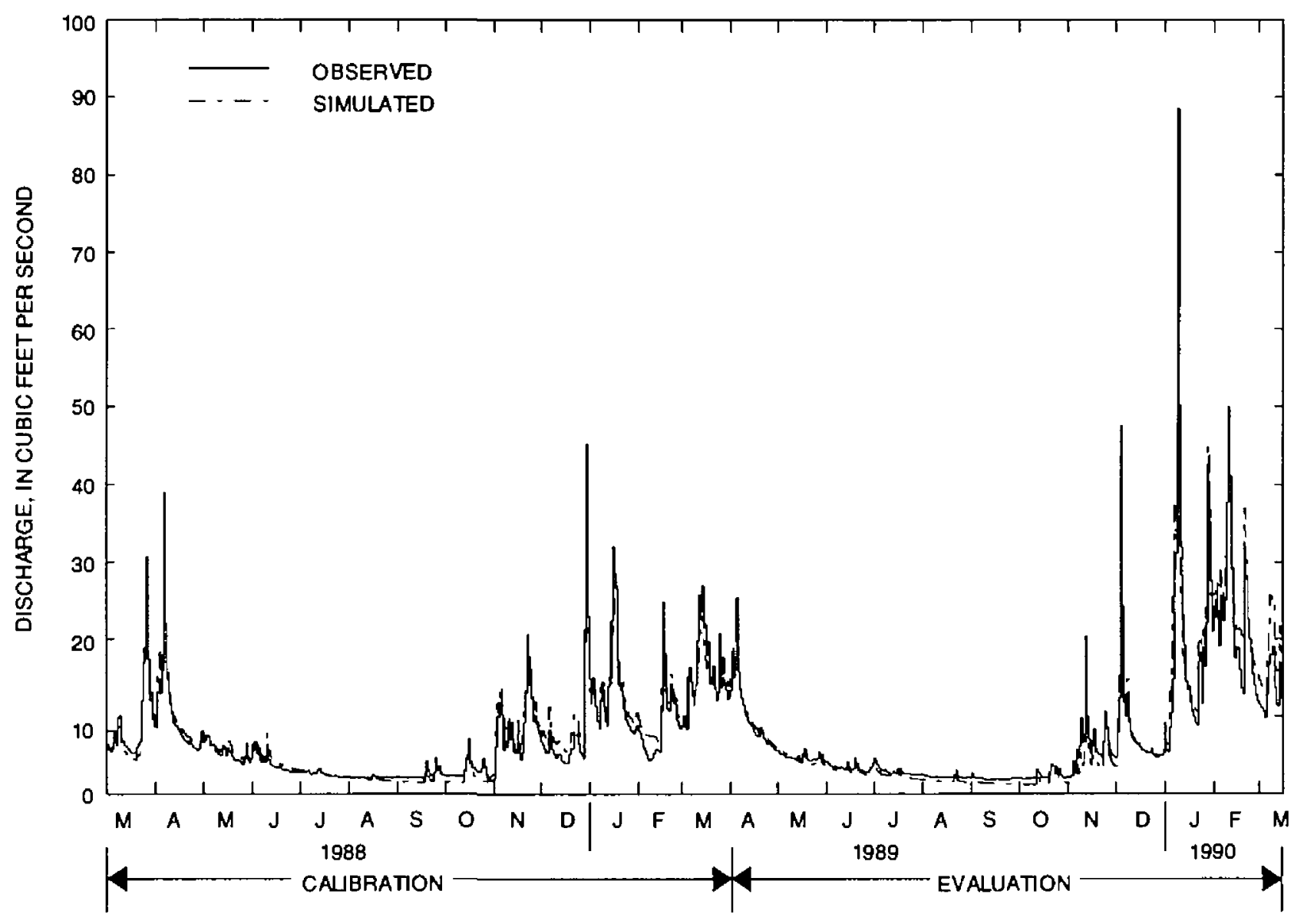

Figure 10.--Observed and simulated daily mean discharges for Percival Creek near Olympia, Washington (station 12078730), in the Percival Creek Basin. Simulated discharges are from the first-year calibrated model applied to the period March 1, 1988, through March 15, 1990. 


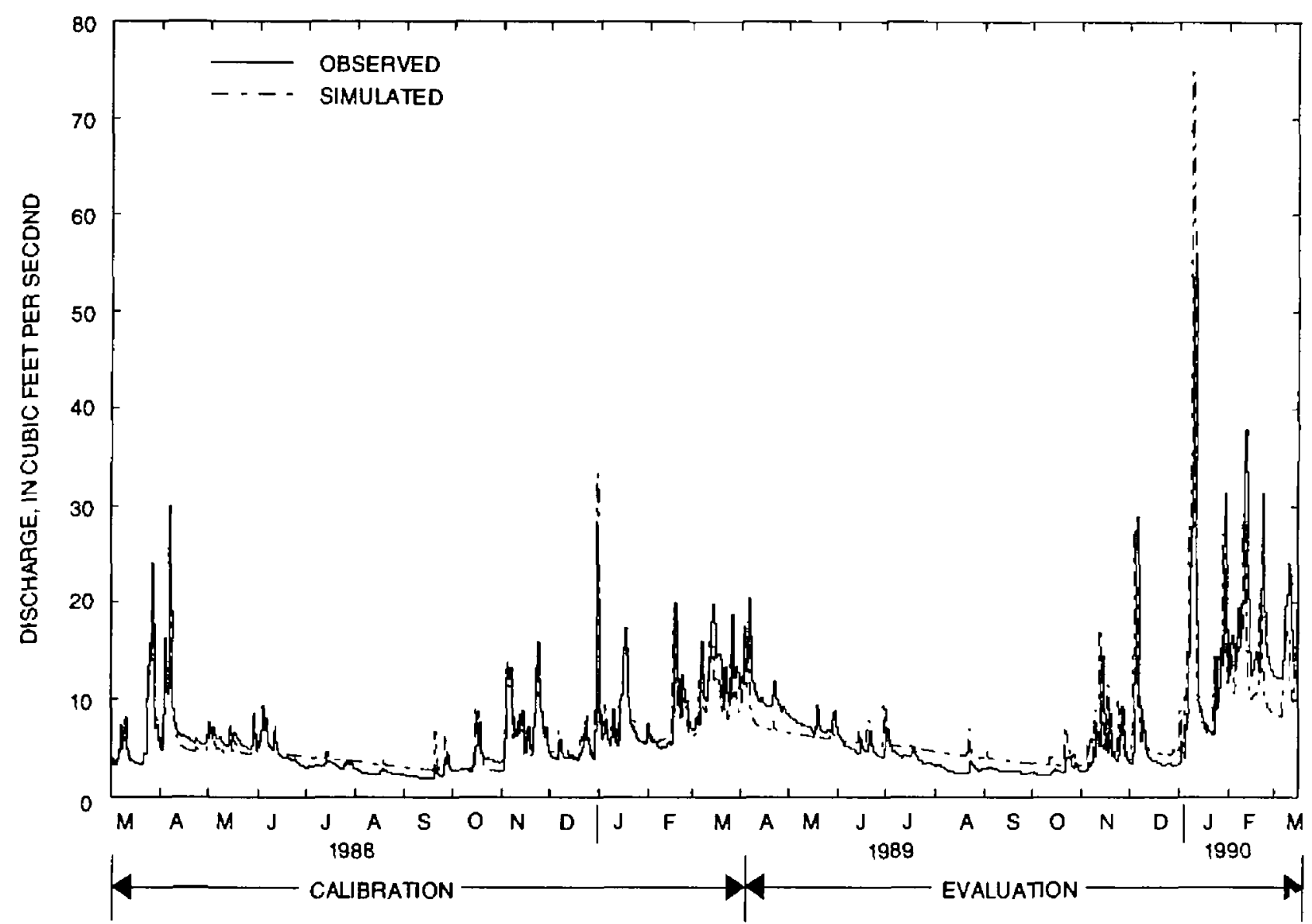

Figure 11.--Observed and simulated daily mean discharges for Woodard Creek near Olympia, Washington (station 12080500), in the Woodard Creek Basin. Simulated discharges are from the first-year calibrated model applied to the period March 1, 1988, through March 15, 1990.

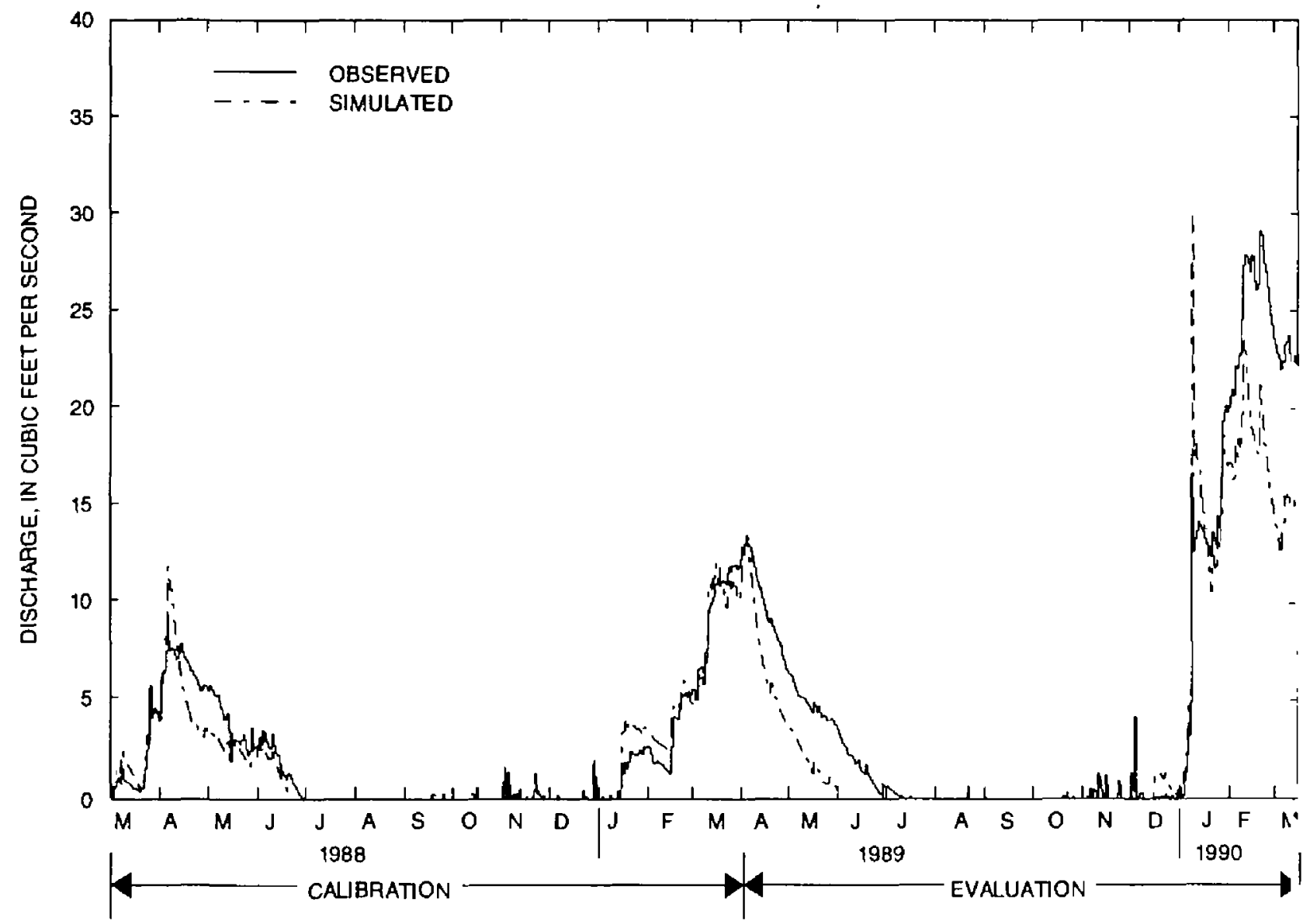

Figure 12.--Observed and simulated daily mean discharges for Woodland Creek at Martin Way at Lacey, Washington (station 12080670), in the Woodland Creek Basin. Simulated discharges are from the first-year calibrated model applied to the period March 1, 1988, through March 15, 1990. 


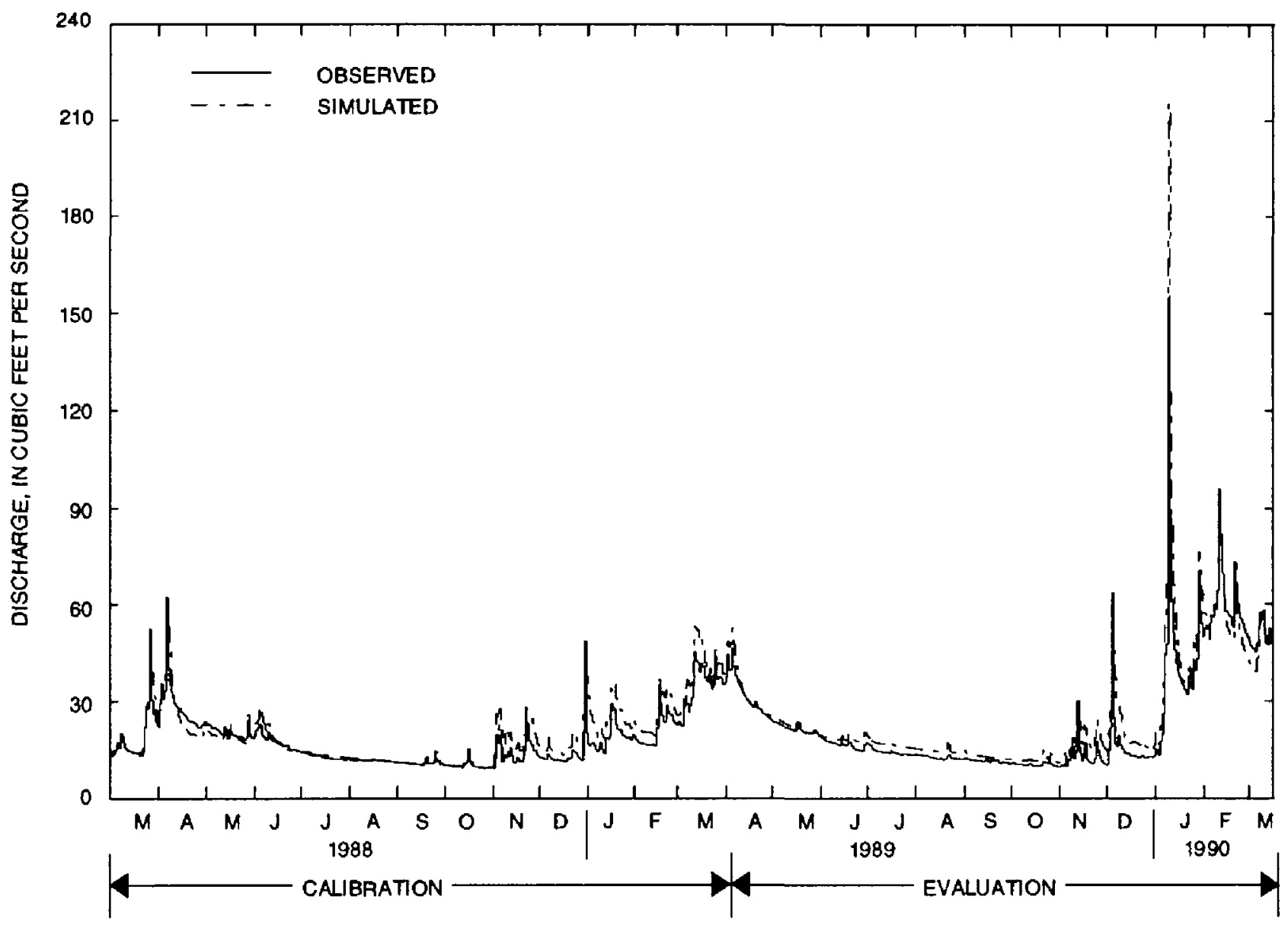

Figure 13.--Observed and simulated daily mean discharges for Woodland Creek near Olympia, Washington (station 12081000), in the Woodland Creek Basin. Simulated discharges are from the first-year calibrated model applied to the period March 1, 1988, through March 15, 1990. 
Table 8.--Measures of difference between simulated and observed daily mean discharges of Woodland Creek, Woodard Creek, and Percival Creek for the first-year calibrated models during the calibration period March 1, 1988, through March 29, 1989

\begin{tabular}{|c|c|c|c|c|c|c|c|}
\hline \multirow{2}{*}{$\begin{array}{l}\text { Station } \\
\text { number }\end{array}$} & \multirow{2}{*}{$\begin{array}{l}\text { Flow } \\
\text { regime }^{2}\end{array}$} & \multicolumn{2}{|c|}{$\begin{array}{c}\text { Mean } \\
\text { absolute difference }^{3}\end{array}$} & \multicolumn{2}{|c|}{$\begin{array}{c}\text { Root mean } \\
\text { square difference }\end{array}$} & \multicolumn{2}{|c|}{ Bias } \\
\hline & & Average & Percent & Average & Percent & Average & Percent \\
\hline \multirow[t]{4}{*}{12078720} & Low & 1.278 & 19.1 & 1.708 & 32.3 & -0.431 & 3.2 \\
\hline & Medium & 3.705 & 14.1 & 4.573 & 17.2 & 3.392 & 12.8 \\
\hline & High & 3.783 & 6.3 & 4.636 & 7.7 & 1.059 & 2.1 \\
\hline & Total & 2.912 & 13.2 & 3.877 & 21.7 & 1.332 & 6.0 \\
\hline \multirow[t]{4}{*}{12078730} & Low & .434 & 17.7 & .531 & 21.4 & -.272 & -12.2 \\
\hline & Medium & 1.029 & 20.0 & 1.248 & 25.0 & .685 & 13.4 \\
\hline & High & 1.337 & 10.0 & 1.750 & 12.5 & .156 & 4.1 \\
\hline & Total & .934 & 15.9 & 1.278 & 20.4 & .195 & 1.9 \\
\hline \multirow[t]{4}{*}{12080500} & Low & .696 & 26.2 & .855 & 32.2 & .571 & 22.6 \\
\hline & Medium & .599 & 12.2 & .798 & 16.3 & -.092 & -1.4 \\
\hline & High & 1.215 & 11.5 & 1.594 & 13.9 & -.723 & -5.9 \\
\hline & Total & .838 & 16.5 & 1.145 & 22.2 & -.089 & 4.9 \\
\hline \multirow[t]{4}{*}{12080670} & Low & .526 & 60.7 & .712 & 71.6 & .214 & 8.5 \\
\hline & Medium & .760 & 28.6 & .916 & 36.7 & .057 & 6.9 \\
\hline & High & 1.285 & 19.1 & 1.564 & 24.3 & -.560 & -9.7 \\
\hline & Total & .856 & 36.5 & 1.124 & 49.0 & -.096 & 1.8 \\
\hline \multirow[t]{4}{*}{12081000} & Low & .938 & 8.1 & 1.578 & 13.5 & .782 & 6.6 \\
\hline & Medium & 2.657 & 17.0 & 3.683 & 23.5 & 2.286 & 14.7 \\
\hline & High & 4.205 & 16.1 & 5.049 & 19.7 & 2.693 & 9.9 \\
\hline & Total & 2.583 & 13.7 & 3.706 & 19.3 & 1.909 & 10.3 \\
\hline
\end{tabular}

${ }^{1}$ Station names for the displayed station numbers are shown in table 7.

${ }^{2}$ Low, medium, and high flow regimes are the lower, middle, and upper thirds of the daily mean dischargo values from each station. Total refers to the complete daily mean discharge record specified for the stations.

${ }^{3}$ AVERAGE $=$ sum $(|\mathrm{S}-\mathrm{M}| / \mathrm{n})$ for all $\mathrm{M}>0.1$

PERCENT $=100.0 *$ [sum(IS-M|/M)]/n for all $\mathrm{M}>0.1$ (where $\mathrm{S}=$ simulated daily mean discharge in crbic feet per second; $M=$ observed daily mean discharge in cubic feet per second; sum = summation over days for which $M>0.1$ in the calibration period; $n=$ number of pairs of daily values for which $M>0.1$ in the calibration period; and I I = absolute value. NOTE: Because of the method of computing percentages, measured daily mean discharges below 0.1 cubic foot per second are considered as "dry" and are not considered in this analysis).

${ }^{4}$ AVERAGE $=$ square $\operatorname{root}\{\operatorname{sum}[(\mathrm{S}-\mathrm{M}) * * 2] / \mathrm{n}\}$ for all $\mathrm{M}>0.1$

PERCENT $=100.0 *$ square $\operatorname{root}(\operatorname{sum}\{[(\mathrm{S}-\mathrm{M}) / \mathrm{M}] * * 2\} / \mathrm{n})$ for all $\mathrm{M}>0.1$

${ }^{5}$ AVERAGE $=$ sum $(\mathrm{S}-\mathrm{M}) / \mathrm{n}$ for all $\mathrm{M}>0.1$

PERCENT $=100.0 *\{$ sum $[(\mathrm{S}-\mathrm{M}) / \mathrm{M}] / \mathrm{n}\}$ for all $\mathrm{M}>0.1$ 
Table 9.--Measures of difference between simulated and observed daily mean discharges of Woodland Creek, Woodard Creek, and Percival Creek for the first-year calibrated models during the evaluation period March 30, 1989, through March 15, 1990

\begin{tabular}{|c|c|c|c|c|c|c|c|}
\hline \multirow{2}{*}{$\begin{array}{l}\text { Station } \\
\text { number }\end{array}$} & \multirow{2}{*}{$\begin{array}{l}\text { Flow } \\
\text { regime }^{2}\end{array}$} & \multicolumn{2}{|c|}{$\begin{array}{c}\text { Mean } \\
\text { absolute difference }\end{array}$} & \multicolumn{2}{|c|}{$\begin{array}{c}\text { Root mean } \\
\text { square difference }\end{array}$} & \multicolumn{2}{|c|}{ Bias } \\
\hline & & Average & Percent & Average & Percent & Average & Percent \\
\hline \multirow[t]{4}{*}{12078720} & Low & 1.053 & 24.3 & 1.306 & 36.1 & 0.942 & 22.8 \\
\hline & Medium & 2.051 & 8.8 & 2.755 & 10.7 & .886 & 4.4 \\
\hline & High & 7.359 & 8.4 & 11.840 & 11.5 & 6.482 & 7.0 \\
\hline & Total & 3.448 & 13.7 & 6.981 & 22.6 & 2.722 & 11.2 \\
\hline \multirow{4}{*}{12078730} & Low & .578 & 26.6 & .601 & 27.8 & -.565 & -26.0 \\
\hline & Medium & .542 & 11.8 & .715 & 14.9 & -.355 & -8.4 \\
\hline & High & 2.631 & 16.7 & 3.606 & 22.2 & 1.553 & 12.4 \\
\hline & Total & 1.244 & 18.3 & 2.143 & 22.2 & .206 & -7.3 \\
\hline \multirow[t]{4}{*}{12080500} & Low & 1.186 & 42.6 & 1.244 & 45.2 & 1.186 & 42.6 \\
\hline & Medium & .908 & 18.4 & 1.109 & 23.3 & .578 & 13.6 \\
\hline & High & 3.196 & 21.8 & 4.161 & 24.1 & -2.081 & -15.5 \\
\hline & Total & 1.771 & 27.7 & 2.597 & 32.6 & -.110 & 13.6 \\
\hline \multirow[t]{4}{*}{12080670} & Low & .673 & 161.4 & .919 & 288.5 & -.278 & 61.4 \\
\hline & Medium & 2.827 & 53.1 & 2.894 & 58.6 & -2.758 & -51.1 \\
\hline & High & 5.196 & 23.3 & 6.240 & 27.3 & -4.222 & -16.6 \\
\hline & Total & 2.922 & 79.1 & 4.047 & 171.0 & -2.432 & -1.6 \\
\hline \multirow[t]{4}{*}{12081000} & Low & 2.226 & 19.3 & 2.611 & 22.5 & 2.223 & 19.3 \\
\hline & Medium & 2.883 & 18.9 & 4.075 & 26.0 & 2.871 & 18.8 \\
\hline & High & 4.645 & 9.6 & 8.747 & 14.9 & 2.248 & 5.2 \\
\hline & Total & 3.260 & 15.9 & 5.799 & 21.6 & 2.442 & 14.3 \\
\hline
\end{tabular}

${ }^{1}$ Station names for the displayed station numbers are shown in table 7.

${ }^{2}$ Low, medium, and high flow regimes are the lower, middle, and upper thirds of the daily mean discharg. values from each station. Total refers to the complete daily mean discharge record specified for the stations.

${ }^{3}$ AVERAGE $=$ sum $(\mid \mathrm{S}-\mathrm{M} \mathrm{M} / \mathrm{n})$ for all $\mathrm{M}>0.1$

PERCENT $=100.0^{*}[\operatorname{sum}(\mid \mathrm{S}-\mathrm{Ml} / \mathrm{M})] / \mathrm{n}$ for all $\mathrm{M}>0.1$ (where $\mathrm{S}=$ simulated daily mean discharge in cubic feet per second; $M=$ observed daily mean discharge in cubic feet per second; sum = summation over days for which $M>0.1$ in the calibration period; $n=$ number of pairs of daily values for which $M>0.1$ in the calibration period; and II = absolute value. NOTE: Because of the method of computing percentages, measured daily mean discharges below 0.1 cubic foot per second are considered as "dry" and are not considered in this analysis).

${ }^{4}$ AVERAGE $=$ square $\operatorname{root}\left\{\operatorname{sum}\left[(\mathrm{S}-\mathrm{M})^{* *} 2\right] / \mathrm{n}\right\}$ for all $\mathrm{M}>0.1$

PERCENT $=100.0 *$ square $\left.\operatorname{root}\left(\operatorname{sum}\{[(\mathrm{S}-\mathrm{M}) / \mathrm{M}]]^{* *} 2\right\} / \mathrm{n}\right)$ for all $\mathrm{M}>0.1$

${ }^{5}$ AVERAGE $=\operatorname{sum}(\mathrm{S}-\mathrm{M}) / \mathrm{n}$ for all $\mathrm{M}>0.1$

PERCENT $=100.0 *\{$ sum $[(\mathrm{S}-\mathrm{M}) / \mathrm{M}] / \mathrm{n}\}$ for all $\mathrm{M}>0.1$ 
storm-runoff volumes exceeded 20 percent. Differences for instantaneous peak discharges during that period ranged from 4.1 to 25.5 percent in absolute value, but only 2 of 16 peak discharges exceeded 20 percent.

For the evaluation period, differences in storm runoff volumes ranged from 0.0 to 50.0 percent in absolute value, the largest differences associated with high runoff after the January 8-9, 1990 storm. As table 10 shows, the dates of high runoff sometimes lagged behind the dates of storms because flood waves took time to travel downstream. Differences in peak discharges ranged from 0.3 to 107.0 percent in absolute value, and the largest differences were again associated with the January 8-9 storm. The small differences between observed and simulated storm-runoff volumes and peak discharges resulting from most storms indicated that the models usually produced adequate simulations. Nevertheless, the large differences associated with the January 8-9 storm suggested that further refinements may be required.

\section{Discussion of calibration and evaluation} results.- The preceding results showed that the first-year calibrated models simulated the first year of observed streamflows reasonably well, but differences between simulated and observed streamflows usually increased when the models were evaluated with the second year of observed streamflows. Simulation results indicated that the models needed improvement in the simulation of the amount and timing of ground-water discharge, of low streamflows, and of high streamflows such as those recorded in January 1990. The Percival Creek Basin model, however, adequately simulated streamflows at Percival Creek gaging station 12078730.

The simulation of the quantity and timing of ground-water contributions by the Woodland Creek model needed improvement. Streamflows upstream of Woodland Creek station 12080670 are primarily sustained by ground-water contributions. More than 70 percent of the Woodland Creek Basin area upstream of this station is represented by outwash segment types (table 5), wherein ground-water flow, according to the conceptual model, is the predominant runoff mechanism. Hydrographs from wells in this area indicate that water-table elevations were highest during late winter or spring, the same time that the model underestimated streamflows (N.P. Dion, U.S. Geological Survey, written commun., 1991). The high water-table elevations during these periods suggest that ground-water contributions may have been greater than those simulated by the Woodland Creek model. Like headwater subbasin PE1 in Percival Creek Basin, the upstream portion of the Woodland Creek Basin consists of a flat outwash plain, and the drainage divides for ground water and surface water do not necessarily coincide. Instead, the ground water underlying this area is likely part of a larger ground-water system that is inf uenced by precipitation falling outside the study basin. Additionally, it is likely that the large lakes and wetlands $r$ ere are affected by ground water-surface water interactions Thus, the first-year Woodland Creek model did not adequately represent ground-water contributions influenced by regional ground-water characteristics and stratigrarhy.

The simulation of low flows by the Voodland and Woodard Creek models needed improvement. For the first year of streamflow data, these models showed noticeable discrepancies between observed and simulated low flows (table 8). Subsequently, all the gaging stations, notably in the Woodard Creek Basin, showed increased differences between observed and simulated low flows after simula ting the second year of streamflow data (table 9). Simulated low flows usually exceeded observed low flows during the evaluation period.

The simulation of high flows resulting from storms by all models except for a part of the Percival Creek model needed improvement. Differences between observed and simulated runoff volumes and peak discharges were large during high flows, especially for those resilting from the extremely large January 8-9, 1990, storm in the second year of data collection (table 10). At four of the five gaging stations, simulated peak discharges and runoff volumes exceeded observed amounts. This storm, one of five in early January 1990, dropped 3 to 4 inches of rain in 24 hours, more intense rain than at any otl er time during the study period. The previous four storms between January 4 and 8 had dropped a total of 4 to 6 inches of rain on the study area. The storms provided ar opportunity to calibrate the models to some of the highest streamflows recorded in the region.

Simulation results from the first-year calibrated models indicated that, despite the model shortcomings previously described, the conceptual model--represented in the numerical models by the segmentation scheme and the values of the process-related parameters--adequately described the generation of runoff from the land-segment types in the basins. The process-related parameter values, except for KVARY, obtained from the King and Snohomish County basins (Dinicola, 1990) applied to the basins in Thurston County. The values of KVARY were refined to improve the timing of ground-water discharge to reaches. These refinements were necessary because some areas in Thurston County are underlain by aquifers that respond differently to rainfall than the areas in King and 


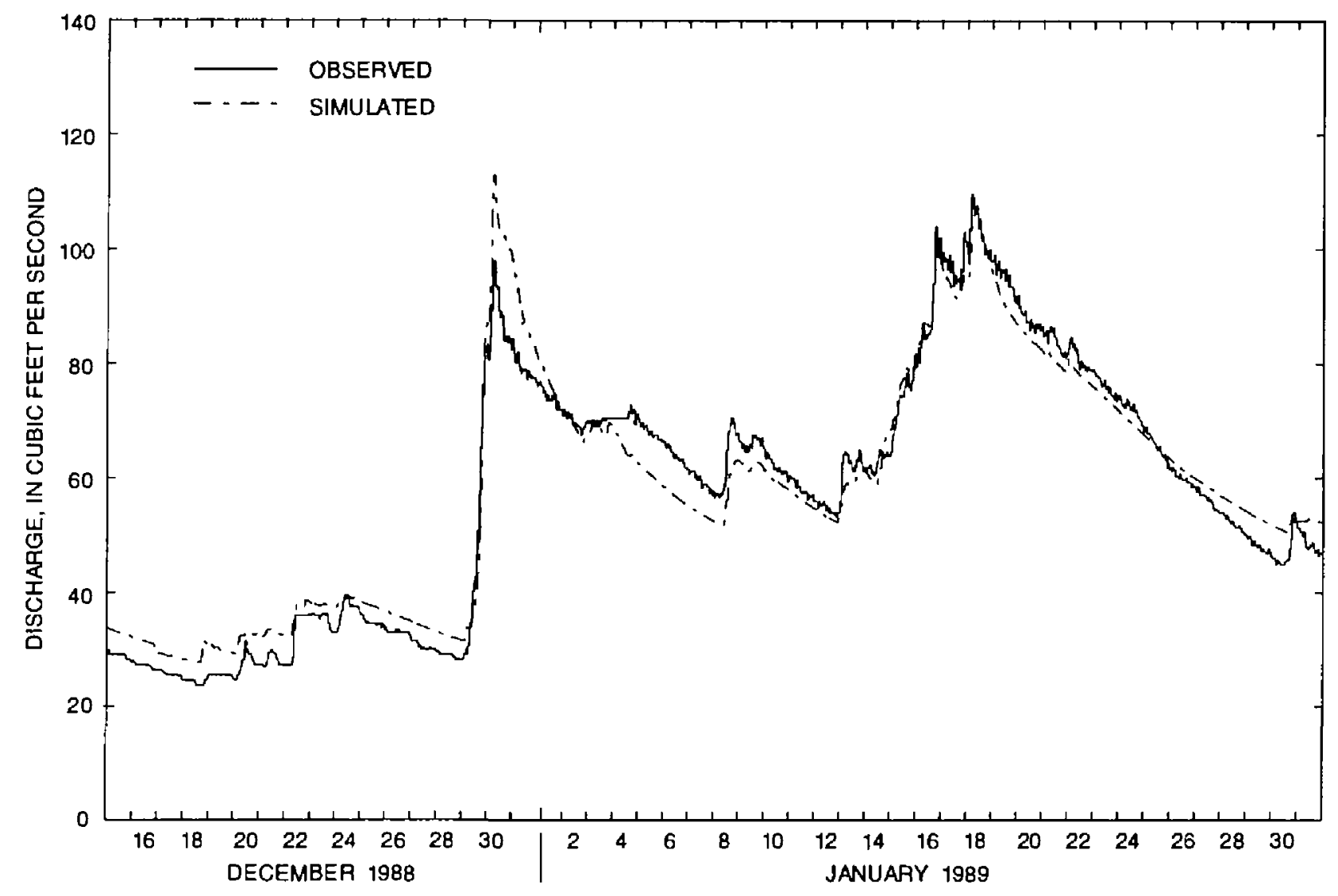

Figure 14.--Observed and simulated hourly mean discharges for Black Lake Ditch near Olympia, Washington (station 12078720), in the Percival Creek Basin. Simulated discharges are from the first-year calibrated model applied to the storm period December 15, 1988, through January 31, 1989.

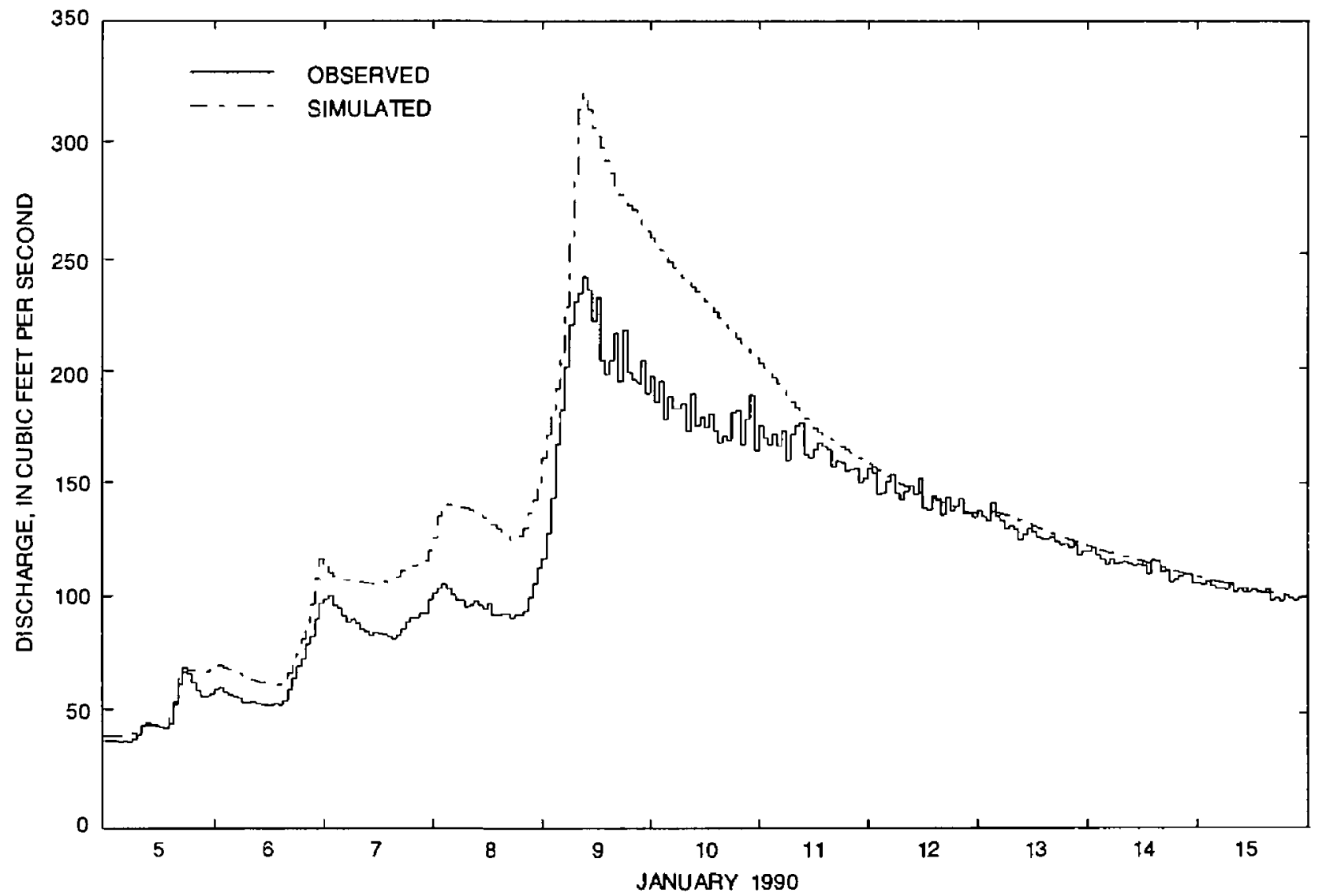

Figure 15.--Observed and simulated hourly mean discharges for Black Lake Ditch near Olympia, Washington (station 12078720), in the Percival Creek Basin. Simulated discharges are from the first-year calibrated model applied to the stom period January 5 through 15, 1990. 


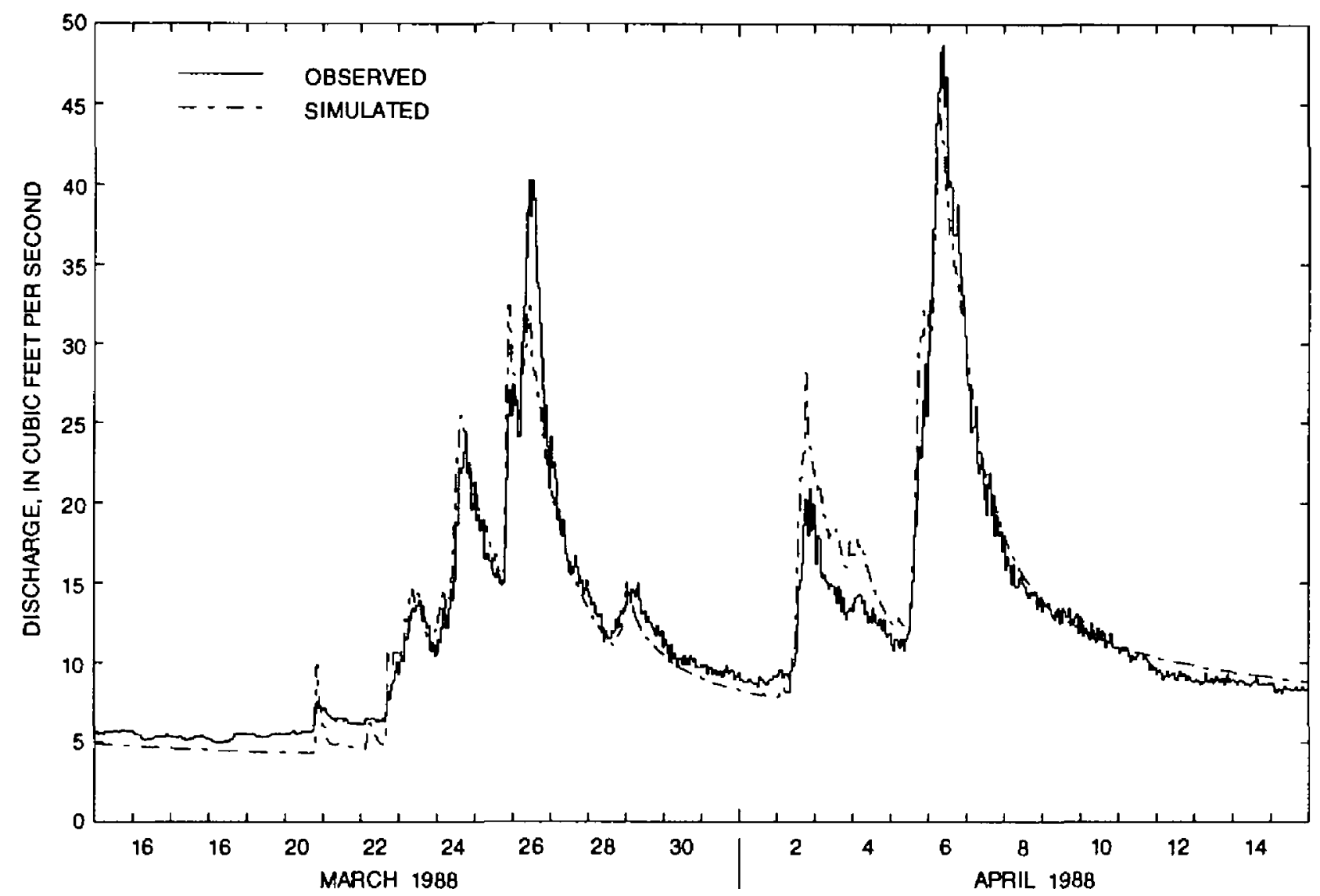

Figure 16.--Observed and simulated hourly mean discharges for Percival Creek near Olympia, Washington (station 12078730), in the Percival Creek Basin. Simulated discharges are from the first-year calibrated model applied to the storm period March 15, 1988, through April 15, 1988.

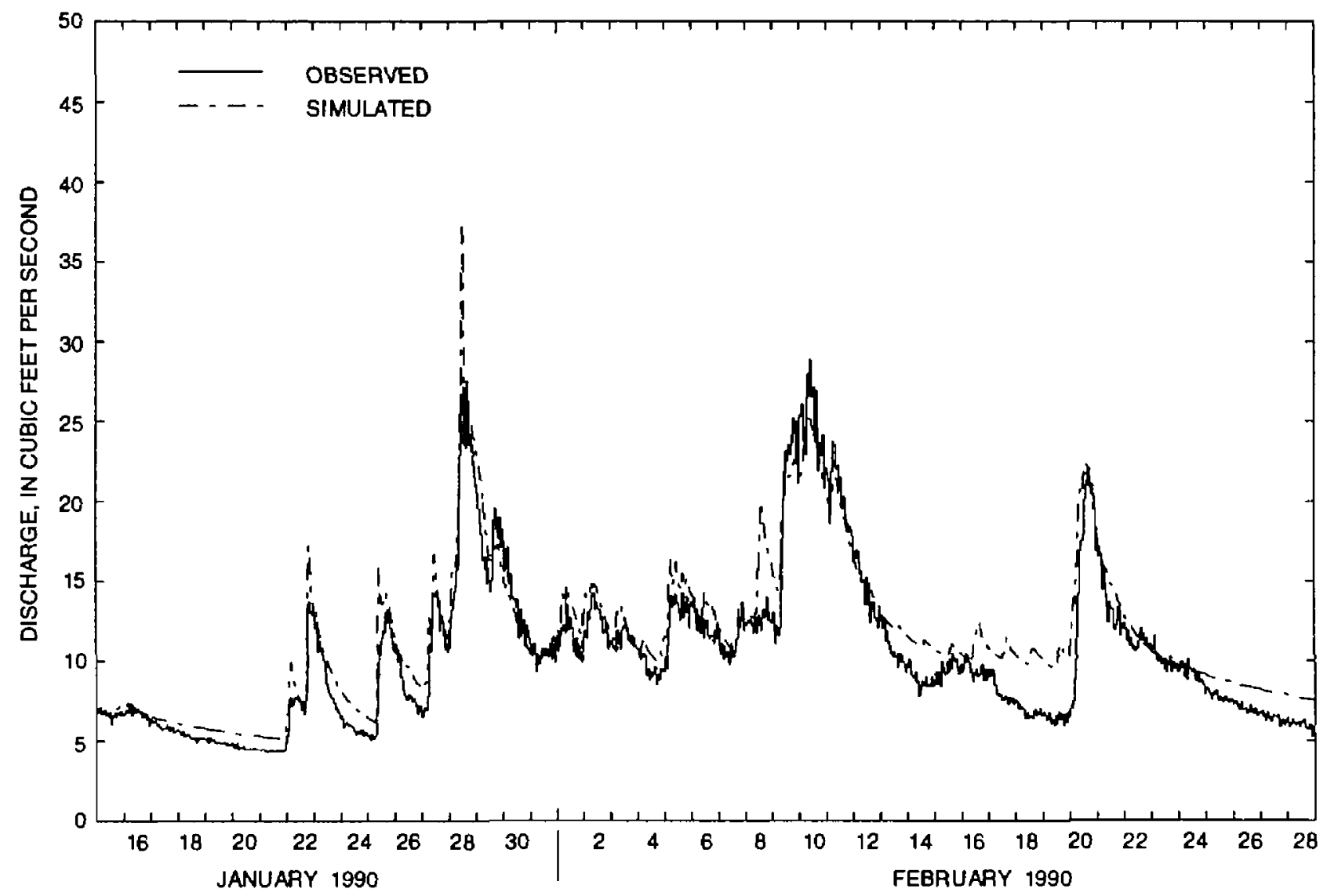

Figure 17.--Observed and simulated hourly mean discharges for Percival Creek near Olympia, Washington (station 12078730), in the Percival Creek Basin. Simulated discharges are from the first-year calibrated model applied to the stom period January 15, 1990, through February 28, 1990. 


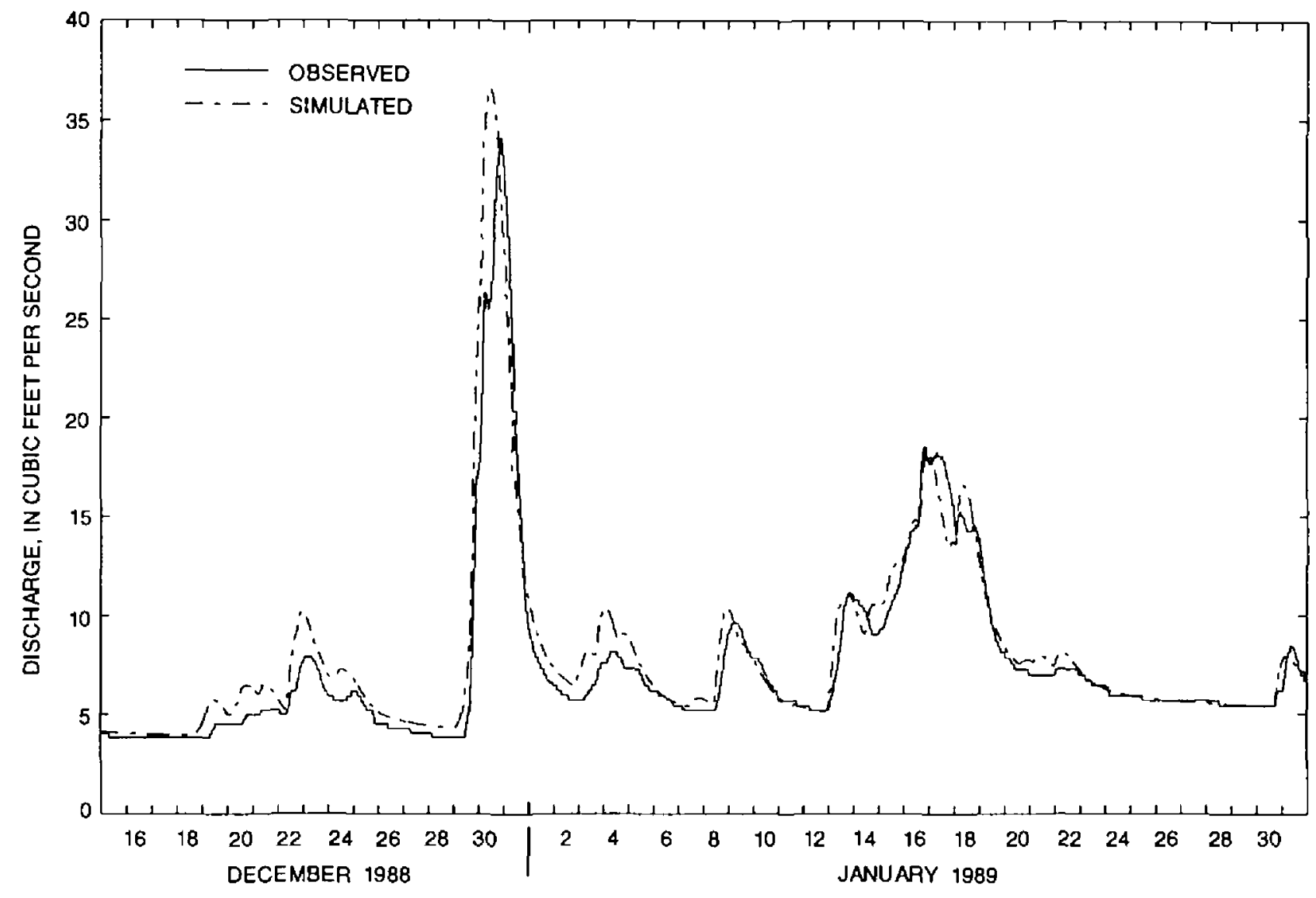

Figure 18.--Observed and simulated hourly mean discharges for Woodard Creek near Olympia, Washington (station 12080500), in the Woodard Creek Basin.

Simulated discharges are from the first-year calibrated model applied to the storm period December 15, 1988, through January 31, 1989.

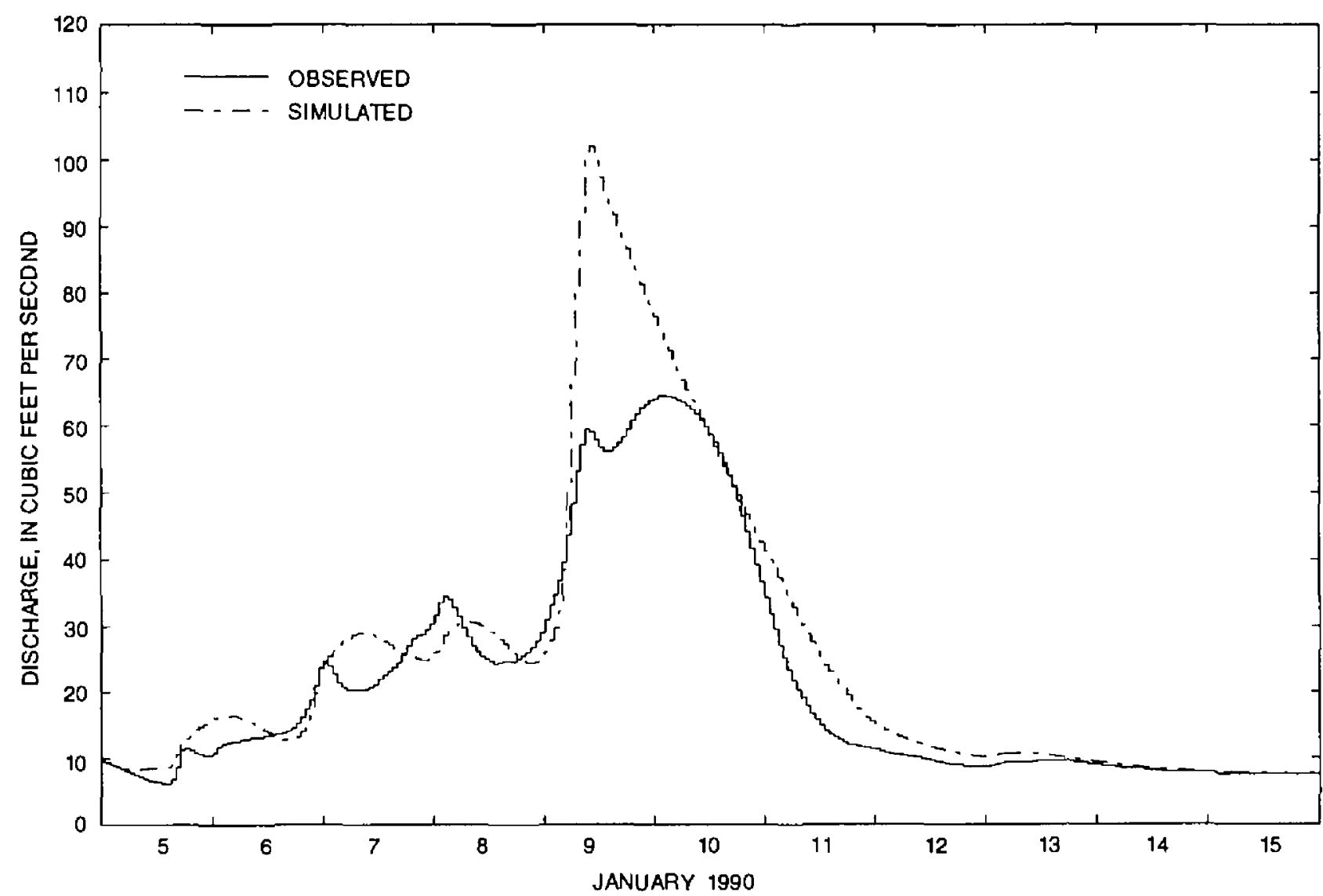

Figure 19..-Observed and simulated hourly mean discharges for Woodard Creek near Olympia, Washington (station 12080500), in the Woodard Creek Basin.

Simulated discharges are from the first-year calibrated model applied to the storm period January 5 through 15, 1990. 


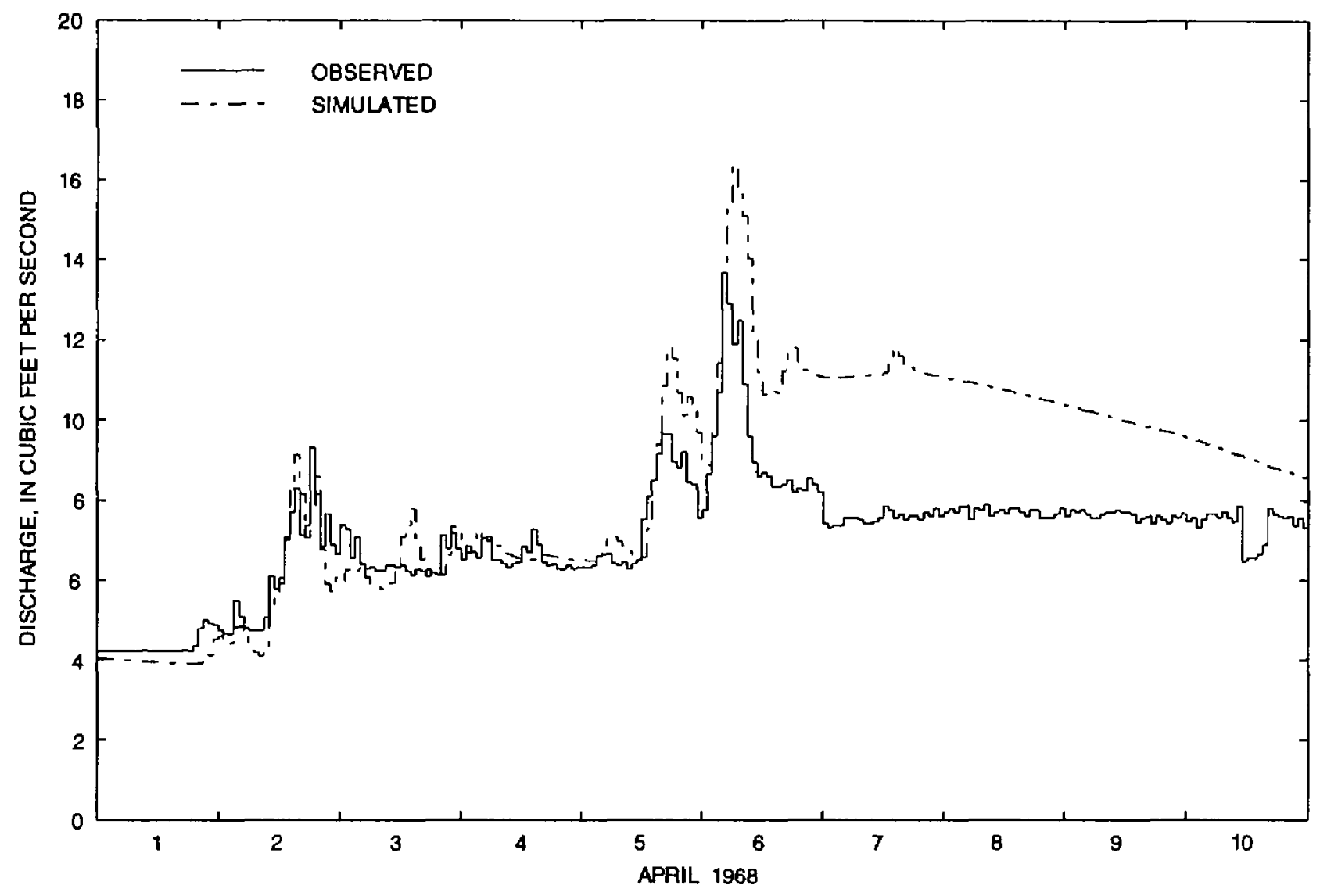

Figure 20.--Observed and simulated hourly mean discharges for Woodland Creek at Martin Way at Lacey, Washington (station 12080670), in the Woodland Creek Basin. Simulated discharges are from the first-year calibrated model applied to the storm period April 1 through 10, 1988.

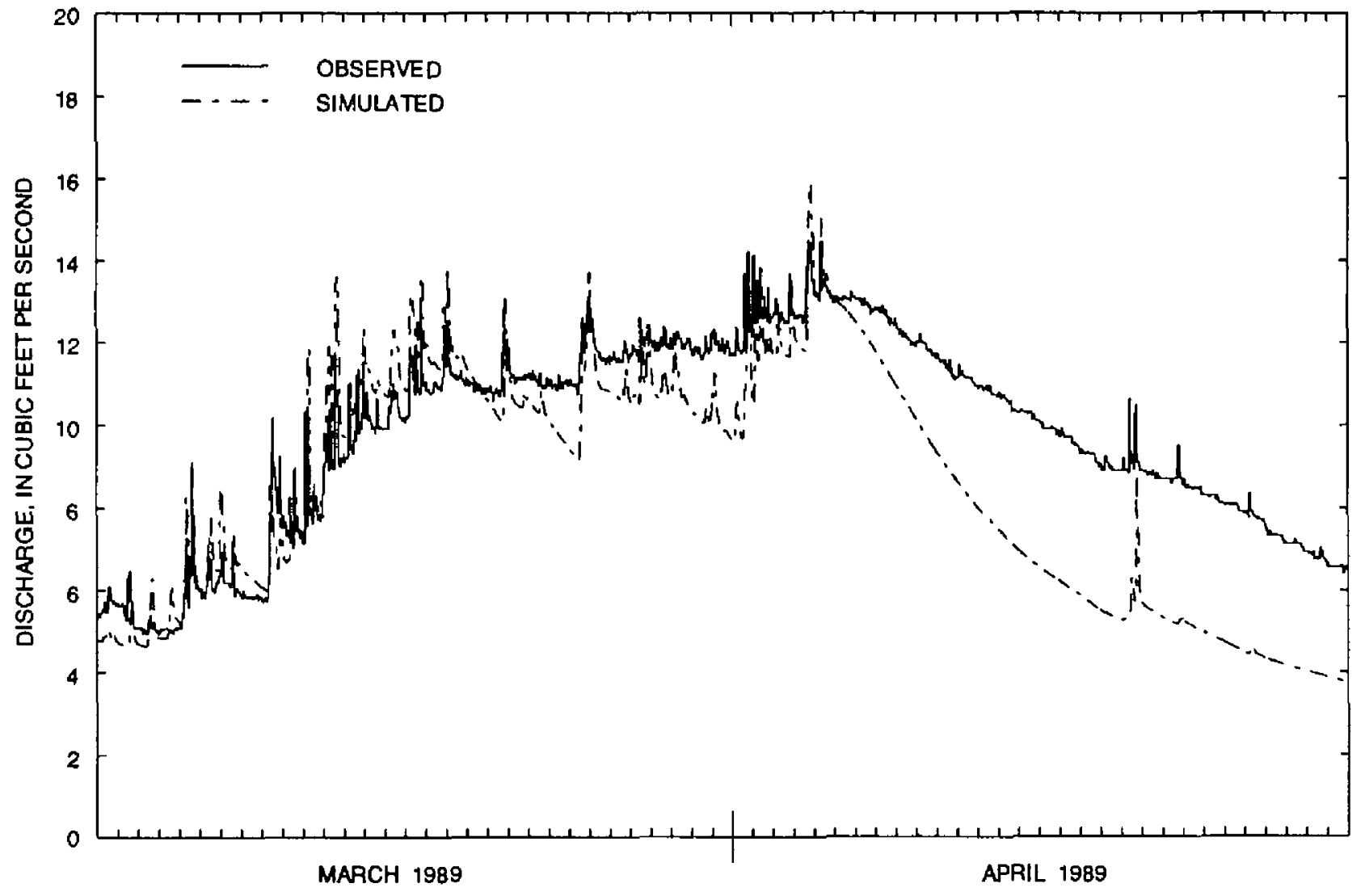

Figure 21.--Observed and simulated hourly mean discharges for Woodland Creek at Martin Way at Lacey, Washington (station 12080670), in the Woodland Creek Basin. Simulated discharges are from the first-year calibrated model applied to the storm period March 1, 1989, through April 30, 1989. 


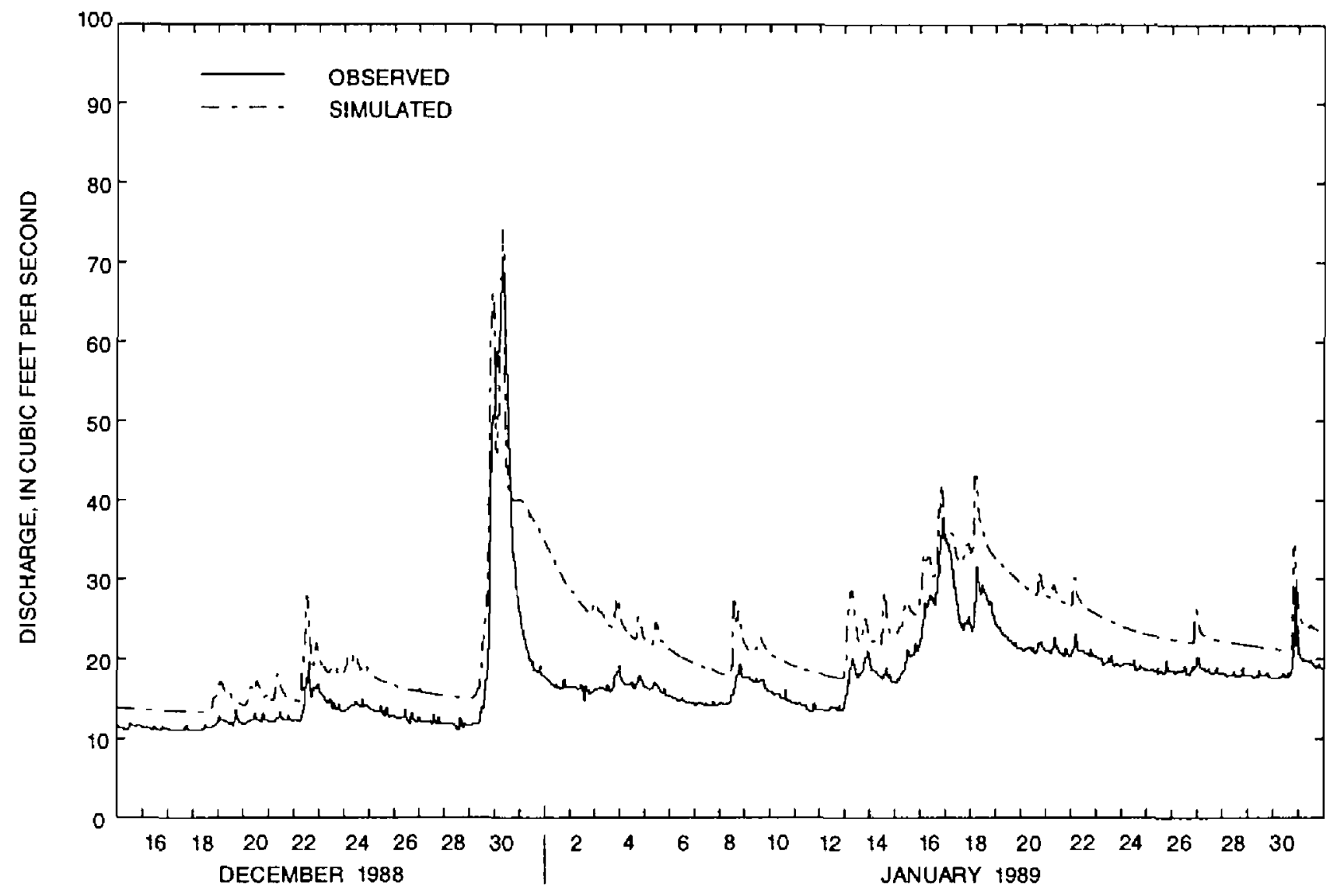

Figure 22.--Observed and simulated hourly mean discharges for Woodland Creek near Olympia, Washington (station 12081000), in the Woodland Creek Basin.

Simulated discharges are from the first-year calibrated model applied to the storm period December 15, 1988, through January 31, 1989.

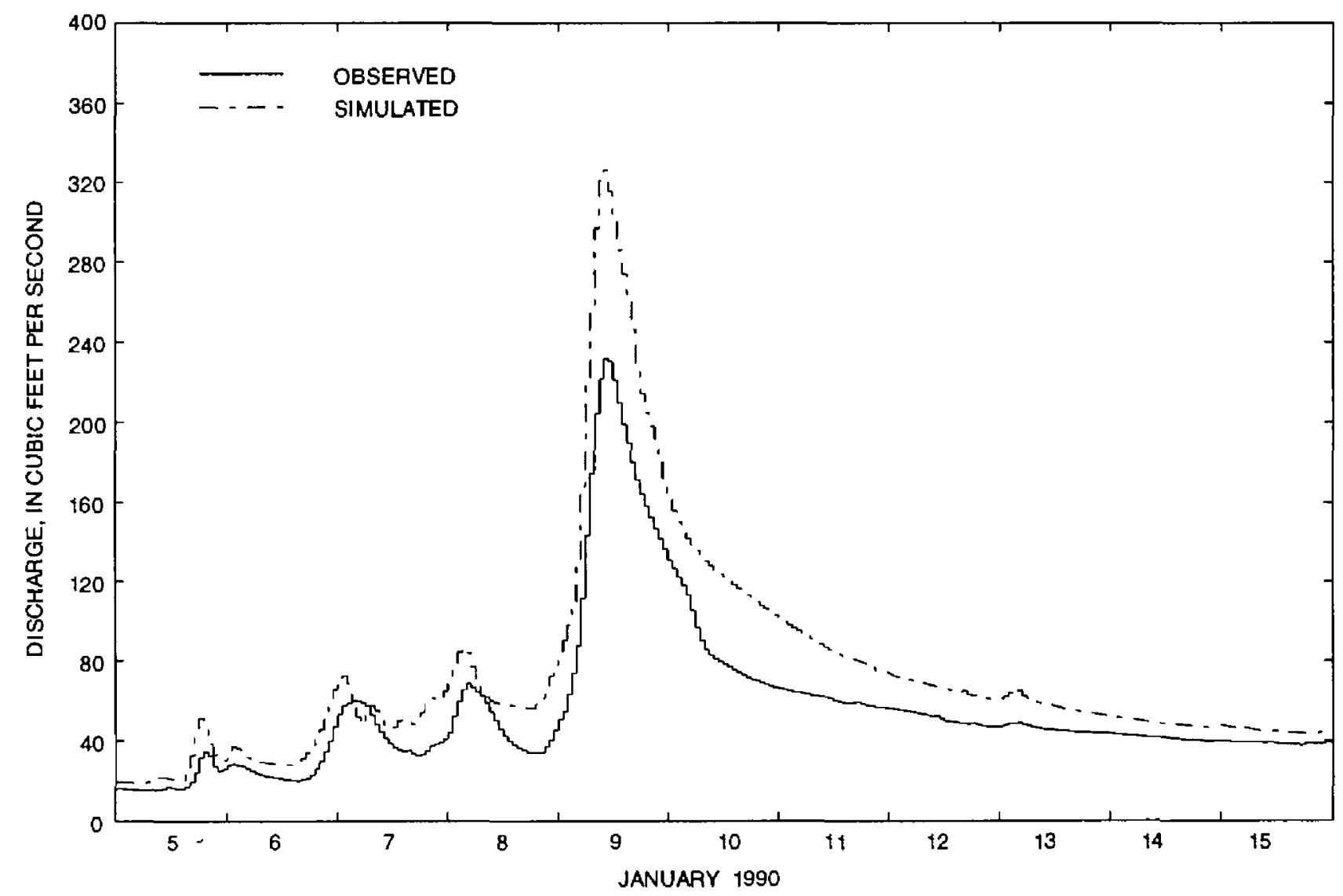

Figure 23.--Observed and simulated hourly mean discharges for Woodland Creek near Olympia, Washington (station 12081000), in the Woodland Creek Basin.

Simulated discharges are from the first-year calibrated model applied to the storm period January 5 through 15, 1990. 
Table 10.--Observed and simulated storm runoff and peak discharge data of Woodland Creek, Woodard Creek, and Percival Creek for the first-year calibrated models

[Obs., observed value; Sim., simulated value; Diff., difference: simulated-observed; Percent diff., percent difference: $100 \times$ [(simulate- observed)/observed], in percent]

\begin{tabular}{|c|c|c|c|c|c|c|c|c|c|c|}
\hline \multirow[b]{2}{*}{$\begin{array}{l}\text { Station } \\
\text { number } 1\end{array}$} & \multirow{2}{*}{$\begin{array}{l}\text { Date } \\
\text { of } \\
\text { storm }\end{array}$} & \multirow{2}{*}{$\begin{array}{l}\text { Date } \\
\text { of } \\
\text { peak }\end{array}$} & \multicolumn{4}{|c|}{ Storm runoff, in inches ${ }^{2}$} & \multicolumn{4}{|c|}{ Peak discharge, in cubic feet per second ${ }^{3}$} \\
\hline & & & Obs. & Sim. & Diff. & $\begin{array}{c}\text { Percent } \\
\text { diff. }\end{array}$ & Obs. & Sim. & Diff. & $\begin{array}{c}\text { Percent } \\
\text { diff. }\end{array}$ \\
\hline \multirow[t]{10}{*}{12078720} & $3 / 25-28 / 88$ & $3 / 26 / 88$ & 2.28 & 2.53 & 0.25 & 11.0 & 97.3 & 106.4 & 9.1 & 9.4 \\
\hline & $4 / 5-8 / 88$ & $4 / 6 / 88$ & 2.86 & 2.74 & -.12 & -4.2 & 123.1 & 118.0 & -5.1 & -4.1 \\
\hline & $/ 29 / 88-1 / 1 / 89$ & $12 / 30 / 88$ & 2.11 & 2.29 & .18 & 8.5 & 102.0 & 114.1 & 12.1 & 11.9 \\
\hline & $1 / 16-20 / 89$ & $1 / 18 / 89$ & 3.44 & 3.36 & -.08 & -2.3 & 115.0 & 107.6 & -7.4 & -6.4 \\
\hline & $3 / 12-19 / 89$ & $3 / 16 / 89$ & 4.68 & 4.93 & .25 & 5.3 & 91.0 & 95.0 & 4.0 & 4.4 \\
\hline & $12 / 3-7 / 89$ & $12 / 4 / 89$ & 3.24 & 3.35 & .11 & 3.4 & 130.0 & 119.1 & -10.9 & -8.4 \\
\hline & $1 / 9-10 / 90$ & $1 / 9 / 90$ & 2.76 & 3.58 & .82 & 29.7 & ${ }^{4} 239.9$ & 319.9 & 80.0 & 33.3 \\
\hline & $1 / 28-30 / 90$ & $1 / 29 / 90$ & 2.55 & 3.06 & .51 & 20.0 & 142.5 & 186.1 & 43.6 & 30.6 \\
\hline & $2 / 9-14 / 90$ & $2 / 11 / 90$ & 6.51 & 6.86 & .35 & 5.4 & ${ }^{4} 175.8$ & 187.9 & 12.1 & 6.9 \\
\hline & $2 / 20-23 / 90$ & $2 / 20 / 90$ & 3.28 & 3.50 & .22 & 6.7 & 135.0 & 150.1 & 15.1 & 11.2 \\
\hline \multirow[t]{9}{*}{12078730} & $3 / 23-27 / 88$ & $3 / 26 / 88$ & 1.57 & 1.54 & -.03 & -1.9 & 44.0 & 32.8 & -11.2 & .25 .5 \\
\hline & $4 / 5-7 / 88$ & $4 / 6 / 88$ & 1.25 & 1.27 & .02 & 1.6 & ${ }^{4} 48.7$ & 45.7 & -3.0 & -6.2 \\
\hline & $12 / 29-31 / 88$ & $12 / 30 / 88$ & 1.43 & 1.39 & -.04 & -2.8 & ${ }^{4} 55.9$ & 62.9 & 7.0 & 12.5 \\
\hline & $1 / 14-19 / 89$ & $1 / 16 / 89$ & 2.30 & 2.00 & -.30 & -13.0 & 41.0 & 31.7 & -9.3 & -22.7 \\
\hline & $12 / 4-5 / 89$ & $12 / 4 / 89$ & 1.16 & 1.09 & -.07 & -6.0 & ${ }^{4} 62.2$ & 48.3 & -13.9 & -22.3 \\
\hline & $1 / 9-10 / 90$ & $1 / 9 / 90$ & 2.26 & 2.00 & -.26 & -11.5 & ${ }^{4} 141.6$ & 103.7 & -37.9 & -26.8 \\
\hline & $1 / 27-30 / 90$ & $1 / 28 / 90$ & 2.04 & 2.14 & .10 & 4.9 & 59.3 & 78.5 & 19.2 & 32.4 \\
\hline & $2 / 9-12 / 90$ & $2 / 10 / 90$ & 2.56 & 2.51 & -.05 & -2.0 & ${ }^{4} 57.7$ & 50.5 & -7.2 & -12.5 \\
\hline & $2 / 20-22 / 90$ & $2 / 20 / 90$ & 1.34 & 1.47 & .13 & 9.7 & 47.4 & 44.9 & -2.5 & -5.3 \\
\hline \multirow[t]{8}{*}{12080500} & $3 / 23-27 / 88$ & $3 / 26 / 88$ & .88 & .78 & -.10 & -11.4 & 28.1 & 25.1 & -3.0 & -10.7 \\
\hline & $4 / 5-7 / 88$ & $4 / 6 / 88$ & .65 & .59 & -.06 & -9.2 & 33.5 & 30.3 & -3.2 & -9.6 \\
\hline & $/ 29 / 88-1 / 1 / 89$ & $12 / 30 / 88$ & .67 & .75 & .08 & 11.9 & 34.5 & 36.6 & 2.1 & 6.1 \\
\hline & $12 / 2-6 / 89$ & $12 / 5 / 89$ & .88 & .86 & -.02 & -2.3 & 34.0 & 33.8 & -.2 & -.6 \\
\hline & $1 / 9-11 / 90$ & $1 / 10 / 90$ & 1.38 & 1.74 & .36 & 26.1 & 64.4 & 102.6 & 38.2 & 59.3 \\
\hline & $1 / 27-30 / 90$ & $1 / 29 / 90$ & .96 & .92 & -.04 & -4.2 & 36.3 & 36.2 & -.1 & -.3 \\
\hline & $2 / 9-12 / 90$ & $2 / 10 / 90$ & 1.21 & .91 & -.30 & -24.8 & 43.0 & 32.5 & -10.5 & -24.4 \\
\hline & $2 / 20-22 / 90$ & $2 / 21 / 90$ & .78 & .58 & -.20 & -25.6 & 35.7 & 26.1 & -9.6 & -26.9 \\
\hline \multirow[t]{5}{*}{12080670} & $4 / 5-7 / 88$ & $4 / 6 / 88$ & .07 & .08 & .01 & 14.3 & 15.5 & 16.5 & 1.0 & 6.5 \\
\hline & $4 / 1-8 / 89$ & $4 / 2 / 89$ & .31 & .27 & -.04 & -12.9 & 16.4 & 16.0 & -.4 & -2.4 \\
\hline & $1 / 8-10 / 90$ & $1 / 9 / 90$ & .10 & .15 & .05 & 50.0 & 25.6 & 53.0 & 27.4 & 107.0 \\
\hline & $2 / 9-12 / 90$ & $2 / 11 / 90$ & .31 & .25 & -.06 & -19.4 & 33.6 & 31.8 & -1.8 & -5.4 \\
\hline & $2 / 20-21 / 90$ & $2 / 20 / 90$ & .16 & .12 & -.04 & -25.0 & 31.1 & 23.6 & -7.5 & -24.1 \\
\hline \multirow[t]{8}{*}{12081000} & $3 / 23-28 / 88$ & $3 / 26 / 88$ & .28 & .30 & .02 & 7.1 & 72.6 & 64.0 & -8.6 & -11.8 \\
\hline & $4 / 5-8 / 88$ & $4 / 6 / 88$ & .26 & .31 & .05 & 19.2 & 84.8 & 80.2 & -4.6 & -5.4 \\
\hline & $/ 29 / 88-1 / 1 / 89$ & $12 / 30 / 88$ & .16 & .24 & .08 & 50.0 & 71.2 & 74.5 & 3.3 & 4.6 \\
\hline & $12 / 4-6 / 89$ & $12 / 4 / 89$ & .17 & .22 & .05 & 29.4 & 99.3 & 75.9 & -23.4 & -23.6 \\
\hline & $1 / 9-10 / 90$ & $1 / 9 / 90$ & .37 & .54 & .17 & 45.9 & 233.6 & 327.7 & 94.1 & 40.3 \\
\hline & $1 / 28-30 / 90$ & $1 / 28 / 90$ & .28 & .33 & .05 & 17.9 & 100.5 & 110.8 & 10.3 & 10.2 \\
\hline & $2 / 9-12 / 90$ & $2 / 10 / 90$ & .48 & .48 & .00 & .0 & 118.0 & 107.3 & -10.7 & -9.1 \\
\hline & $2 / 20-22 / 90$ & $2 / 20 / 90$ & .30 & .28 & -.02 & -6.7 & 85.3 & 73.8 & -11.5 & -13.5 \\
\hline
\end{tabular}

${ }^{1}$ Station names for the displayed station numbers are in table 7.

${ }^{2}$ Storm runoff data are the total streamflow volumes for the period of each storm.

${ }^{3}$ Peak discharge data are the maximum 15-minute mean discharges for each storm.

${ }^{4}$ Observed peak discharge data are hourly mean discharges during periods of extreme surge at a stream-gaging station. 
Snohomish Counties that were used to determine this parameter value. The adequacy of the conceptual model describing runoff generation is not affected because this parameter represents the timing rather than the volume of ground-water flow.

Calibration indicated that the conceptual model, however, did not adequately describe the routing of outflows along flow paths from land segments to the subbasin reaches. Thus, an initial guideline used for model construction had to be modified during calibration. This initial guideline had designated all rain falling on a subbasin either to evapotranspiration or to runoff that discharges to the reach and through the surface-water outlet of that same subbasin. Modifications reduced the initial contributions of runoff to reaches during calibration. These modifications represented outflows from land segments that sometimes recharged inactive ground water and at other times discharged to reaches in other subbasins. Despite the modifications of runoff contributions to subbasin reaches, the model shortcomings previously discussed were apparent during evaluation of the basin models.

The model shortcomings apparent during model evaluation indicated that calibration to only 1 year of streamflow data was not adequate to describe the complex variations of runoff contributions to reaches. Further calibration of the basin models to both years of streamflow data led to improved simulation results, particularly for the Woodland Creek model. However, no further modifications were made to the part of the Percival Creek Basin model that represented subbasins PE1, PE2, and PE3 because the model adequately simulated streamflows at station 12078730, located in subbasin PE3. The following sections of this report describe further adjustments and refinements to model parameters, and results from calibration of the basin models with 2 years of observed data.

\section{Final Calibration}

As the evaluation of the first-year calibrated models revealed, most of the models needed improvement in the simulation of the amount and timing of ground-water discharge, of low flows, and of high streamflows such as those recorded in January 1990. Only a part of the Percival Creek model, representing the Percival Creek Basin upstream of gaging station 12078730 (subbasins PE1, PE2, and PE3), did not require further calibration. In final calibration, simulation results were improved by further modification of (1) the value of the process-related parameter KVARY in the PERLND block, (2) the surface- and ground-water contributions from subbasins to drainage networks in the NETWORK bloc ${ }^{\mathrm{c}}$. and (3) the hydraulic parameters of stream reaches in the F-tables of the RCHRES block. Also, a "ground-water controller" was added that entailed modifications to th $\geqslant$ PERLND, NETWORK, and RCHRES blocks. The controller improved simulation of ground-water contributions to Woodland Creek upstream of station 12080670. Final calibration was performed using the entire data set collected from March 1, 1988, through March 15, 1990.

The input sequences for the final calil rated HSPFbased models of the Woodland, Woodard, and Percival Creek Basins appear in tables 17-19 at the end of the report. The format and parameters of HSP ${ }^{-}$input sequences are explained fully in the Hydro'ogical Simulation Program-FORTRAN Users Manual (U.S. Environmental Protection Agency, 1984).

\section{Modifications to Process-Related Parameter Values}

Modifications to the process-related parameter values during final calibration again included adjusting the values of KVARY, the active ground-water flow modifier in the PERLND block, for all land-segment types in the Woodard Creek model. In addition, parameter values were determined for new land-segment typ ss that were defined solely to recharge a ground-water controller in the final Woodland Creek model. A later section on the ground-water controller will discuss these new landsegment types and their associated parametor values.

The value for KVARY was increased for all landsegment types in the Woodard Creek mode'. First calibration results revealed that the decreased KVARY values used in the first-year models did not result in accurate simulations of the timing of ground-water discharge. Raising the KVARY values increased ground-water flow contributions to reaches during winter and spring wet periods and decreased these contributions durirg the summer dry spells. As a result, simulated streamflows after runoff peaks receded more gradually, and simulated baseflow increased in winter and spring and decreased in summer. Simulated streamflows thus more closely matched observed flows.

The final values for the process-related parameters for all land-segment types, except those assnciated with the ground-water controller, appear in table 11. 


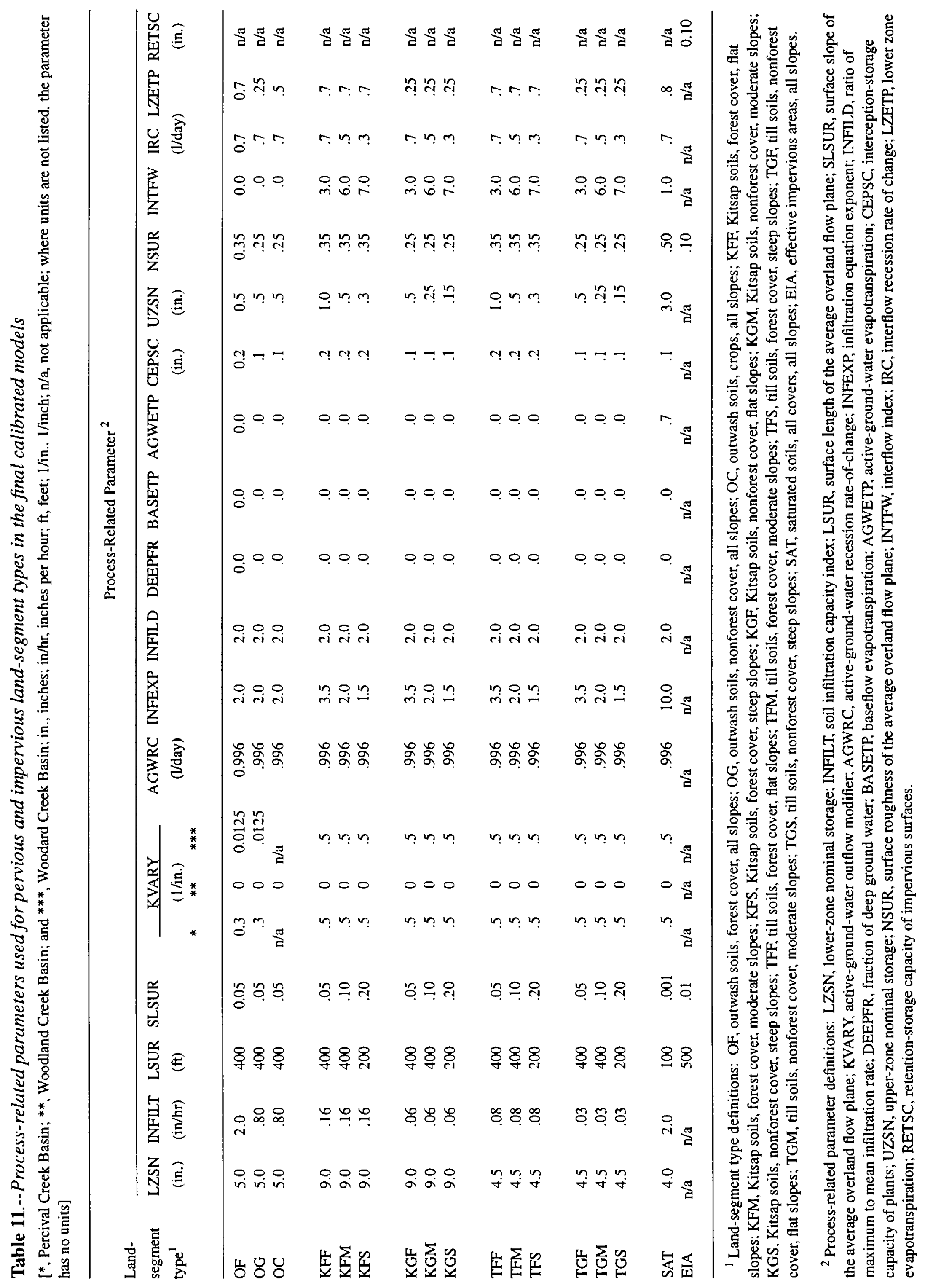




\section{Modifications to Subbasins}

In the NETWORK block of the final models, subbasins were added and aggregated, and contributions to stream reaches from ground-water, subsurface, and overland flow were further adjusted. The subbasin addition involved separating one Woodard Creek subbasin into two new subbasins, WD2 and WD3, to allow more refined simulation of peak flows. Results from the first calibration had shown that simulated peak flows in the original subbasin exceeded observed peak flows after the large storm on January 8-9, 1990, and reconnaissance indicated the reach draining the upstream part of that subbasin controlled those peak flows. The upstream part of the original subbasin was divided from the lower part. In turn, the two new subbasins divided the original reach into a new upstream reach and a new downstream reach. Each reach had a new, separate volume-discharge relation in an F-table. These changes resulted in more accurate simulations of peak flows after large storms.

Other Woodard and Woodland Creek subbasins that had been subdivided during first calibration were recombined. These previously separated subbasins had identical hydraulic connections to the same reach, and their aggregation simplified the Woodard and Woodland Creek models. The configuration of subbasins in the three final calibration models appears in figures 5 and 6.

In subbasins where contributions from ground-water, subsurface, or overland flow had been adjusted during first calibration, differences between simulated and observed streamflows were either positive or negative; that is, simulated streamflows sometimes exceeded and sometimes fell short of observed streamflows. In subbasins where contributions had not been adjusted during first calibration, differences between simulated and observed streamflows were usually positive; simulated streamflows exceeded observed streamflows. As in the first calibration, these differences, along with specific characteristics of simulated hydrographs, indicated which flow contributions to stream reaches needed adjustment.

If observed and simulated hydrographs showed large differences during baseflow periods or periods when streamflow responses to rainfall were slow and attenuated, then simulated ground-water contributions were adjusted. This was done most often for subbasins with large areas of outwash segment types. If large differences appeared when streamflow responses to rainfall were neither slow and attenuated nor extremely quick and peaked, then shallow subsurface flow contributions were adjusted. This was done most commonly for subbasins with large areas of till or Kitsap segment types. If differences were large for high flows and streamflow peaks when streamflow responses to rainfall were quick and peaked, then overland flow contributions were adjusted. This was done most often for subbasins with large areas of effertive impervious cover and saturated segment types.

Final calibration, like first calibration. also involved representing till segments with outwash segments for Woodland Creek subbasin WL23. Till segments that were not directly connected to a reach usually lay uphill from outwash segments in this subbasin, and the simulated runoff peaks were higher and more peaked than the observed runoff peaks. The concept behind this modification was that overland or shallow subsurface flow generated from up-slope till segments could drain directly into recharge ground water once the flow reached downslope outwash deposits. The modification reduced the differences between observed and simulated hydrograph peaks, especially the peak following the storm of Januэry 8-9, 1990. All of the subbasins affected by this modification appear at the end of this section in a list that presents conditions that warranted restricting flow contributions to reaches and the affected subbasins.

The first-year calibrated models for th e Woodland and Woodard Creek Basins sometimes produced simulated hydrograph peaks higher and flashier than observed hydrograph peaks for some highly urbanized subbasins with large areas of outwash segment types. For the final calibration, the adjustments to percent effe rtive impervious area for the partially impervious land cover classes were extended to three new subbasins. (See the discussion of effective impervious area adjustments ir the "Modifications to Subbasins" subsection of the section "First Calibration and Evaluation.") Like those subbasins adjusted in first calibration, these subbasins contained drainage systems of grassy swales that could store and infiltrate runoff from impervious areas and decrease overland flow contributions to streams. The adjustments were made in Woodard Creek subbasin WD2 and parts of WD3 and in parts of Woodland Creek subbasin WL2. All of the subbasins affected by this modification appear at the end of this section in a list that presents condition? that warrant restricting flow contributions to reaches ant the affected subbasins.

Although it was initially assumed that all precipitation falling on a subbasin was either evapotranspired or was discharged out the surface-water outlet. of that same subbasin, this assumption was not adequate for many Woodland, Woodard, and Percival Creek sıbbasins. The first-year calibrated models produced, during the 
evaluation period, simulated low flows and after-storm peak flows that often exceeded observed streamflows. Consequently, during the final calibration, simulated ground-water, shallow subsurface, and overland flow contributions from certain subbasins were decreased. Information collected from the field suggested seven specific subbasin conditions that warranted restricting flow contributions to reaches. The first four had been recognized during first calibration, and the latter three were added during final calibration. The subbasin conditions that warranted restricting flow contributions to reaches and the subbasins affected are as follows (more than one of the following conditions may apply to any given subbasin).

(1) A subbasin contained large areas of outwash that drained to regional rather than local aquifers. This condition was found in Woodland Creek subbasins WL2, WL4, WL6, WL6B, WL6C, WL6D, WL6E, WL9, WL10, WL12, WL13, WL14, and WL20; and Woodard Creek subbasin WD1.

(2) The mouth of a subbasin or parts of a subbasin's surface-water drainage network were above the ground-water table, so ground-water flow contributions to the drainage network decreased. This condition was found in Woodland Creek subbasins WL2, WL6B, WL6C, WL6D, WL6E, WL9, WL10, WL12, WL13, WL14, WL20, WL21, WL22, WL23; Woodard Creek subbasin WD1; and Percival Creek subbasins PE5, PE7, PE8, PE9, PE10, PE11, and PE12.

(3) Complex ground water-surface water interactions in lakes modified ground-water flow contribution to drainage networks. This condition was found in Woodland Creek subbasins WL4 and WL6 and Percival Creek subbasin PE5.

(4) The subbasin contained man-made conveyance systems, infiltration facilities, grassy swales, dry wells, or hummocky areas with many closed depressions that modified contributions of subsurface flow or overland flow to drainage networks. This condition was found in Woodland Creek subbasins WL2, WL6, WL6B, WL6C, WL8, WL9, WL10, WL12, WL13, WL14, and WL19; Woodard Creek subbasins WD1, WD2, and WD3; and Percival Creek subbasin PE11.

(5) A subbasin was closed, with no hydraulic connection between land segments and the surface drainage system. This condition was found in Woodland Creek subbasins WL1, WL5B, WL6A, WL7, WL11, WL20A, and WL22A; and Woodard Creek subbasins WD4A, WD5A, and WD5B.

(6) A subbasin was closed, but ground-water flow drained to a lower elevation reach in another, usually adjacent, subbasin. This condition was found in Woodland Creek subbasins WL1A, WL3, WL5A, WL8A, WL8B, WL9A, WL13A, WL16, WL16A, and WL25B; and Woodard Creek subbas'ns WD3A, WD4B, and WD6A.

(7) A subbasin contained areas of outwarh soils adjacent to drainage networks and downgradient from glacial till areas. Overland and subsurface flow generated from the till recharged ground water in the outwash deposits. This condition was found in Woodland Creek subbasins WL13, WL14, WL15, WL16, WL16A, WL17, WL19, WL20, WL21, and WL23; and Woodard Creek subbasin WD3.

Schematic diagrams of the hydraulic connections from subbasins to drainage networks are shown in figures 39-41 on pages 73-76.

\section{Modifications to Reach ?s}

Final revisions to the RCHRES blo:ks of the basin models consisted of constructing three new stream reaches and their associated F-tables and of making final adjustments to reach losses and to volume-discharge relations. One of the new reaches was the major component of the ground-water controller discussed in the following section. The other two new reaches, both ir the Woodard Creek Basin, were constructed for subbasins WD2 and WD3 when the subdivision of an existing subbasin created these new subbasins.

In final calibration, the volume-discharge relations in the F-tables were adjusted to account for higher storage volumes in the drainage network and for greater channel losses during high flows. Hydrographs simulated by the first-year calibrated models had exceeded observed hydrographs during peak flows, and field information indicated that the volume and the loss components of the F-tables could be higher. For example, field observations indicated that during high-flow periods, once-dry depressions and swales often filled with water and flowed toward major channels. The drainage networks expanded, and the number of channels flowing toward major reaches increased during these periods. Field observations also indicated that low-lying areas near some major channels 
stored large amounts of channel backwater and channel overflow and then released the stored water back to the channel as streamflows receded. In both of these instances, larger volumes of water were stored in the actual reaches than were accounted for in the F-table volumes of the first-year calibrated models. Thus, in the part of the F-tables pertaining to high volumes and discharges, volumes often were increased in relation to corresponding discharges, and, by doing so, greater volumes were required to increase discharges during high flows. The adjustments reduced the simulated peak flows and, consequently, their differences from observed volumes.

Another reach-related adjustment to reduce simulated peak flows was prompted by the observation that in flat, low-lying areas adjacent to channels, storage areas received overflow water that was diverted away from the drainage network. This water would eventually infiltrate or evaporate. To represent these losses in the basin models, a second outflow was added to the F-tables of certain reaches. Streamflow directed to this second outflow was considered to be lost from the basin model either to inactive ground water (ground water not available for runoff) or to evaporation.

To improve simulations during periods of moderate or low flows, many minor adjustments of the same kinds discussed above were made. These adjustments dealt with reach losses stemming from interactions of ground water and surface water in subbasins containing lakes and large areas of outwash soils or containing channels that flowed through outwash soils. Tables 17-19 (at the end of the report) show the F-tables within the input sequences for the three basin models.

\section{Ground-Water Controller}

After the first-year calibrated model underestimated daily mean flows in late winter and spring at Woodland Creek station 12080670 (see fig. 12), it was concluded that the simplified representation of the behavior of a groundwater system in the HSPF PERLND block could not adequately simulate ground-water recharge, storage, flow, and discharge of the large aquifer system that underlies several subbasins in the Woodland Creek Basin. To compensate for this shortcoming, a "ground-water controller" was developed to better simulate the many complex aquifer features that underlie the flat outwash plains upstream of Woodland Creek station 12080670 . The controller was not designed to explicitly simulate the actual movement and storage of water in an aquifer, but it cculd accurately simulate the magnitude and timing of ground-water discharge to Woodland Creek.

The major component of the controller was an F-table that governed the outflow of the ground-water system as a function of simulated ground-vater storage. The simulated ground-water system could store large volumes of water supplied by outflows from the PERLND and NETWORK blocks of the model, and it could delay the discharge of this water by using a threshold F-table volume. Below the threshold, discharge would be zero, and above it discharge to Woodland Creek took place. A second discharge outflow defined in the F-tables allowed for drainage of stored water to inactive ground water. If simulated ground-water storage fell below the threshold storage, drainage was directed to inactive ground water, which did not discharge to the creek. During summer and fall dry periods, the storage in the simulate 1 ground-water system was too small to maintain ground-vater discharge to Woodland Creek, and during the late winter or spring, the storage rose above the threshold, and g-nund water was discharged to the creek.

To simulate recharge to the controller reach, the PERLND component of the ground-water controller used simulated ground-water recharge from certain land segments within some designated subbasins ir the flat outwash plains of the Woodland Creek Basin upstream of Woodland Creek station 12080670 . These land segments did not contribute runoff to reaches in the first-year calibrated Woodland Creek model. Outwash land segments contributed a large portion of the recharge to the ground-water controller, but till and saturated land segments also contributed some recharge. The outwash land segments that recharged to the controller reach were assigned to newly defined controller land-segment types. These controller land-segment types were designated outwash-forest ground water, outwash-nonforest ground water, and outwash-crops ground water, and they retained the same process-related parameter values, except for KVARY values, as their counterparts in the regular land-segment types. The active ground-water modifier, KVARY, though, received a value of $0.2 \mathrm{fcr}$ all controller segment types. Determined by calibration the KVARY value fine-tuned both large and small level : of groundwater discharge from the land segments to the reach. The till and saturated land segments that contrijuted recharge to the ground-water controller were classif ed into the same land-segment types and assigned the same process-related parameter values as their counterparts that drained to reaches. 
The NETWORK component of the ground-water controller served (1) to designate specific areas in some Woodland Creek subbasins to land-segment types that recharged the controller reach; (2) to supply the recharge water to the controller reach for storage and delayed discharge; and (3) to discharge the ground water from the controller reach to Woodland Creek. Large parts of Woodland Creek subbasins WL2, WL3, WL5A, WL6, and WL6E, consisting mostly of outwash segments but also some till and saturated segments, were designated to recharge the controller reach. These parts had not previously contributed runoff to the creek. The areas assigned to the controller land-segment types were determined by trial-and-error model runs repeated until enough recharge was directed to the controller to yield satisfactory simulations. These areas, selected by calibration and available ground-water information, did not necessarily represent the actual areas that recharged to the actual ground-water system under this part of the Woodland Creek Basin. Nevertheless, the segments of these areas in fact did lie in subbasins uphill from the controller discharge point, Long Lake, located in subbasin WL6.

\section{Calibration Results}

First calibration had identified three general features requiring additional calibration to improve runoff simulation: ground-water contributions to Woodland Creek, low streamflows in both Woodland and Woodard Creeks, and high streamflows, especially after the large January storm, in Woodland, Woodard, and Percival Creeks. Simulations of those three features were improved during final calibration. The ground-water controller in the final Woodland Creek model noticeably improved runoff simulations for late winter and spring at Woodland Creek station 12080670. Refinements in the contributions of groundwater, shallow subsurface, and overland flows and in the volume-discharge relations improved runoff simulations of both high and low flows in all three basin models.

Yearly and seasonal runoff.--The relatively small simulation differences for yearly, winter, and spring runoff (total volumes) suggest that the final models simulated runoff generation adequately for most of the year. Table 12 shows the observed and simulated yearly and seasonal runoff volumes for the entire study period from the final calibrated models for the five gaging stations, and table 13 shows similar results from the first-year calibrated models for comparison. For the whole study period, the absolute differences produced by the final models between observed and simulated yearly runoff ranged from 1.4 to 5.2 percent, and for individual water years, from 0.4 to
7.5 percent. For winter and spring runoff during the entire study period, the absolute differences ranged from 1.8 to 7.9 percent and from 0.2 to 6.9 percent, respectively. For summer runoff, the differences ranged between 0.3 and 100 percent, but the large percent differences reflect small differences between observed and simulated runoff volumes. Indeed, simulation results from th? final Woodland Creek model showed the greatest improvement over results from the first-year model: the absnlute difference for all years decreased from 18.3 to 1.4 percent at station 12080670 and from 12.7 to 3.9 percent at station 12081000 .

Daily mean discharge.--The final calibrated models adequately simulated daily mean discharges and performed best with medium and high flows. Tables 14 and 15 list the statistical measures of difference for daily mean discharges simulated by the final calibrated and first-year calibrated models. Mean absolute differences for all flows were between 7.5 to 32.0 percent, compared with 13.4 to 57.3 percent differences produced by the first-year calibrated models. Once again, the largest percent differences occurred during low-flow periods, when absolute differences were relatively small. Figures 24 through 28 show the observed and simulated hydrographs of daily mean discharges from the final calibrated models.

The final calibration of the Woodlard Creek model showed the greatest improvement over the first calibration. The addition of the ground-water control"er and the refinements to flow contributions and to the F-tables greatly improved the simulation results. At station 12080670, mean absolute differences in daily discharges were reduced from 109.4 to 66.2 percent for the low flow regime and from 57.3 to 32.0 percent for all flows. Large percent differences were reported for the low-flow regime, but again the actual differences were small (less than 0.5 cubic foot per second). Streamflow records indicated that during low-flow periods Woodland Creek became ephemeral (fig. 27), and percent differences were especially high for these periods because percentages were computed using extremely low observed flows.

Storm runoff and peak discharge.--Hourly mean discharge hydrographs and statistical measu"es confirm that the final calibrated models improved storm runoff and peak discharge simulations (figs. 29-38 and table 16). Absolute differences between simulated and observed storm runoff volumes ranged from 0.0 to 31.2 percent, though only 1 of 40 runoff volumes excesded 20 percent difference. By comparison, absolute differences from first-year calibrated models had ranged from 0.0 to 50.0 percent, with 10 of 40 runoff volumes ex seeding 


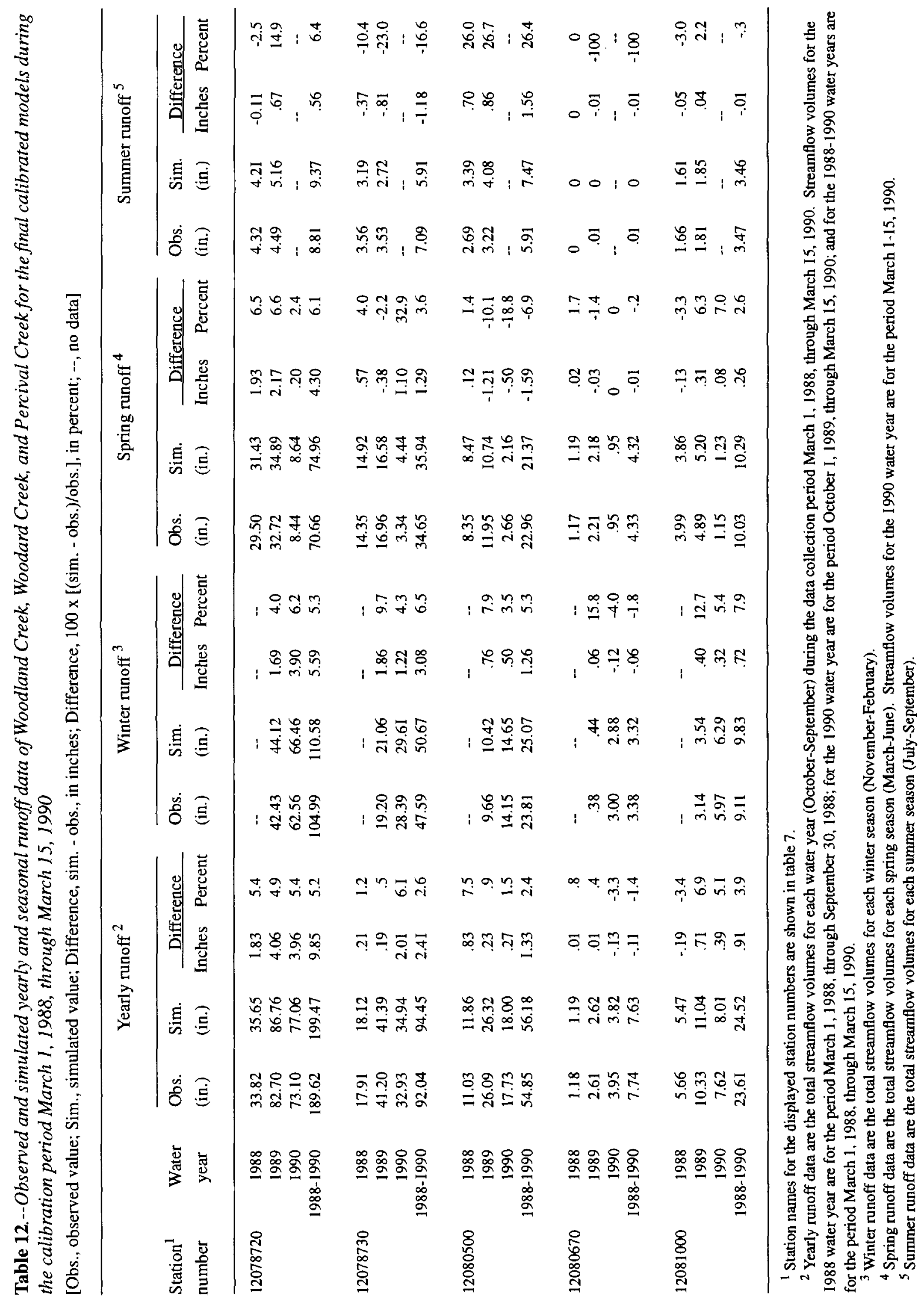




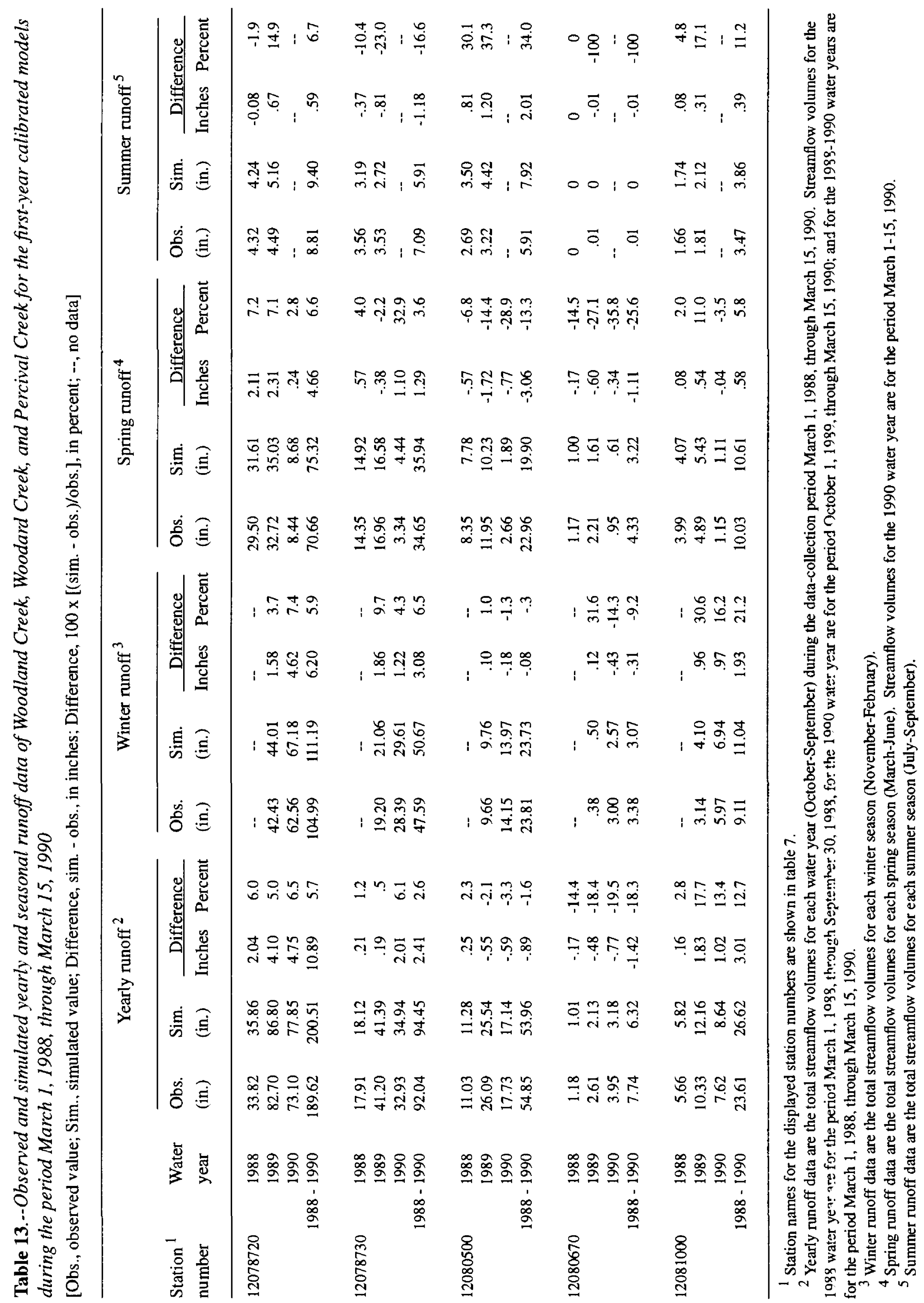


Table 14.--Measures of difference between simulated and observed daily mean discharges of Woodland Creek, Woodard Creek, and Percival Creek for the final calibrated models during the calibration period March 1, 1988, through March 15, 1990

\begin{tabular}{|c|c|c|c|c|c|c|c|}
\hline \multirow{2}{*}{$\begin{array}{l}\text { Station } \\
\text { number }\end{array}$} & \multirow{2}{*}{$\begin{array}{l}\text { Flow } \\
\text { regime } 2\end{array}$} & \multicolumn{2}{|c|}{$\begin{array}{c}\text { Mean } \\
\text { absolute difference }\end{array}$} & \multicolumn{2}{|c|}{$\begin{array}{c}\text { Root mean } \\
\text { square difference }\end{array}$} & \multicolumn{2}{|c|}{ Bias $^{5}$} \\
\hline & & Average & Percent & Average & Percent & Average & Percent \\
\hline \multirow[t]{4}{*}{12078720} & Low & 1.057 & 20.6 & 1.350 & 33.4 & 0.327 & 13.0 \\
\hline & Medium & 2.873 & 11.8 & 3.657 & 14.7 & 1.951 & 7.3 \\
\hline & High & 5.084 & 7.1 & 6.960 & 9.2 & 3.121 & 3.9 \\
\hline & Total & 3.002 & 13.2 & 4.606 & 21.8 & 1.796 & 8.1 \\
\hline \multirow[t]{4}{*}{12078730} & Low & .489 & 21.5 & .549 & 24.3 & -.416 & -18.9 \\
\hline & Medium & .822 & 16.6 & 1.055 & 21.4 & .209 & 3.5 \\
\hline & High & 1.944 & 13.1 & 2.782 & 17.6 & .827 & 8.1 \\
\hline & Total & 1.083 & 17.1 & 1.742 & 21.3 & .207 & -2.4 \\
\hline \multirow[t]{4}{*}{12080500} & Low & .847 & 30.5 & .981 & 35.0 & .777 & 28.4 \\
\hline & Medium & .778 & 16.0 & .988 & 20.4 & .454 & 9.8 \\
\hline & High & 1.828 & 14.8 & 2.542 & 18.2 & -.695 & -4.0 \\
\hline & Total & 1.152 & 20.4 & 1.675 & 25.6 & .177 & 11.3 \\
\hline \multirow[t]{4}{*}{12080670} & Low & .446 & 66.2 & .604 & 75.5 & -.032 & -22.6 \\
\hline & Medium & .741 & 21.6 & .906 & 26.9 & -.187 & -1.1 \\
\hline & High & .989 & 8.3 & 1.200 & 10.7 & -.159 & -.6 \\
\hline & Total & .726 & 32.0 & .936 & 46.6 & -.126 & -8.1 \\
\hline \multirow[t]{4}{*}{12081000} & Low & .725 & 6.6 & .908 & 8.2 & -.236 & -2.4 \\
\hline & Medium & 1.177 & 7.4 & 1.770 & 10.9 & .527 & 3.2 \\
\hline & High & 2.728 & 8.5 & 3.866 & 11.5 & .526 & 1.5 \\
\hline & Total & 1.539 & 7.5 & 2.505 & 10.3 & .271 & .7 \\
\hline
\end{tabular}

${ }^{1}$ Station names for the displayed station numbers are shown in table 7.

${ }^{2}$ Low, medium, and high flow regimes are the lower, middle, and upper thirds of the daily mean discharg a values from each station. Total refers to the complete daily mean discharge record specified for the stations.

${ }^{3}$ AVERAGE $=$ sum $(\mathrm{IS}-\mathrm{M} \mid / \mathrm{n})$ for all $\mathrm{M}>0.1$

PERCENT $=100.0 *$ [sum(IS-M1/M)]/n for all $M>0.1$ (where $S=$ simulated daily mean discharge in cr bic feet per second; $M=$ observed daily mean discharge in cubic feet per second; sum = summation over days for which $M>0.1$ in the calibration period; $n=$ number of pairs of daily values for which $M>0.1$ in the calibration poriod; and I I= absolute value. NOTE: Because of the method of computing percentages, measured daily mean discharges below 0.1 cubic feet per second are considered as "dry" and are not considered in this analysis).

${ }^{4}$ AVERAGE $=$ square $\operatorname{root}\{\operatorname{sum}[(\mathrm{S}-\mathrm{M}) * * 2] / \mathrm{n}\}$ for all $\mathrm{M}>0.1$

PERCENT $=100.0 *$ square $\operatorname{root}(\operatorname{sum}\{[(\mathrm{S}-\mathrm{M}) / \mathrm{M}] * * 2\} / \mathrm{n})$ for all $\mathrm{M}>0.1$

${ }^{5}$ AVERAGE $=\operatorname{sum}(\mathrm{S}-\mathrm{M}) / \mathrm{n}$ for all $\mathrm{M}>0.1$

PERCENT $=100.0 *\{$ sum $[(\mathrm{S}-\mathrm{M}) / \mathrm{M}] / \mathrm{n}\}$ for all $\mathrm{M}>0.1$ 
Table 15.--Measures of difference between simulated and observed daily mean discharges of Woodland Creek, Woodard Creek, and Percival Creek for the first-year calibrated models during the period March 1, 1988, through March 15, 1990

\begin{tabular}{|c|c|c|c|c|c|c|c|}
\hline \multirow{2}{*}{$\begin{array}{l}\text { Station } \\
\text { number }\end{array}$} & \multirow{2}{*}{$\begin{array}{l}\text { Flow } \\
\text { regime }^{2}\end{array}$} & \multicolumn{2}{|c|}{$\begin{array}{c}\text { Mean } \\
\text { absolute difference } \\
\end{array}$} & \multicolumn{2}{|c|}{$\begin{array}{c}\text { Root mean } \\
\text { square difference }\end{array}$} & \multicolumn{2}{|c|}{ Bias $^{5}$} \\
\hline & & Average & Percent & Average & Percent & Average & Percent \\
\hline \multirow[t]{4}{*}{12078720} & Low & 1.062 & 20.7 & 1.362 & 33.7 & 0.336 & 13.2 \\
\hline & Medium & 3.034 & 12.3 & 3.882 & 15.3 & 2.252 & 8.4 \\
\hline & High & 5.404 & 7.3 & 8.718 & 9.7 & 3.382 & 3.9 \\
\hline & Total & 3.164 & 13.4 & 5.568 & 22.1 & 1.987 & 8.5 \\
\hline \multirow{4}{*}{12078730} & Low & .489 & 21.5 & .549 & 24.3 & -.416 & -18.9 \\
\hline & Medium & .822 & 16.6 & 1.055 & 21.4 & .209 & 3.5 \\
\hline & High & 1.944 & 13.1 & 2.782 & 17.6 & .827 & 8.1 \\
\hline & Total & 1.083 & 17.1 & 1.742 & 21.3 & .207 & -2.4 \\
\hline \multirow[t]{4}{*}{12080500} & Low & .945 & 34.5 & 1.082 & 39.5 & .881 & 32.6 \\
\hline & Medium & .712 & 14.6 & .898 & 18.8 & .171 & 4.6 \\
\hline & High & 2.175 & 16.5 & 3.101 & 19.6 & -1.338 & -10.0 \\
\hline & Total & 1.278 & 21.8 & 1.967 & 27.6 & -.099 & 9.0 \\
\hline \multirow[t]{4}{*}{12080670} & Low & .564 & 109.4 & .765 & 208.1 & .079 & 39.6 \\
\hline & Medium & 1.461 & 39.5 & 1.805 & 48.8 & -1.025 & -23.3 \\
\hline & High & 3.548 & 22.9 & 4.681 & 27.2 & -2.744 & -15.8 \\
\hline & Total & 1.862 & 57.3 & 2.938 & 124.4 & -1.234 & .2 \\
\hline \multirow[t]{4}{*}{12081000} & Low & 1.527 & 13.3 & 2.117 & 18.3 & 1.443 & 12.4 \\
\hline & Medium & 2.937 & 18.8 & 3.993 & 25.2 & 2.714 & 17.4 \\
\hline & High & 4.258 & 12.1 & 7.010 & 16.8 & 2.329 & 6.8 \\
\hline & Total & 2.902 & 14.7 & 4.807 & 20.4 & 2.160 & 12.2 \\
\hline
\end{tabular}

${ }^{1}$ Station names for the displayed station numbers are shown in table 7.

${ }^{2}$ Low, medium, and high flow regimes are the lower, middle, and upper thirds of the daily mean discharg a values from each station. Total refers to the complete daily mean discharge record specified for the stations.

${ }^{3}$ AVERAGE $=$ sum $($ IS-M $/ / n)$ for all $M>0.1$

PERCENT $=100.0 *$ [sum( $|\mathrm{S}-\mathrm{M}| \mathrm{M}$ ) $] / \mathrm{n}$ for all $\mathrm{M}>0.1$ (where $\mathrm{S}=$ simulated daily mean discharge in crubic feet per second; $M=$ observed daily mean discharge in cubic feet per second; sum = summation over days for which $M>0.1$ in the calibration period; $n=$ number of pairs of daily values for which $M>0.1$ in the calibration period; and II = absolute value. NOTE: Because of the method of computing percentages, measured daily mean discharges below 0.1 cubic feet per second are considered as "dry" and are not considered in this analysis).

${ }^{4}$ AVERAGE $=$ square root $\left\{\operatorname{sum}\left[(\mathrm{S}-\mathrm{M})^{* *} 2\right] / \mathrm{n}\right\}$ for all $\mathrm{M}>0.1$

PERCENT $=100.0^{*}$ square $\operatorname{root}\left(\operatorname{sum}\left\{[(\mathrm{S}-\mathrm{M}) / \mathrm{M}]^{* *} 2\right\} / \mathrm{n}\right)$ for all $\mathrm{M}>0.1$

${ }^{5}$ AVERAGE $=\operatorname{sum}(\mathrm{S}-\mathrm{M}) / \mathrm{n}$ for all $\mathrm{M}>0.1$

PERCENT $=100.0 *\{$ sum $[(\mathrm{S}-\mathrm{M}) / \mathrm{M}] / \mathrm{n}\}$ for all $\mathrm{M}>0.1$ 


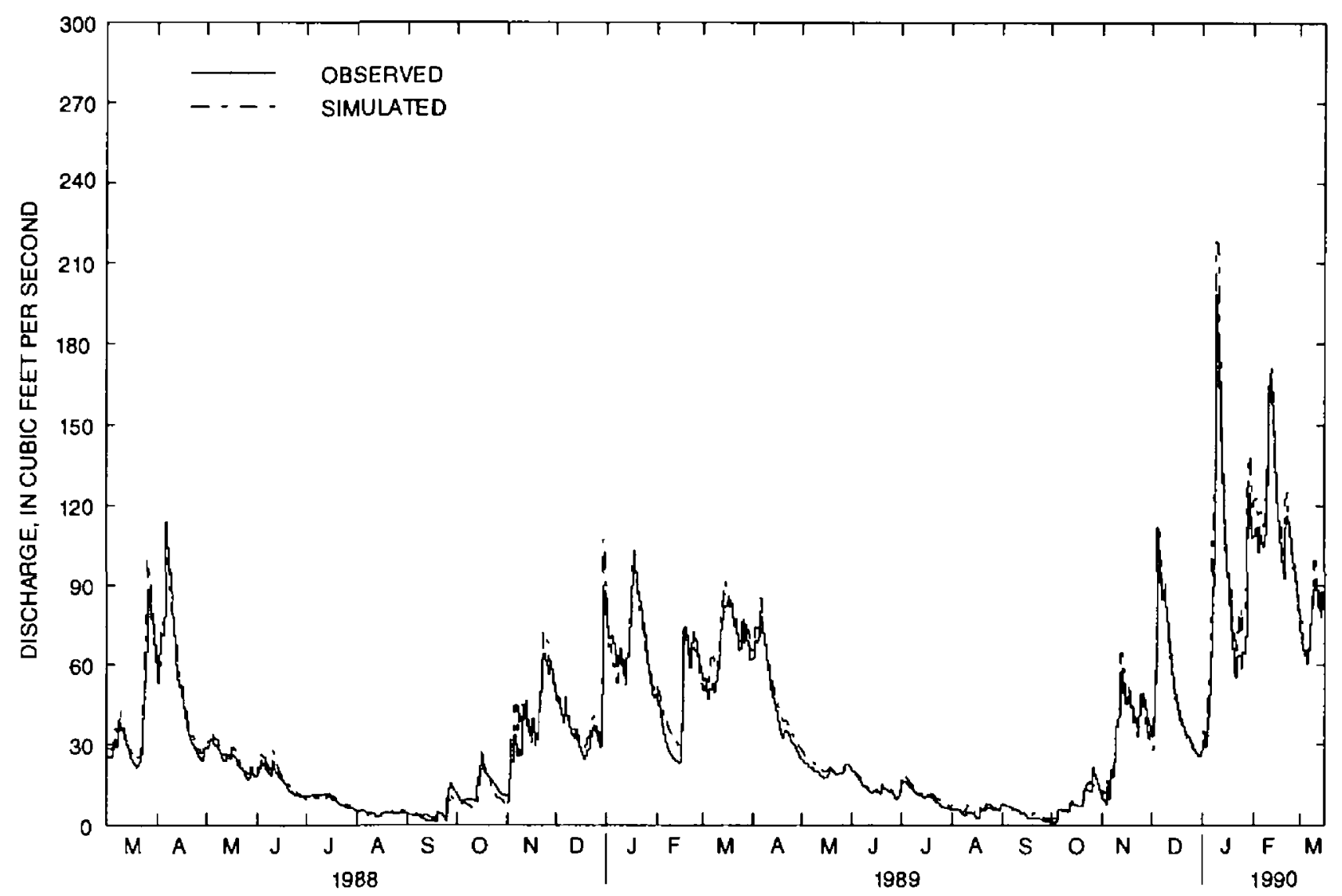

Figure 24.--Observed and simulated daily mean discharges for Black Lake Ditch near Olympia, Washington (station 12078720), in the Percival Creek Basin. Simulated discharges are from the final calibrated model applied to the period March 1, 1988, through March 15, 1990.

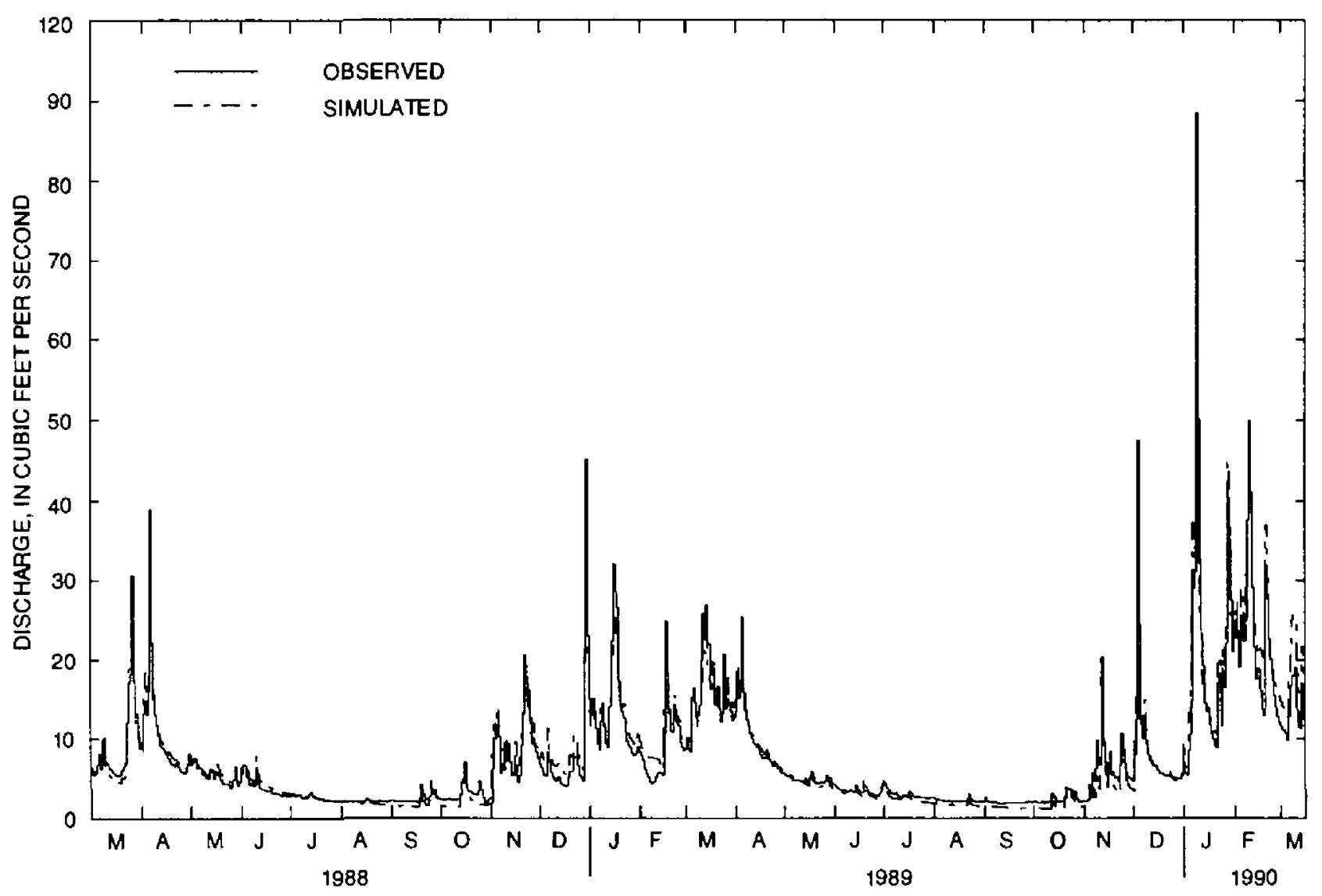

Figure 25.--Observed and simulated daily mean discharges for Percival Creek near Olympia, Washington (station 12078730), in the Percival Creek Basin. Simulated discharges are from the final calibrated model applied to the period March 1, 1988, through March 15, 1990. 


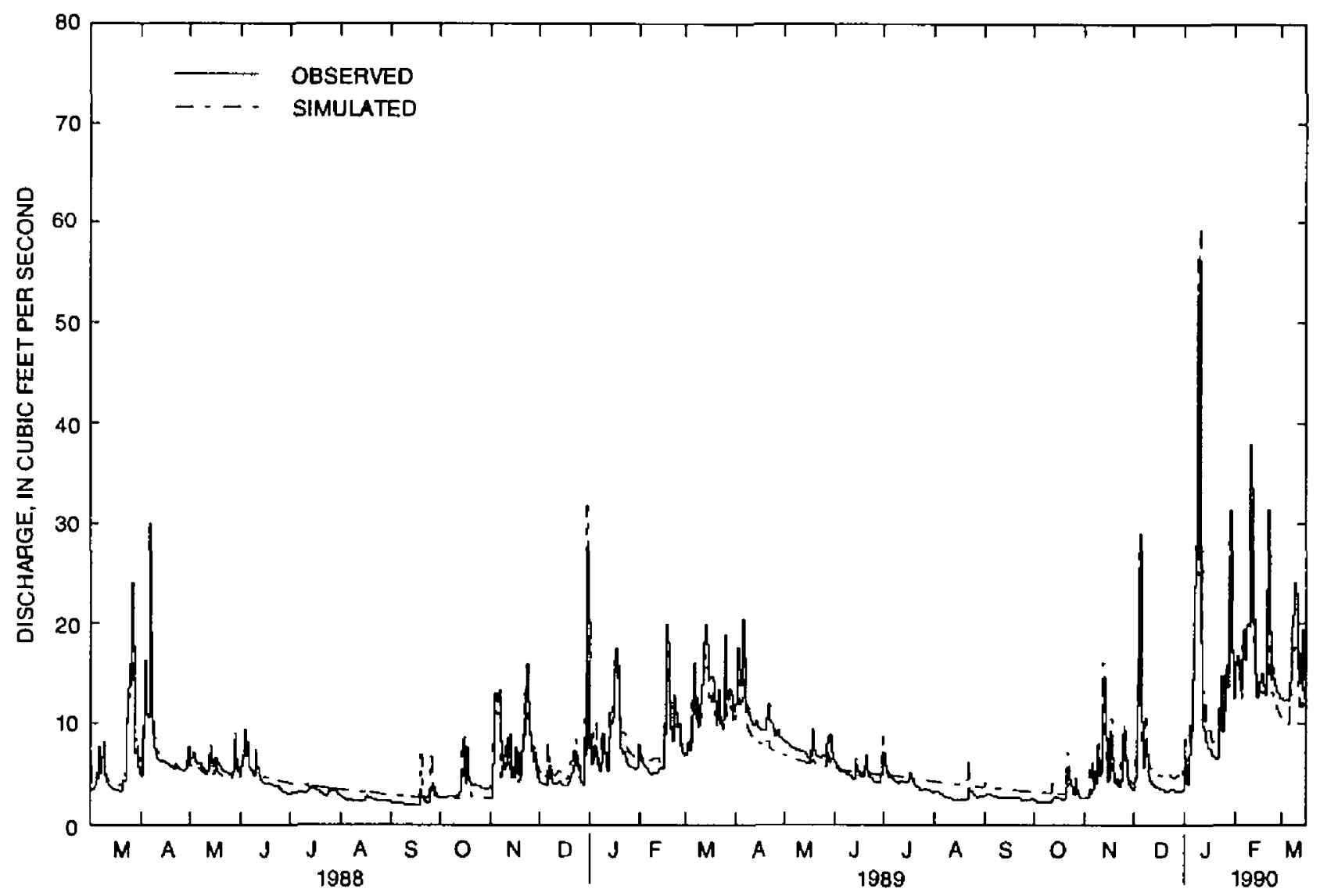

Figure 26.--Observed and simulated daily mean discharges for Woodard Creek near Olympia, Washington (station 12080500), in the Woodard Creek Basin. Simulated discharges are from the final calibrated model applied to the period March 1, 1988, through March 15, 1990.

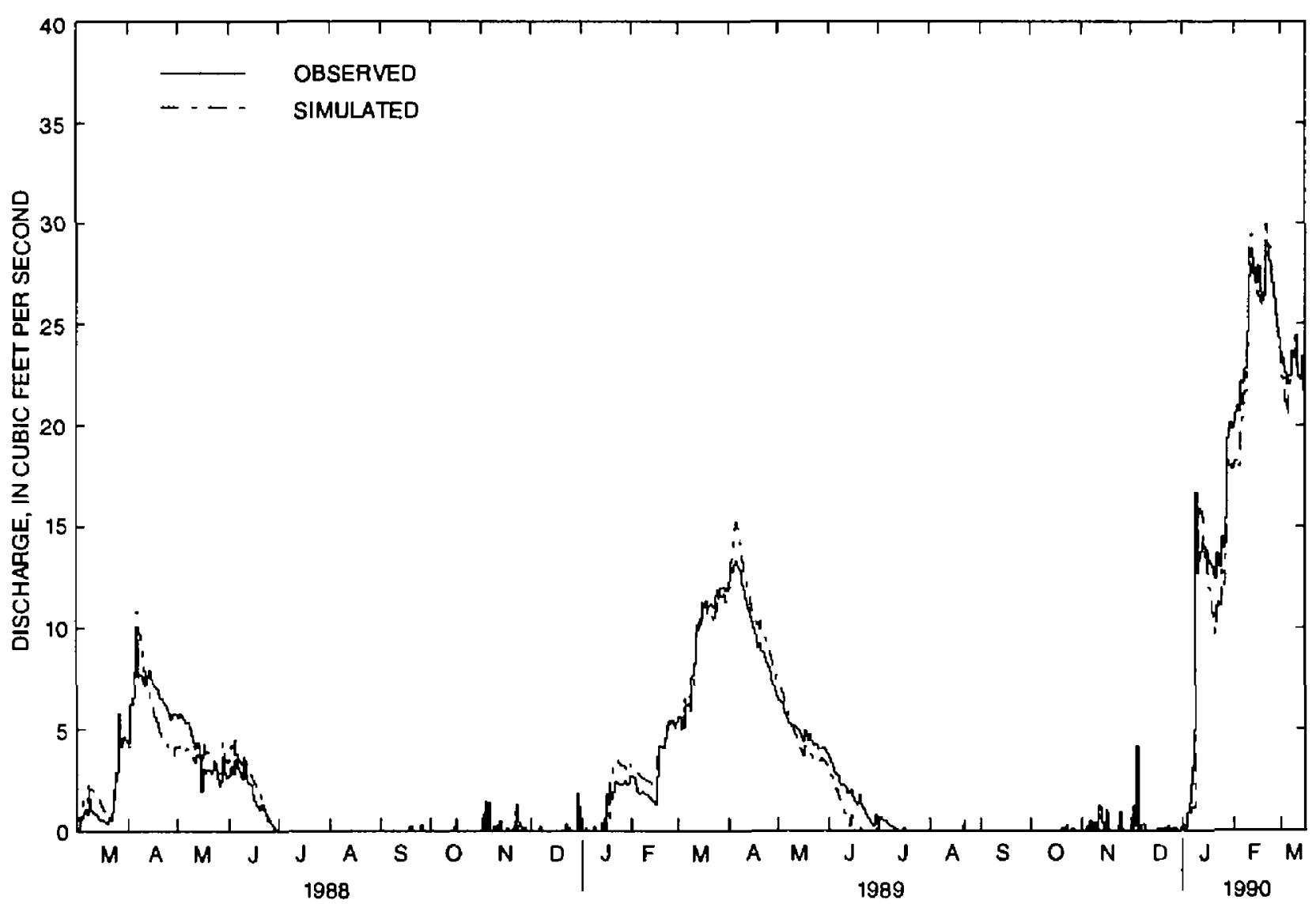

Figure 27.--Observed and simulated daily mean discharges for Woodland Creek at Martin Way at Lacey, Washington (station 12080670), in the Woodland Creek Basin. Simulated discharges are from the final calibrated model applied to the period March 1, 1988, through March 15, 1990. 


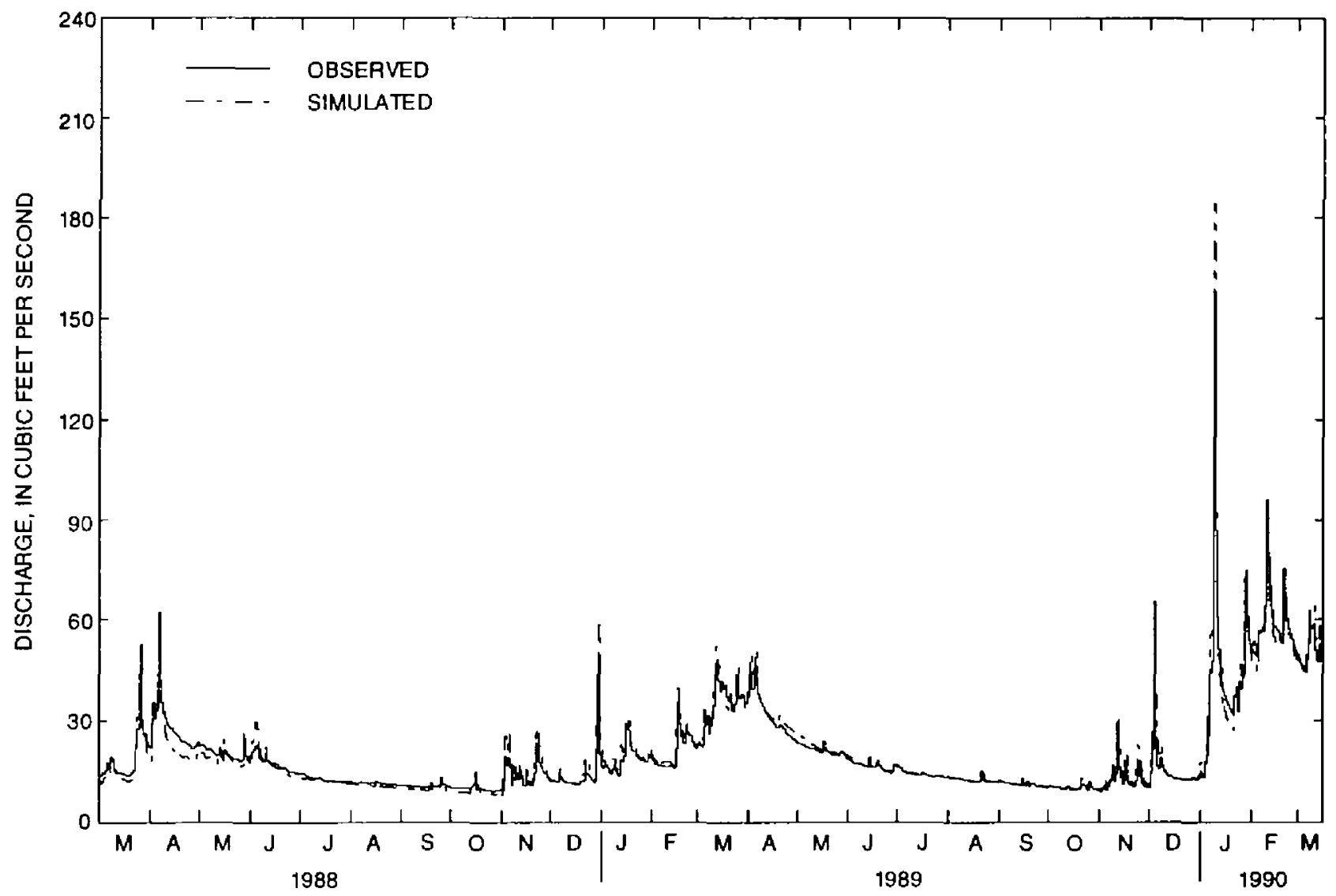

Figure 28.--Observed and simulated daily mean discharges for Woodland Creek near Olympia, Washington (station 12081000), in the Woodland Creek Basin. Simulated discharges are from the final calibrated model applied to the period March 1, 1988, through March 15, 1990. 
20 percent difference (table 10). Furthermore, absolute differences between simulated and observed peak discharges from the final models were between 0.0 and 32.4 percent, but only 4 of 40 peak discharges exceeded 25 percent difference. Again by comparison, absolute differences from the firstyear calibrated models were between 0.3 and 107 percent, with 9 of 40 peak discharges exceeding 25 percent difference.

The final models produced much improved simulations of the high streamflows resulting from the large January 1990 storm. At station 12078720 , absolute differences in runoff volume from this storm decreased from 29.7 percent for the first-year calibration to 14.1 percent for the final calibration. Absolute differences in peak discharges for the same station decreased from 33.3 to 0.7 percent. At station 12080500 , absolute differences in runoff volume decreased from 26.1 to 16.7 percent, and in peak discharge, from 59.3 to 5.9 percent.

Discussion of calibration results.--The preceding results displayed the successful streamflow simulations by the basin models calibrated to 2 years of observed streamflow data. Additionally, the results of final calibration indicate that the simulation of ground-water discharge, low streamflows, and high streamflows improved from the results of model calibration to only 1 year of streamflow data.

During final calibration, like first calibration, the only process-related parameter value adjusted was KVARY. Other final values of process-related parameters assigned to land-segment types were the same as those determined for the same land-segment types in King and Snohomish County basins by Dinicola (1990). All process-related parameter values, other than KVARY, were those originally assigned to represent the features of runoff generation in the conceptual model. Thus, the conceptual model is adequate to represent runoff generation in the three Thurston County basins. However, the conceptual model--represented in the basin models by process-related parameters and land-segment types--does not adequately represent the hydraulic connectivity, or flow paths, from land segments to reaches when all outflows from land segments in sub-basins do not contribute to reaches in the same subbasins.

Final calibration demonstrated that contributions of runoff to streamflow are strongly influenced by flow paths of land segment outflows to channel reaches. Outflows from land segments in a subbasin commonly recharge inactive ground water or contribute to streamflow in other subbasins. Additionally, ground-water contributions to streamflow are variable, not only depending on the quantity and timing of rainfall, but also depending on both period (season) and geographic location and elevation of a given reach relative to the local water table.

The inadequacy of the conceptual model in describing flow paths prompted more data collection than was originally thought to be necessary. However, basin properties related to flow paths (such as geologic stratigraphy, aquifer characteristics, and subbasin topography) were difficult to measure directly and to incorforate directly in the basin models, which are based primarily on the relation of surficial physiography and storm runoff generation. Thus, additional streamflow data, lake-stage data, and field observations of subbasin conditions (see the discussion of "Modifications to Subbasins" in this section) had to be used as the most practical method to estimate runoff contributions and generalized flow paths to reaches.

Although final calibration results were satisfactory, obtaining adequate streamfiow simulatiors at most gaging stations required extensive streamflow da ${ }^{+} a$ and field information. Additionally, in most cases, calibration to only 1 year of streamflow data simply was not adequate to describe the complex variation of runoff contributions to reaches. Only the model representing the part of Percival Creek Basin upstream of gaging station 12078730 did not require calibration to both years of strean flow data. This part of Percival Creek, except for the hea Jwater subbasin PEl, is the only gaged study basin with c'early defined subbasin boundaries along high ridges. Additionally, it is the only study basin where all ground-water flow, shallow subsurface flow, and overland flow genercted in a subbasin contributed to streamflow in that same suhbasin.

Although results from final calibration show successful streamflow simulations to 2 years of cbserved data, streamflow simulations may not be as accurate either (1) outside of the gaged areas in the basins or (2) outside of the calibration period. The basin models simulated runoff generation and streamflows for each entire basin, including the ungaged parts between the farthest downstream gaging stations and the basin mouths. Field information guided modifications to the models for the ungaged parts of the basins in the same manner as the gaged parts of the basins. However, because observed streamflow information about the ungaged parts of the basins was not available for model calibration and evaluation the accuracy of streamflow simulations there is uncertain.

Evaluation of the first-year calibrate 1 models demonstrated that, in most cases, differences between observed and simulated streamflows could increase when the basin 


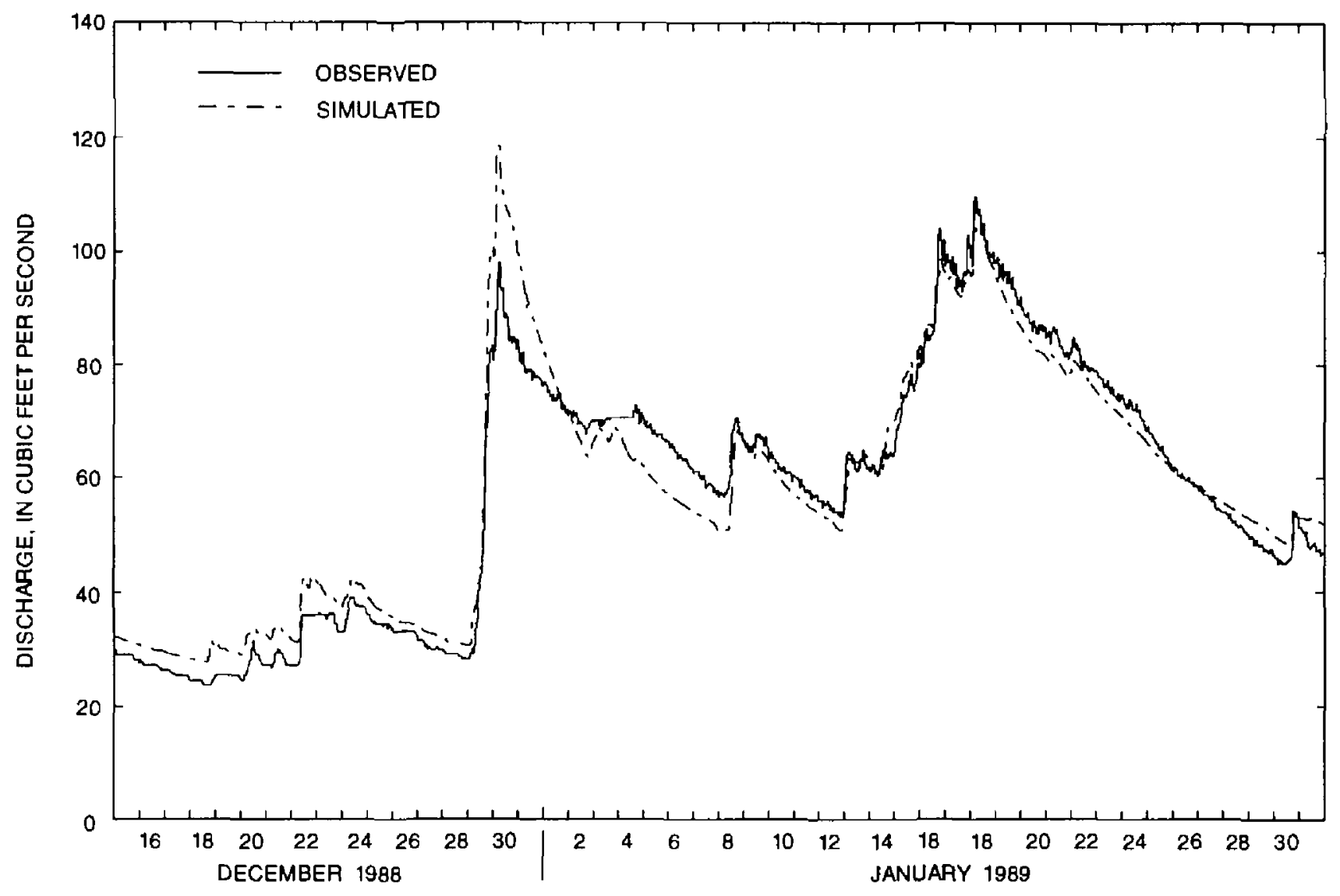

Figure 29.--Observed and simulated hourly mean discharges for Black Lake Ditch near Olympia, Washington (station 12078720), in the Percival Creek Basin. Simulated discharges are from the final calibrated model applied to the storm period December 15, 1988, through January 31, 1989.

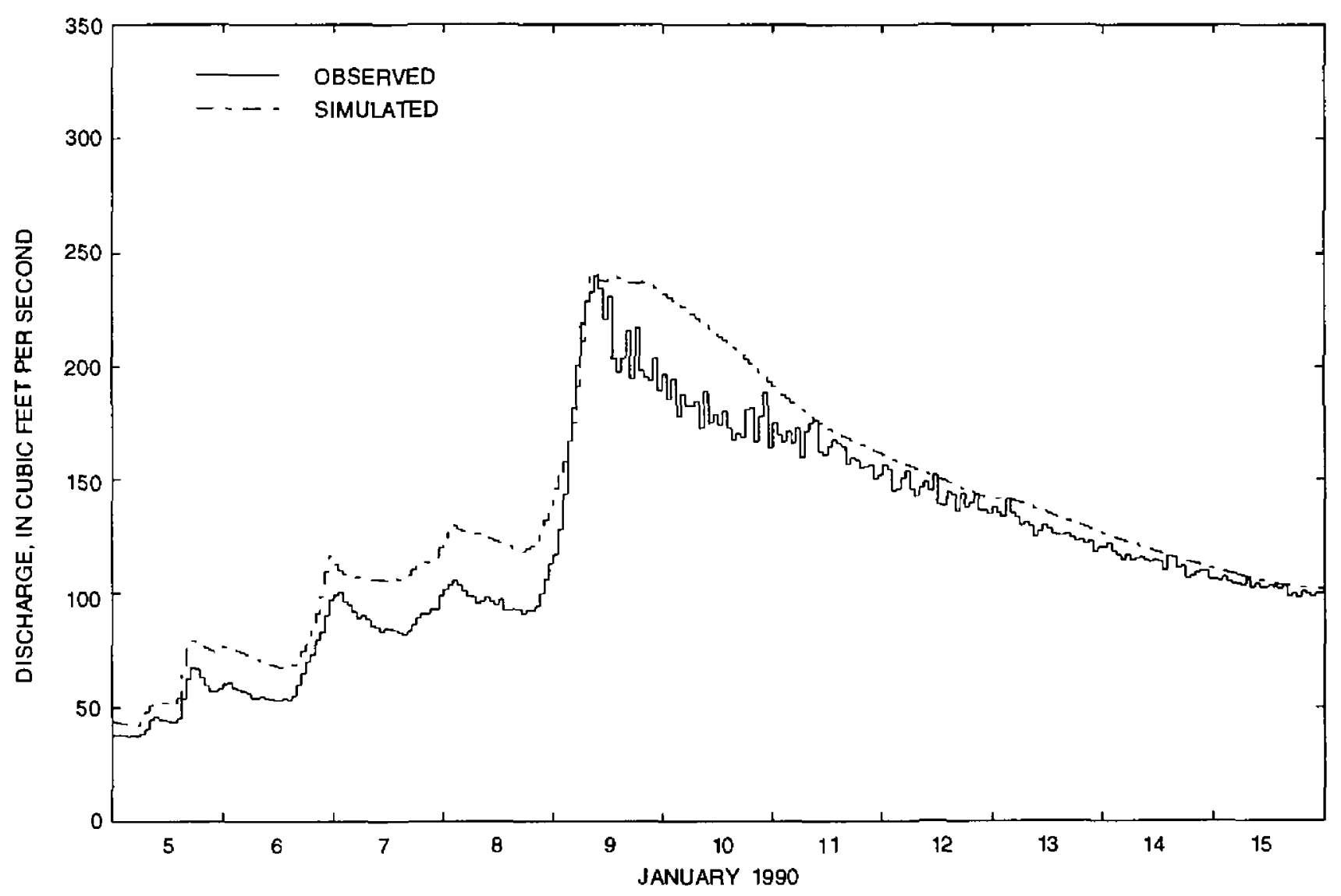

Figure 30.--Observed and simulated hourly mean discharges for Black Lake Ditch near Olympia, Washington (station 12078720), in the Percival Creek Basin. Simulated discharges are from the final calibrated model applied to the storm period January 5 through 15, 1990. 


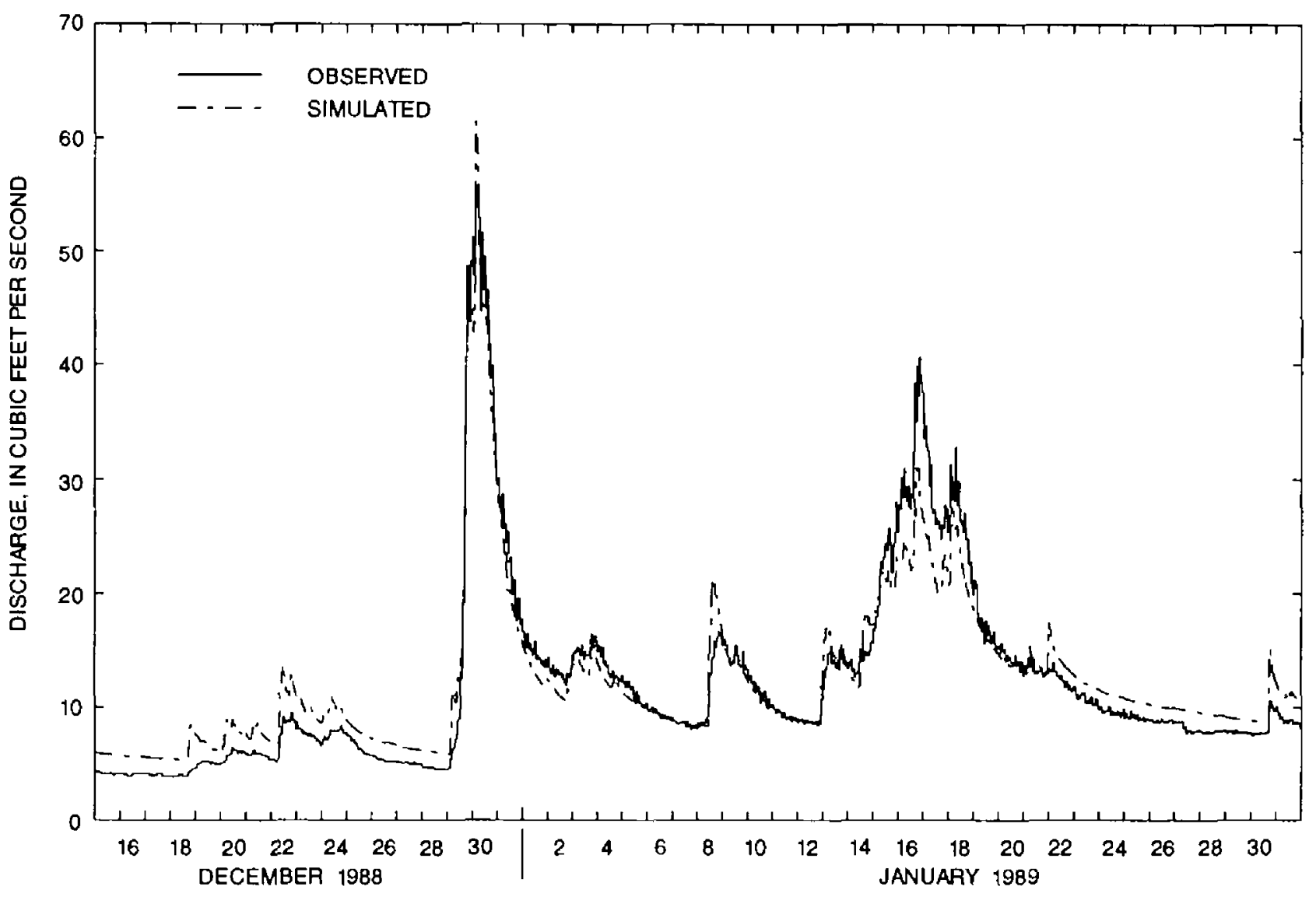

Figure 31.--Observed and simulated hourly mean discharges for Percival Creek near Olympia, Washington (station 12078730), in the Percival Creek Basin. Simulated discharges are from the final calibrated model applied to the storm period December 15, 1988, through January 31, 1989.

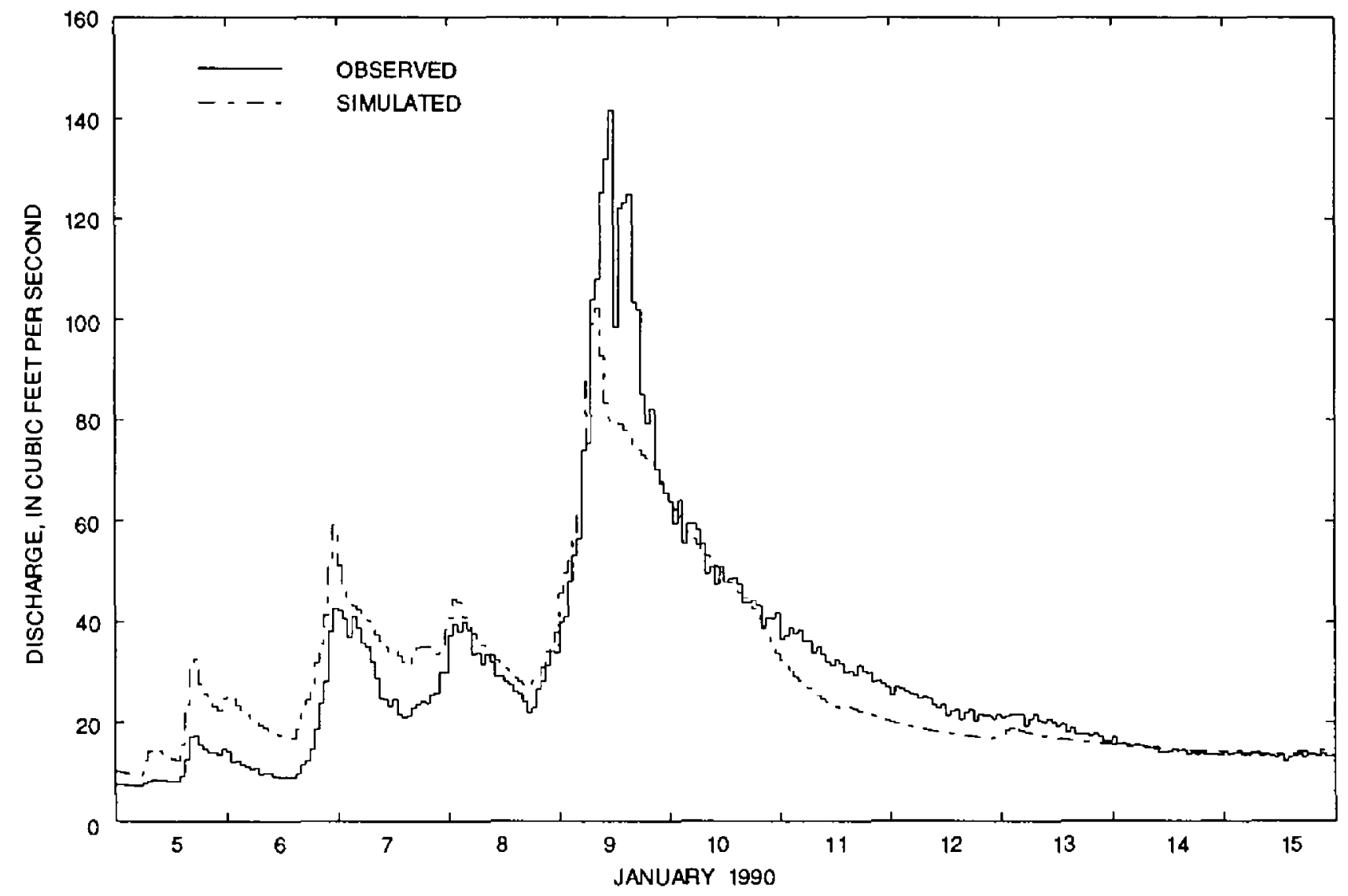

Figure 32.--Observed and simulated hourly mean discharges for Percival Creek near Olympia, Washington (station 12078730), in the Percival Creek Basin. Simulated discharges are from the final calibrated model applied to the stom period January 5 through 15, 1990. 


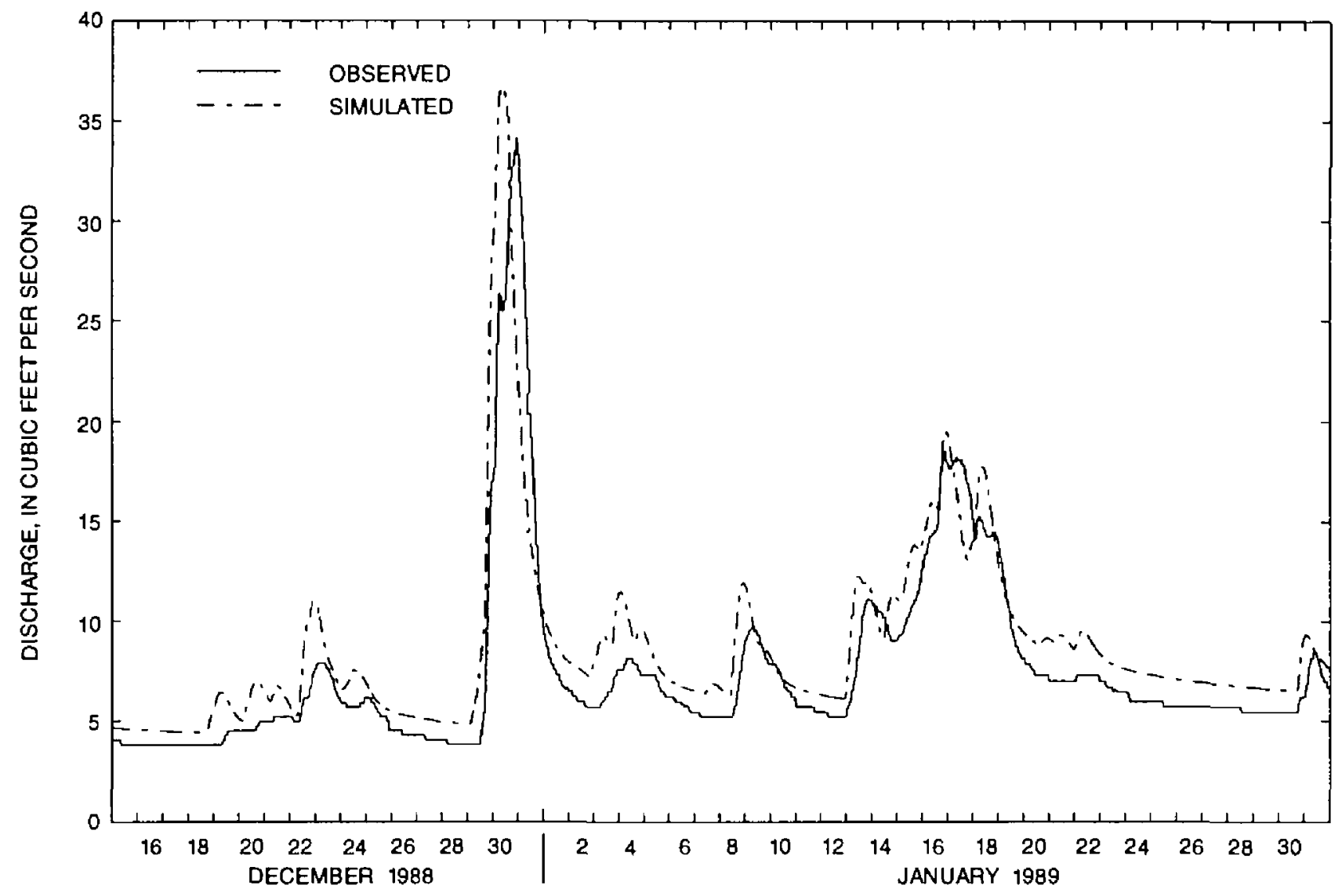

Figure 33.--Observed and simulated hourly mean discharges for Woodard Creek near Olympia, Washington (station 12080500), in the Woodard Creek Basin. Simulated discharges are from the final calibrated model applied to the storm period December 15, 1988, through January 31, 1989.

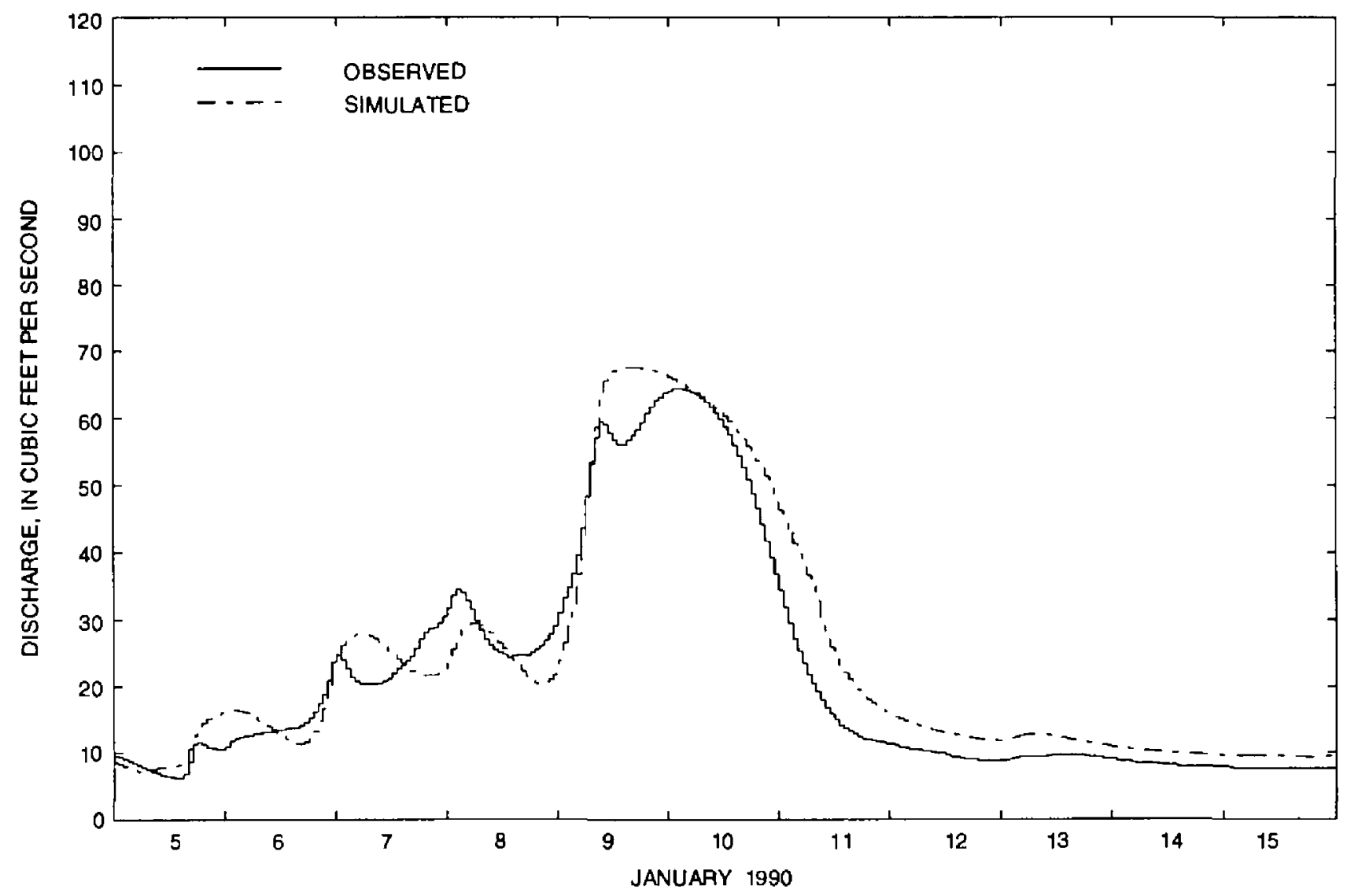

Figure 34.--Observed and simulated hourly mean discharges for Woodard Creek near Olympia, Washington (station 12080500), in the Woodard Creek Basin. Simulated discharges are from the final calibrated model applied to the storm period January 5 through 15, 1990. 


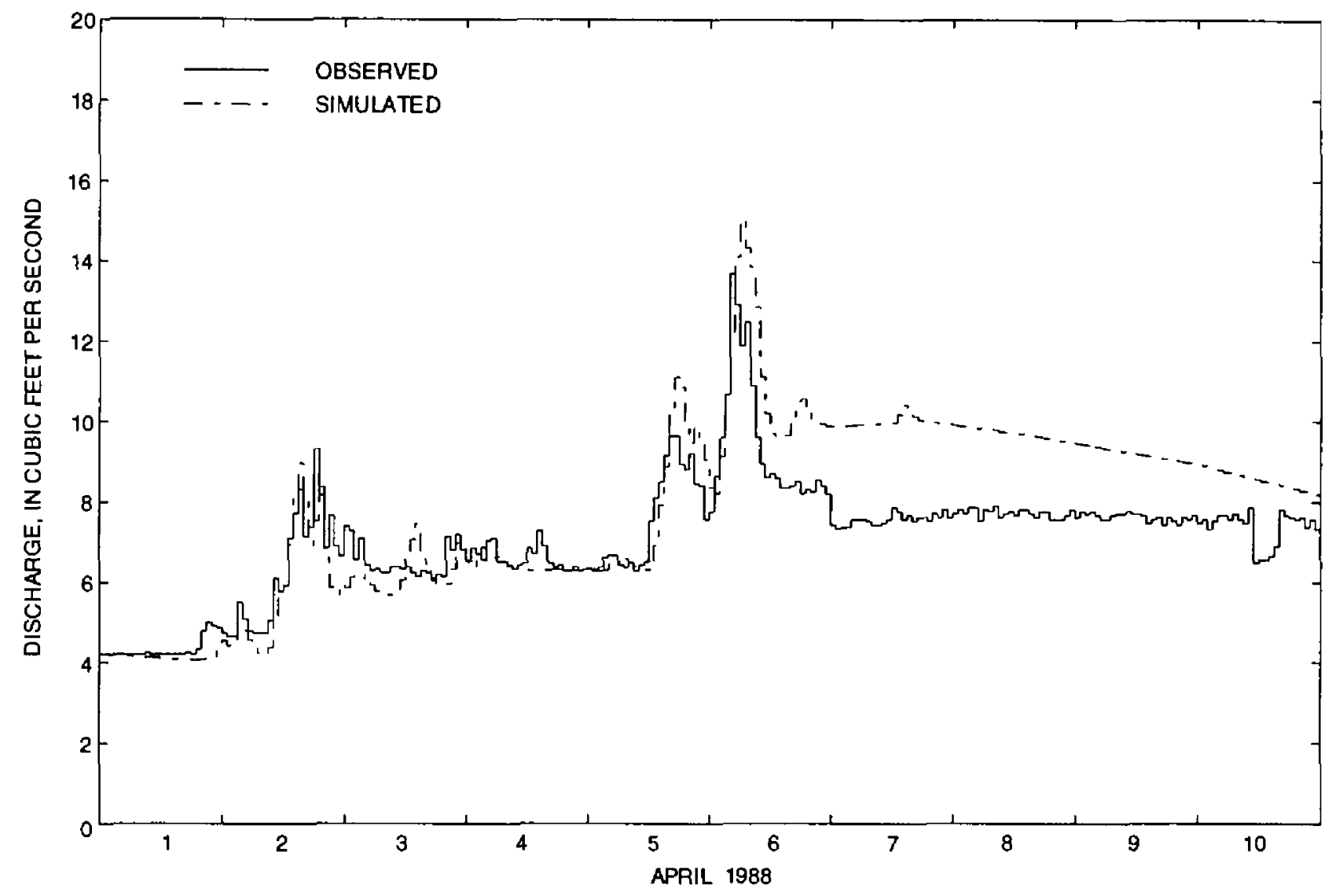

Figure 35.--Observed and simulated hourly mean discharges for Woodland Creek at Martin Way at Lacey, Washington (station 12080670), in the Woodland Creek Basin. Simulated discharges are from the final calibrated model applied to the storm period April 1 through 10, 1988.

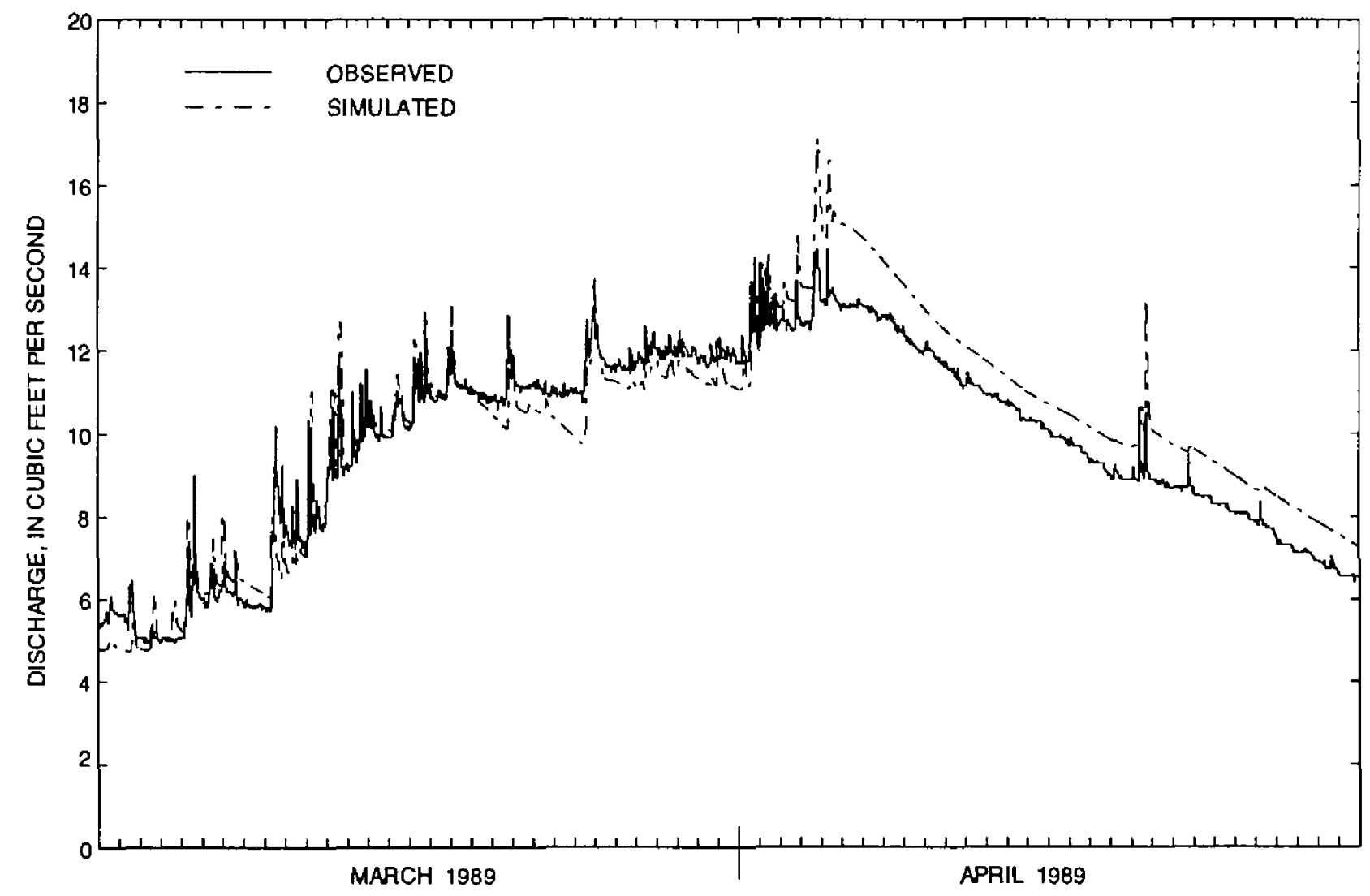

Figure 36.--Observed and simulated hourly mean discharges for Woodland Creek at Martin Way at Lacey, Washington (station 12080670), in the Woodland Creek Basin. Simulated discharges are from the final calibrated model applied to the storm period March 1, 1989, through April 30, 1989. 


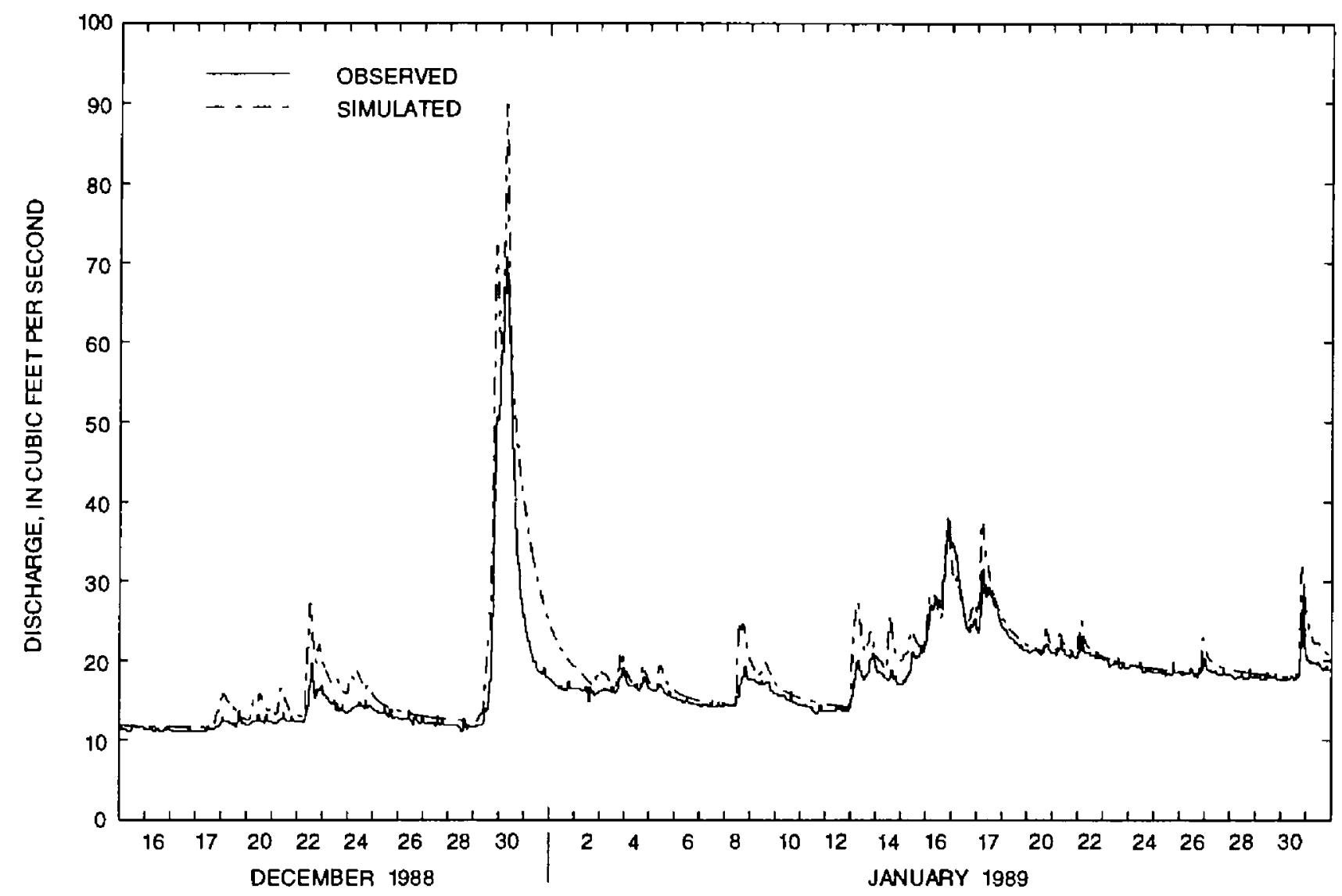

Figure 37.--Observed and simulated hourly mean discharges for Woodland Creek near Olympia, Washington (station 12081000), in the Woodland Creek Basin. Simulated discharges are from the final calibrated model applied to the storm period December 15, 1988, through January 31, 1989.

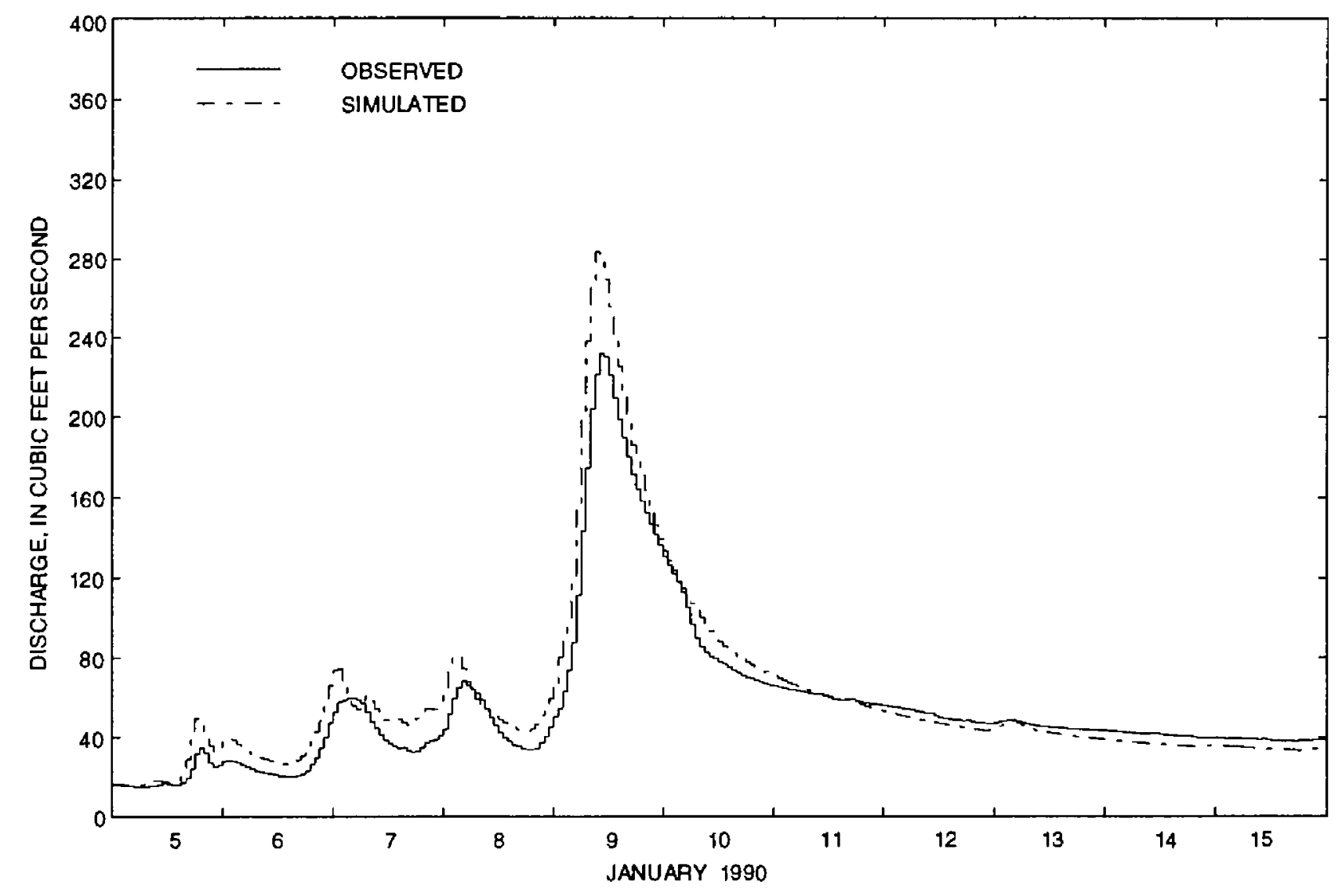

Figure 38.--Observed and simulated hourly mean discharges for Woodland Creek near Olympia, Washington (station 12081000), in the Woodland Creek Basin. Simulated discharges are from the final calibrated model applied to the storm period January 5 through 15, 1990. 
Table 16.--Observed and simulated storm runoff and peak discharge data of Woodland Creek, Woodard Creek, and Percival Creek for the final calibrated models

[Obs., observed value; Sim., simulated value; Diff., difference: simulated-observed; Percent diff., percent difference: $100 \times$ [(simulatedobserved)/observed], in percent]

\begin{tabular}{|c|c|c|c|c|c|c|c|c|c|c|}
\hline \multirow[b]{2}{*}{$\begin{array}{l}\text { Station } \\
\text { number }\end{array}$} & \multirow{2}{*}{$\begin{array}{l}\text { Date } \\
\text { of } \\
\text { storm }\end{array}$} & \multirow{2}{*}{$\begin{array}{l}\text { Date } \\
\text { of } \\
\text { peak }\end{array}$} & \multicolumn{4}{|c|}{ Storm runoff, in inches ${ }^{2}$} & \multicolumn{4}{|c|}{ Peak discharge, in cubic feet per second ${ }^{3}$} \\
\hline & & & $\begin{array}{l}\text { Obs. } \\
\text { (in.) }\end{array}$ & $\begin{array}{l}\text { Sim. } \\
\text { (in.) }\end{array}$ & $\begin{array}{l}\text { Diff. } \\
\text { (in.) }\end{array}$ & $\begin{array}{l}\text { Percent } \\
\text { diff. }\end{array}$ & $\begin{array}{l}\text { Obs. } \\
\text { (in.) }\end{array}$ & $\begin{array}{l}\text { Sim. } \\
\text { (in.) }\end{array}$ & $\begin{array}{l}\text { Diff. } \\
\text { (in.) }\end{array}$ & $\begin{array}{l}\text { Percent } \\
\text { diff. }\end{array}$ \\
\hline \multirow[t]{10}{*}{12078720} & $3 / 25-28 / 88$ & $3 / 26 / 88$ & 2.28 & 2.59 & -0.31 & -13.6 & 97.3 & 105.7 & 8.4 & 8.6 \\
\hline & $4 / 5-8 / 88$ & $4 / 6 / 88$ & 2.86 & 2.70 & -.16 & -5.6 & 123.1 & 113.7 & -9.4 & -7.6 \\
\hline & /29/88-1/1/89 & $12 / 30 / 88$ & 2.11 & 2.41 & .30 & 14.2 & 102.0 & 119.9 & 17.9 & 17.5 \\
\hline & $1 / 16-20 / 89$ & $1 / 18 / 89$ & 3.44 & 3.35 & -.09 & -2.6 & 115.0 & 104.2 & -10.8 & -9.4 \\
\hline & $3 / 12-19 / 89$ & $3 / 16 / 89$ & 4.68 & 4.94 & .26 & 5.6 & 91.0 & 94.1 & 3.1 & 3.4 \\
\hline & $12 / 3-7 / 89$ & $12 / 4 / 89$ & 3.24 & 3.42 & .18 & 5.6 & 130.0 & 117.9 & -12.1 & -9.3 \\
\hline & $1 / 9-10 / 90$ & $1 / 9 / 90$ & 2.76 & 3.15 & .39 & 14.1 & ${ }^{4} 239.9$ & 241.6 & 1.7 & .7 \\
\hline & $1 / 28-30 / 90$ & $1 / 29 / 90$ & 2.55 & 2.90 & .35 & 13.7 & 142.5 & 157.6 & 15.1 & 10.6 \\
\hline & $2 / 9-14 / 90$ & $2 / 11 / 90$ & 6.51 & 6.70 & .19 & 2.9 & ${ }^{4} 175.8$ & 177.0 & 1.2 & .7 \\
\hline & $2 / 20-23 / 90$ & $2 / 20 / 90$ & 3.28 & 3.45 & .17 & 5.2 & 135.0 & 135.0 & .0 & .0 \\
\hline \multirow[t]{9}{*}{12078730} & $3 / 23-27 / 88$ & $3 / 26 / 88$ & 1.57 & 1.54 & -.03 & -1.9 & 44.0 & 32.8 & -11.2 & -25.5 \\
\hline & $4 / 5-7 / 88$ & $4 / 6 / 88$ & 1.25 & 1.27 & .02 & 1.6 & ${ }^{4} 48.7$ & 45.7 & -3.0 & -6.2 \\
\hline & $12 / 29-31 / 88$ & $12 / 30 / 88$ & 1.43 & 1.39 & -.04 & -2.8 & 455.9 & 62.9 & 7.0 & 12.5 \\
\hline & $1 / 14-19 / 89$ & $1 / 16 / 89$ & 2.30 & 2.00 & -.30 & -13.0 & 41.0 & 31.7 & -9.3 & -22.7 \\
\hline & $12 / 4-5 / 89$ & $12 / 4 / 89$ & 1.16 & 1.09 & -.07 & -6.0 & 462.2 & 48.3 & -13.9 & -22.3 \\
\hline & $1 / 9-10 / 90$ & $1 / 9 / 90$ & 2.26 & 2.00 & -.26 & -11.5 & ${ }^{4} 141.6$ & 103.7 & -37.9 & -26.8 \\
\hline & $1 / 27-30 / 90$ & $1 / 28 / 90$ & 2.04 & 2.14 & .10 & 4.9 & 59.3 & 78.5 & 19.2 & 32.4 \\
\hline & $2 / 9-12 / 90$ & $2 / 10 / 90$ & 2.56 & 2.51 & -.05 & -2.0 & ${ }^{4} 57.7$ & 50.5 & -7.2 & -12.5 \\
\hline & $2 / 20-22 / 90$ & $2 / 20 / 90$ & 1.34 & 1.47 & .13 & 9.7 & 47.4 & 44.9 & -2.5 & -5.3 \\
\hline \multirow{8}{*}{12080500} & $3 / 23-27 / 88$ & $3 / 26 / 88$ & .88 & .78 & -.10 & -11.4 & 28.1 & 26.4 & -1.7 & -6.0 \\
\hline & $4 / 5-7 / 88$ & $4 / 6 / 88$ & .65 & .60 & -.05 & -7.7 & 33.5 & 33.1 & -.4 & -1.2 \\
\hline & 29/88-1/1/89 & $12 / 30 / 88$ & .67 & .73 & .06 & 9.0 & 34.5 & 37.0 & 2.5 & 7.2 \\
\hline & $12 / 2-6 / 89$ & $12 / 5 / 89$ & .88 & .78 & -.10 & -11.4 & 34.0 & 32.9 & -1.1 & -3.2 \\
\hline & $1 / 9-11 / 90$ & $1 / 10 / 90$ & 1.38 & 1.61 & .23 & 16.7 & 64.4 & 68.2 & 3.8 & 5.9 \\
\hline & $1 / 27-30 / 90$ & $1 / 29 / 90$ & .96 & .94 & -.02 & -2.1 & 36.3 & 37.0 & .7 & 1.9 \\
\hline & $2 / 9-12 / 90$ & $2 / 10 / 90$ & 1.21 & .99 & -.22 & -18.2 & 43.0 & 34.7 & -8.3 & -19.3 \\
\hline & $2 / 20-22 / 90$ & $2 / 21 / 90$ & .78 & .64 & -.14 & -17.9 & 35.7 & 28.9 & -6.8 & -19.0 \\
\hline \multirow[t]{5}{*}{12080670} & $4 / 5-7 / 88$ & $4 / 6 / 88$ & .07 & .08 & .01 & 14.3 & 15.5 & 15.1 & -.4 & -2.6 \\
\hline & $4 / 1-8 / 89$ & $4 / 2 / 89$ & .31 & .31 & .00 & .0 & 16.4 & 17.3 & .9 & 5.5 \\
\hline & $1 / 8-10 / 90$ & $1 / 9 / 90$ & .10 & .09 & -.01 & -10.0 & 25.6 & 26.5 & .9 & 3.5 \\
\hline & $2 / 9-12 / 90$ & $2 / 11 / 90$ & .31 & .31 & .00 & .0 & 33.6 & 36.3 & 2.7 & 8.0 \\
\hline & $2 / 20-21 / 90$ & $2 / 20 / 90$ & .16 & .16 & .00 & .0 & 31.1 & 31.9 & .8 & 2.6 \\
\hline \multirow[t]{8}{*}{12081000} & $3 / 23-28 / 88$ & $3 / 26 / 88$ & .28 & $.3 I$ & .03 & 10.7 & 72.6 & 67.4 & -5.2 & -7.2 \\
\hline & $4 / 5-8 / 88$ & $4 / 6 / 88$ & .26 & .27 & .01 & 3.8 & 84.8 & 84.2 & -.6 & -.7 \\
\hline & $/ 29 / 88-1 / 1 / 89$ & $12 / 30 / 88$ & .16 & .21 & .05 & 31.2 & 71.2 & 90.6 & 19.4 & 27.2 \\
\hline & $12 / 4-6 / 89$ & $12 / 4 / 89$ & .17 & .20 & .03 & 17.6 & 99.3 & 85.5 & -13.8 & -13.9 \\
\hline & $1 / 9-10 / 90$ & $1 / 9 / 90$ & .37 & .44 & .07 & 18.9 & 233.6 & 288.2 & 54.6 & 23.4 \\
\hline & $1 / 28-30 / 90$ & $1 / 28 / 90$ & .28 & .31 & .03 & 10.7 & 100.5 & 110.4 & 9.9 & 9.8 \\
\hline & $2 / 9-12 / 90$ & $2 / 10 / 90$ & .48 & .47 & -.01 & -2.1 & 118.0 & 111.5 & -6.5 & -5.5 \\
\hline & $2 / 20-22 / 90$ & $2 / 20 / 90$ & .30 & .31 & $.0 \mathrm{I}$ & 3.3 & 85.3 & 85.3 & .0 & .0 \\
\hline
\end{tabular}

${ }^{1}$ Station names for the displayed station numbers are in table 7.

${ }^{2}$ Storm runoff data are the total streamflow volumes for the time period of each storm.

${ }^{3}$ Peak discharge data are the maximum instantaneous discharges for each storm.

${ }^{4}$ Observed peak discharge data are mean hourly discharges during periods of extreme surge at a stream-gaging station. 
models were applied outside of a calibration period. Refinements to the basin models during final calibration were based on observed information during the 2-year calibration period. However, most of these refinements were not designed to explicitly simulate many hydrologic processes, such as the routing of runoff along actual flow paths to reaches or the actual movement and storage of water in aquifers. These refinements were designed only to simulate the amount of runoff contributions to streamflow. Although the 2-year calibration period included a variety of hydrologic conditions, ranging from the low streamflows present in the summer of 1988 to the high streamflows present in the winter of 1990, all possible sequences and magnitudes of flow conditions cannot be present in a calibration period of only 2 years. Because many hydrologic processes could not be explicitly simulated, streamflow simulations for hydrologic conditions not represented in the calibration period may indicate that further model refinements will be necessary.

\section{SUMMARY}

The U.S. Geological Survey and the Thurston County Department of Public Works conducted a cooperative study to conceptualize and simulate the generation of runoff from rainfall in three complex drainage basins in north-central Thurston County, located at the southern end of the Puget Sound Lowland of western Washington. These drainage basins--Percival Creek, Woodard Creek, and Woodland Creek--face urban development that will modify hydrologic processes and affect runoff characteristics. These basins are complex because the basin properties (such as geology, soils, topography, land cover, and climate) that influence runoff characteristics vary from one part of each basin to another. A hydrologic-simulation program can represent how basin properties affect the hydrologic processes involved in runoff generation from rainfall. Once calibrated to existing conditions, a hydrologic-simulation program can be a helpful tool to assess how urban development may affect runoff characteristics. Hydrological Simulation Program-FORTRAN (HSPF) was the program used to construct basin models for the simulation of runoff generation in these basins. Streamflow data collected at five streamflow-gaging stations over a 2-year period from March 1988 to March 1990 were used for model calibration.

From a description of the physical properties of the study area, a conceptual model was derived that linked the physical properties to associated drainage mechanisms and hydrologic processes. These links were formalized in seven conceptual features about runoff generation. The features, obtained from a previous study of rainfall-runoff relations in headwater basins of King and Snohomish Counties, about 60 miles northeast of Thurston County, were modified to account for shallow soils underlain by bedrock or fine-grained lacustrine deposits in the study area that were not found in the King and Snohomish County basins.

The conceptual features differentiater the drainage mechanisms of runoff in undisturbed and disturbed areas of the study basins. The main runoff mect anisms of undisturbed areas were identified as shallo" subsurface flow from hillslopes mantled with glacial till, bedrock, and, to a lesser degree, lacustrine deposits; as groundwater flow from glacial-outwash deposits; and as saturation overland flow from depressions, stream bottoms, and flat upland areas underlain by glacial till or, less so, lacustrine deposits. Although Hortonian overland flow was not an important mechanism in undisturbed areas, it was the dominant mechanism in disturbed impervious areas, primarily urban areas. In pervious disturbed areas, Hortonian overland flow also was a viable mechanism in combination with some of the other mechanisms. The study also noted that surface detention and retention storage, interception, and plant transpiration were less characteristic of disturbed areas than of undisturbed areas.

From the conceptual model of the Thrrston County basins, a simulation model for each of the three basins, called a basin model, was constructed. Th? basin models, based on Hydrological Simulation Program-FORTRAN (HSPF), were numerical approximations capable of confirming the features of the conceptual model if they produced accurate simulations. Construction of the basin models involved three phases: division of each study basin into land-segment types, subbasins, and stream reaches.

In the first phase, each study basin was divided into as many as 17 land-segment types (16 types that describe pervious areas on the basis of soil types, land cover, and slope; and 1 type that describes impervious areas). Numerical values were assigned to process-related parameters of each of the 17 land-segment types. Initial parameter values were the same as those from a previous study (Dinicola, 1990) for 10 land-segment types that also had appeared in King and Snohomish County headwater basins, but parameter values were estimater for the other 7 land-segment types not present in the basirs of the earlier study. In the second phase of model construction, each basin was divided into subbasins. Initially, all subbasins, except closed basins, were designed so tha ${ }^{+}$all overland flow, shallow subsurface flow, and ground-water flow 
generated in those basins discharged to the reaches and through the mouths of the originating subbasins. Similarly, all closed subbasins discharged their ground-water flow to the nearest reach draining a downhill subbasin. Finally, in the last phase of model construction, the drainage network was divided into reaches with uniform hydraulic characteristics that drained and connected subbasins. To represent the hydraulic characteristics of each reach, volume-discharge relations were defined in F-tables of each model and used for routing streamflow through the basins.

The basin models, initially constructed using the same general approach and parameter values as those determined by Dinicola (1990), did not adequately simulate observed streamflows. Therefore, the simulation models required calibration and further evaluation.

The basin models were calibrated to observed streamflows at five gaging stations for two purposes: to minimize the differences between the simulated and the observed streamflows and more generally to evaluate the adequacy of the conceptual model of runoff generation. When the models were calibrated to a little over 1 year (March 1988 through March 1989) and evaluated to a second year (March 1989 through March 1990) of observed streamflows, refinements were needed (1) to the process-related parameter, KVARY (active ground-water outflow modifier), (2) to the number of subbasins, (3) to the surface- and ground-water contributions to stream reaches, and (4) to the volume-discharge relations of stream reaches.

Differences between observed and simulated streamflows commonly increased when the models were evaluated with a second year of observed streamflow data. Absolute differences between observed and simulated runoff volumes for the first calibration ranged from 1.7 to 12.8 percent and, for evaluation, from 1.6 to 25.1 percent at five gaging stations. The mean absolute differences between observed and simulated daily mean discharges ranged between 13.2 and 36.5 percent for the first calibration and between 13.7 and 79.1 percent for evaluation. Absolute differences between storm runoff volumes ranged from 1.6 to 50.0 percent and from 0.0 to 50.0 percent for the first calibration and evaluation respectively. Finally, absolute differences between peak discharges ranged between 4.1 and 25.5 percent for the first calibration and between 0.3 and 107.0 percent for evaluation.

The evaluation results indicated that the models needed to improve simulations of (1) ground-water contributions in one drainage basin, (2) low flows in two basins, and (3) high flows after large storms in all three basins. Simulation results from both calibration and evaluation indicated that the conceptual model--represented in the basin models by parameter values assigred to landsegment types--adequately described the generation of runoff from the land-segment types in the three basins. The conceptual model, however, did not adequately describe the routing of ground-water flo'w, shallow subsurface flow, and overland flow along flow paths from land segments to stream reaches. Model shortcomings indicated that calibration to only 1 year of streamflow data was not adequate for satisfactory streamflow simulations. Thus, the basin models were calibrated to both years of observed streamflow data during final calibration.

In final calibration of the models, which used both years of observed streamflows (March 1988 through March 1990), further refinements were made to the process-related parameter KVARY for one basin, the number of subbasins, the surface- and ground-water contributions to reaches, and the volume-discharge relations of certain reaches. In addition, a ground-water cortroller was constructed for the Woodland Creek Basin model to improve the timing and magnitude of ground-water contributions to streamflow. Final calibration did improve simulations. For the entire 2-year period, absolute differences between observed and simulated streamflow values were less than 6 percent for total runoff volumes, equal to or less than an average of 32 percent for daily mean discharges, less than 32 percent for storm runoff volumes, and less than 33 percent for peak discharges.

The successful streamflow simulations from the final calibrated models confirmed that the corceptual model of runoff generation in the study area was applicable to the basins in Thurston County. The results also demonstrated that, except for KVARY, the process-related parameters obtained from an earlier rainfall-runoff investigation in another part of the Puget Sound Lowland (Dinicola, 1990) applied as well to Thurston County basins. The values of KVARY, though, needed to be refined because areas in Thurston County underlain by aquifers responded differently to rainfall than did areas in the King and Snohomish County that originally determined this parameter value. This parameter, thus, is likely to vary elsewhere in the Puget Sound Lowland.

The conceptual model represented runoff generation from land segments in the three Thurston County basins fairly well. The conceptual model, however, did not adequately represent the flow paths from land segments to stream reaches when all ground-water fl $\supset$ w, shallow subsurface flow, and overland flow generated in a subbasin 
did not contribute to streamflow in that same subbasin. During calibration, it was necessary to adjust the initial ground-water, shallow subsurface, and overland flow contributions to reaches. Calibration indicated that the initial guideline that all rain falling on a subbasin either evapotranspires or discharges out the surface-water outlet of that same subbasin was an inadequate assumption for many subbasins. Sometimes rainfall recharged to inactive ground water, and at other times it discharged to reaches in other subbasins. Finally, during calibration, the volume-discharge relations in the F-tables needed adjustment to adequately simulate channel-bottom seepage and the magnitude and timing of peak flows.

Because the conceptual model did not adequately describe flow paths from land segments to stream reaches, it was necessary to obtain extensive streamflow data and field information to obtain satisfactory streamflow simulations. Additionally, it was necessary to calibrate the basin models to 2 years of streamflow data to obtain satisfactory streamflow simulation. It is uncertain if streamflow simulations will be as accurate as those presented in this report for hydrologic conditions not represented in the calibration period because many hydrologic processes could not be explicitly simulated by the basin models.

\section{REFERENCES CITED}

Alley, William A., and Veenhuis, Jack E., 1983, Effective impervious area in urban runoff modeling: Journal of Hydrological Engineering, ASCE, v. 109, no. 2, February 1983, p. 313-319.

Bauer, H.H., and Vaccaro, J.J., 1986, Documentation of a deep percolation model for estimating ground-water recharge: U.S. Geological Survey Open-File Report 86-536, $180 \mathrm{p}$.

Bortleson, G.B., Dion, N.P., McConnell, J.B., and Nelson, L.M., 1976, Reconnaissance data on lakes in Washington: U.S. Geological Survey Water-Supply Bulletin 43, v. 4, 197 p.

Burges, Stephen J., Stoker, B.A., Wigmosta, M.S., and Moeller, R.A., 1989, Hydrologic information and analyses required for mitigating hydrologic effects of urbanization: University of Washington Department of Civil Engineering Water Resources Series Technical Report no. 117, $131 \mathrm{p}$.
Dinicola, R.S., 1990, Characterization and simulation of rainfall-runoff relations for headwater basins in western King and Snohomish Counties, Washington: U.S. Geological Survey Water-Resou'ses Investigations Report 89-4052, 52 p.

Dunne, Thomas, and Black, Richard D., 1970, An experimental investigation of runoff production in permeable soils: Water Resources Research, v. 6, no. 2 , p. $478-490$.

Dunne, Thomas, and Leopold, Luna B., 1978, Water in environmental planning: San Francis $: 0$, W.H. Freeman and Company, $818 \mathrm{p}$.

Farnsworth, Richard K., and Thompson, Etwin S., 1982, Mean monthly, seasonal, and annual pan evaporation for the United States: National Oceanic and Atmospheric Administration Technical Report NWS 34, U.S. Department of Commerce, C'fice of Hydrology, National Weather Service, $82 \mathrm{p}$.

Heath, Ralph C., 1983, Basic ground-water hydrology: U.S. Geological Survey Water-Supply Paper 2220, $84 \mathrm{p}$.

National Oceanic and Atmospheric Administration, 1982, Monthly normals of temperature, precipitation, and heating and cooling degree days 1951-1958, Washington: Climatography of the U $\because$ ited States no. 81 (by state), unnumbered.

Noble, John B., and Wallace, Eugene F., 1966, Geology and ground-water resources of Thurston County, Washington, v. 2: State of Washingten Division of Water Resources Water-Supply Bulletin no. 10, $141 \mathrm{p}$.

Pearce, A.J., Stewart, M.K., and Sklash, M.G., 1986, Storm runoff generation in humid headwater catchments 1 . where does the water come from?: Water Resources Research, v. 22, no. 8 , p. 1,263-1,272.

Skaggs, R.W., and Khaleel, R., 1982, Infilt -ation, in Haan, C.T., and others, eds., Small watersheds: American Society of Agricultural Engineers, ASAE Monograph \#5, p. 121-160. 
Steinbrenner, E.C., and Gessel, S.P., 1955, The effect of tractor logging on physical properties of some forest soils in Southwestern Washington: Soil Science Society Proceedings, p. 372-376.

U.S. Department of Agriculture, 1986, Urban hydrology for small watersheds: U.S. Department of Agriculture Soil Conservation Service Engineering Division, Technical Release 55, 156 p.

U.S. Department of Agriculture, 1990, Soil survey of Thurston County, Washington: U.S. Department of Agriculture Soil Conservation Service, 283 p.
U.S. Department of Commerce, 1973, Precipitationfrequency atlas of the western United States, v. IX--Washington: NOAA Atlas 2, National Oceanic and Atmospheric Administration, National Weather Service, Silver Spring, Maryland, $43 \mathrm{p}$.

U.S. Environmental Protection Agency, 1984, Hydrological simulation program-FiRTRAN (HSPF), users' manual for release 8.0 : Environmental Protection Agency report 601/3-84-066, Environmental Research Laboratory. 767 p.

Viessman, Warren, Jr., Knapp, J.W., Lewis, G.L., and Harbaugh, T.E., 1977, Introduction to hydrology: New York, Harper and Row, 704 p. 


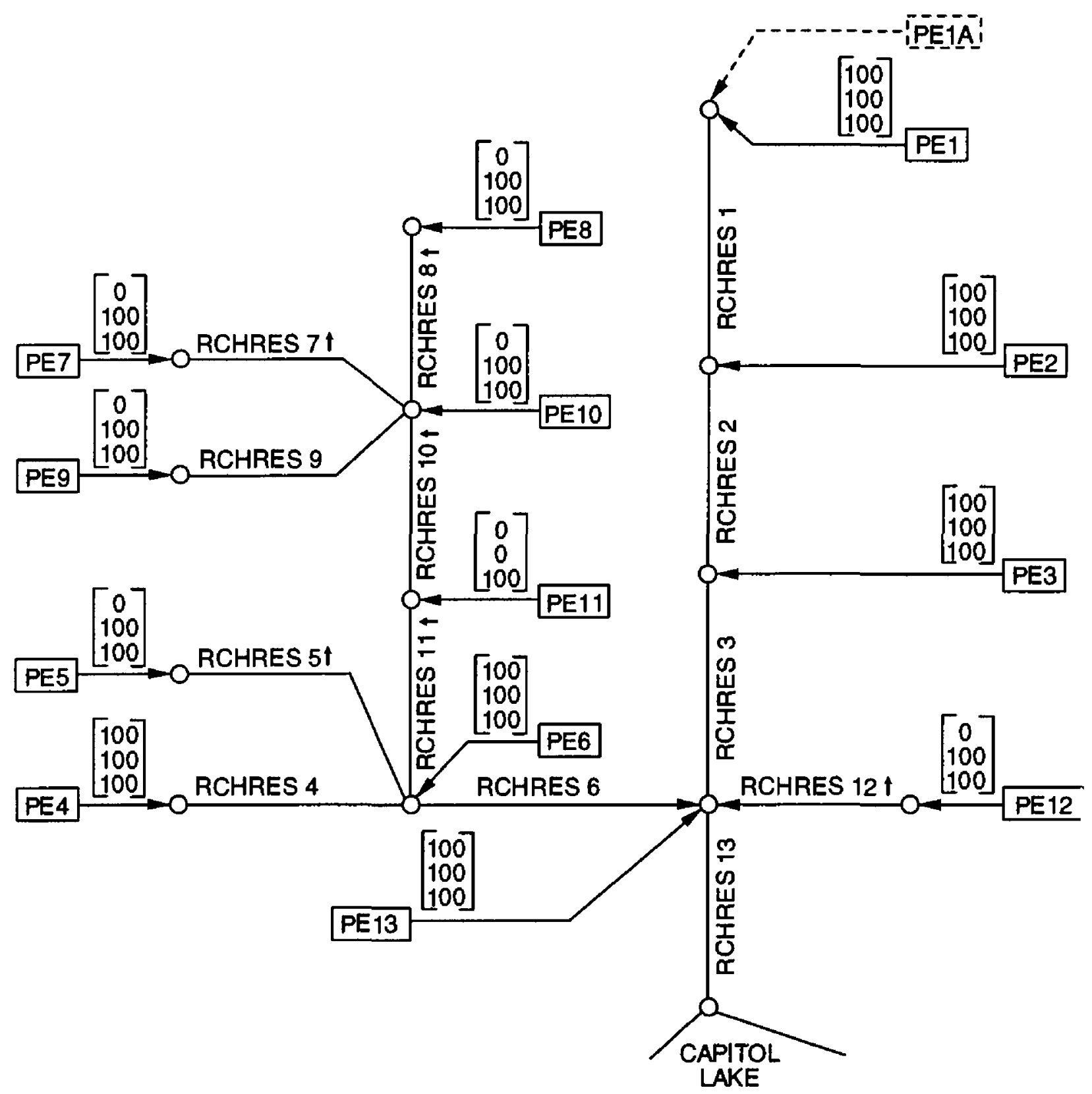

EXPLANATION

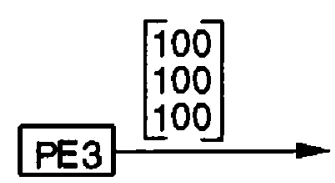

CPEIA-

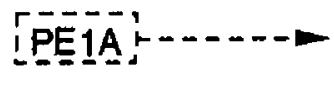

ORCHRES 5 †
Percival Creek subbasin prefix and number. Solid arrow indicates ground-water, shallow subsurface, and overland flow contributions to a stream reach from pervious and impervious areas within the specifled subbasin. Ground-water flow (top number in brackets), shallow subsurface flow (middle number), and overland flow (bottom number) are expressed as percentages of the total flow generated that contribute to a stream reach.

Dummy subbasin prefix and number. Dashed arrow indicates ground-water flow contributions to a stream reach.

Stream reach and number. Presence of arrow indicates losing reach.

Figure 39.--A diagram of the hydraulic linkages between subbasins and stream reaches for the final calibrated model for Percival Creek Basin. 


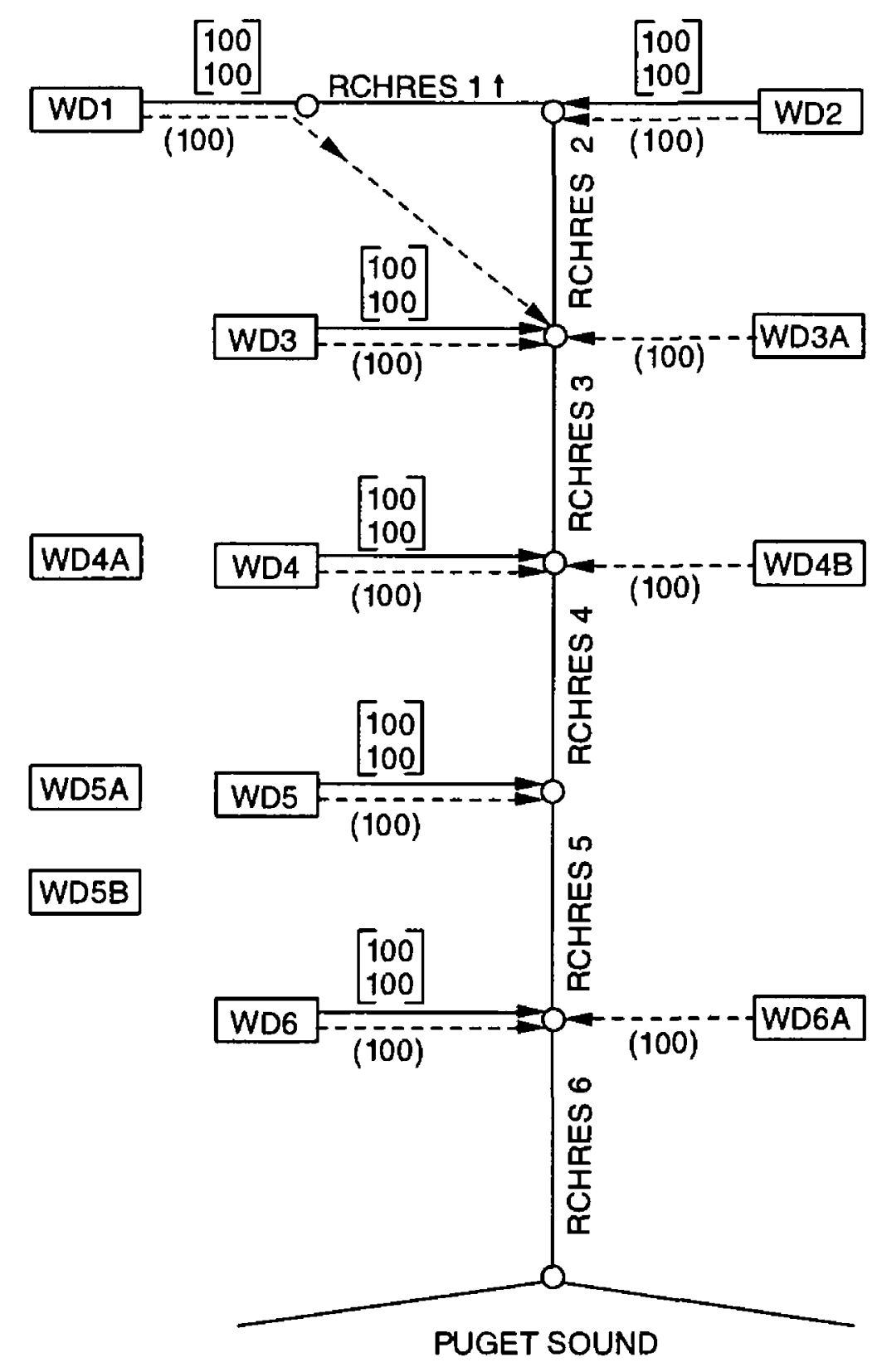

\section{EXPLANATION}

WD4A

WD3A $(100)-1$

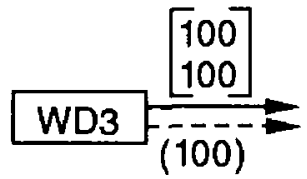

RCHRES $1 \uparrow 0$
Woodard Creek subbasin prefix and number; closed subbasin that does not contribite any fiow to stream reaches in Woodard Creek Basin.

Ground-water flow (dashed arrow) from the specified subbasin that contributes to a stream reach. Number in parentheses is the contribution of ground-water flow, expressed as a percentage of the total ground-water flow generated in a subbasin.

Solid arrow indicates shallow subsurface and overland fiow that contributes to a stream reach from pervious and impervious areas within the specified subbasin. Top bracke.ts indicate contributions of shallow subsurface flow (top number) and overland flow (bcttom number), expressed as percentages of the total flow of that type generated in a subt asin. Dashed arrow and number in bottom parentheses indicate ground-water flow, as indicated above.

Stream reach and number. Presence of arrow indicates losing reach.

Figure 40.--A diagram of the hydraulic linkages between subbasins and stream reaches for the final calibrated model for Woodard Creek Basin. 


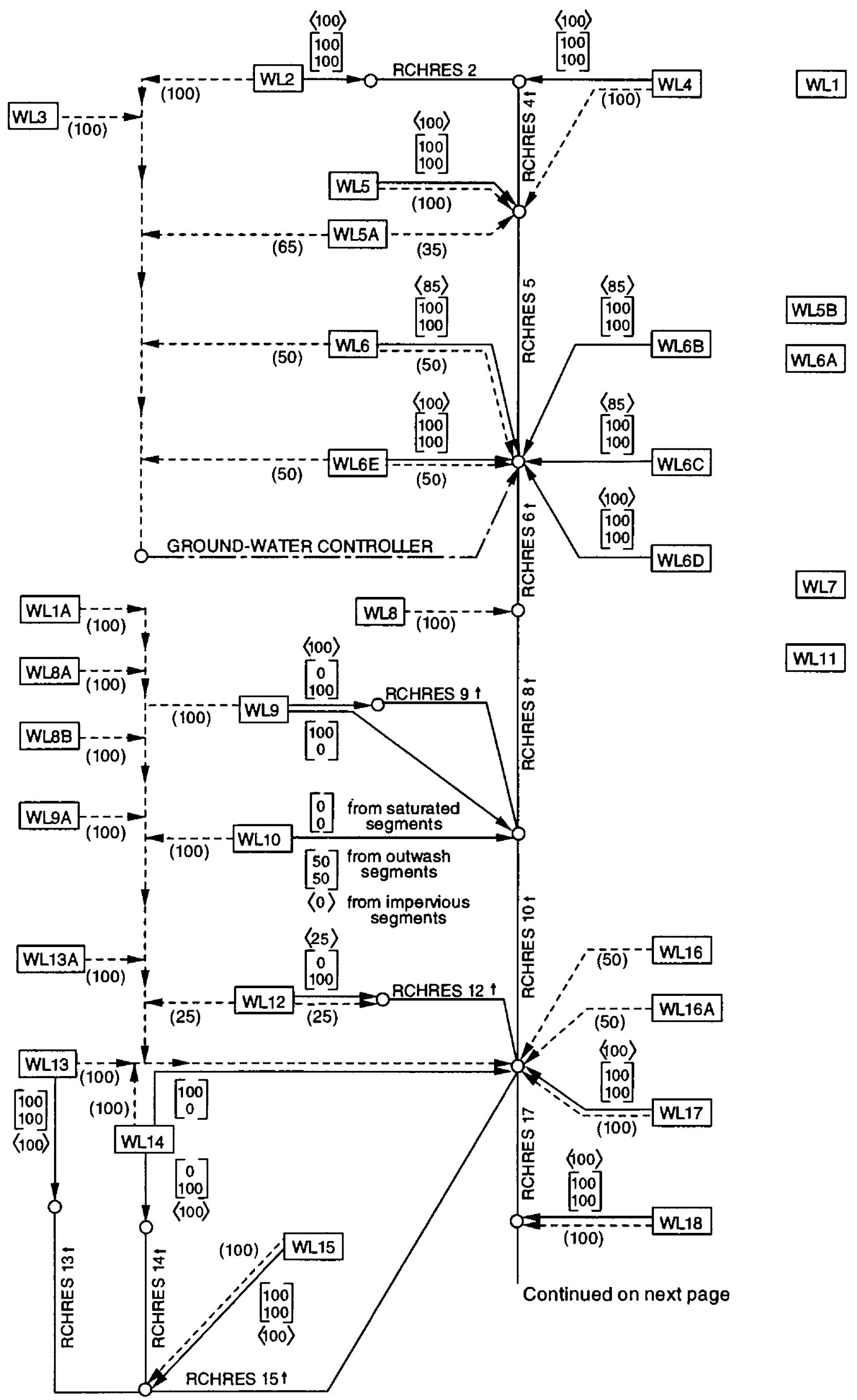

Figure 41.--A diagram of the hydraulic linkages between subbasins and stream reaches for the final calibrated model for Woodland Creek Basin. 


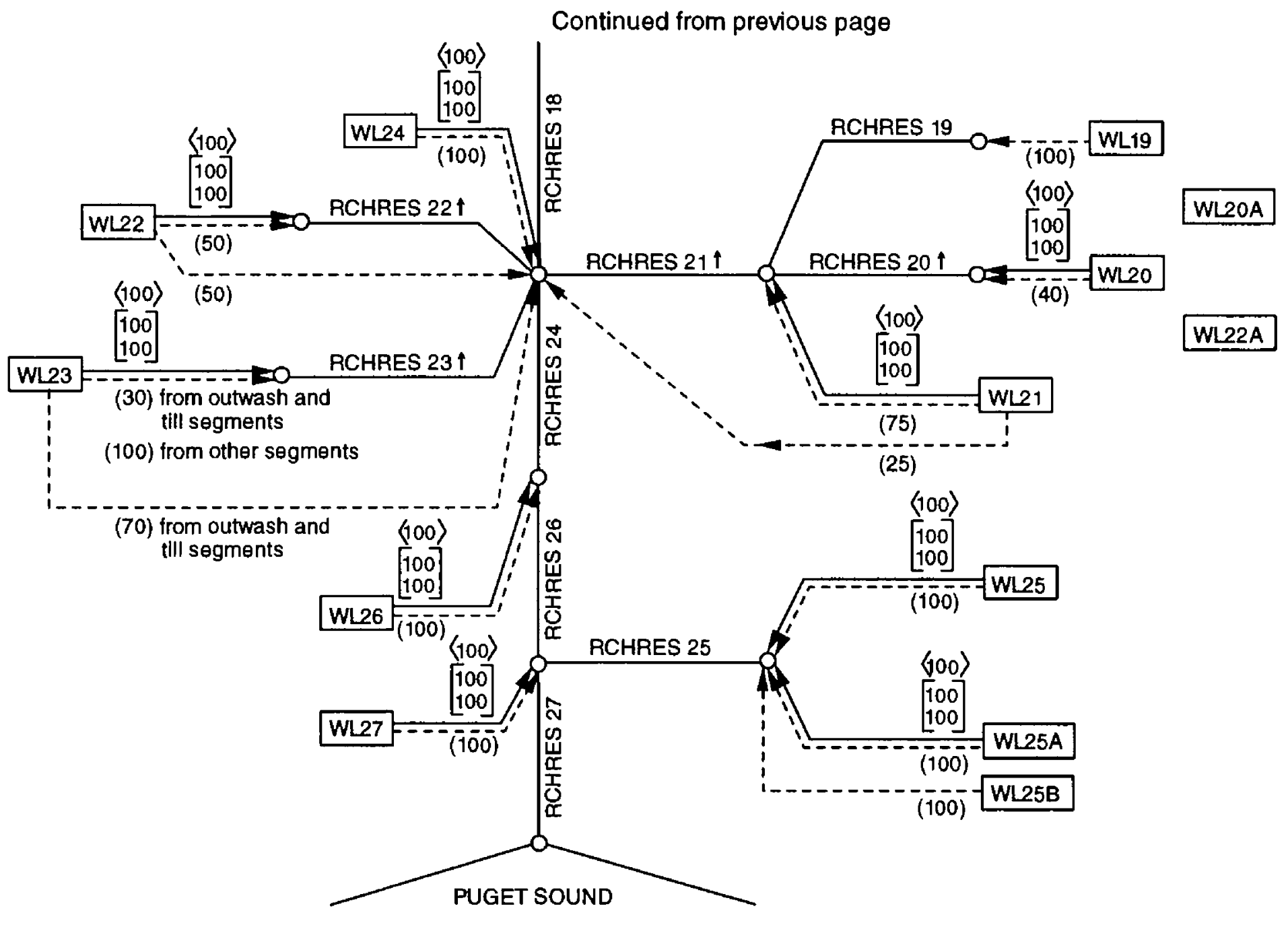

EXPLANATION
WL7 Woodland Creek subbasin preflx and number; closed subbasin that does not contribute any flow to stream reaches in Woodland Creek Basin.
WL13A Ground-water flow (dashed arrow) from the specifled subbasin that contributes to a stream reach. Number in parentheses is the contribution of ground-water flow, expressed as a percentage of the total ground-water flow generated in a subbasin.
Wh24 Shaliow subsurface and overland flow (solid arrow) that contribute to a stream from pervious and impervious areas within the specified subbasin.

[1007 Contribution of shallow subsurface flow (top number) and overland

100 flow (bottom number), each expressed as a percentage of the total flow of that type generated in a subbasin.

(100) Percentage of effective impervious area in a subbasin that generates overland flow that contributes to a stream reach.

ORCHRES $12 \uparrow$ O

Stream reach and number. Presence of arrow indicates losing reach.

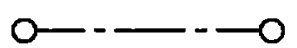

Ground-water controller.

Figure 41.--Continued. 
Table 17.--Input sequence of the Percival Creek model used to run Hydrological Simulation Program-FORTRAN (HSPF)

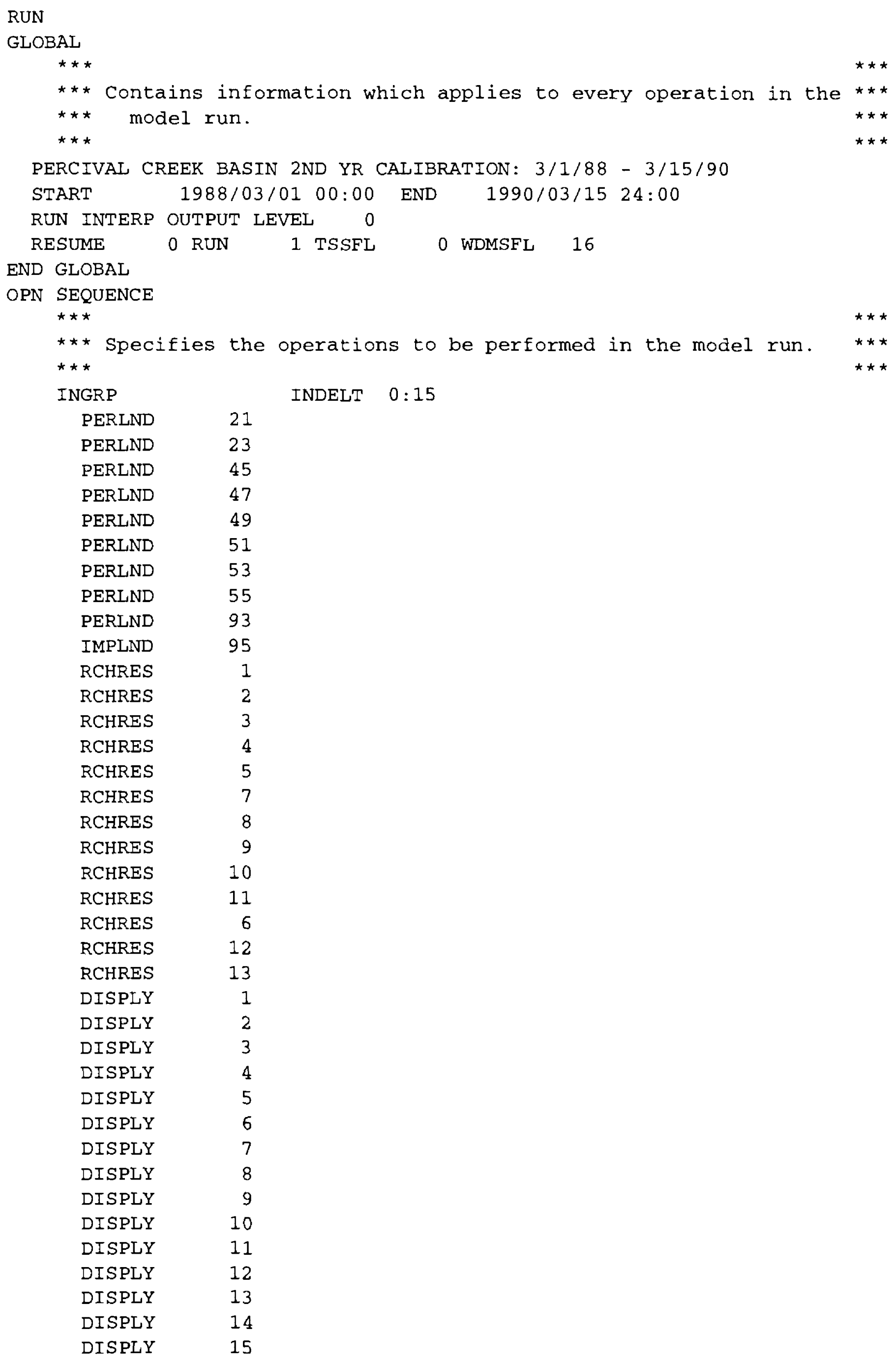


Table 17.-- Input sequence of the Percival Creek model used to run Hydrological Simulation Program-FORTRAN (HSPF)--Continued

END INGRP

END OPN SEQUENCE

PERLND

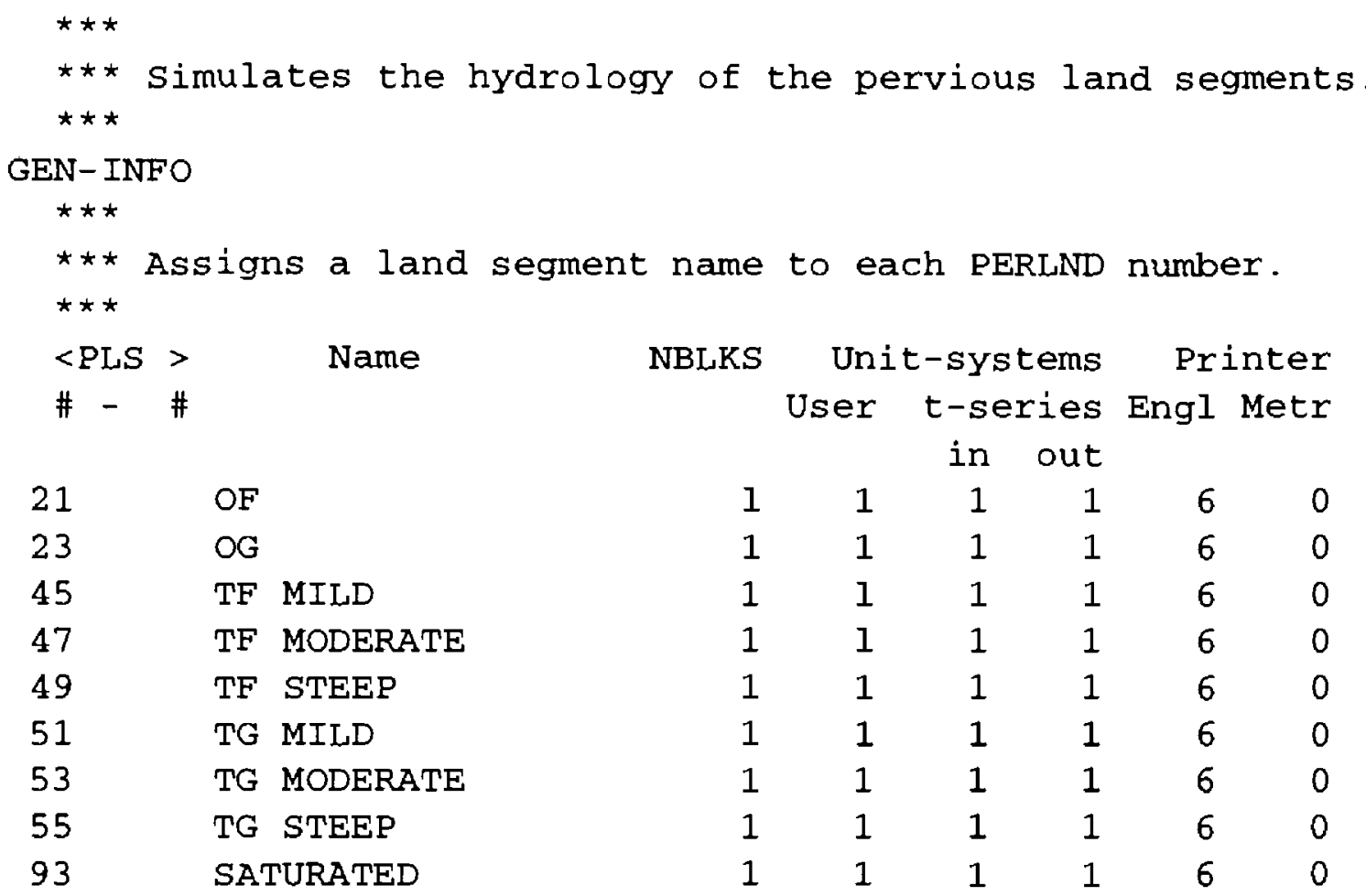$$
\star \star \star
$$ 
Table 17.--Input sequence of the Percival Creek model used to run Hydrological Simulation Program-FORTRAN (HSPF)--Continued

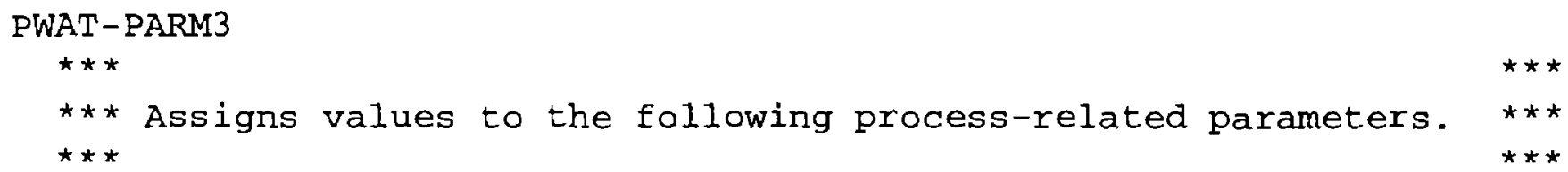

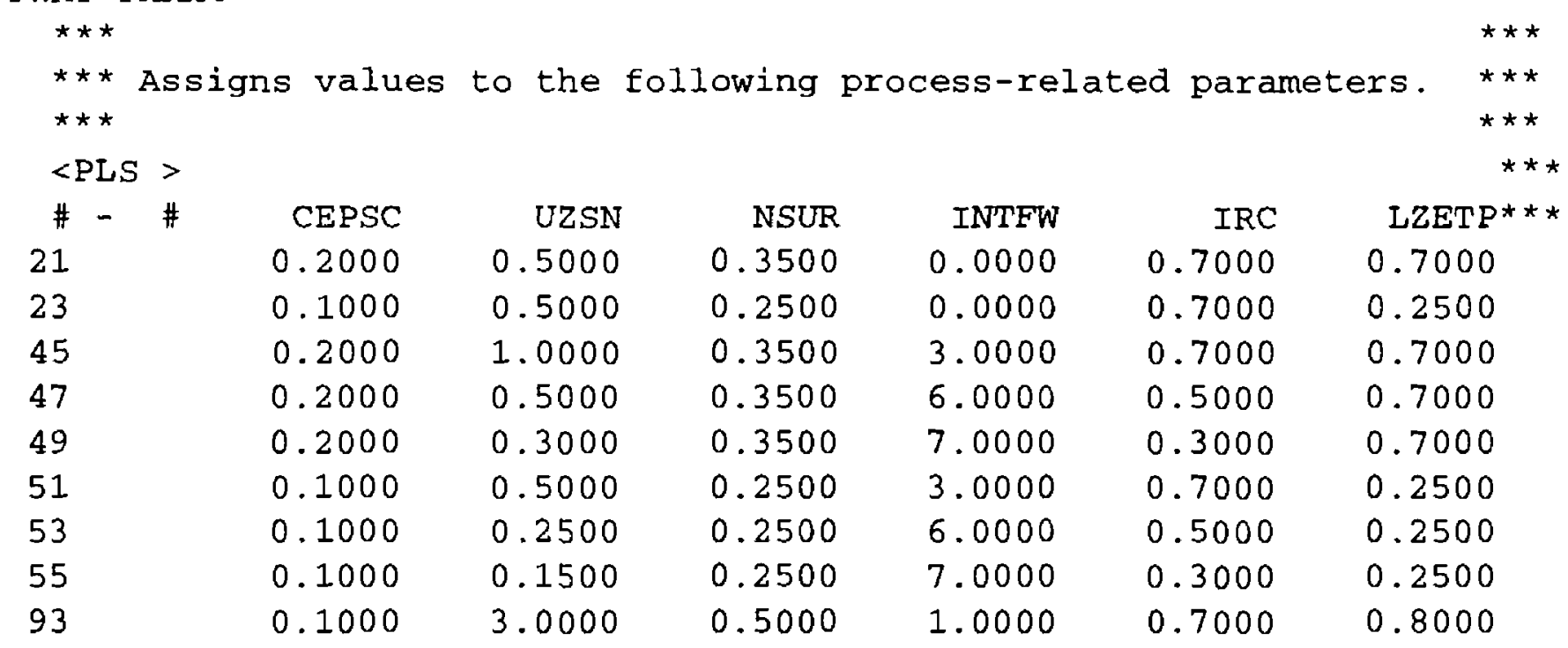

\section{END PWAT-PARM4}

PWAT-STATEI

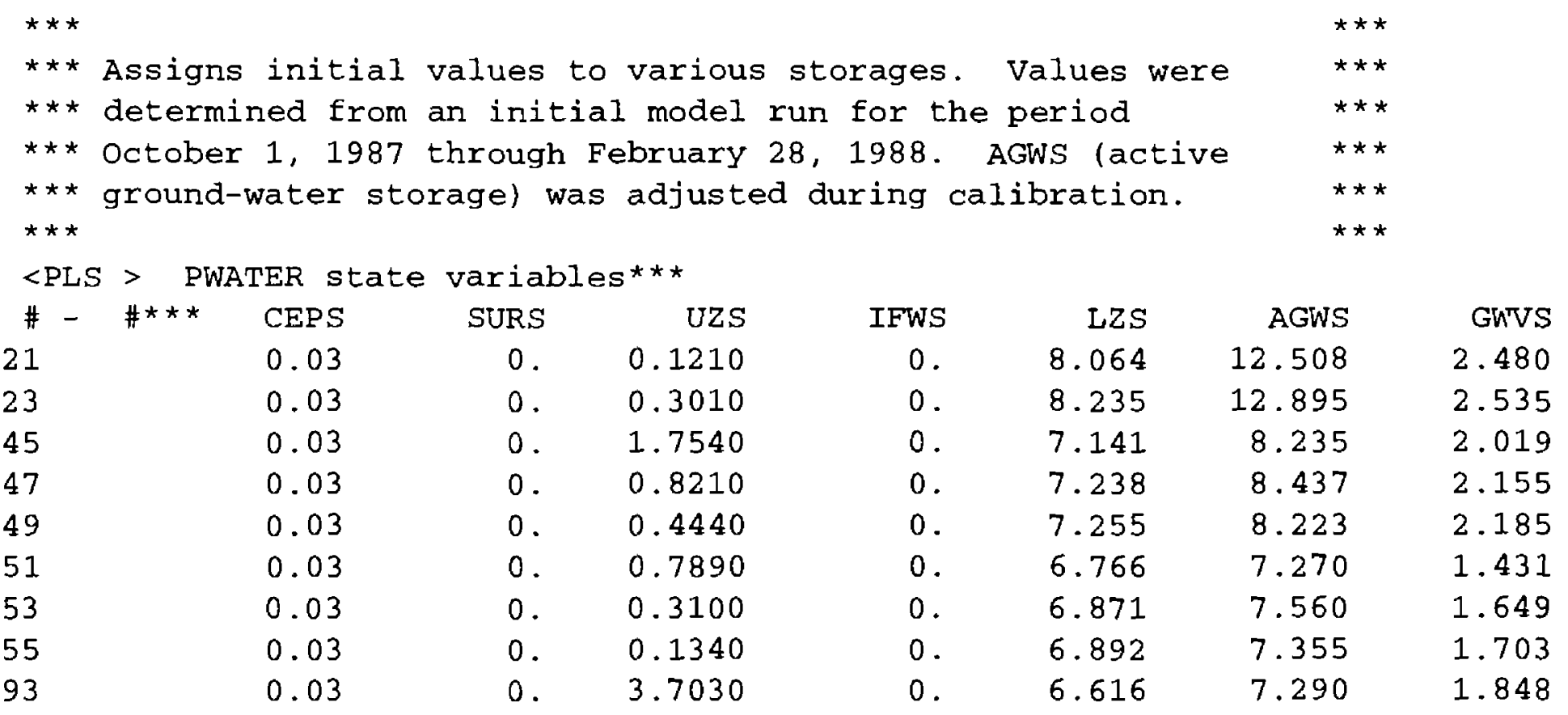

END PWAT-STATE1

END PERLND 
Table 17.-- Input sequence of the Percival Creek model used to run Hydrological Simulation Program-FORTRAN (HSPF)--Continued

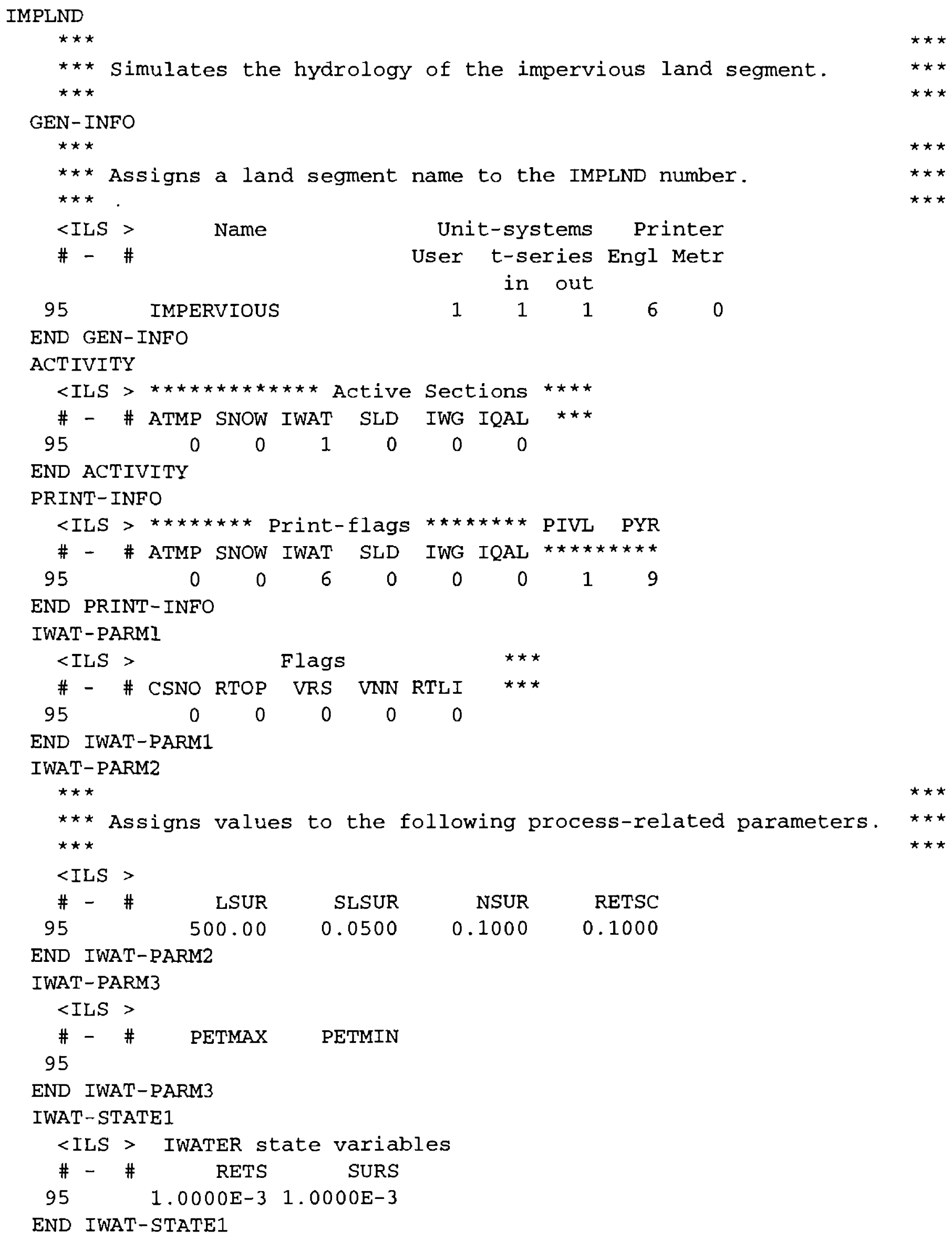

END IMPLND 
Table 17.--Input sequence of the Percival Creek model used to run Hydrological Simulation Program-FORTRAN (HSPF)--Continued

\begin{tabular}{|c|c|c|c|c|c|c|c|c|c|}
\hline \multirow[t]{8}{*}{ EXT } & \multicolumn{9}{|c|}{ SOURCES } \\
\hline & $\star \star \star$ & & & & & & & \multicolumn{2}{|l|}{$\star \star \star$} \\
\hline & $\star \star \star$ & Specifies & he time series which are & e input $t$ & to the & operatior & ons & \multicolumn{2}{|l|}{$\star \star \star$} \\
\hline & $\star \star \star$ & from exter & rnal WDM files. & & & & & \multicolumn{2}{|l|}{$\star \star \star$} \\
\hline & $\star \star \star$ & & & & & & & \multicolumn{2}{|l|}{$\star \star \star$} \\
\hline & $\star \star \star 1$ & NOTE: The or & nly RCHRES that precip & and PET a & are app. & lied to & are & \multicolumn{2}{|l|}{$\star \star \star$} \\
\hline & $\star \star \star$ & lakes. & & & & & & \multicolumn{2}{|l|}{$\star \star \star$} \\
\hline & $\star \star \star$ & & & & & & & \multicolumn{2}{|l|}{$\star \star \star$} \\
\hline \multicolumn{2}{|c|}{$<-$ Volume- $>$} & $-><$ Member $>$ & SsysSgap $<--$ Mult-->Tran & $<-$ Target & $t$ vols> & $<-$ Grp $><$ & \multicolumn{2}{|c|}{$<-$ Member-> } & $\star \star \star$ \\
\hline$<$ Nam & & \# <Name> \# & tem strg<-factor->strg & $<$ Name $>$ & $\#$ & & $<$ Nam & ne> \# \# & $\star \star *$ \\
\hline WDM & & 4 PRCP & ENGL & PERLND & 21 & EXTNL & PREC & & \\
\hline WDM & & 4 PRCP & ENGL & PERLND & 23 & EXTNL & PREC & & \\
\hline WDM & & $4 \mathrm{PRCP}$ & ENGL & PERLND & 45 & EXTNL & PREC & & \\
\hline WDM & & 4 PRCP & ENGL & PERLND & 47 & EXTNL & PREC & & \\
\hline WDM & & 4 PRCP & ENGL & PERLND & 49 & EXTNL & PREC & & \\
\hline WDM & & 4 PRCP & ENGL & PERLND & 51 & EXTNL & PREC & & \\
\hline WDM & & 4 PRCP & ENGL & PERLND & 53 & EXTNL & PREC & & \\
\hline WDM & & 4 PRCP & ENGL & PERLND & 55 & EXTNL & PREC & & \\
\hline WDM & & 4 PRCP & ENGL & PERLND & 93 & EXTNL & PREC & & \\
\hline WDM & & 4 PRCP & ENGL & IMPLND & 95 & EXTNL & PREC & & \\
\hline WDM & & 6 EVAP & ENGL & PERLND & 2193 & EXTNL & PETII & $\mathrm{NP}$ & \\
\hline WDM & & 6 EVAP & ENGL & IMPLND & 95 & EXTNL & PETII & NP & \\
\hline WDM & & 4 PRCP & ENGL & RCHRES & 1 & EXTNL & PREC & & \\
\hline WDM & & 4 PRCP & ENGL & RCHRES & 5 & EXTNL & PREC & & \\
\hline WDM & & 4 PRCP & ENGL & RCHRES & 7 & EXTNL & PREC & & \\
\hline WDM & & 6 EVAP & ENGL & RCHRES & 1 & EXTNL & POTE & & \\
\hline WDM & & 6 EVAP & ENGL & RCHRES & 5 & EXTNL & POTE & & \\
\hline WDM & & 6 EVAP & ENGL & RCHRES & 7 & EXTNL & POTE & & \\
\hline WDM & & 4 PRCP & ENGL & DISPLY & 1 & INPUT & TIMS & $\mathrm{ER}$ & \\
\hline WDM & & 6 EVAP & ENGL & DISPLY & 2 & INPUT & TIMSI & ER & \\
\hline WDM & & 1 FLOW & .020661 SAME & RCHRES & 4 & EXTNL & IVOL & & \\
\hline & $\star \star \star$ & & & & & & & $\star \star \star$ & \\
\hline & $\star \star \star 1$ & Note: The ab & bove MULTFACTOR converts & $s$ cubic $f$ & feet per & r se & & $\star \star \star$ & \\
\hline & $\star \star \star$ & to acre-fe & eet per 15 minutes. The & e MULTFAC & CTORS be & elow & & $\star \star \star$ & \\
\hline & $\star \star \star$ & convert $\mathrm{cu}$ & ubic feet per second to & inches o & of runos & ff per & & $\star \star \star$ & \\
\hline & $\star \star \star$ & 15 minutes & & & & & & $\star \star \star$ & \\
\hline & $\star \star \star$ & & & & & & & $\star \star \star$ & \\
\hline WDM & & 1 FLOW & ENGL & DISPLY & 3 & INPUT T & TIMSI & SER & \\
\hline WDM & & 2 FLOW & ENGL & DISPLY & 4 & INPUT I & TIMSI & SER & \\
\hline WDM & & 2 FLOW & ENGL & DISPLY & 5 & INPUT & TIMS & SER & \\
\hline WDM & & 2 FLOW & .000076 & DISPLY & 6 & INPUT & TIMS & SER & \\
\hline WDM & & 3 FLOW & ENGL & DISPLY & 7 & INPUT & TIMS & $\mathrm{ER}$ & \\
\hline WDM & & 3 FLOW & ENGL & DISPLY & 8 & INPUT & TIMS & SER & \\
\hline WDM & & 3 FLOW & .000170 & DISPLY & 9 & INPUT & TIMSI & SER & \\
\hline
\end{tabular}


Table 17.--Input sequence of the Percival Creek model used to run Hydrological Simulation Program-FORTRAN (HSPF)--Continued

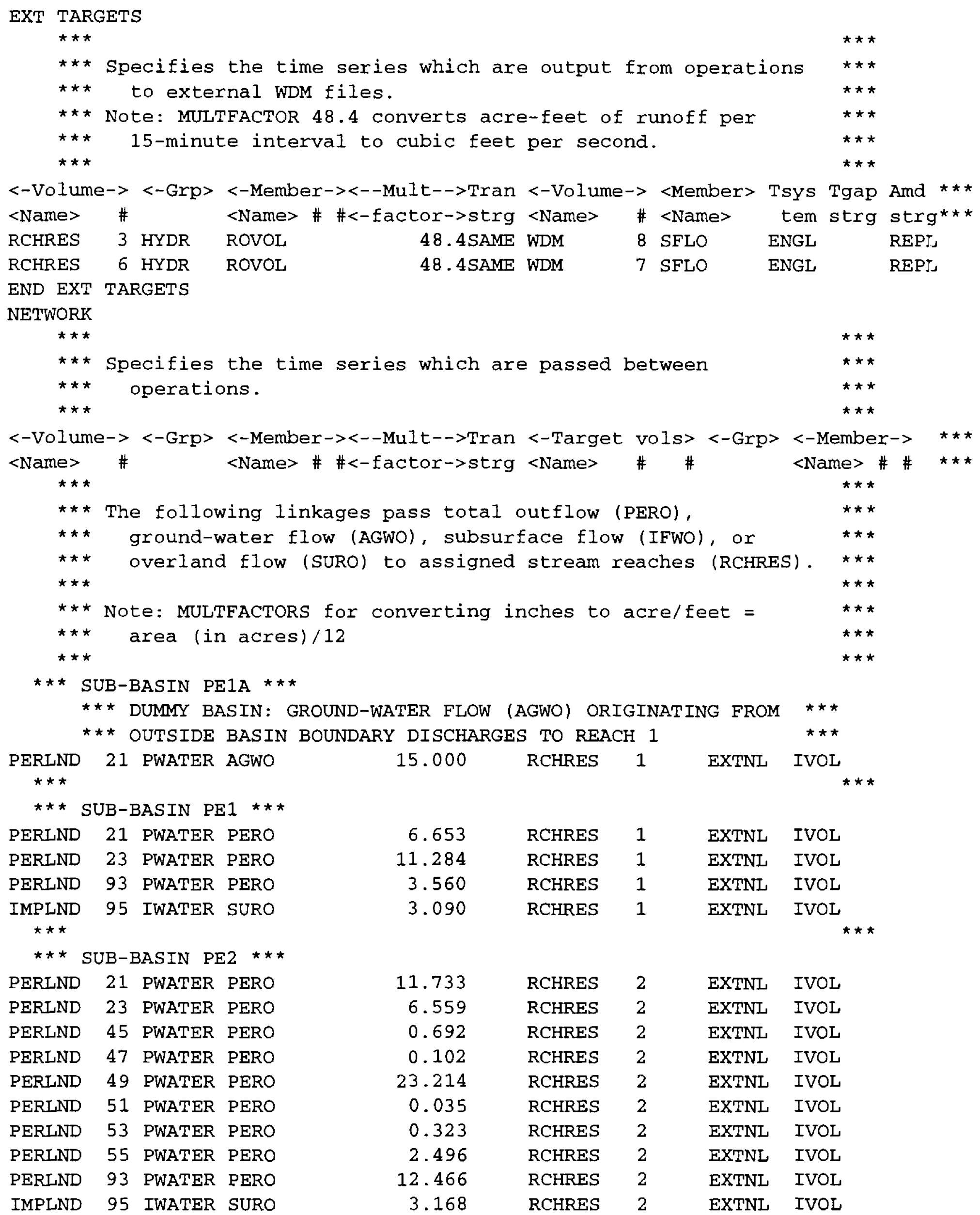


Table 17.--Input sequence of the Percival Creek model used to run Hydrological Simulation Program-FORTRAN (HSPF)--Continued

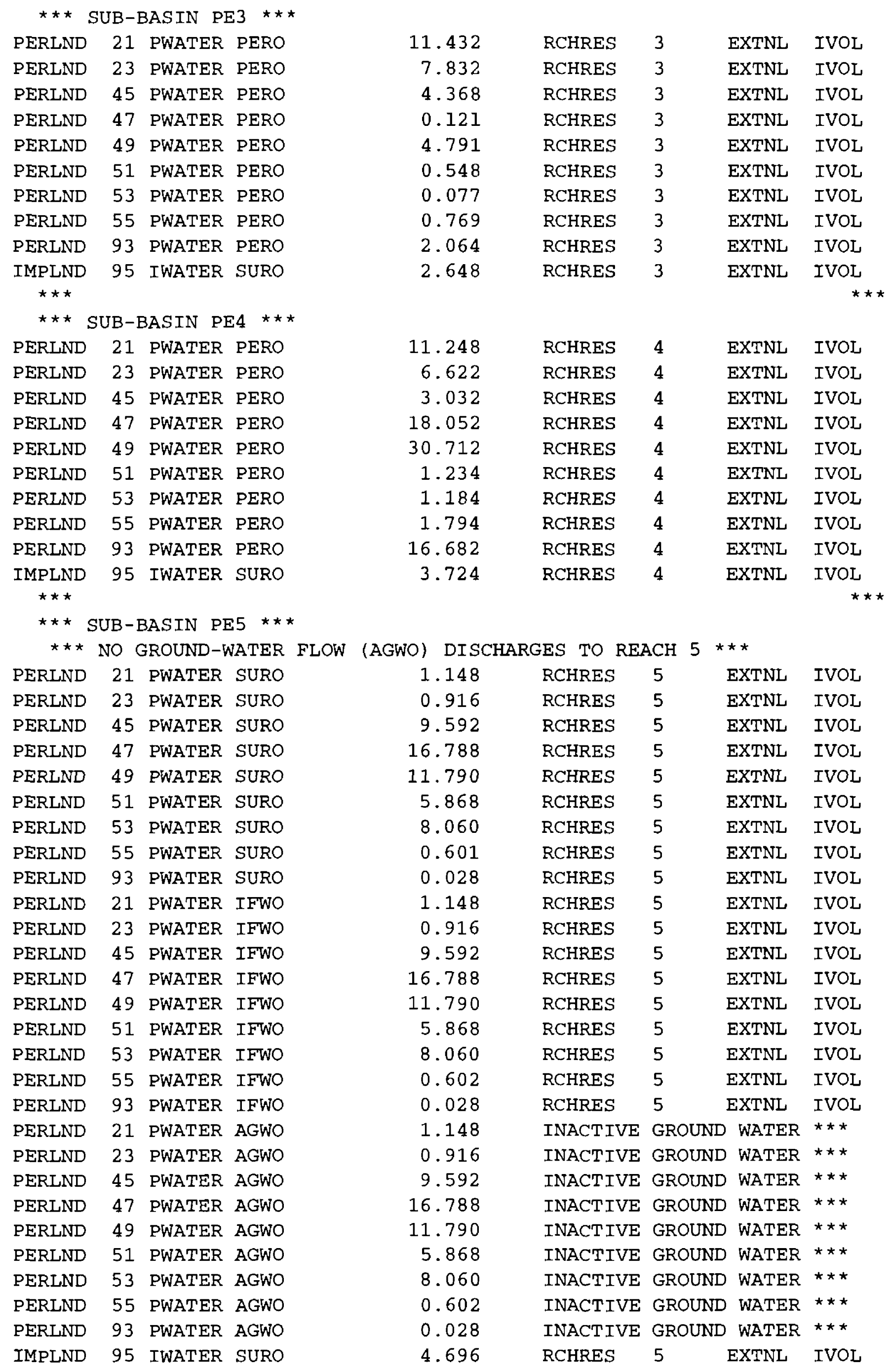


Table 17.--Input sequence of the Percival Creek model used to run Hydrological Simulation Program-FORTRAN (HSPF)--Continued

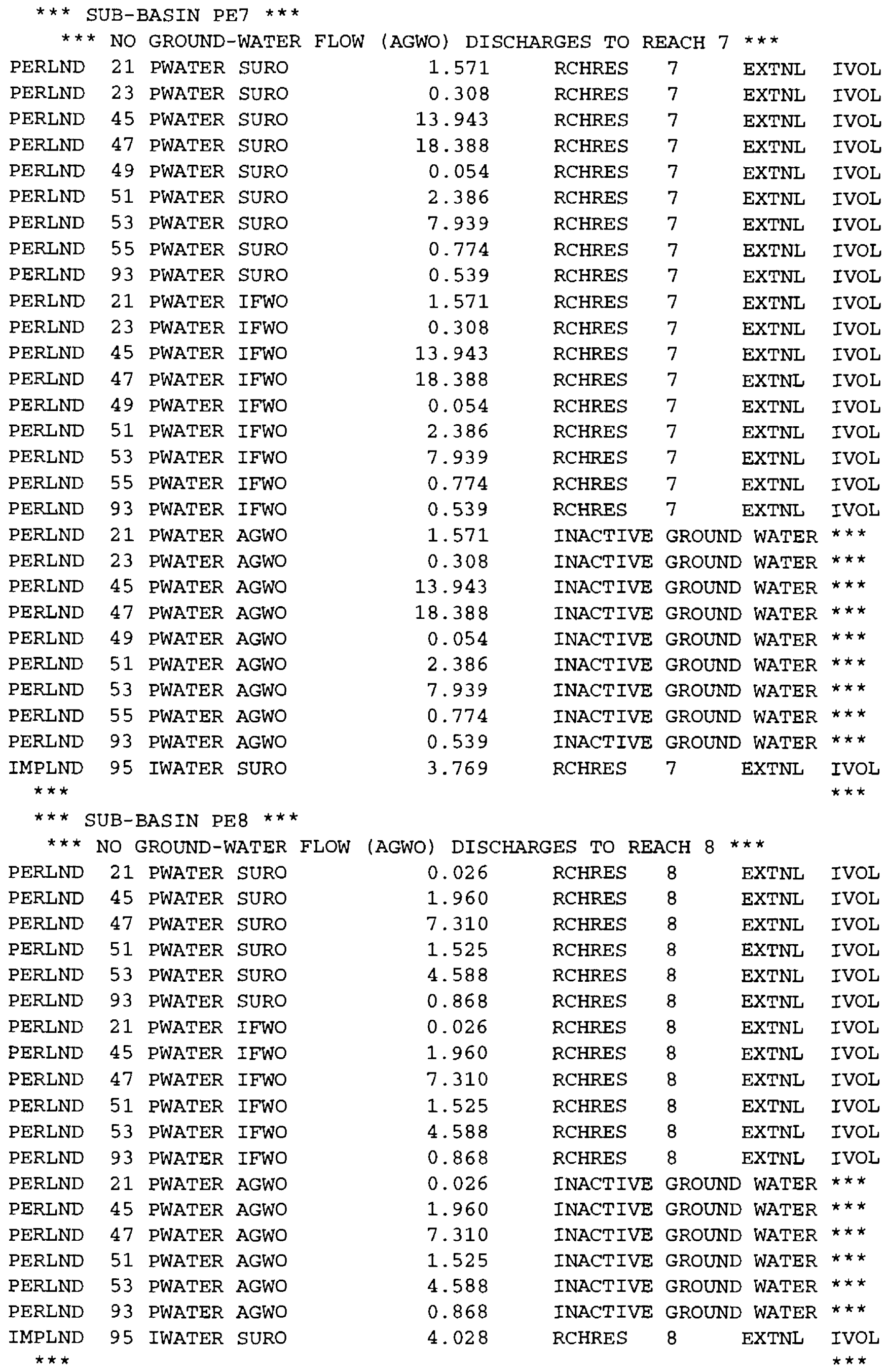


Table 17.--Input sequence of the Percival Creek model used to run Hydrological Simulation Program-FORTRAN (HSPF)--Continued

** SUB-BASIN PE9 $* \star \star$

* * * NO GROUND-WATER FLOW DISCHARGES TO REACH 9 ***

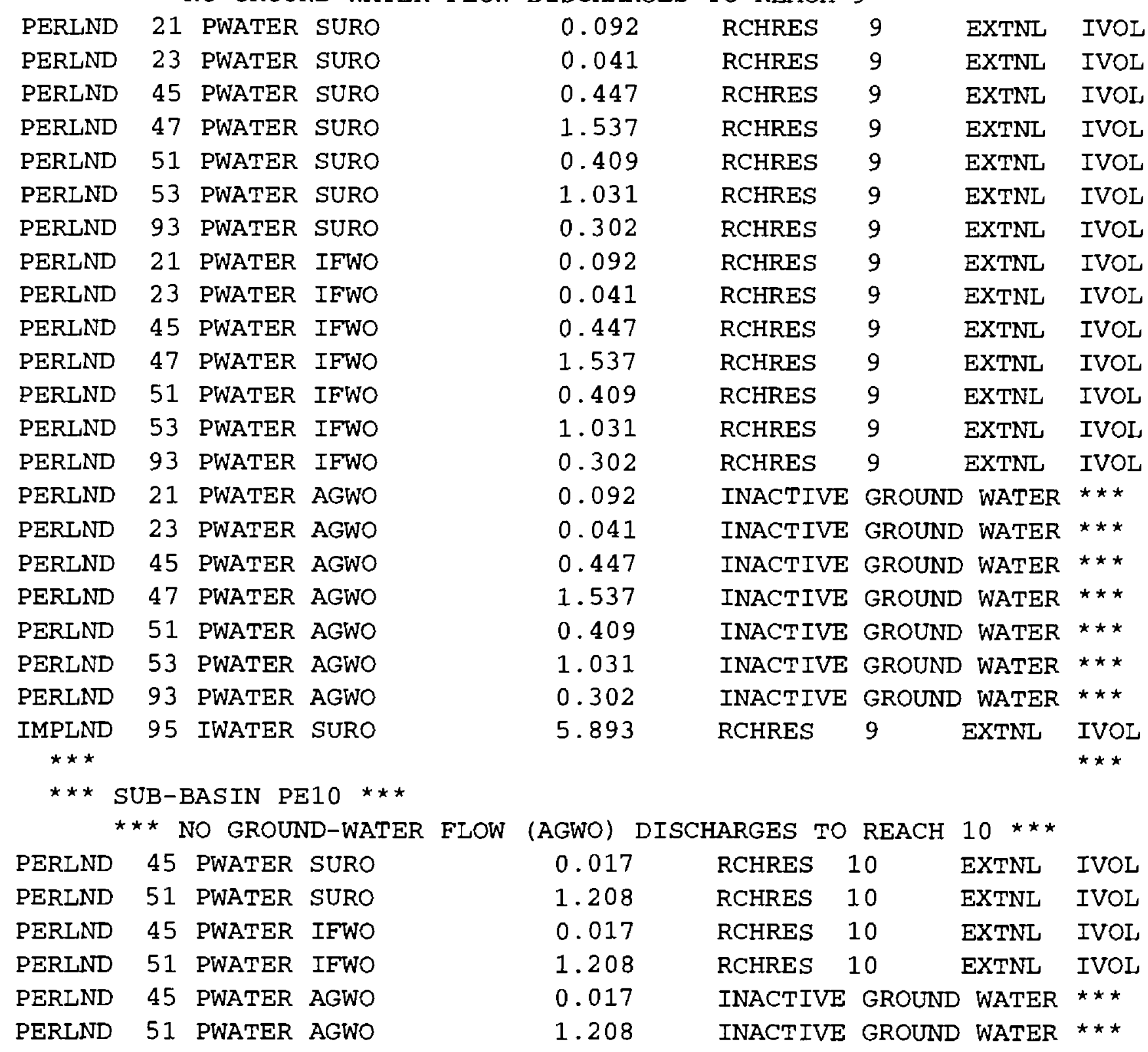


Table 17.--Input sequence of the Percival Creek model used to run Hydrological Simulation Program-FORTRAN (HSPF)--Continued

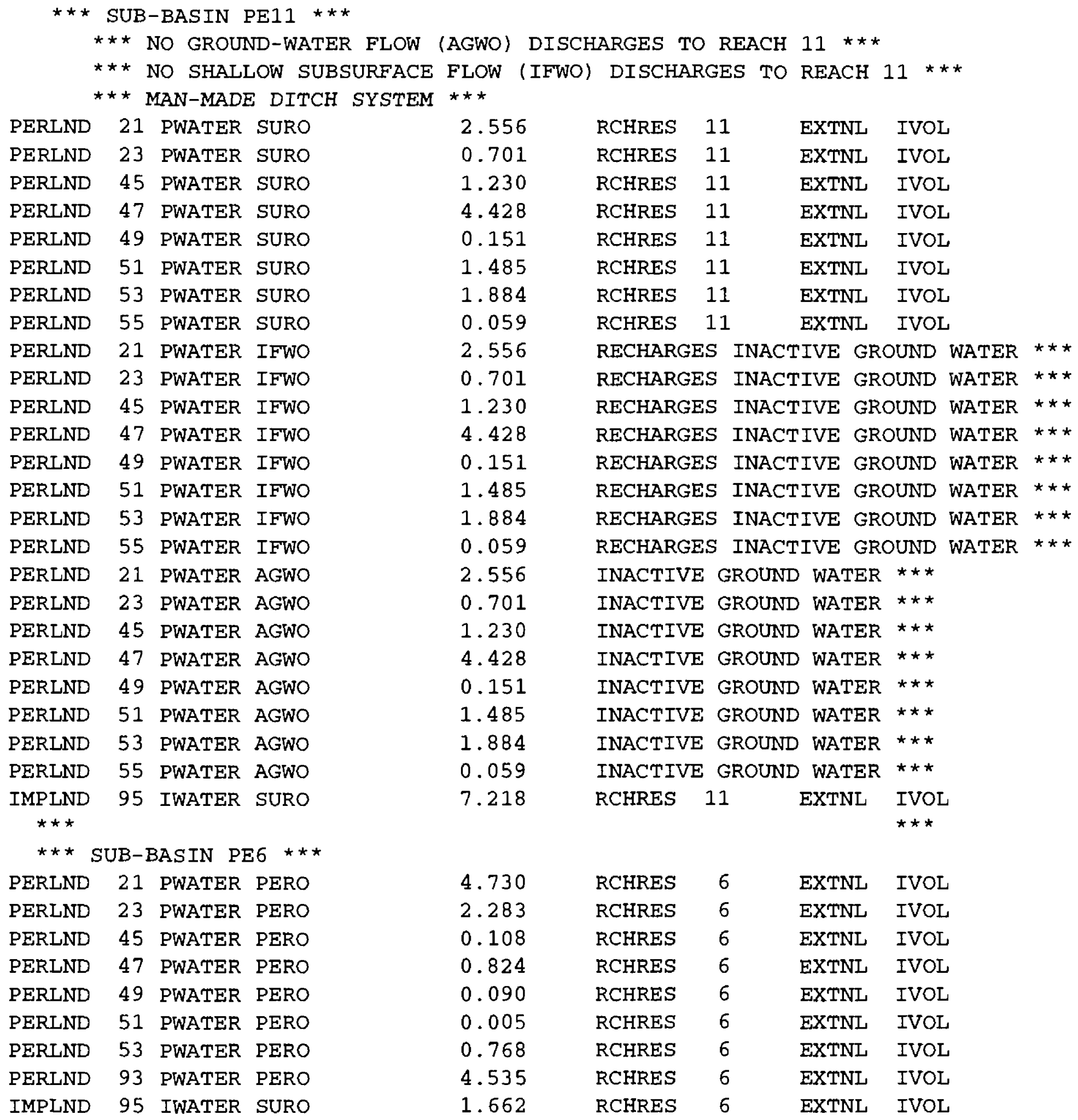


Table 17.--Input sequence of the Percival Creek model used to run Hydrological Simulation Program-FORTRAN (HSPF)--Continued

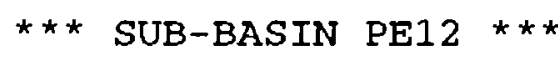

\begin{tabular}{|c|c|c|c|c|}
\hline 0.288 & RCHRES & 12 & EXTNL & IVOL \\
\hline 0.472 & RCHRES & 12 & EXTNL & IVOL \\
\hline 2.853 & RCHRES & 12 & EXTNL & IVOL \\
\hline 1.937 & RCHRES & 12 & EXTNL & IVOL \\
\hline 0.143 & RCHRES & 12 & EXTNL & IVOL \\
\hline 0.656 & RCHRES & 12 & EXTNL & IVOL \\
\hline 2.502 & RCHRES & 12 & EXTNL & IVOL \\
\hline 0.288 & RCHRES & 12 & EXTNL & IVOL \\
\hline 0.472 & RCHRES & 12 & EXTNL & IVOL \\
\hline 2.853 & RCHRES & 12 & EXTNL & IVOL \\
\hline 1.937 & RCHRES & 12 & EXTNL & IVOL \\
\hline 0.143 & RCHRES & 12 & EXTNL & IVOL \\
\hline 0.656 & RCHRES & 12 & EXTNL & IVOL \\
\hline 2.502 & RCHRES & 12 & EXTNL & IVOL \\
\hline 0.288 & INACTIVE & GROUND & WATER & $\star \star \star$ \\
\hline 0.472 & INACTIVE & GROUND & WATER & $\star \star \star$ \\
\hline 2.853 & INACTIVE & GROUND & WATER & $\star \star \star$ \\
\hline 1.937 & INACTIVE & GROUND & WATER & $\star \star \star$ \\
\hline 0.143 & INACTIVE & GROUND & WATER & $\star \star \star$ \\
\hline 0.656 & INACTIVE & GROUND & WATER & $\star \star \star *$ \\
\hline 2.502 & INACTIVE & GROUND & WATER & $\star \star \star$ \\
\hline 3.218 & RCHRES & 12 & EXTNL & $\begin{array}{l}\text { IVOL } \\
\star \star \star\end{array}$ \\
\hline 4.611 & RCHRES & 13 & EXTNL & IVOL \\
\hline 3.007 & RCHRES & 13 & EXTNL & IVOL \\
\hline 5.312 & RCHRES & 13 & EXTNL & IVOL \\
\hline 6.512 & RCHRES & 13 & EXTNL & IVOL \\
\hline 7.519 & RCHRES & 13 & EXTNL & IVOL \\
\hline 1.112 & RCHRES & 13 & EXTNL & IVOL \\
\hline 1.402 & RCHRES & 13 & EXTNL & IVOL \\
\hline 0.332 & RCHRES & 13 & EXTNL & IVOL \\
\hline 1.165 & RCHRES & 13 & EXTNL & IVOL \\
\hline 5.195 & RCHRES & 13 & EXTNL & IVOL \\
\hline
\end{tabular}


Table 17.--Input sequence of the Percival Creek model used to run Hydrological Simulation Program-FORTRAN (HSPF)--Continued

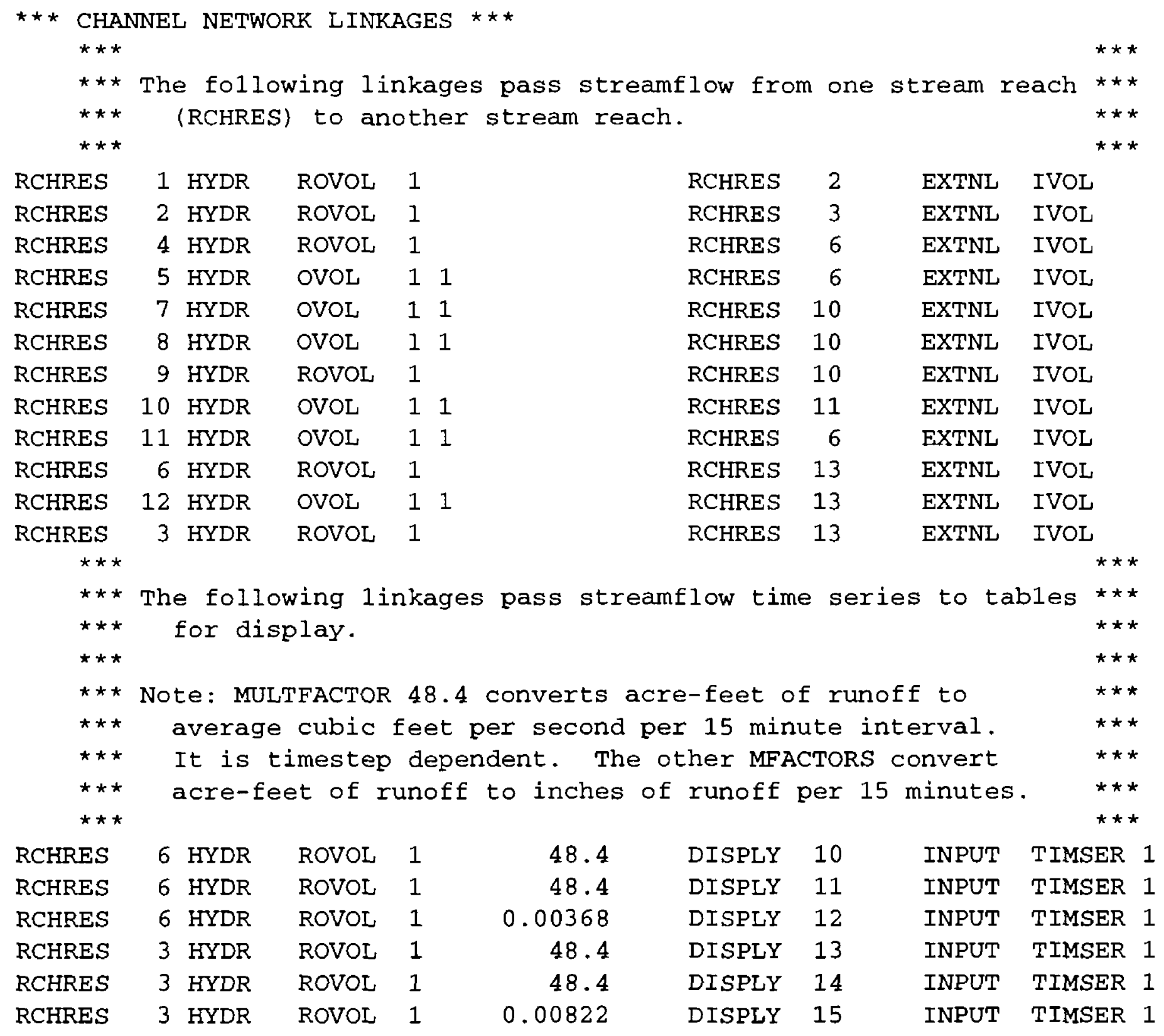

END NETWORK 
Table 17.--Input sequence of the Percival Creek model used to run Hydrological Simulation Program-FORTRAN (HSPF)--Continued

RCHRES

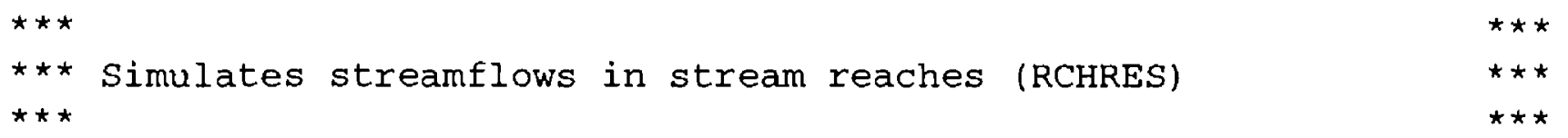

FUNCT for each possible exit $\star \star \star$

$\begin{array}{lllll}2 & 2 & 2 & 2 & 2 \\ 2 & 2 & 2 & 2 & 2 \\ 2 & 2 & 2 & 2 & 2 \\ 2 & 2 & 2 & 2 & 2 \\ 2 & 2 & 2 & 2 & 2 \\ 2 & 2 & 2 & 2 & 2 \\ 2 & 2 & 2 & 2 & 2 \\ 2 & 2 & 2 & 2 & 2 \\ 2 & 2 & 2 & 2 & 2 \\ 2 & 2 & 2 & 2 & 2 \\ 2 & 2 & 2 & 2 & 2\end{array}$

END HYDR-PARM1 
Table 17.--Input sequence of the Percival Creek model used to run Hydrological Simulation Program-FORTRAN (HSPF)--Continued

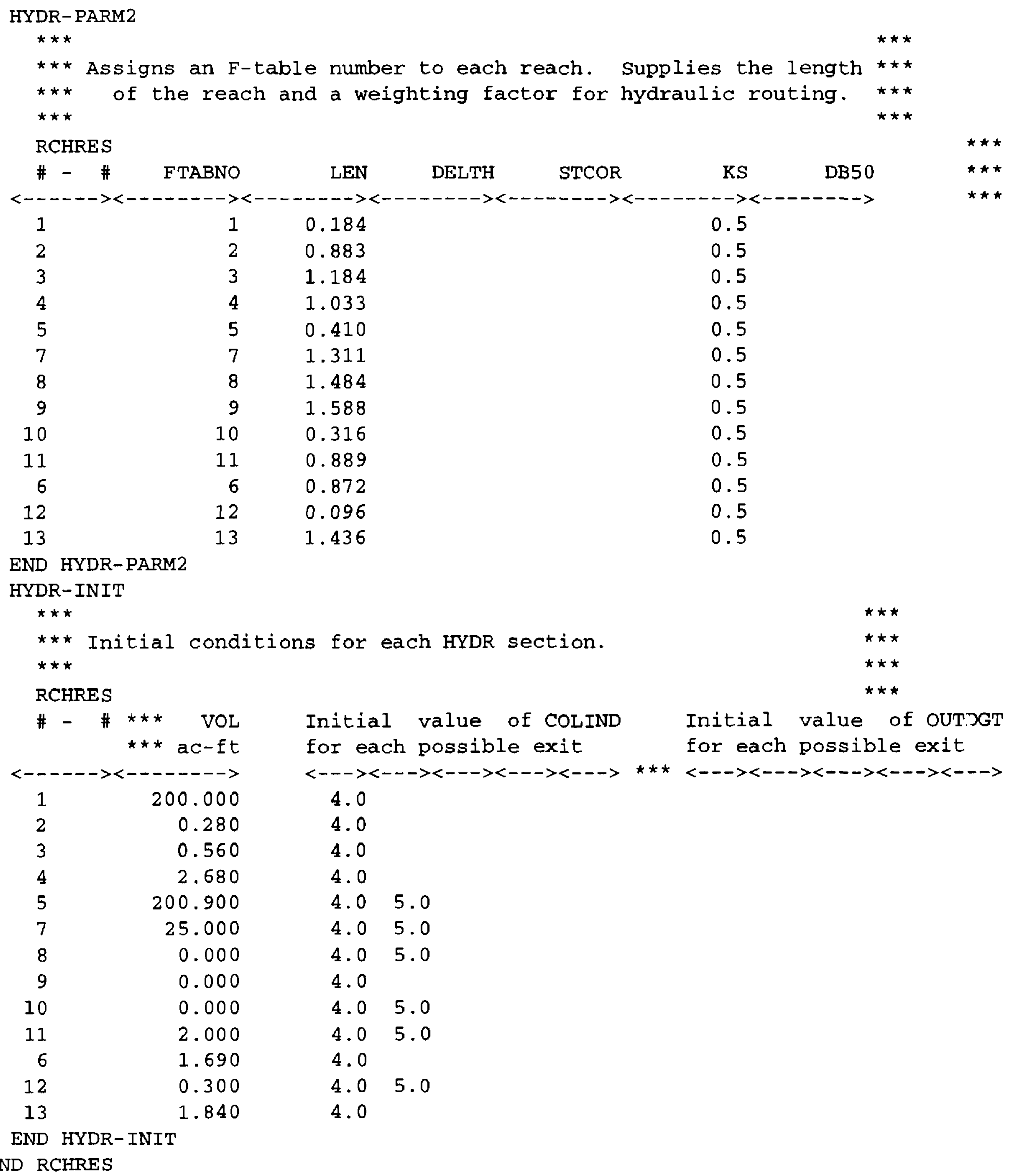


Table 17.--Input sequence of the Percival Creek model used to run Hydrological Simulation Program-FORTRAN (HSPF)--Continued

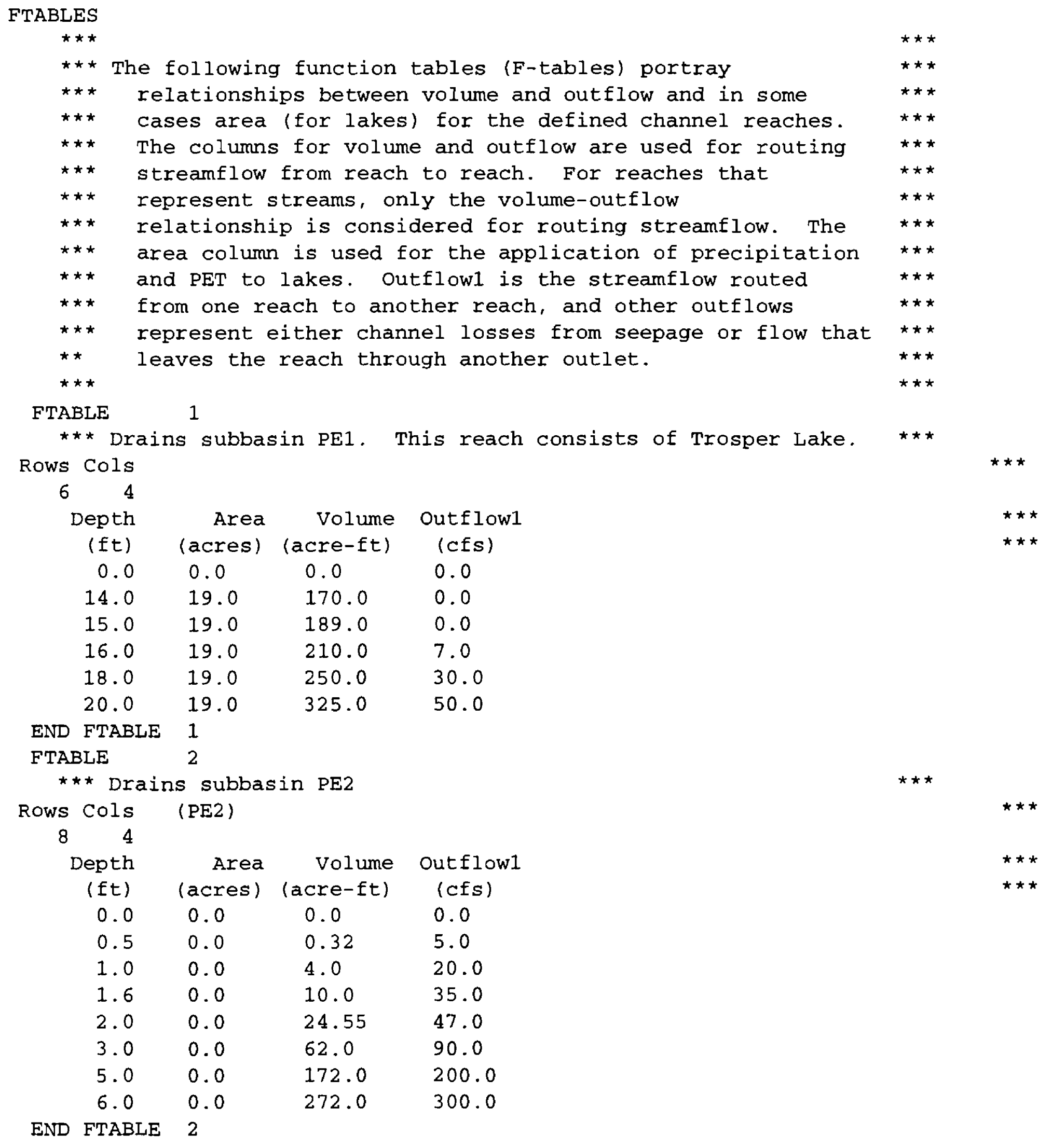


Table 17.--Input sequence of the Percival Creek model used to run Hydrological Simulation Program-FORTRAN (HSPF)--Continued

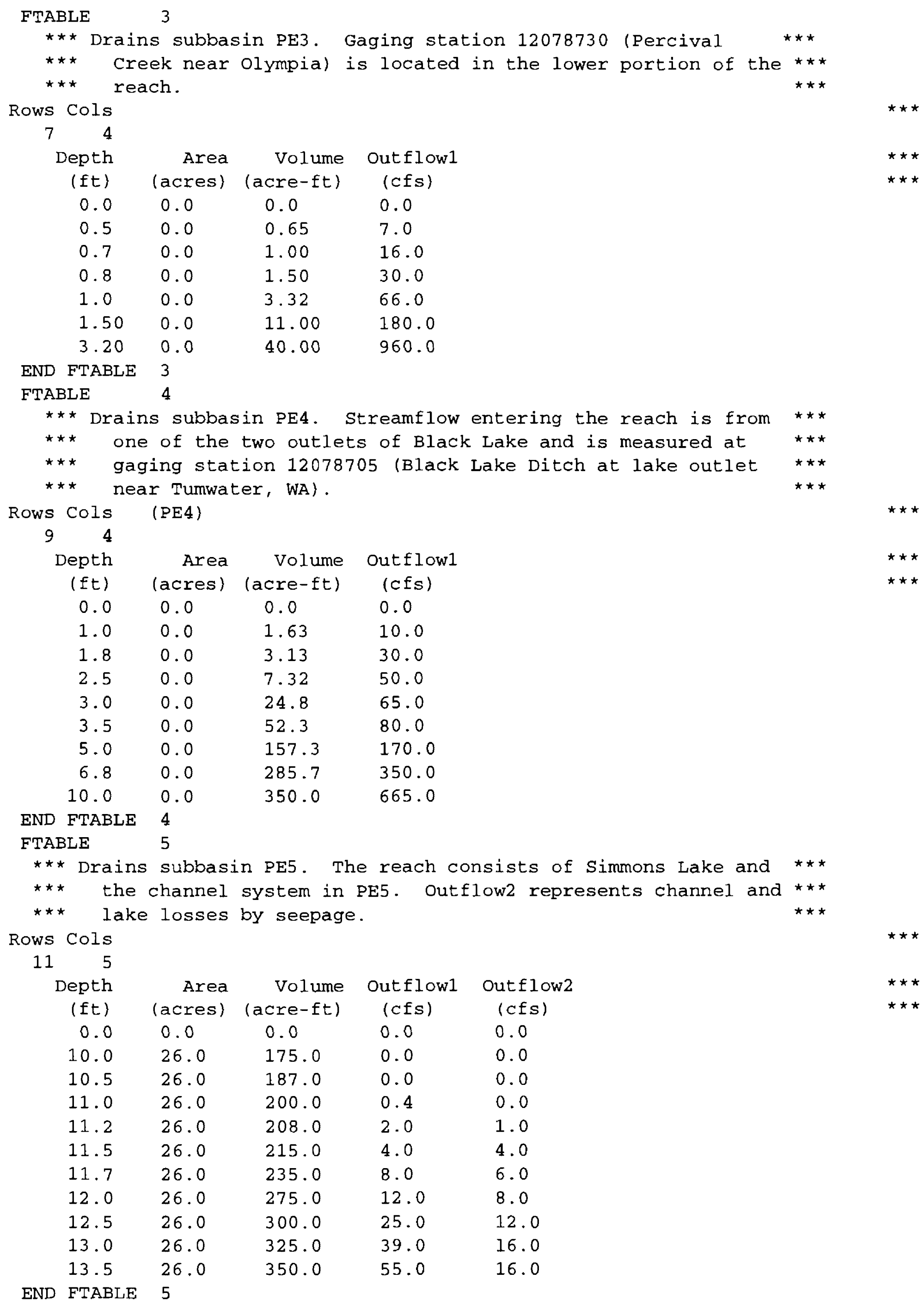


Table 17.--Input sequence of the Percival Creek model used to run Hydrological Simulation Program-FORTRAN (HSPF)--Continued

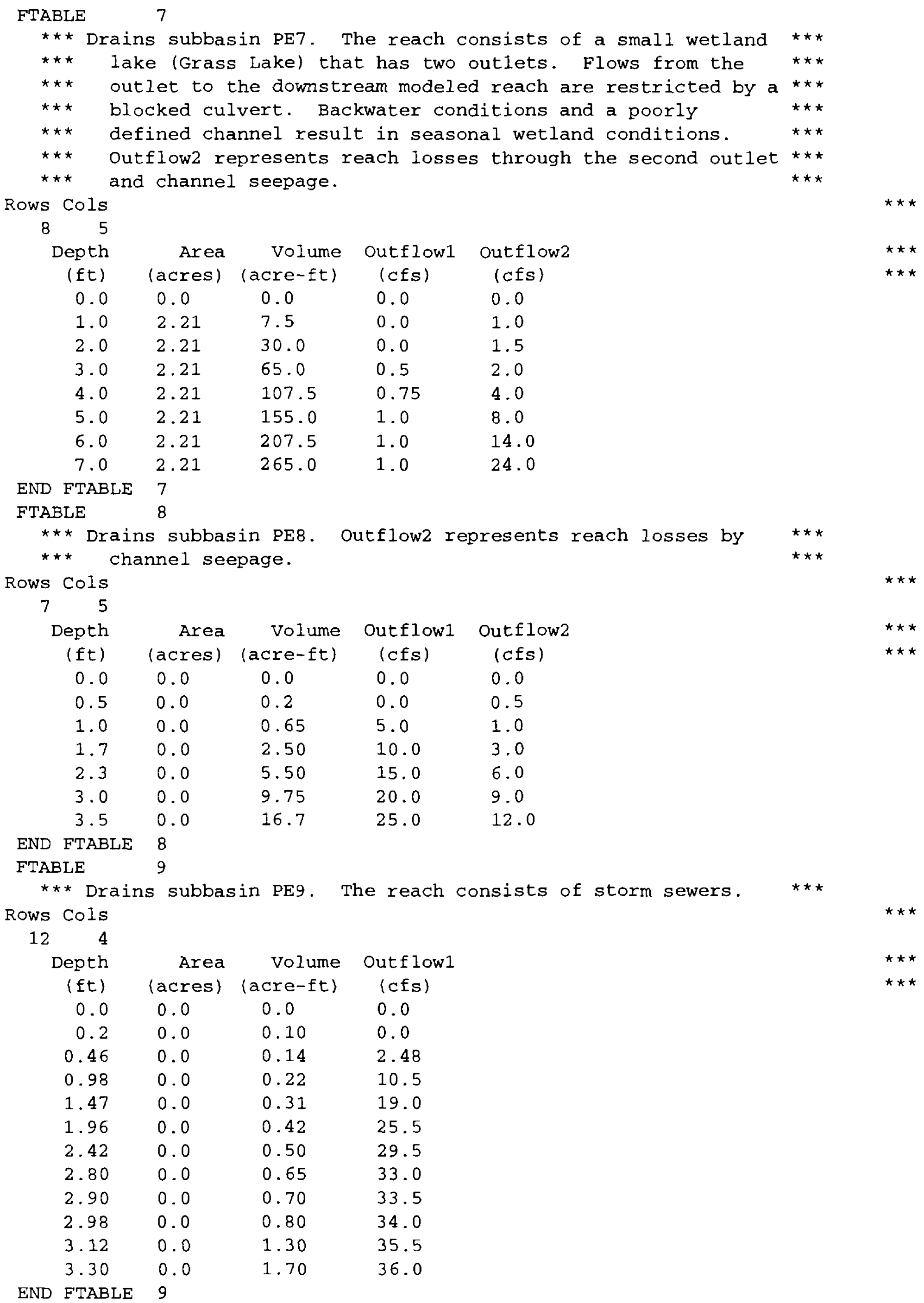


Table 17.--Input sequence of the Percival Creek model used to run Hydrological Simulation Program-FORTRAN (HSPF)--Continued

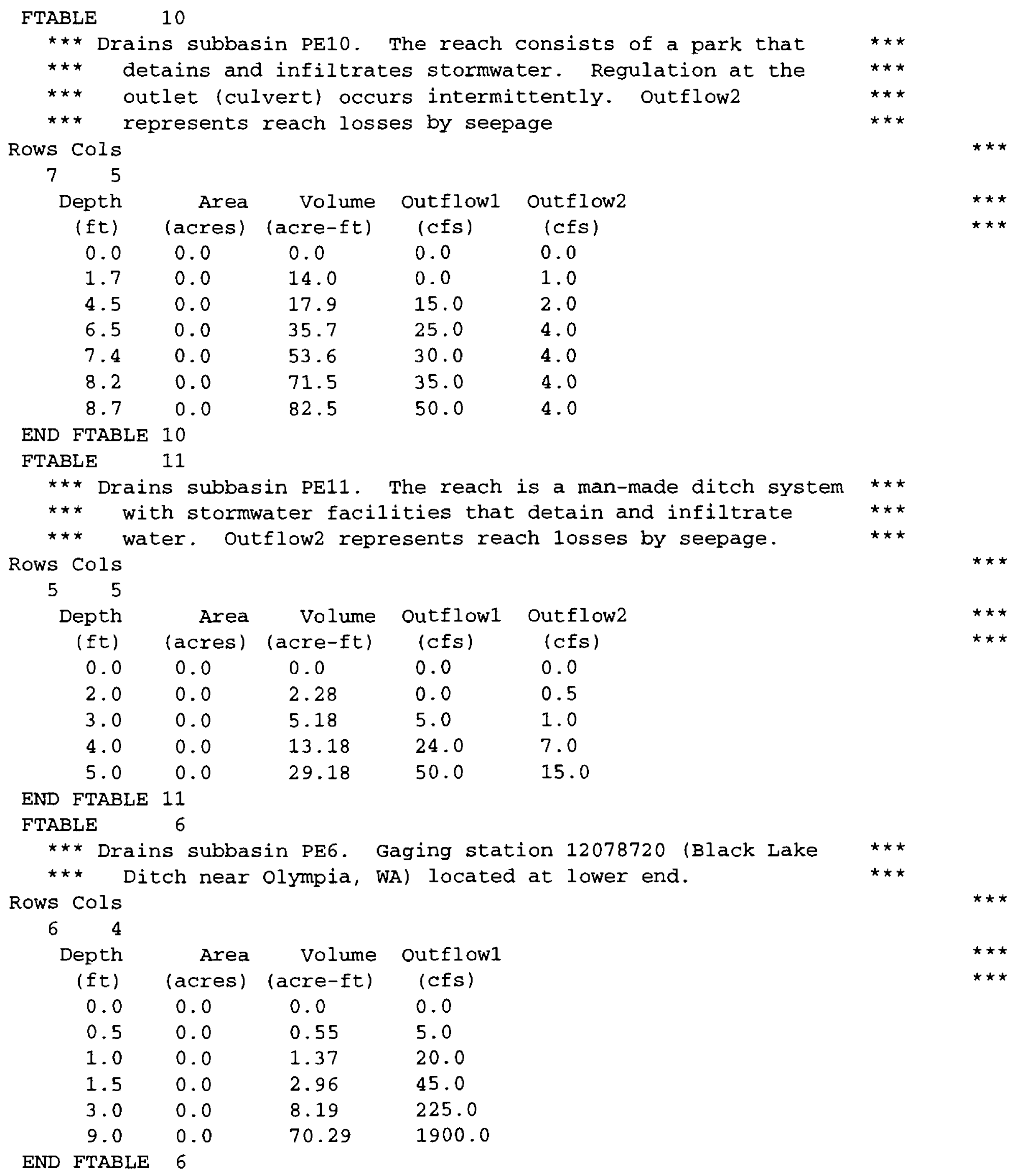


Table 17. - Input sequence of the Percival Creek model used to run Hydrological Simulation Program-FORTRAN (HSPF)--Continued

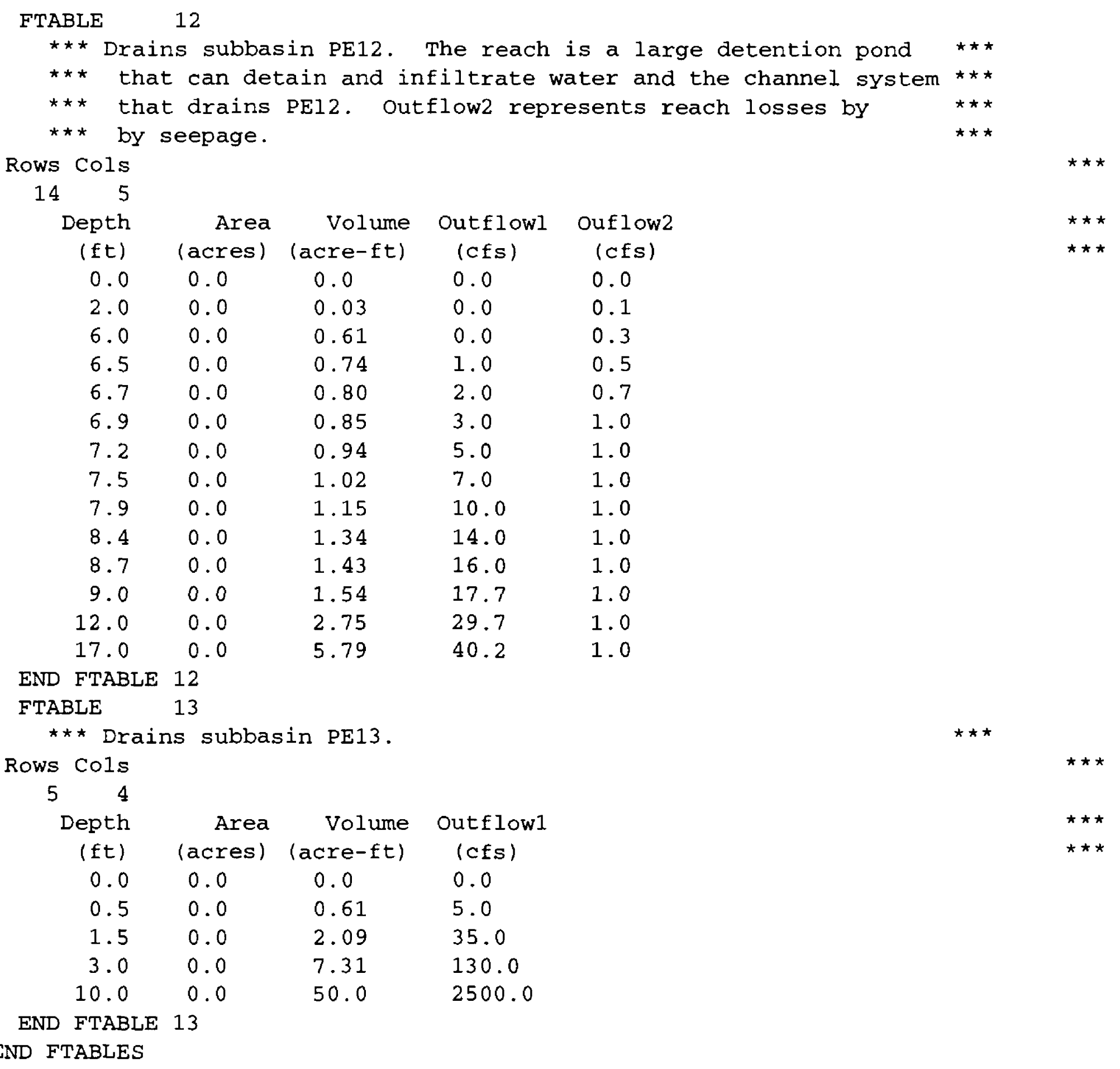


Table 17.--Input sequence of the Percival Creek model used to run Hydrological Simulation Program-FORTRAN (HSPF)--Continued

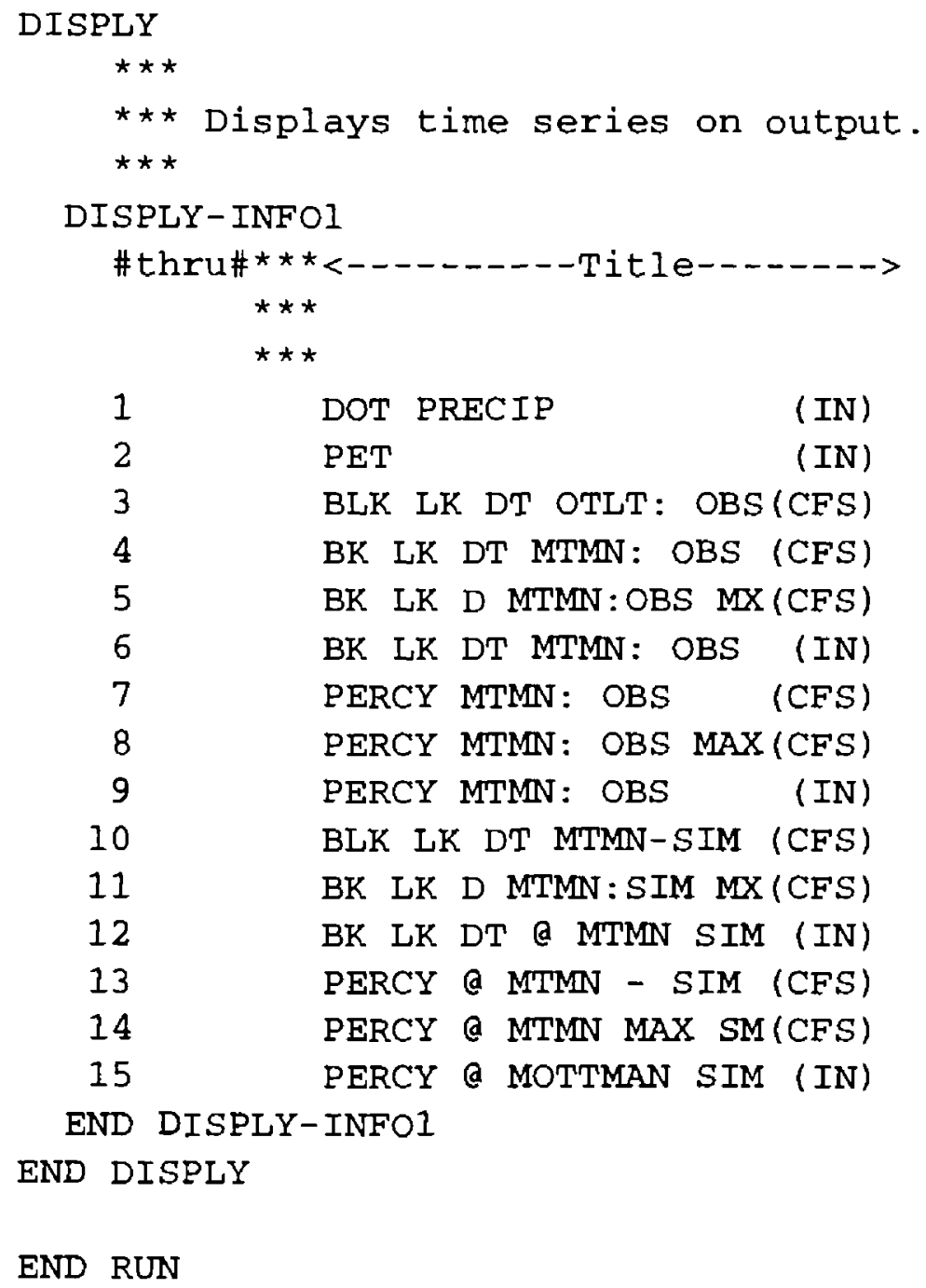

END RUN 
Table 18.--Input sequence of the Woodard Creek model used to run Hydrological Simulation Program-FORTRAN (HSPF)

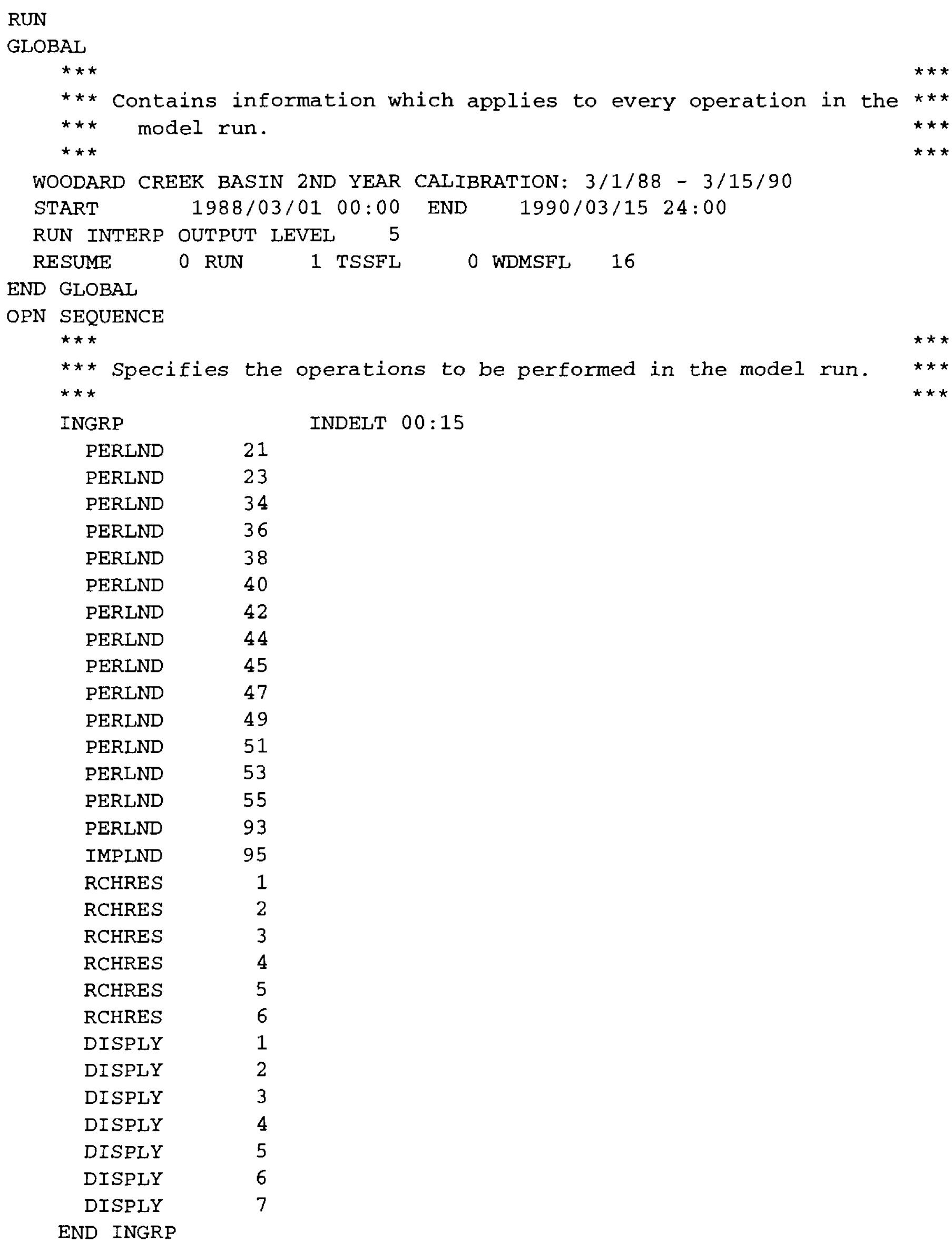


Table 18.--Input sequence of the woodard Creek model used to run Hydrological Simulation Program-FORTRAN (HSPF)--Continued

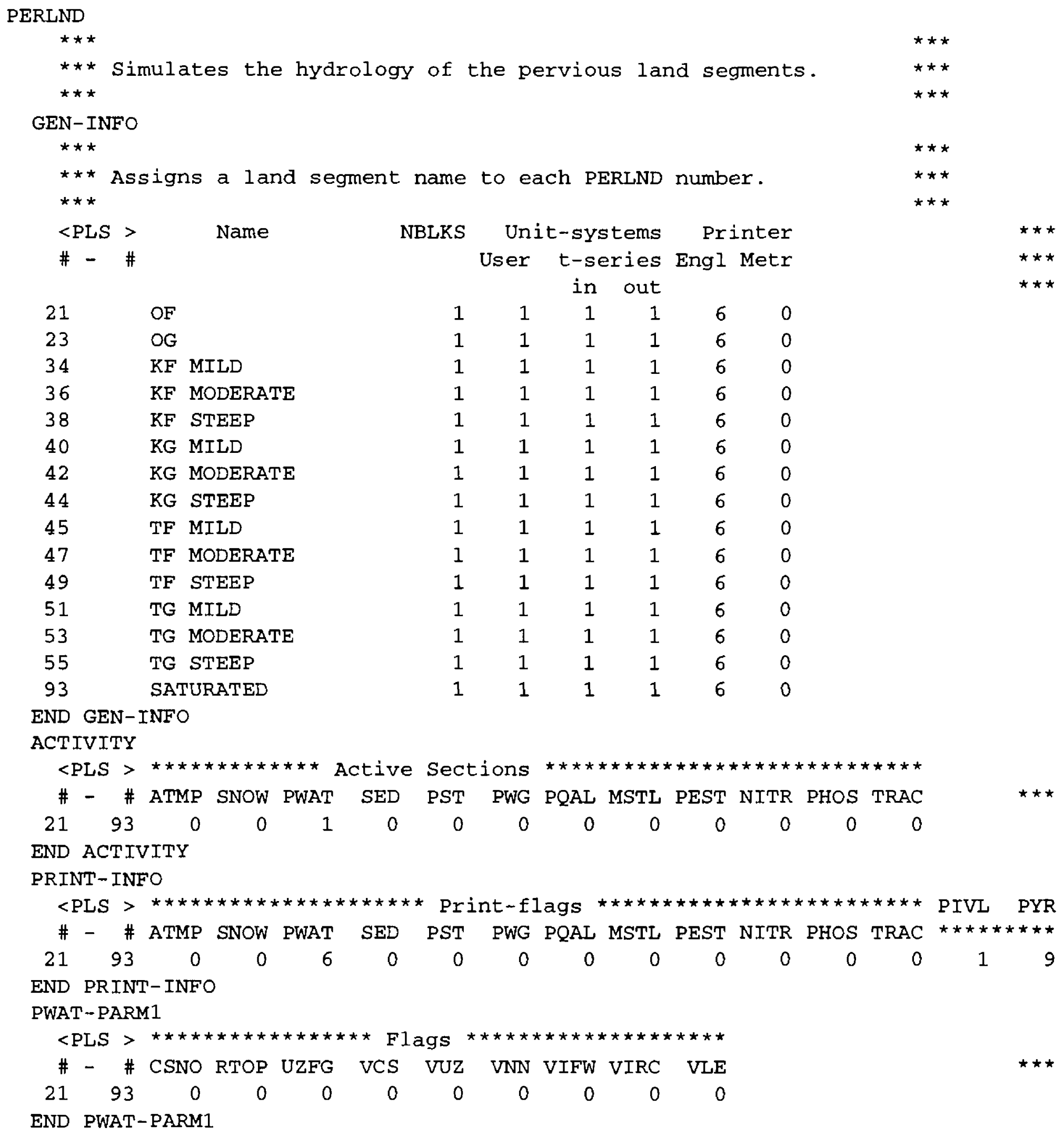


Table 18.--Input sequence of the woodard Creek model used to run Hydrological Simulation Program-FORTRAN (HSPF)--Continued

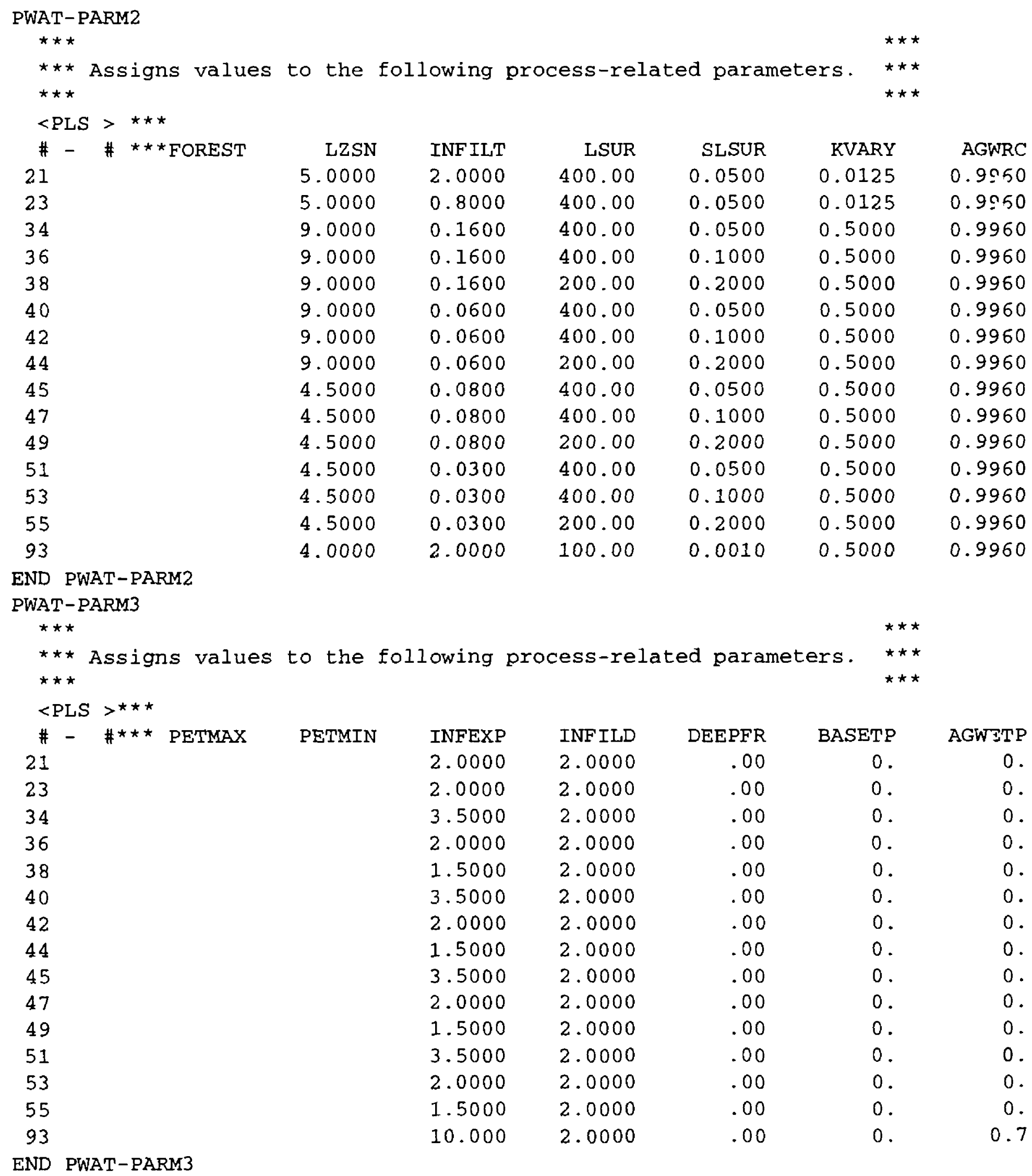


Table 18.--Input sequence of the Woodard Creek model used to run Hydrological Simulation Program-FORTRAN (HSPF)--Continued

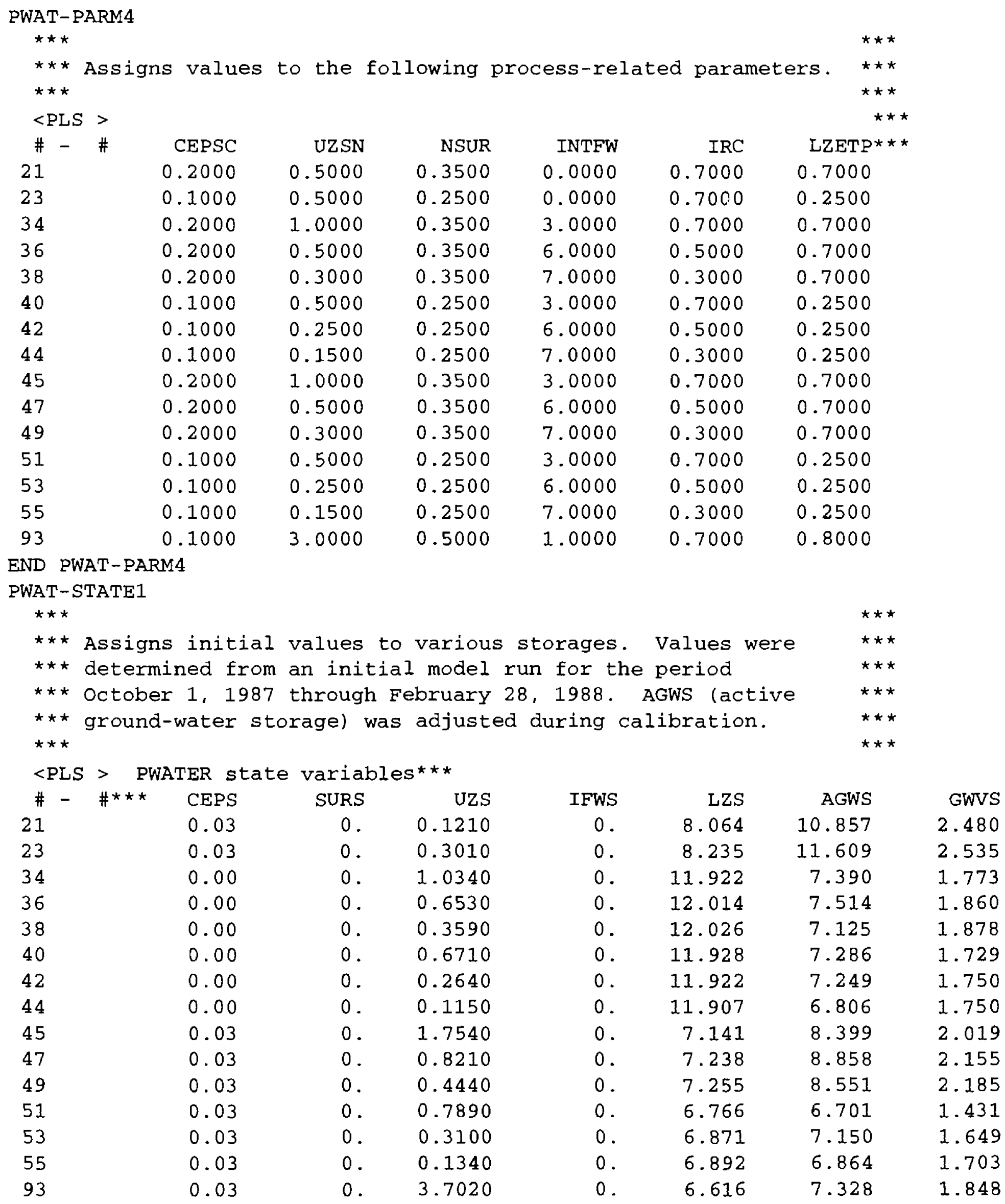

END PWAT-STATE1

END PERLND 
Table 18.--Input sequence of the Woodard Creek model used to run Hydrological Simulation Program-FORTRAN (HSPF)--Continued

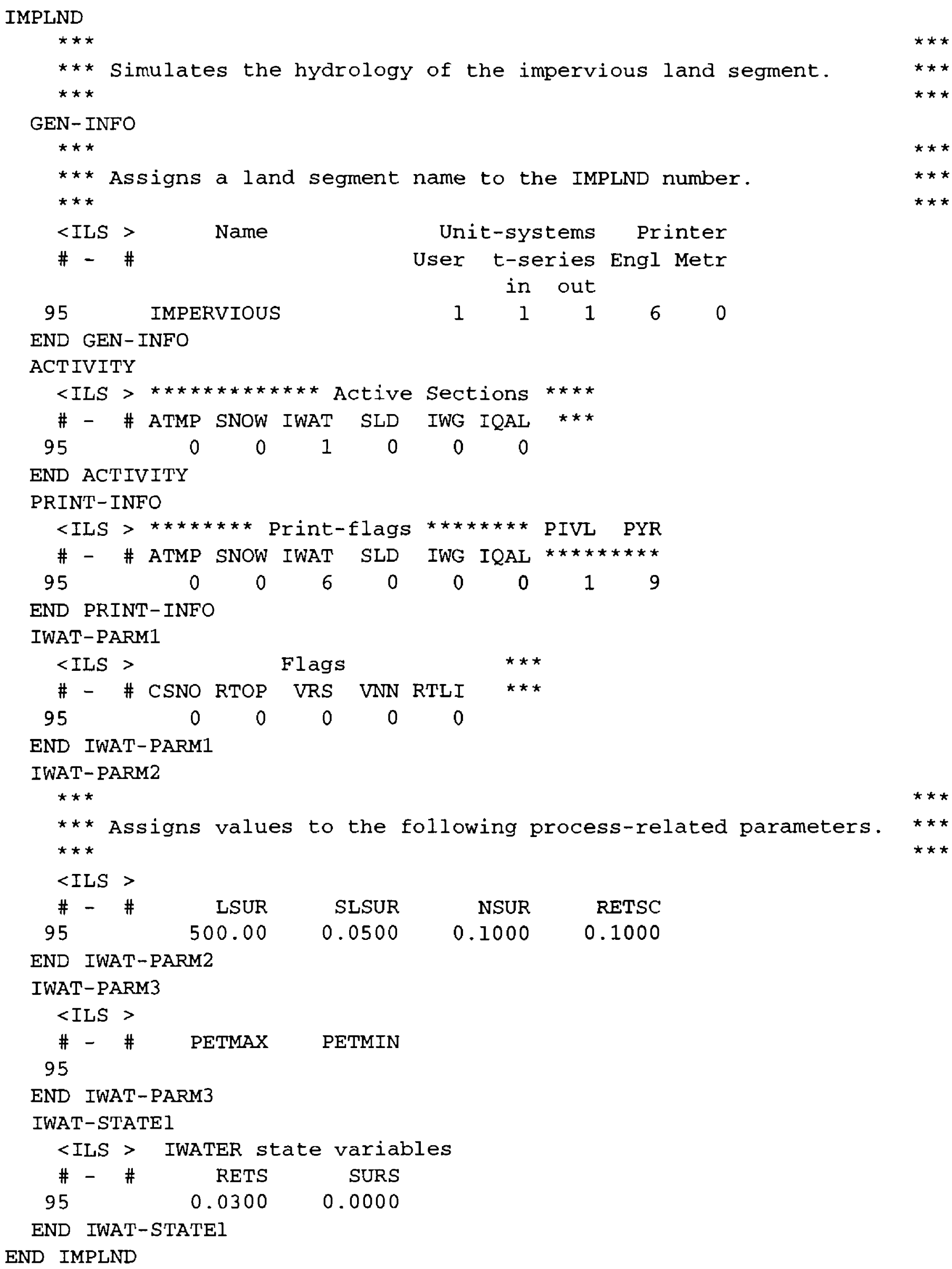


Table 18.--Input sequence of the Woodard Creek model used to run Hydrological Simulation Program-FORTRAN (HSPF)--Continued

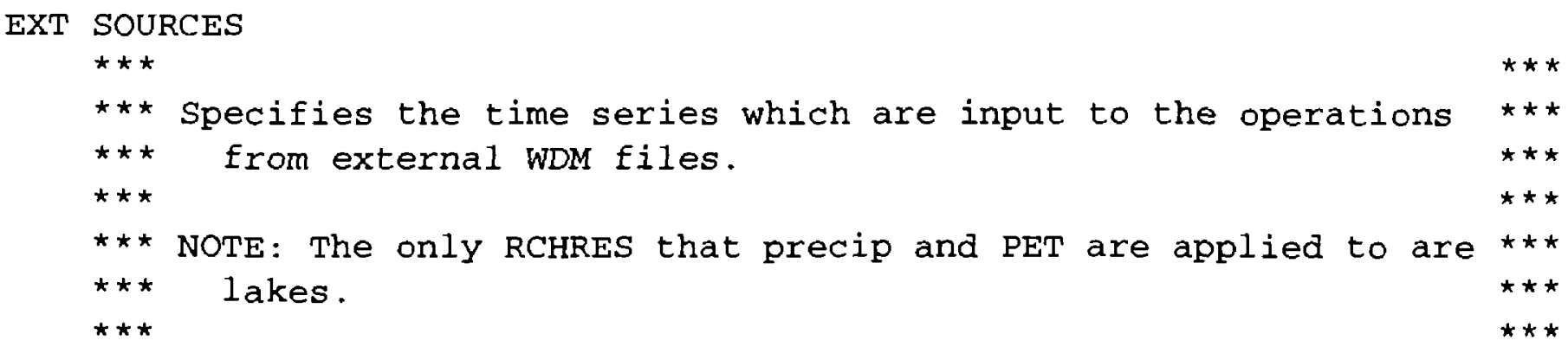


Table 18.--Input sequence of the woodard Creek model used to run Hydrological Simulation Program-FORTRAN (HSPF)--Continued

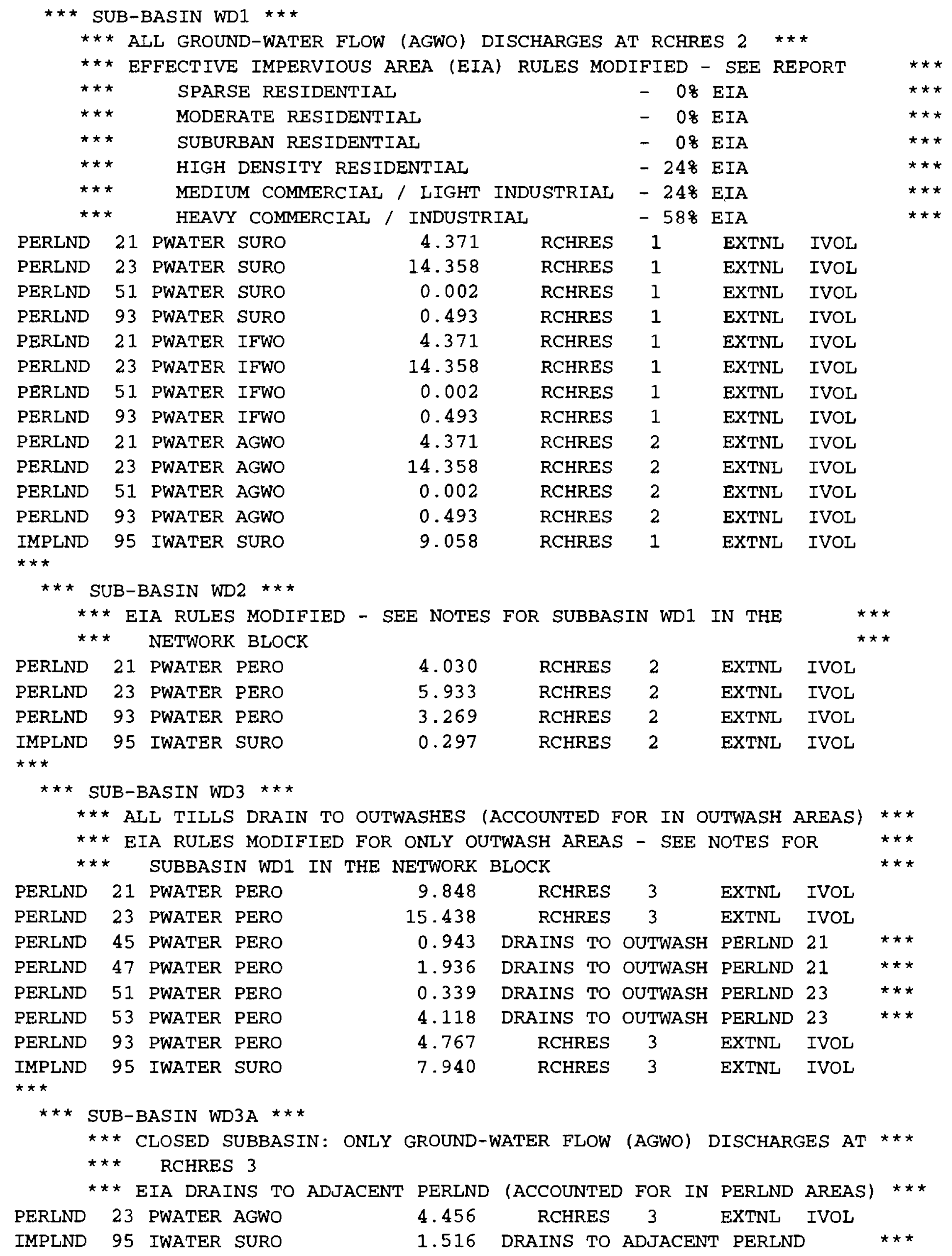


Table 18.--Input sequence of the woodard Creek model used to run Hydrological Simulation Program-FORTRAN (HSPF)--Continued

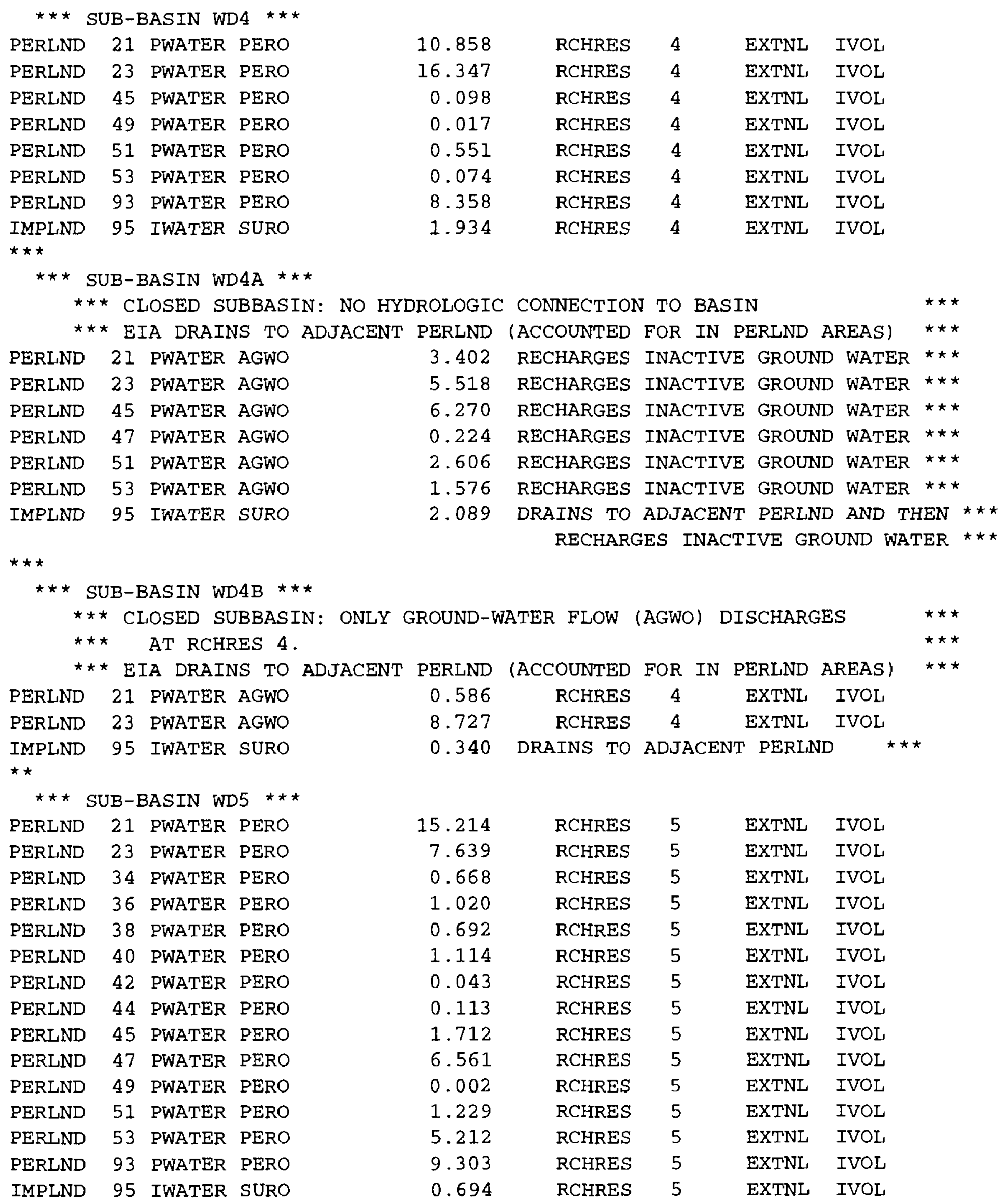


Table 18.--Input sequence of the woodard Creek model used to run Hydrological Simulation Program-FORTRAN (HSPF)--Continued

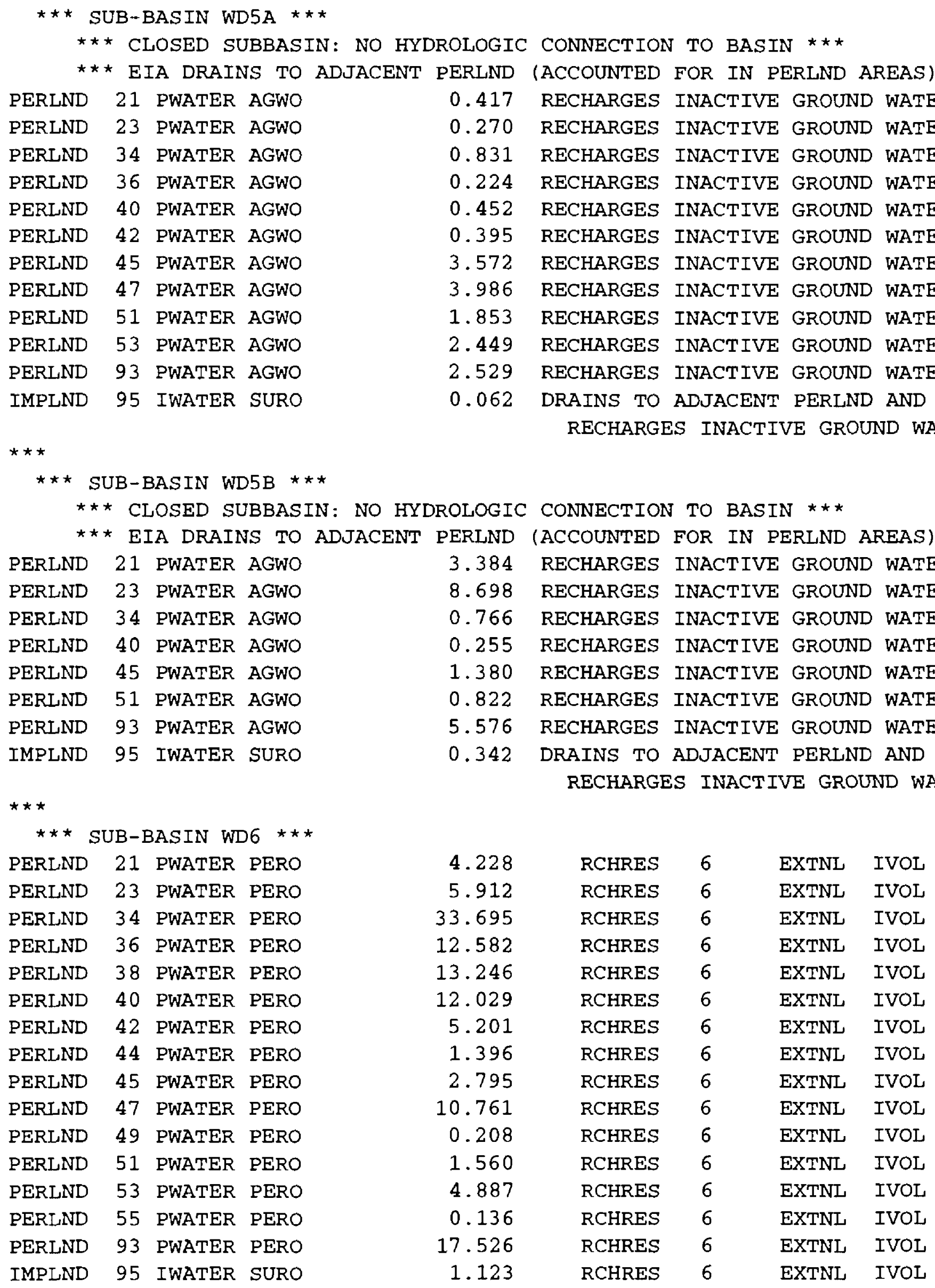


Tab1e 18.--Input sequence of the Woodard Creek model used to run Hydrological Simulation Program-FORTRAN (HSPF)--Continued

$\star \star \star$ SUB-BASIN WD6A ***

$\star \star \star$ CLOSED SUBBASIN: ONLY GROUND-WATER FLOW (AGWO) DISCHARGES $\star \star \star ~$

$\star \star \star \quad$ AT RCHRES 6

*** EIA DRAINS TO ADJACENT PERLND (ACCOUNTED FOR IN PERLND AREAS)

$\begin{array}{llllllll}\text { PERLND } & 21 & \text { PWATER AGWO } & 0.903 & \text { RCHRES } & 6 & \text { EXTNL } & \text { IVOL } \\ \text { PERLND } & 23 & \text { PWATER AGWO } & 0.349 & \text { RCHRES } & 6 & \text { EXTNL } & \text { IVOL } \\ \text { PERLND } & 34 & \text { PWATER AGWO } & 0.433 & \text { RCHRES } & 6 & \text { EXTNL } & \text { IVOL } \\ \text { PERLND } & 36 & \text { PWATER AGWO } & 0.132 & \text { RCHRES } & 6 & \text { EXTNL } & \text { IVOL } \\ \text { PERLND } & 40 & \text { PWATER AGWO } & 0.388 & \text { RCHRES } & 6 & \text { EXTNL } & \text { IVOL } \\ \text { PERLND } & 42 & \text { PWATER AGWO } & 0.214 & \text { RCHRES } & 6 & \text { EXTNL } & \text { IVOL } \\ \text { PERLND } & 47 & \text { PWATER AGWO } & 1.010 & \text { RCHRES } & 6 & \text { EXTNL } & \text { IVOL } \\ \text { PERLND } & 51 & \text { PWATER AGWO } & 0.037 & \text { RCHRES } & 6 & \text { EXTNL } & \text { IVOL } \\ \text { PERLND } & 53 & \text { PWATER AGWO } & 1.362 & \text { RCHRES } & 6 & \text { EXTNL IVOL } \\ \text { IMPLND } & 95 & \text { IWATER SURO } & 0.148 & \text { DRAINS TO ADJACENT PERLND } * *\end{array}$

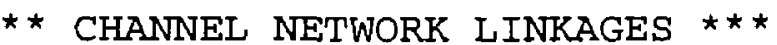

$\star \star \star$

$\star \star \star$ The following linkages pass streamflow from one

$\star \star \star$ (RCHRES) to another stream reach.

$\star \star \star$

RCHRES 1 HYDR OVOL 11

RCHRES 2 HYDR ROVOL I

RCHRES 3 HYDR ROVOL 1

RCHRES 4 HYDR ROVOL 1

RCHRES 5 HYDR ROVOL 1

$\star \star * *$
RCHRES 2 EXTNL IVOL

RCHRES 3 EXTNL IVOL

RCHRES 4 EXTNL IVOL

RCHRES 5 EXTNL IVOL

RCHRES 6 EXTNL IVOL

$\star \star \star$ The following 1 inkages pass streamflow time series to tables

$\star \star \star$ for display.

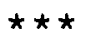

$\star \star \star$ Note: MULTFACTOR 48.4 converts acre-feet of runoff to

$\star \star \star$ average cubic feet per second per 15 minute interval.

$\star \star *$ It is timestep dependent. The other MFACTOR converts

$\star \star *$ acre-feet of runoff to inches of runoff per 15 minutes.

$\star \star \star$

RCHRES 5 HYDR ROVOL 1

RCHRES 5 HYDR ROVOL 1

48.4 DISPLY 5 INPUT TIMSER 1

RCHRES

5 HYDR

ROVOL 1

48.4

DISPLY 6

INPUT TIMSER 1

$\star \star \star \star *$

0.00546

DISPLY 7

INPUT TIMSER 1

END NETWORK 
Table 18.--Input sequence of the woodard Creek model used to run Hydrological Simulation Program-FORTRAN (HSPF)--Continued

RCHRES

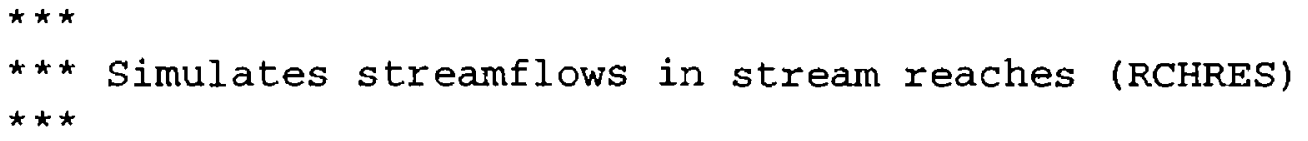

END HYDR-PARM2 
Table 18.--Input sequence of the Woodard Creek model used to run Hydrological Simulation Program-FORTRAN (HSPF)--Continued

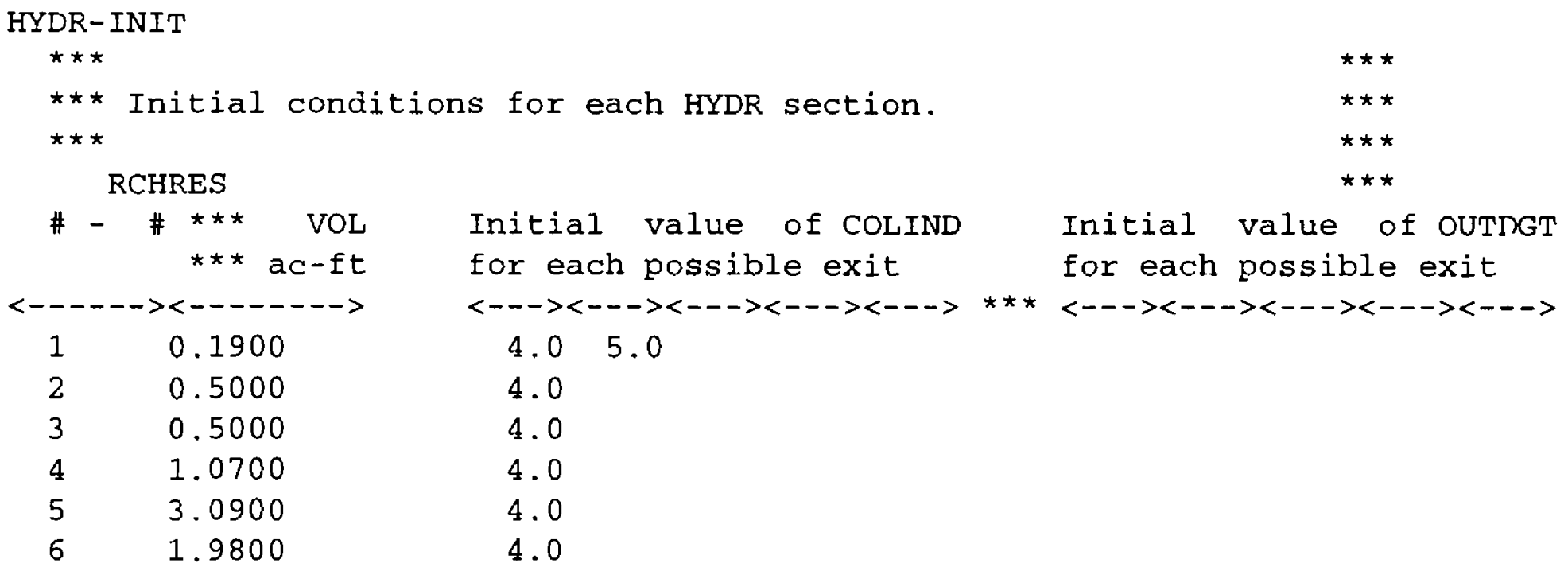

4.0

0.5000

4.0

1.0700

4.0

$\begin{array}{ll}3.0900 & 4.0 \\ 1.9800 & 4.0\end{array}$

END HYDR-INIT

END RCHRES

FTABLES

$\star \star \star *$

$\star \star *$ The following function tables (F-tables) portray

$\star \star \star$ relationships between volume and outflow and in some

$\star \star \star$ cases area (for lakes) for the defined channel reaches.

$\star \star \star$ The columns for volume and outflow are used for routing

$\star \star \star$ streamflow from reach to reach. For reaches that

$\star \star \star$ represent streams, only the volume-outflow

$\star * *$ relationship is considered for routing streamflow. The

$\star \star \star$ area column is used for the application of precipitation

$\star * *$ and PET to lakes. Outflowl is the streamflow routed

$\star \star \star$ from one reach to another reach, and other outflows

$\star \star *$ represent either channel losses from seepage or flow that

** leaves the reach through another outlet.

$\star \star \star$

\section{1}

$\star \star \star$ Drains subbasin WD1. The reach consists of a storm sewer

$\star * *$ and man-made ditch system that can detain and infiltrate

$\star \star \star$ water. Outflow2 represents reach losses by seepage.

Rows Cols

9

$\begin{array}{rcccc}9 \begin{array}{r}5 \\ \text { Depth }\end{array} & \begin{array}{r}\text { Area } \\ \text { (ft) }\end{array} & \begin{array}{r}\text { Volume } \\ \text { (acres) } \\ \text { (acre-ft) }\end{array} & \begin{array}{c}\text { Outflow1 } \\ \text { (cfs) }\end{array} & \begin{array}{c}\text { Outflow2 } \\ \text { (cfs) }\end{array} \\ 0.0 & 0.0 & 0.0 & 0.0 & 0.0 \\ 0.3 & 0.0 & 0.15 & 0.0 & 1.0 \\ 0.5 & 0.0 & 0.30 & 0.0 & 1.0 \\ 0.8 & 0.0 & 0.70 & 1.2 & 2.0 \\ 2.0 & 0.0 & 2.05 & 10.8 & 6.0 \\ 2.8 & 0.0 & 3.40 & 25.0 & 8.0 \\ 3.3 & 0.0 & 4.25 & 36.2 & 12.0 \\ 4.8 & 0.0 & 5.40 & 42.0 & 12.0 \\ 5.5 & 0.0 & 9.25 & 60.0 & 12.0\end{array}$

END FTABLE 1 
Table 18.--Input sequence of the woodard Creek model used to run Hydrological Simulation Program-FORTRAN (HSPF)--Continued

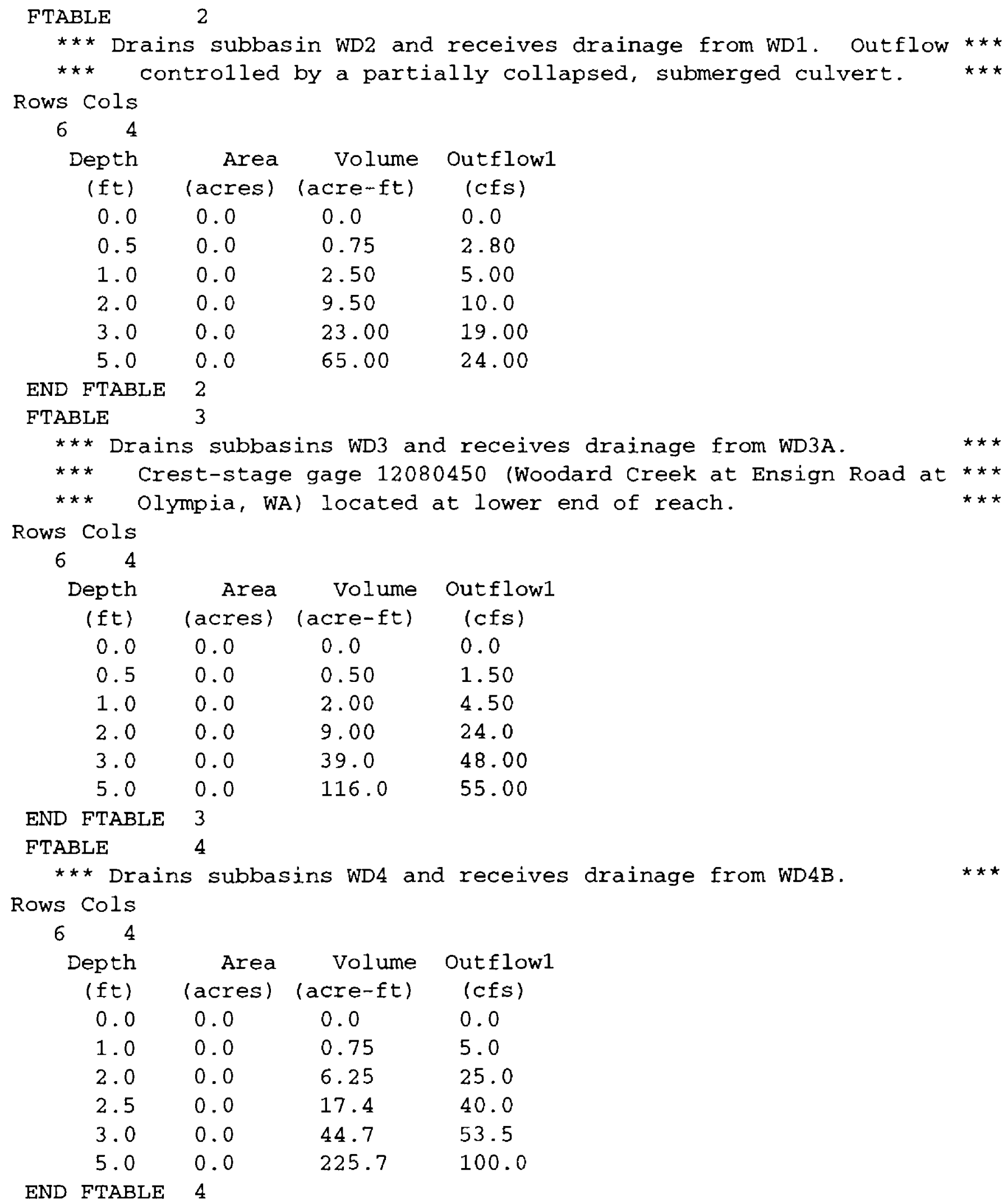


Table 19.--Input sequence of the Woodland Creek mode1 used to run Hydrologicel Simulation Program-FORTRAN (HSPF)

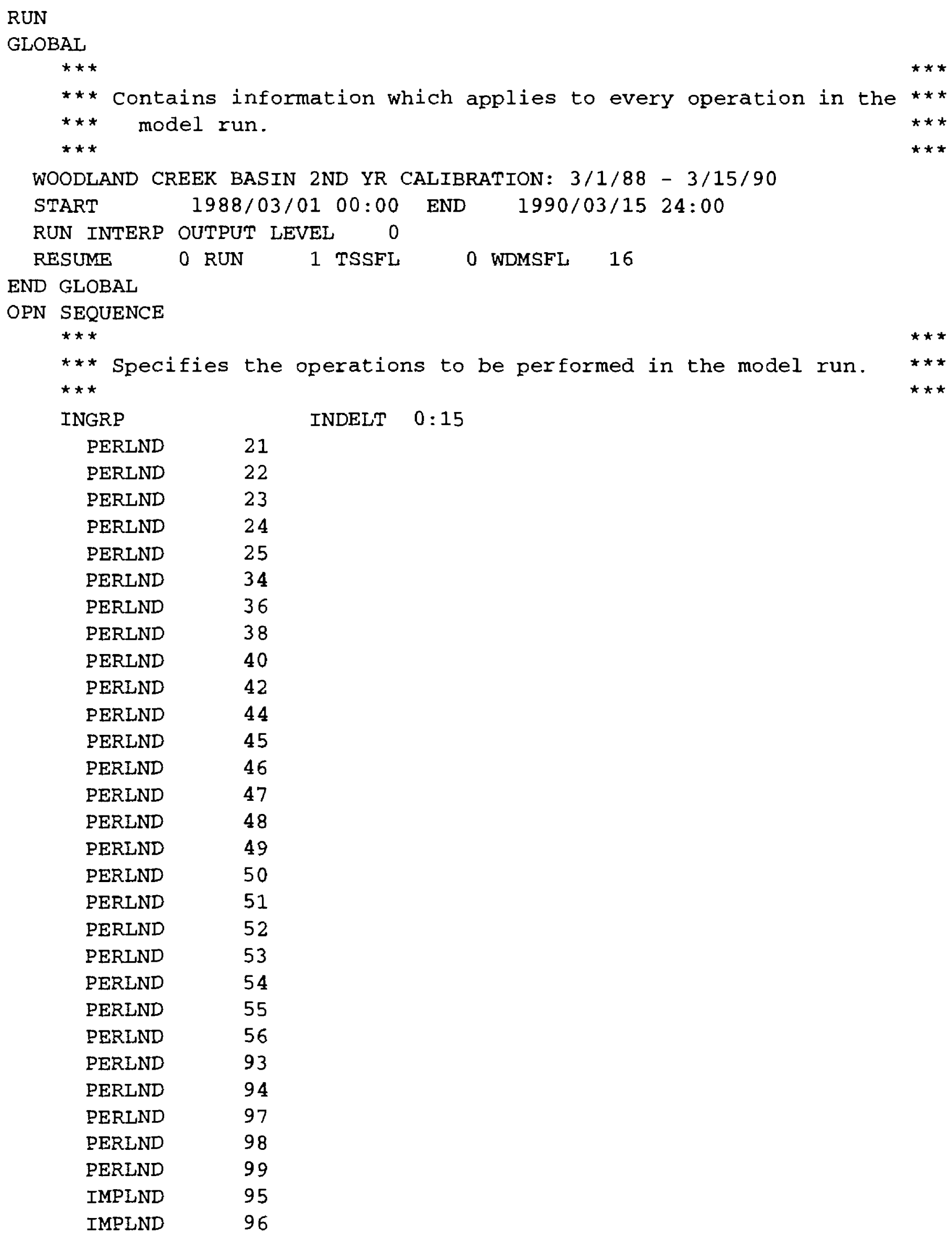


Table 19.--Input sequence of the woodland Creek model used to run Hydrological Simulation Program-FORTRAN (HSPF)--Continued

$\begin{array}{lr}\text { RCHRES } & 2 \\ \text { RCHRES } & 4 \\ \text { RCHRES } & 5 \\ \text { RCHRES } & 50 \\ \text { RCHRES } & 6 \\ \text { RCHRES } & 8 \\ \text { RCHRES } & 9 \\ \text { RCHRES } & 10 \\ \text { RCHRES } & 12 \\ \text { RCHRES } & 13 \\ \text { RCHRES } & 14 \\ \text { RCHRES } & 15 \\ \text { RCHRES } & 17 \\ \text { RCHRES } & 18 \\ \text { RCHRES } & 19 \\ \text { RCHRES } & 20 \\ \text { RCHRES } & 21 \\ \text { RCHRES } & 22 \\ \text { RCHRES } & 23 \\ \text { RCHRES } & 24 \\ \text { RCHRES } & 25 \\ \text { RCHRES } & 26 \\ \text { RCHRES } & 27 \\ \text { DISPLY } & 1 \\ \text { DISPLY } & 2 \\ \text { DISPLY } & 3 \\ \text { DISPLY } & 4 \\ \text { DISPLY } & 5 \\ \text { DISPLY } & 6 \\ \text { DISPLY } & 7 \\ \text { DISPLY } & 8 \\ \text { DISPLY } & 9 \\ \text { DISPLY } & 10 \\ \text { DISPLY } & 11 \\ \text { DISPLY } & 12 \\ \text { DISPLY } & 13 \\ \text { END INGRP } & \\ \text { OPN SEQUENCE } & \\ & \\ \text { OPN } & \\ \end{array}$

END OPN SEQUENCE 
Table 19.--Input sequence of the Woodland Creek model used to run Hydrological Simulation Program-FORTRAN (HSPF)--Continued

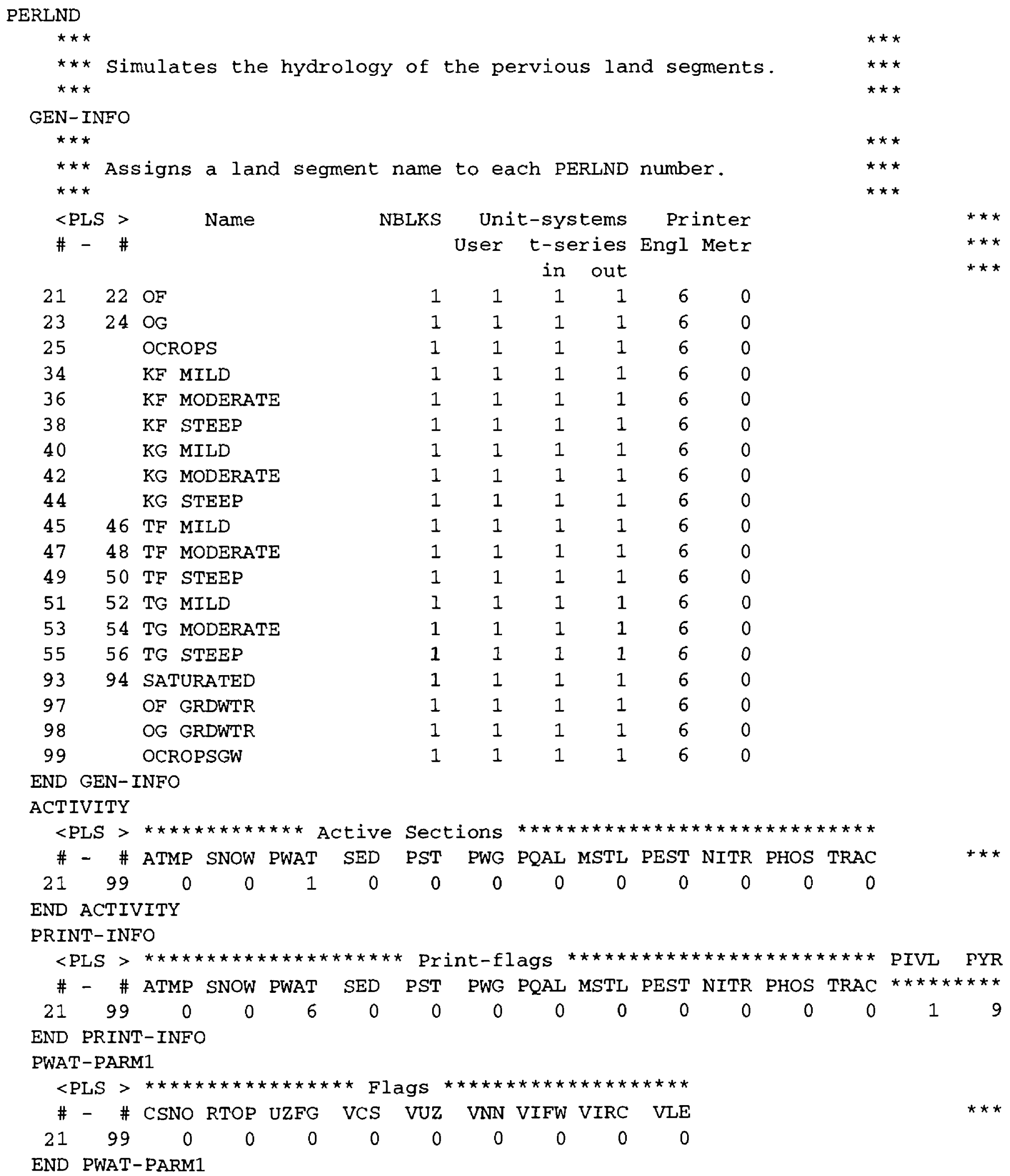


Table 19.--Input sequence of the Woodland Creek model used to run Hydrological Simulation Program-FORTRAN (HSPF)--Continued

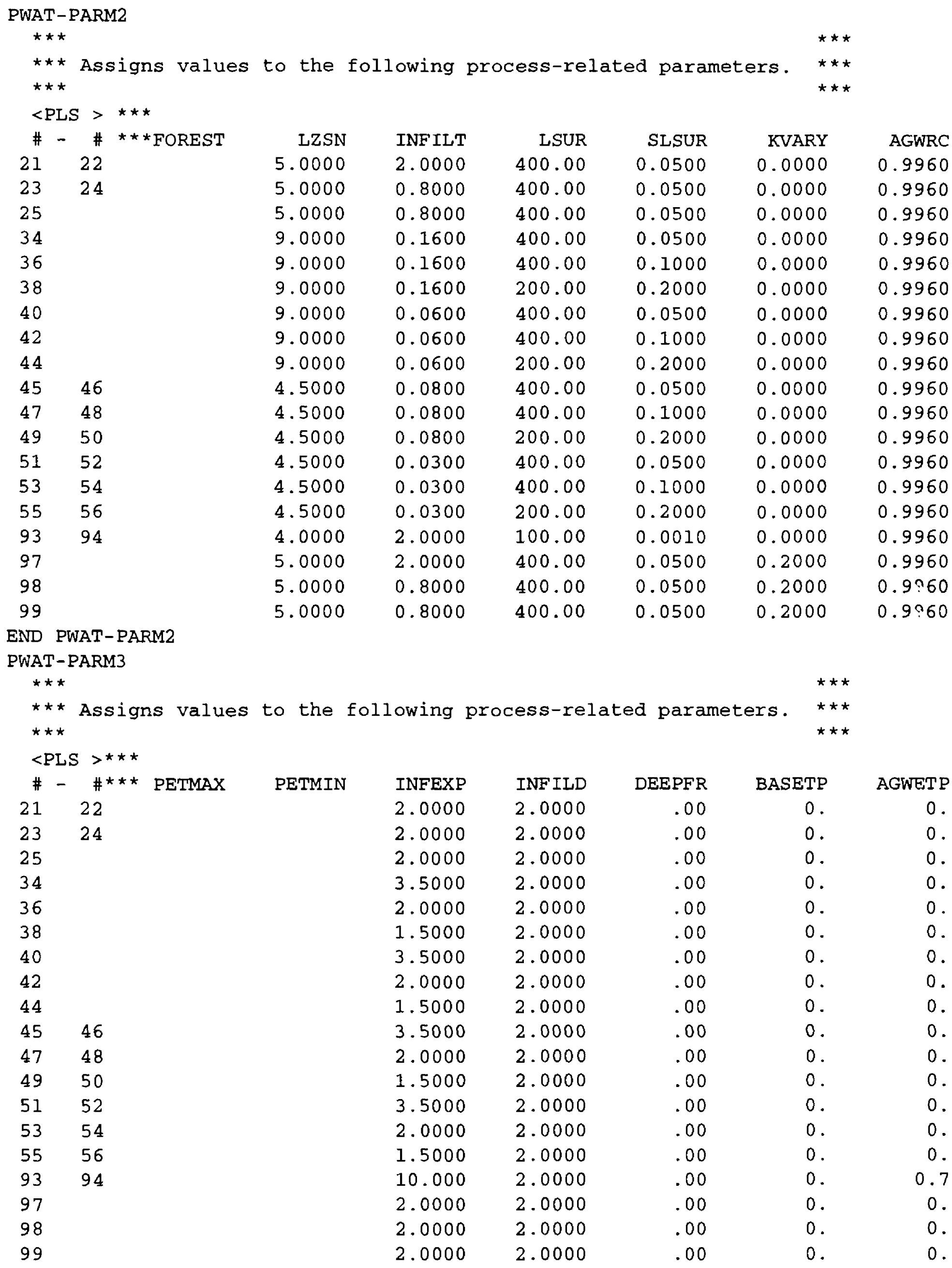

\section{END PWAT-PARM3}


Table 19.--Input sequence of the woodland Creek model used to run Hydrological Simulation Program-FORTRAN (HSPF)--Continued

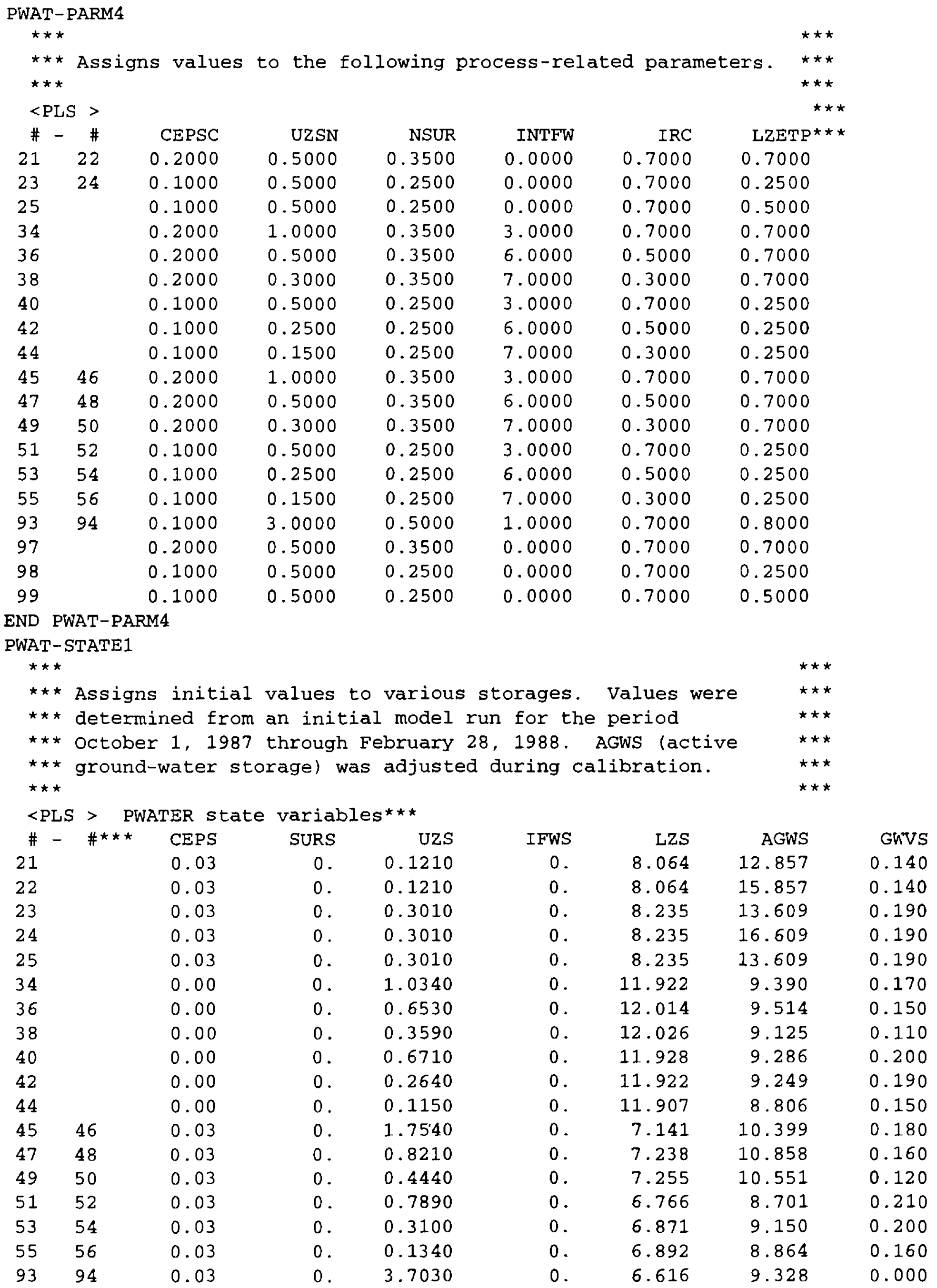


Table 19.-- Input sequence of the Woodland Creek model used to run Hydrological Simulation Program-FORTRAN (HSPF)--Continued

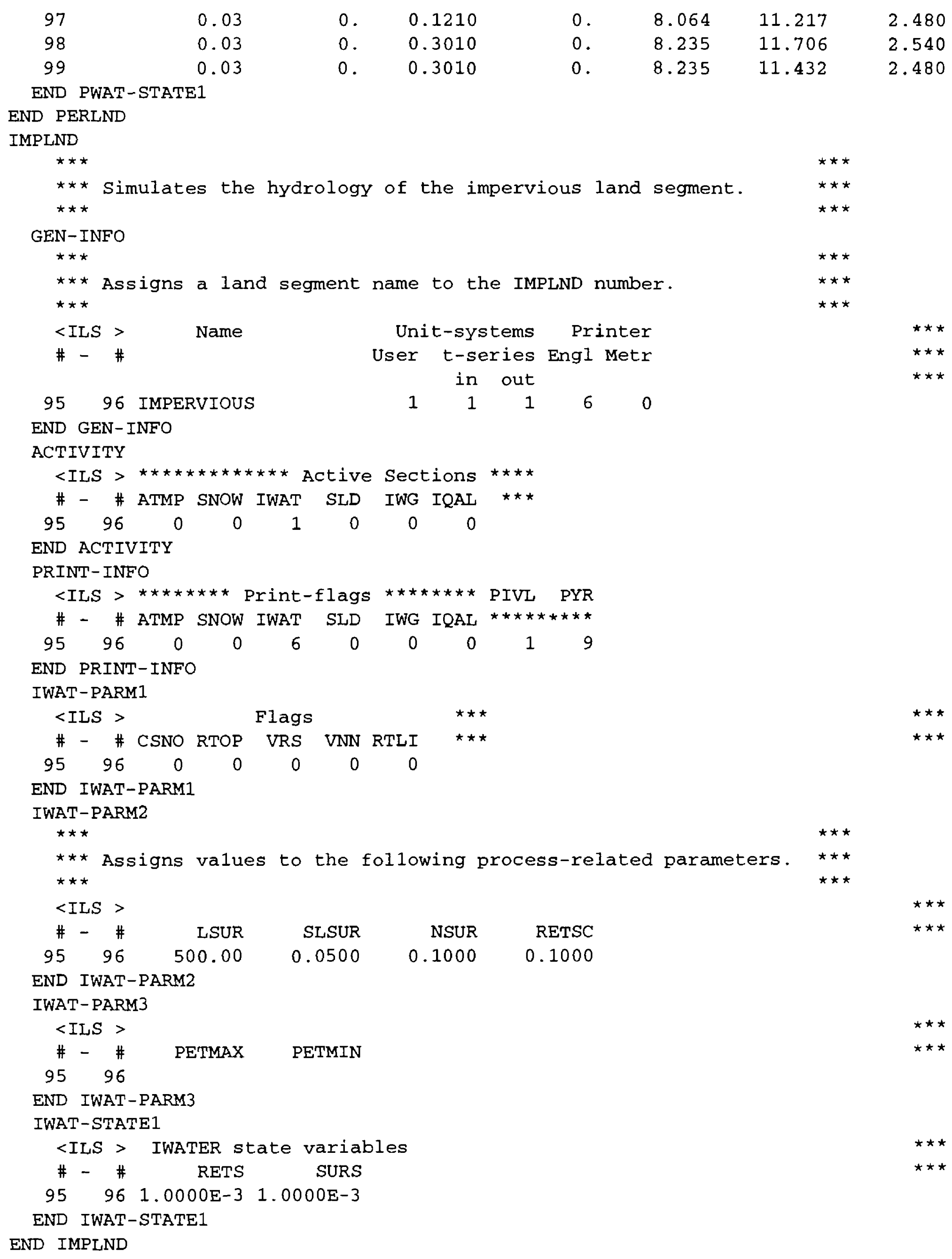


Table 19.--Input sequence of the woodland Creek model used to run Hydrological Simulation Program-FORTRAN (HSPF)--Continued

\section{EXT SOURCES}

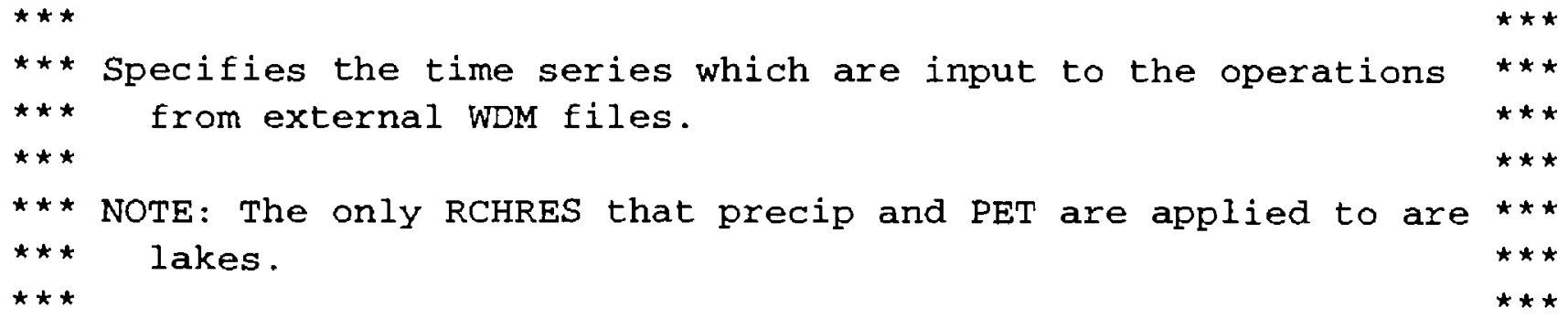

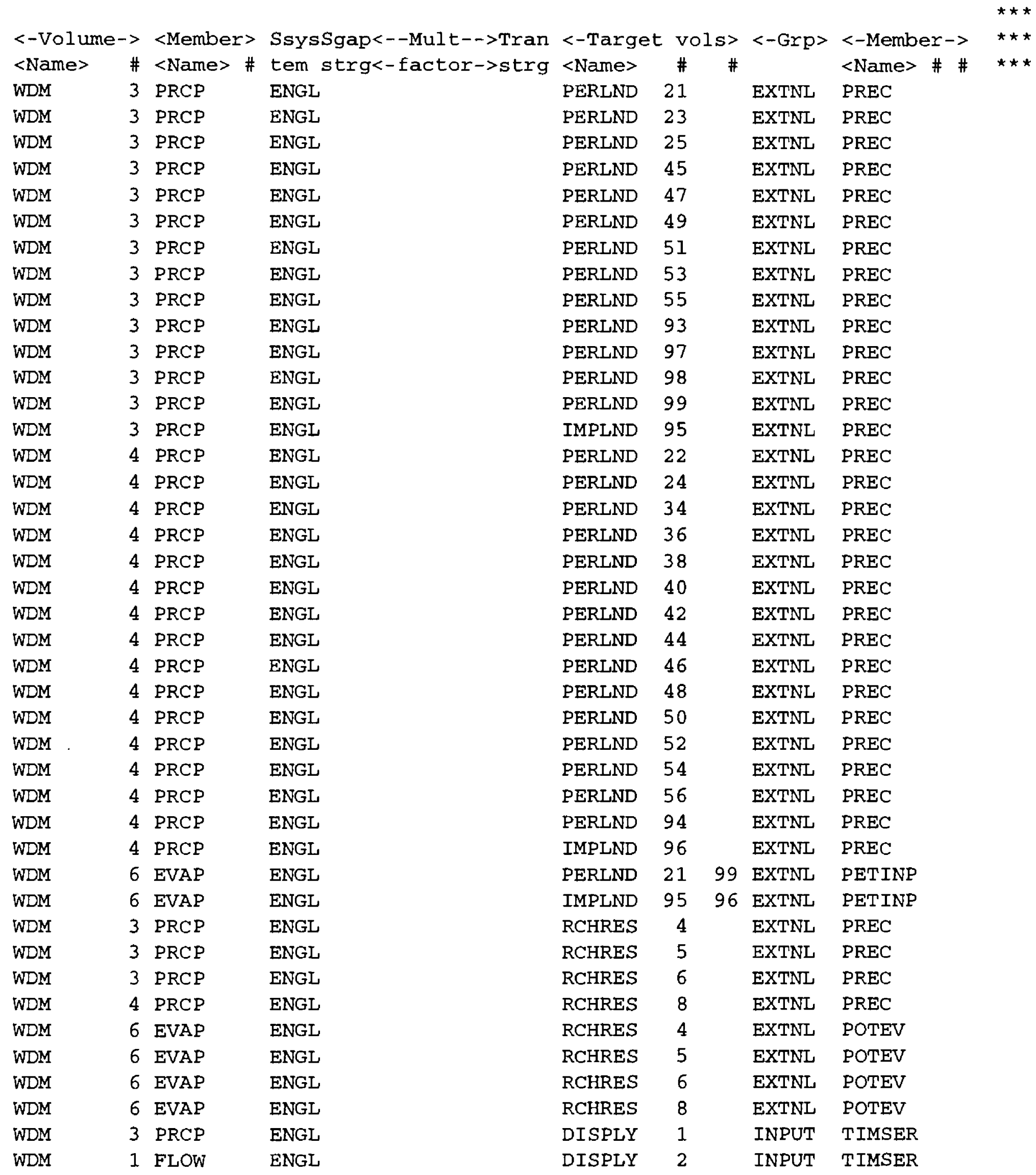


Table 19.--Input sequence of the woodland Creek model used to run Hydrological Simulation Program-FORTRAN (HSPF)--Continued

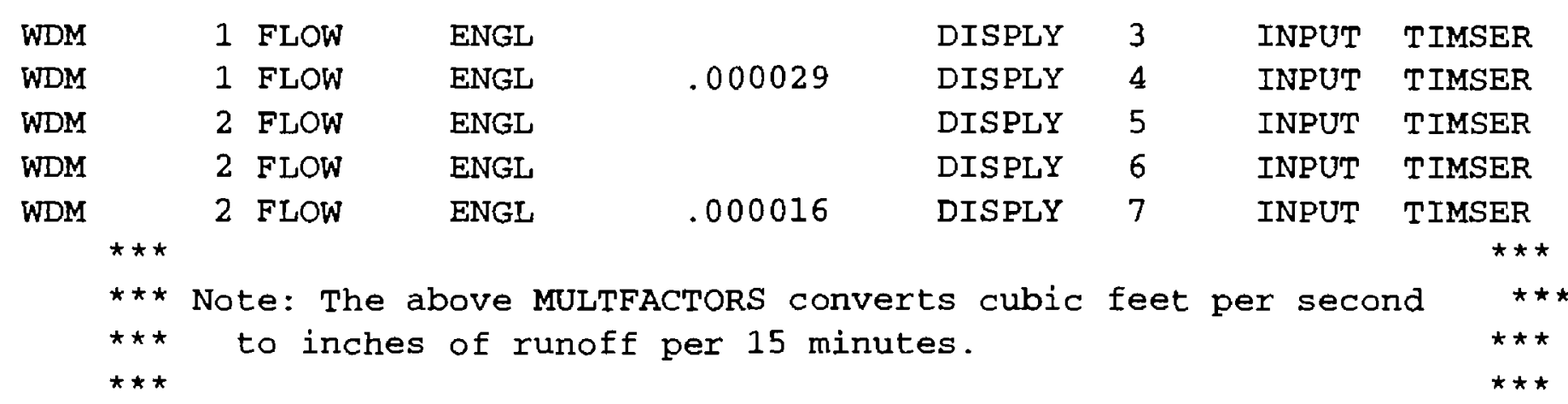

END EXT SOURCES

EXT TARGETS

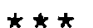

$\star \star \star$ Specifies the time series which are output from operations

$\star \star \star$ to external WDM files.

$\star \star \star$ Note: MULTFACTOR 48.4 converts acre-feet of runoff per

$\star \star \star \quad 15$-minute interval to cubic feet per second.

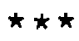

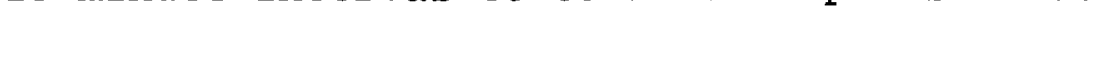


Table 19.--Input sequence of the woodland Creek model used to run Hydrological Simulation Program-FORTRAN (HSPF)--Continued

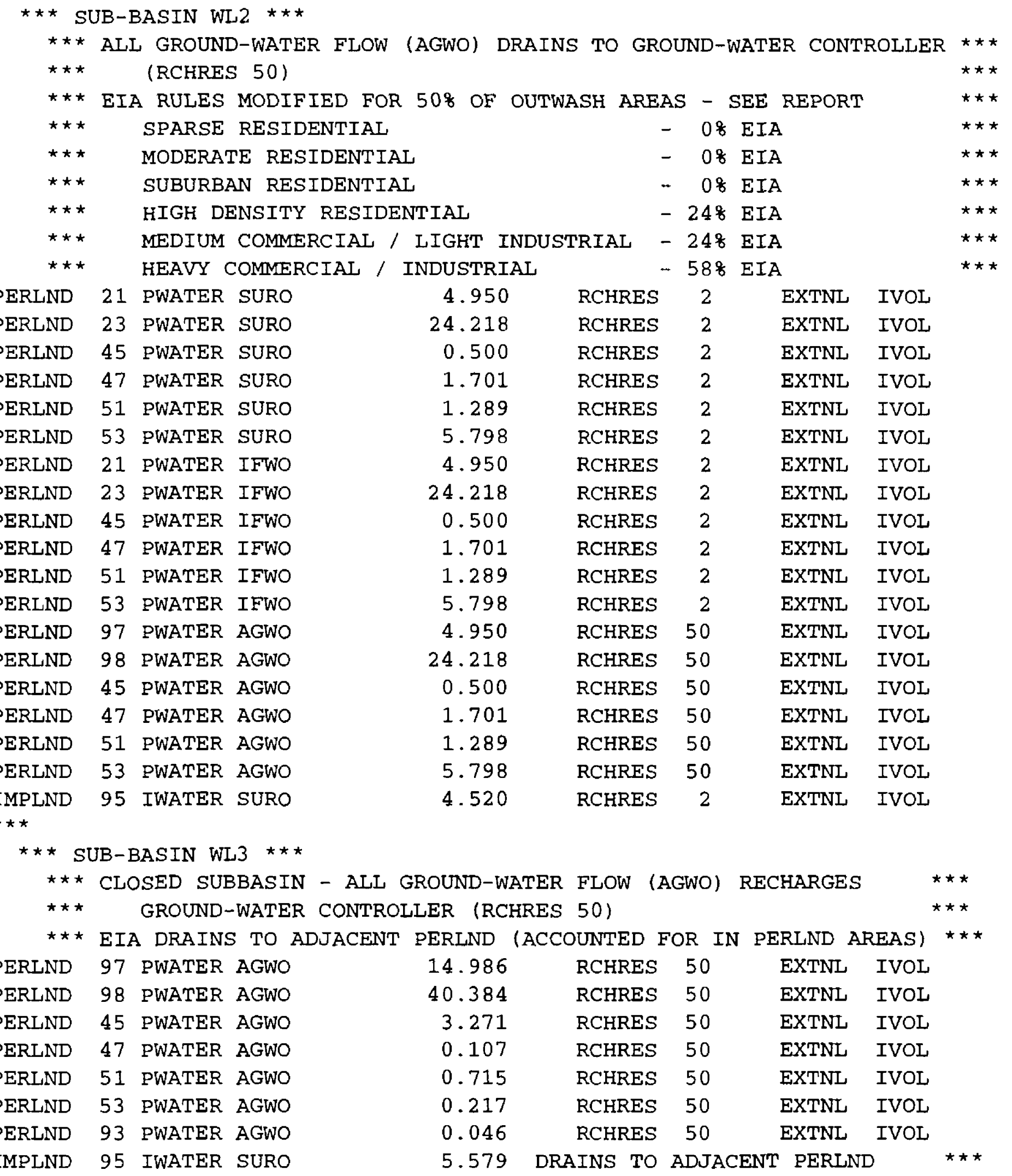


Table 19.--Input sequence of the woodland creek model used to run Hydrological Simulation Program-FORTRAN (HSPF)--Continued

\begin{tabular}{|c|c|c|c|c|c|c|c|c|c|}
\hline$\star \star \star$ & ALL & GROUND & -WATER & FLOW & (AGWO) DIS & RGES AT & RCHRES & 5 & \multirow[b]{2}{*}{ IVOL } \\
\hline PERLND & 21 & PWATER & SURO & & 20.003 & RCHRES & 4 & EXTNL & \\
\hline PERLND & 23 & PWATER & SURO & & 14.672 & RCHRES & 4 & EXTNL & IVOL \\
\hline PERLND & 47 & PWATER & SURO & & 0.546 & RCHRES & 4 & EXTNL & IVOL \\
\hline PERLND & 53 & PWATER & SURO & & 1.354 & RCHRES & 4 & EXTNL & IVOL \\
\hline PERLND & 93 & PWATER & SURO & & 14.835 & RCHRES & 4 & EXTNL & IVOL \\
\hline PERLND & 21 & PWATER & IFWO & & 20.003 & RCHRES & 4 & EXTNL & IVOL \\
\hline PERLND & 23 & PWATER & IFWO & & 14.672 & RCHRES & 4 & EXTNL & IVOL \\
\hline PERLND & 47 & PWATER & IFWO & & 0.546 & RCHRES & 4 & EXTNL & IVOL \\
\hline PERLND & 53 & PWATER & IFWO & & 1.354 & RCHRES & 4 & EXTNL & IVOL \\
\hline PERLND & 93 & PWATER & IFWO & & 14.835 & RCHRES & 4 & EXTNL & IVOL \\
\hline PERLND & 21 & PWATER & AGWO & & 20.003 & RCHRES & 5 & EXTNL & IVOL \\
\hline PERLND & 23 & PWATER & AGWO & & 14.672 & RCHRES & 5 & EXTNL & IVOL \\
\hline PERLND & 47 & PWATER & AGWO & & 0.546 & RCHRES & 5 & EXTNL & IVOL \\
\hline PERLND & 53 & PWATER & AGWO & & 1.354 & RCHRES & 5 & EXTNL & IVOL \\
\hline PERLND & 93 & PWATER & AGWO & & 14.835 & RCHRES & 5 & EXTNL & IVOL \\
\hline $\begin{array}{l}\text { IMPLND } \\
\star \star \star\end{array}$ & 95 & IWATER & SURO & & 4.531 & RCHRES & 4 & EXTNL & IVOL \\
\hline$\star \star \star \star$ & $\mathrm{UB}-1$ & BASIN WI & 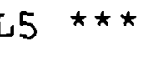 & & & & & & \\
\hline PERLND & 21 & PWATER & SURO & & 23.923 & RCHRES & 5 & EXTNL & IVOL \\
\hline PERLND & 23 & PWATER & SURO & & 25.544 & RCHRES & 5 & EXTNL & IVOL \\
\hline PERLND & 53 & PWATER & SURO & & 0.204 & RCHRES & 5 & EXTNL & IVOL \\
\hline PERLND & 93 & PWATER & SURO & & 8.590 & RCHRES & 5 & EXTNL & IVOL \\
\hline PERLND & 21 & PWATER & IFWO & & 23.923 & RCHRES & 5 & EXTNL & IVOL \\
\hline PERLND & 23 & PWATER & IFWO & & 25.544 & RCHRES & 5 & EXTNL & IVOL \\
\hline PERLND & 53 & PWATER & IFWO & & 0.204 & RCHRES & 5 & EXTNL & IVOL \\
\hline PERLND & 93 & PWATER & IFWO & & 8.590 & RCHRES & 5 & EXTNL & IVOL \\
\hline PERLND & 21 & PWATER & AGWO & & 23.923 & RCHRES & 5 & EXTNL & IVOL \\
\hline PERLND & 23 & PWATER & AGWO & & 25.544 & RCHRES & 5 & EXTNL & IVOL \\
\hline PERLND & 53 & PWATER & AGWO & & 0.204 & RCHRES & 5 & EXTNL & IVOL \\
\hline PERLND & 93 & PWATER & AGWO & & 8.590 & RCHRES & 5 & EXTNL & IVOL \\
\hline IMPLND & 95 & IWATER & SURO & & 6.131 & RCHRES & 5 & EXTNL & IVOL \\
\hline
\end{tabular}


Table 19.--Input sequence of the woodland creek model used to run Hydrological Simulation Program-FORTRAN (HSPF)--Continued

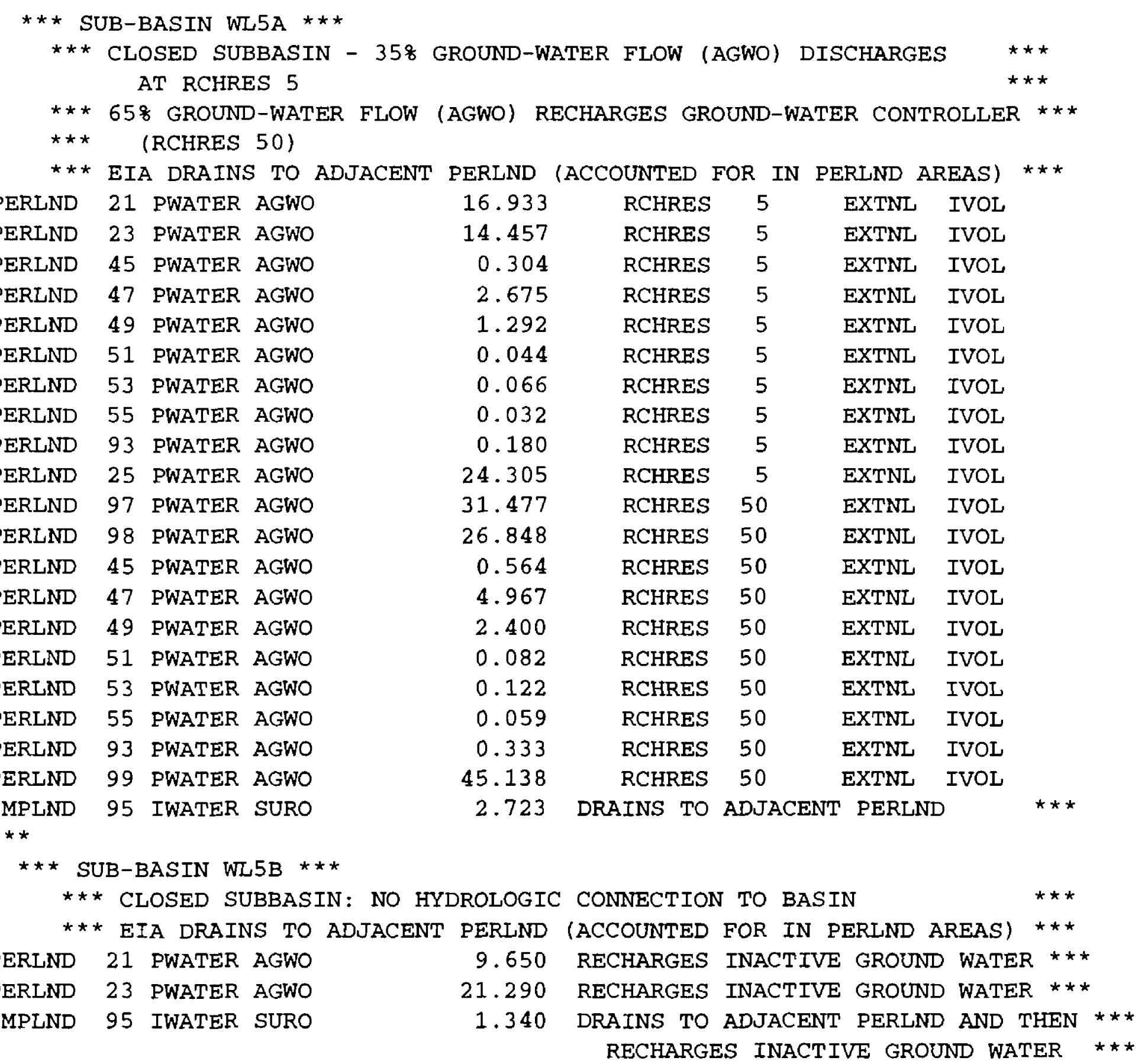


Table 19.--Input sequence of the woodland Creek model used to run Hydrological Simulation Program-FORTRAN (HSPF)--Continued

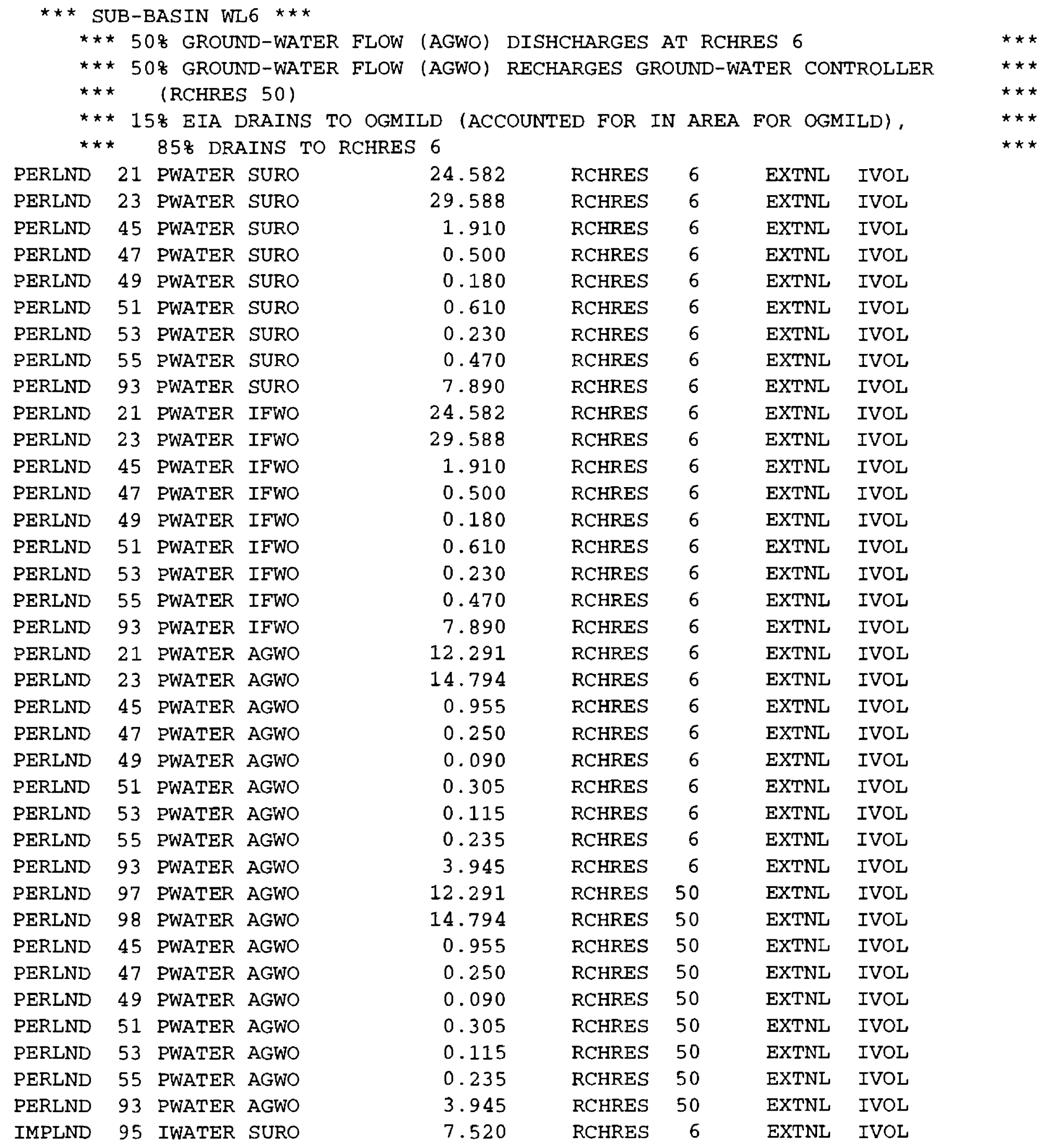


Table 19.--Input sequence of the Woodland Creek model used to run Hydrological Simulation Program-FORTRAN (HSPF)--Continued

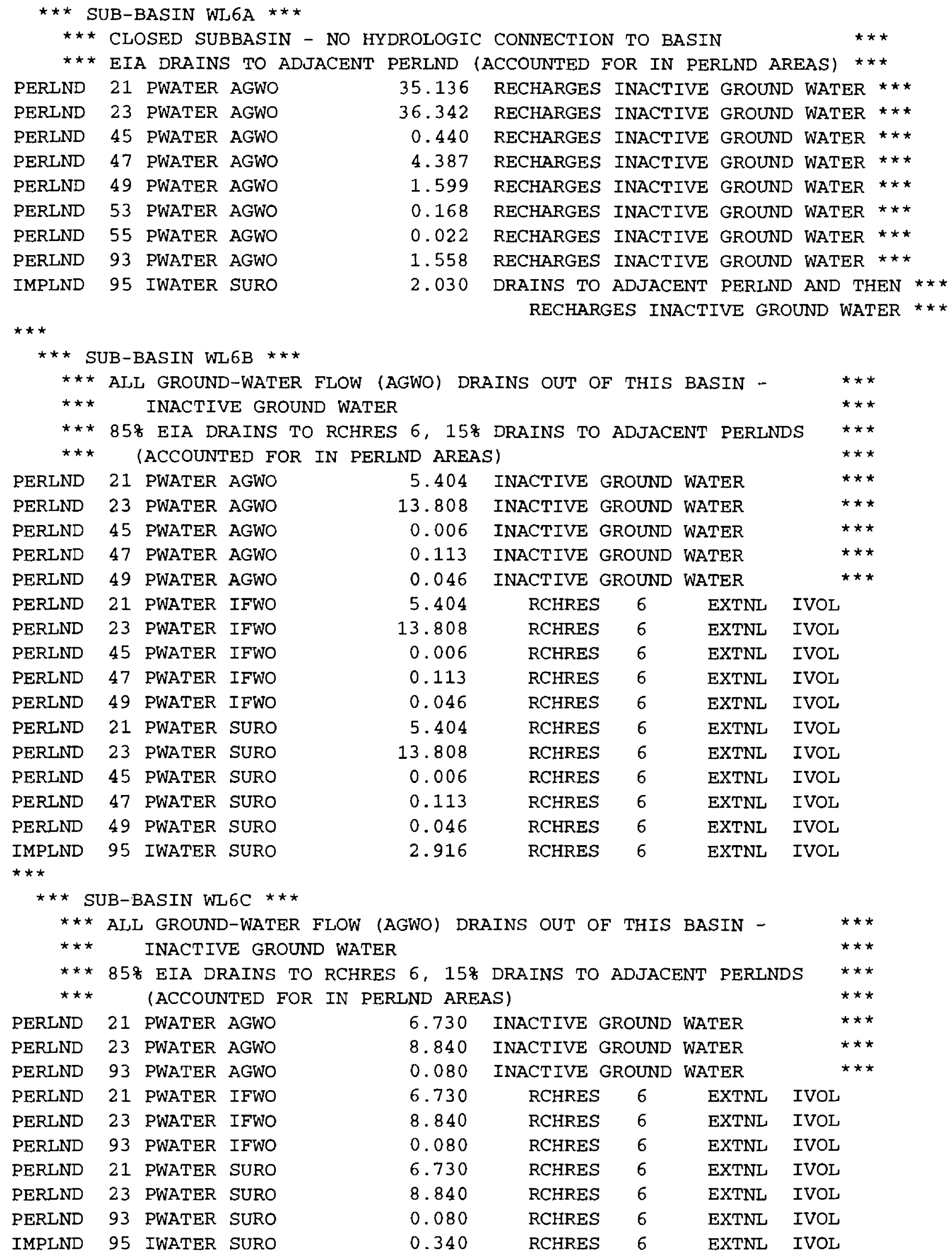


Table 19.--Input sequence of the Woodland Creek model used to run Hydrological Simulation Program-FORTRAN (HSPF)--Continued

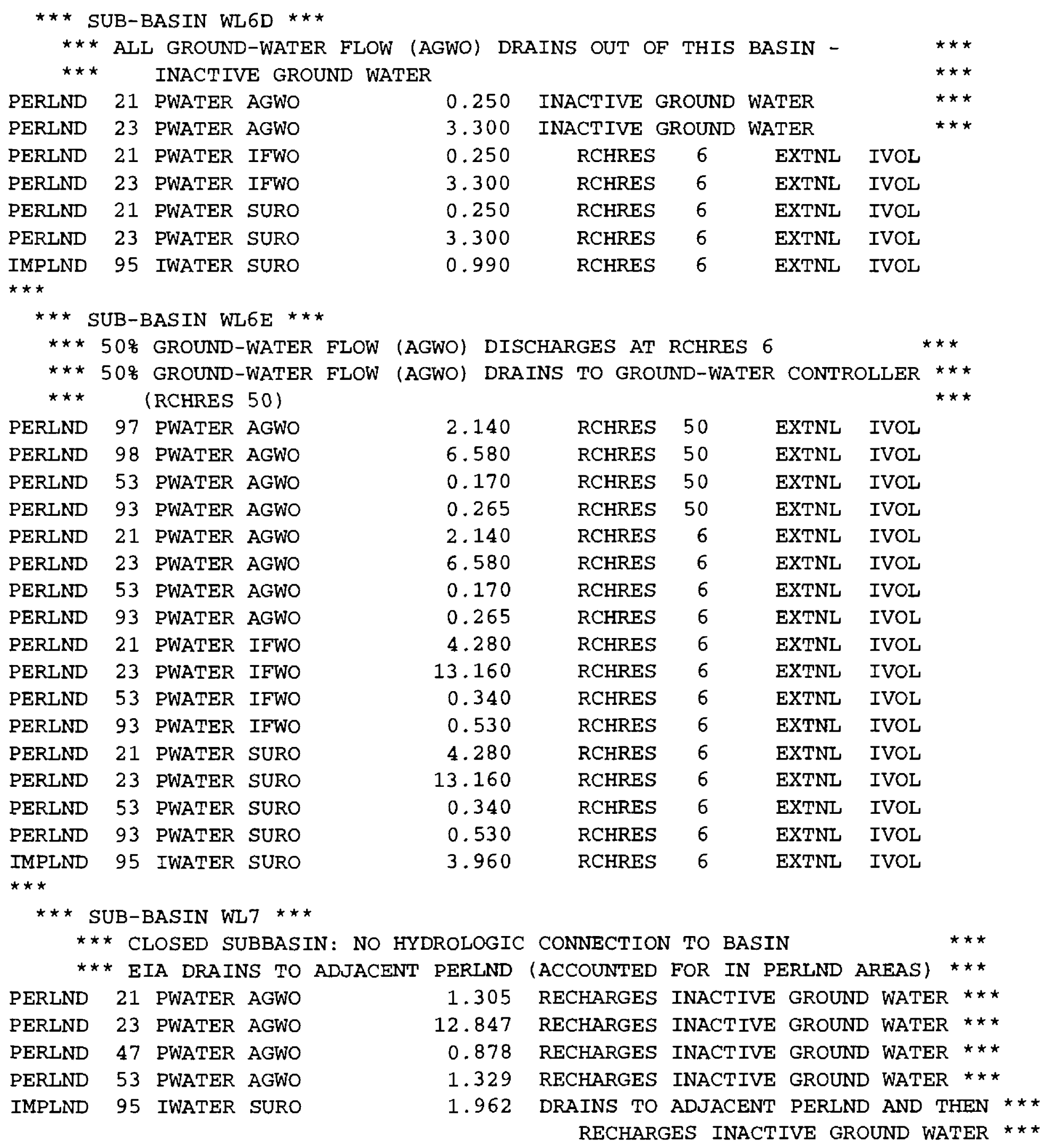


Table 19.--Input sequence of the woodland Creek model used to run Hydrological Simulation Program-FORTRAN (HSPF)--Continued

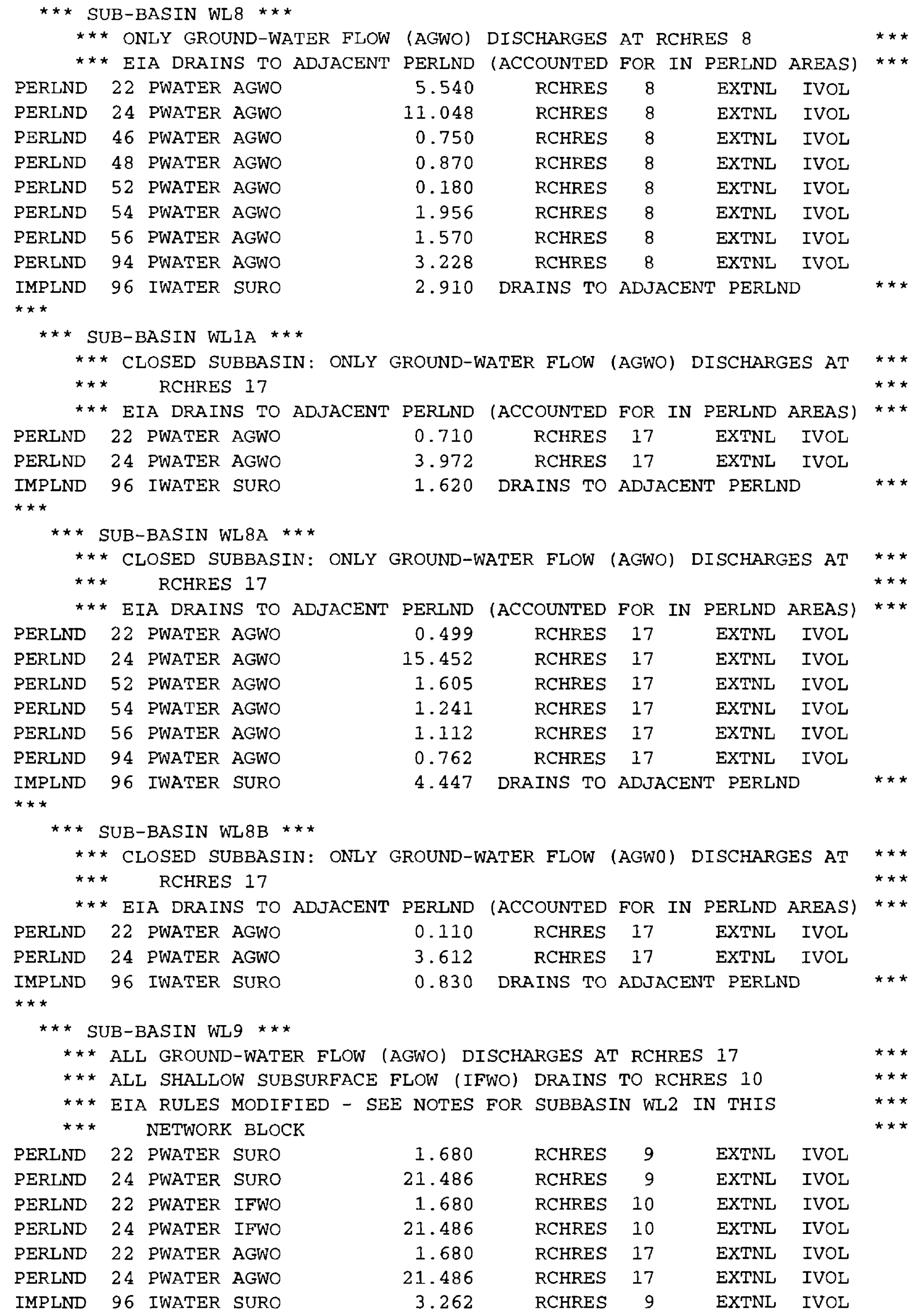


Tab1e 19.--Input sequence of the woodland creek model used to run Hydrological Simulation Program-FORTRAN (HSPF)--Continued

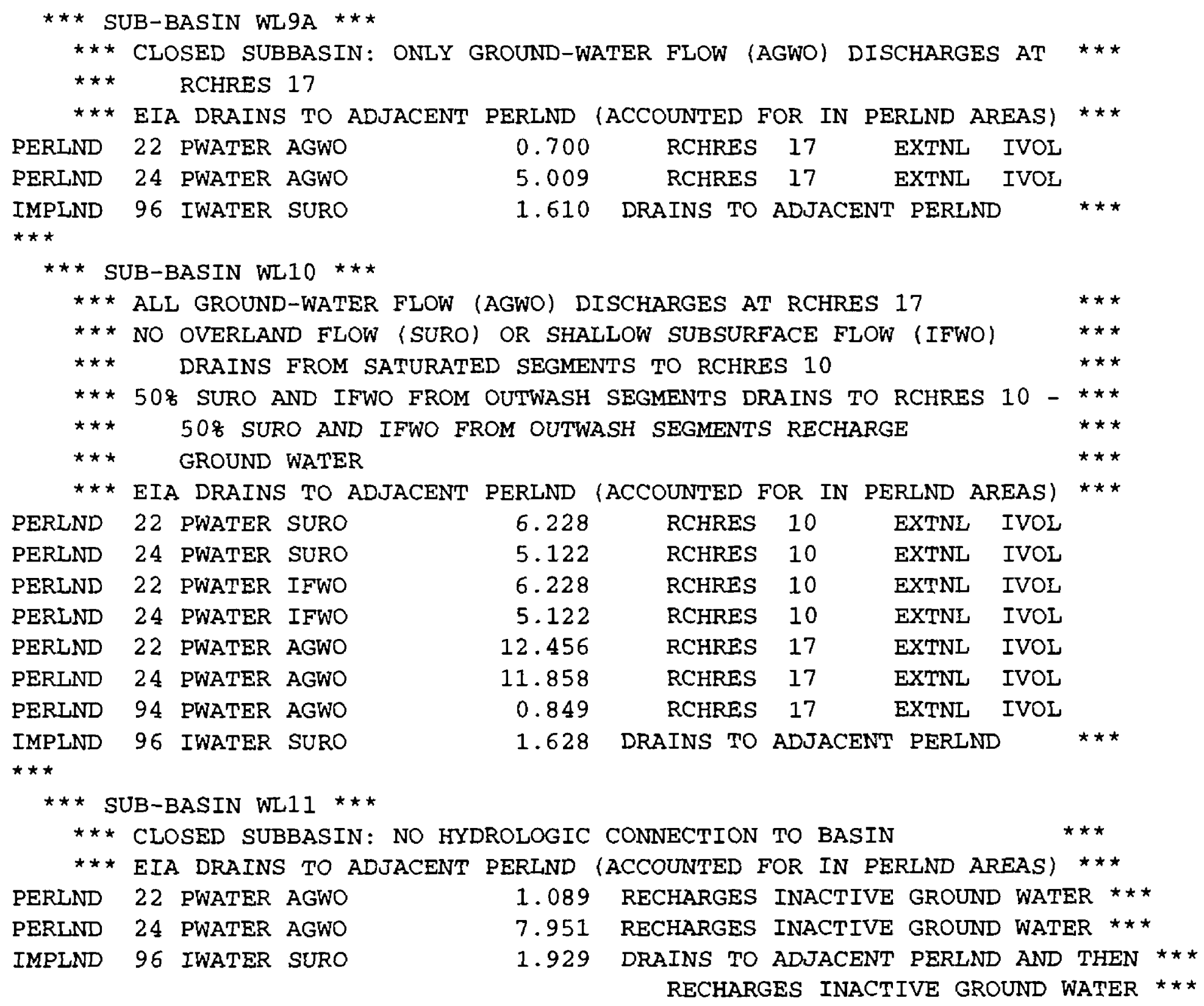


Table 19.--Input sequence of the woodland Creek model used to run Hydrological Simulation Program-FORTRAN (HSPF)--Continued

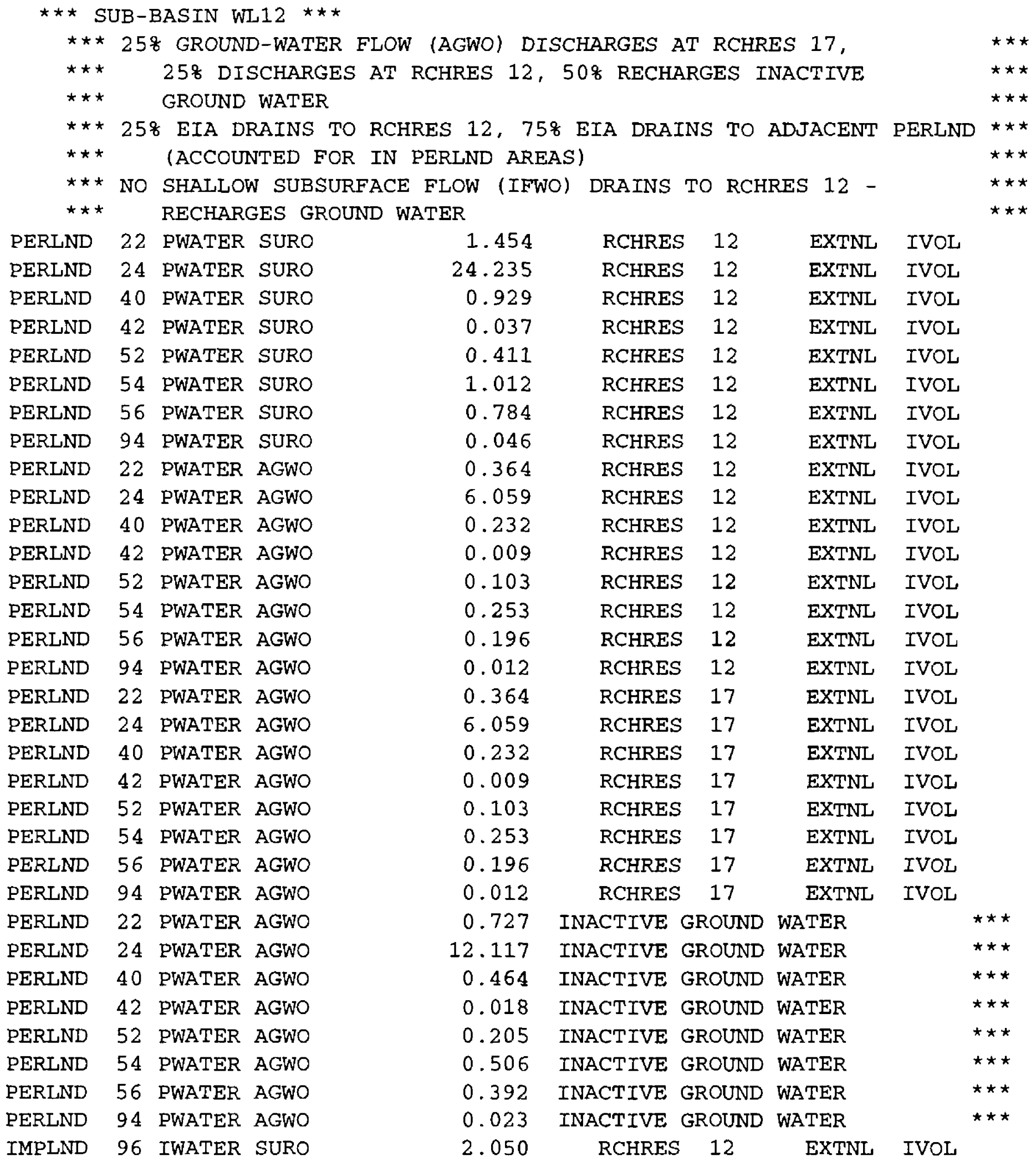


Table 19.--Input sequence of the woodland Creek model used to run Hydrological Simulation Program-FORTRAN (HSPF)--Continued

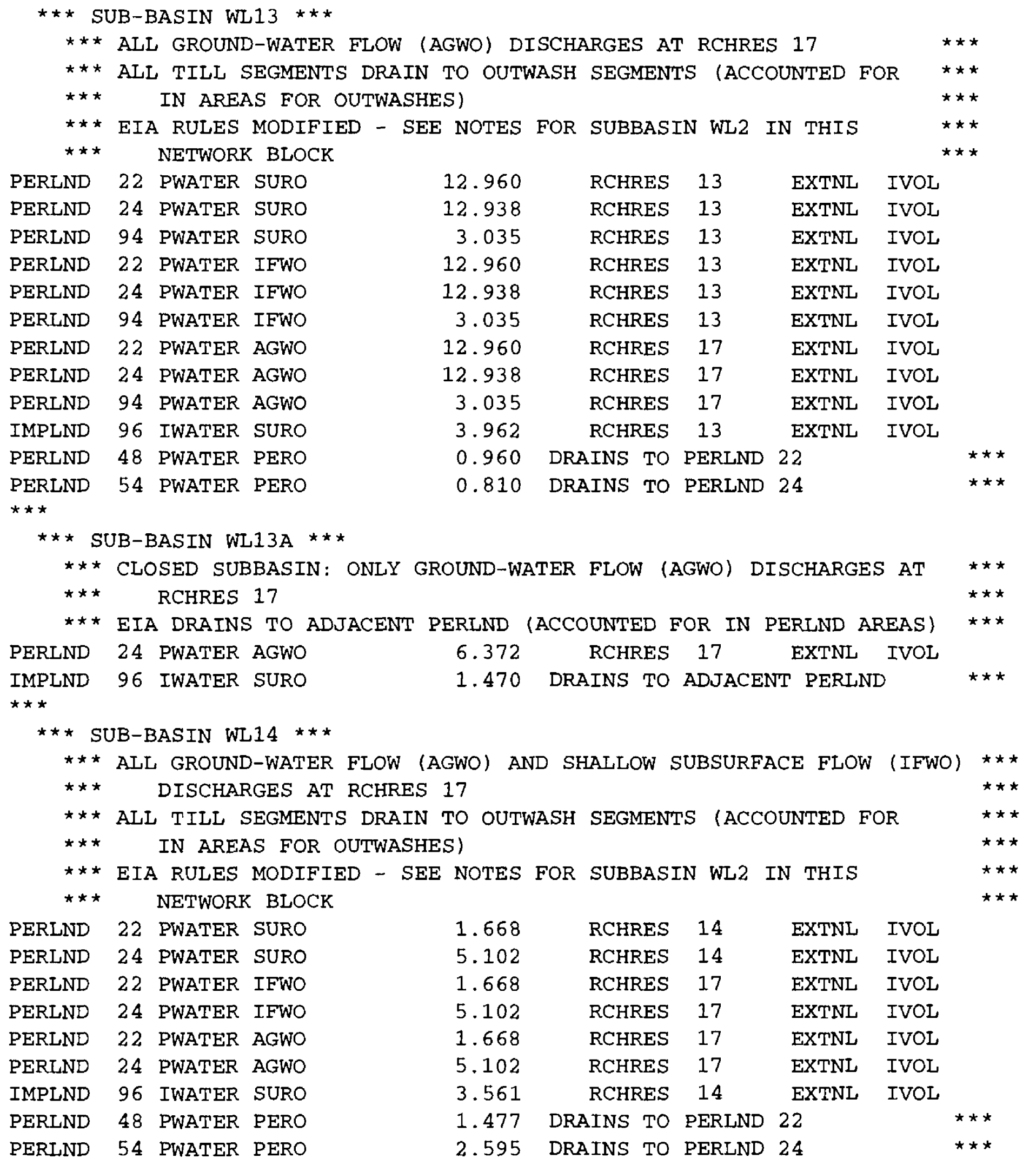


Table 19.--Input sequence of the woodland creek model used to run Hydrological Simulation Program-FORTRAN (HSPF)--Continued

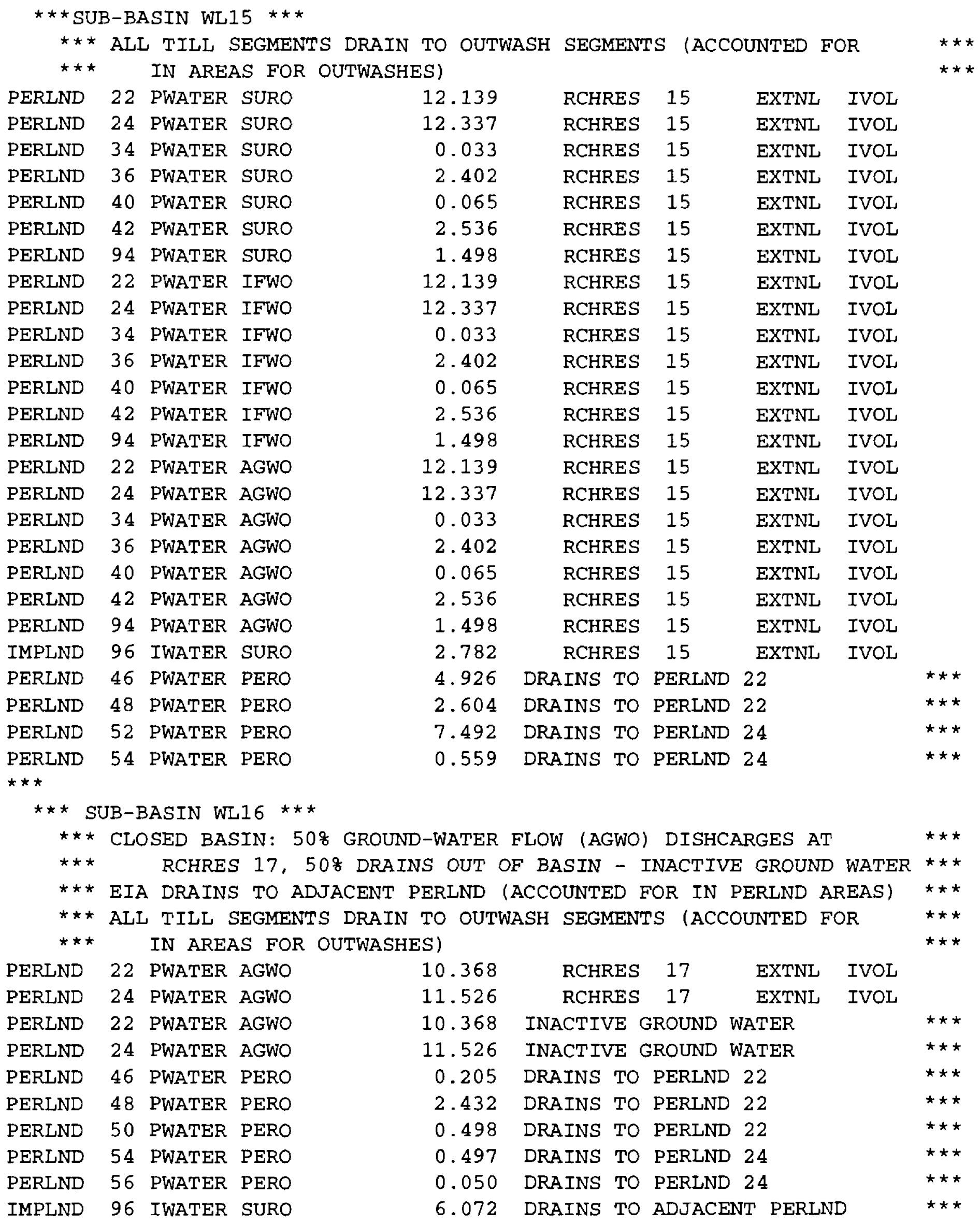


Table 19.--Input sequence of the woodland Creek model used to run Hydrological Simulation Program-FORTRAN (HSPF)--Continued

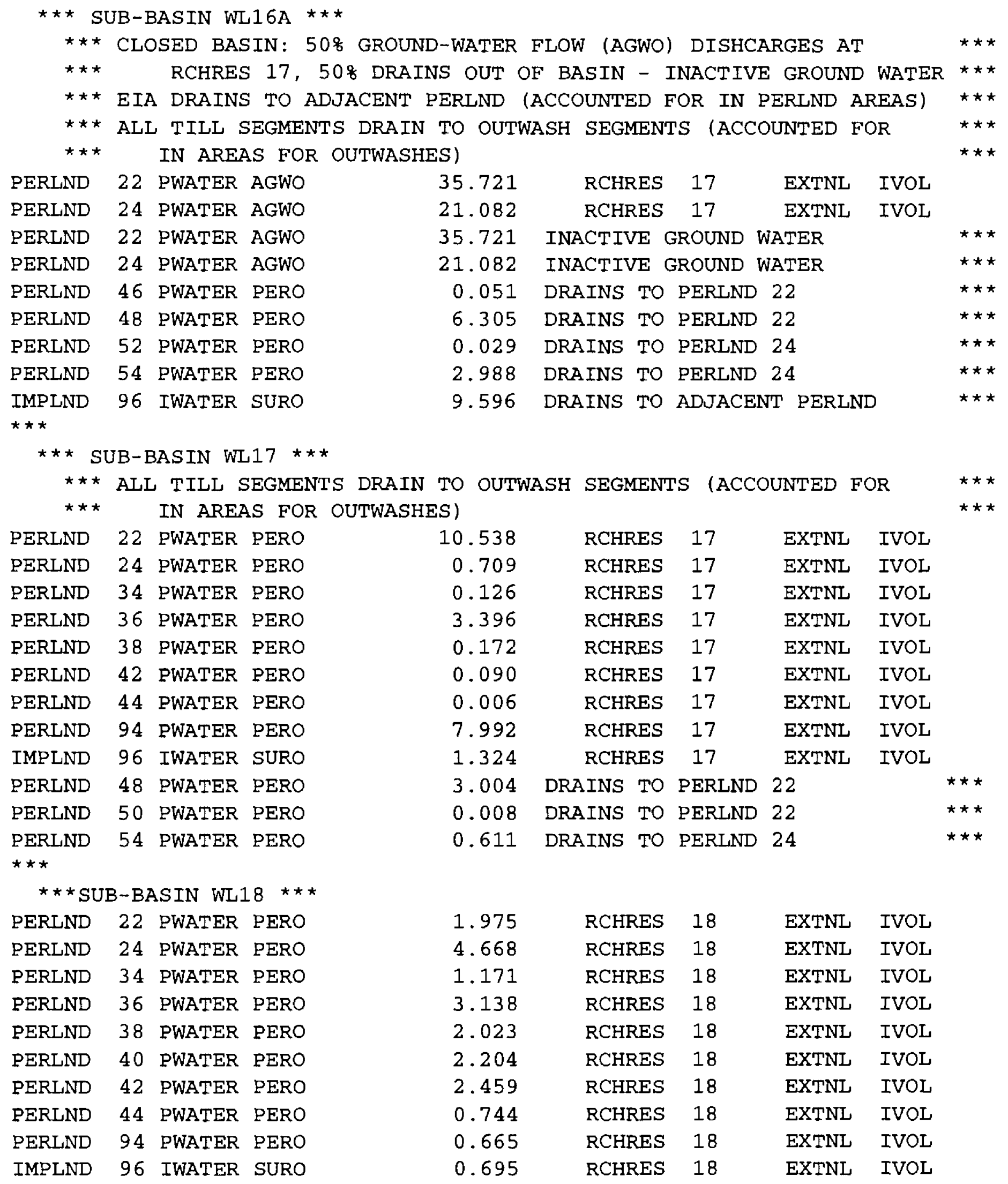


Table 19.--Input sequence of the woodland Creek model used to run Hydrological Simulation Program-FORTRAN (HSPF)--Continued

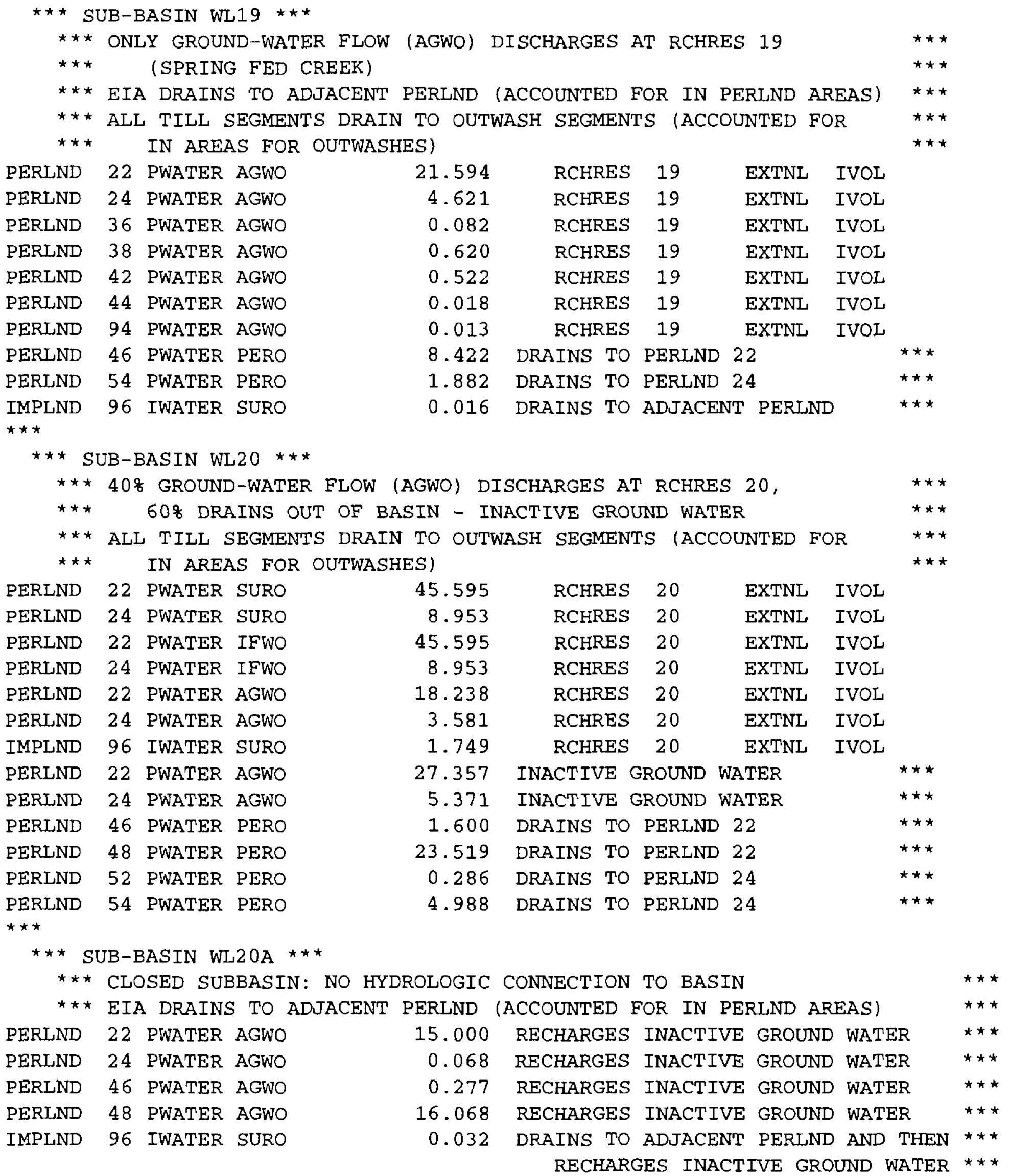


Table 19.--Input sequence of the woodland Creek model used to run Hydrological Simulation Program-FORTRAN (HSPF)--Continued

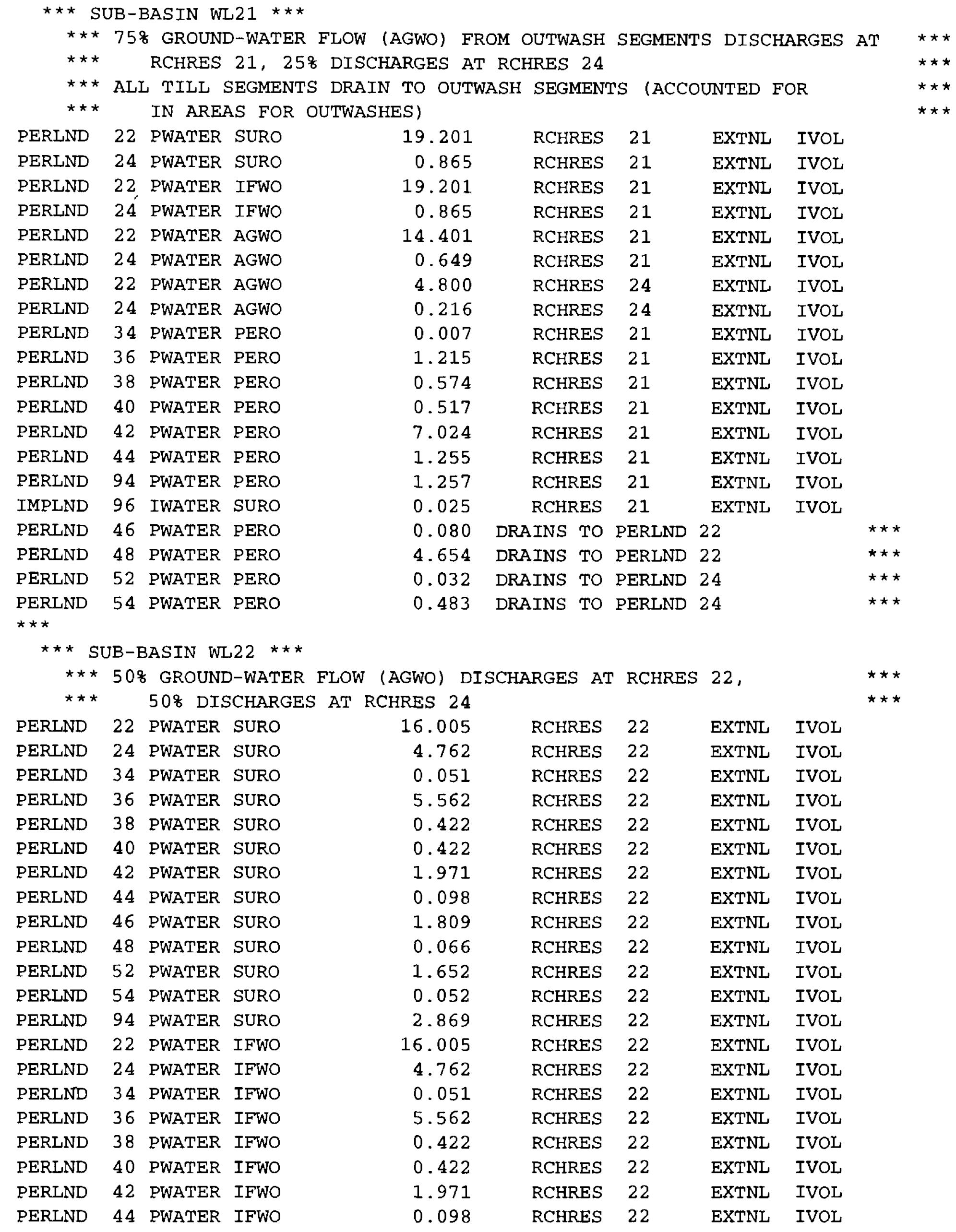


Table 19.--Input sequence of the Woodland Creek model used to run Hydrological Simulation Program-FORTRAN (HSPF)--Continued

\begin{tabular}{|c|c|c|c|c|c|c|c|c|c|}
\hline PERLND & 46 & PWATER & IFWO & 1.809 & RCHRES & 22 & EXTNL & IVOL & \\
\hline PERLND & 48 & PWATER & IFWO & 0.066 & RCHRES & 22 & EXTNL & IVOL & \\
\hline PERLND & 52 & PWATER & IFWO & 1.652 & RCHRES & 22 & EXTNL & IVOL & \\
\hline PERLND & 54 & PWATER & IFWO & 0.052 & RCHRES & 22 & EXTNL & IVOL & \\
\hline PERLND & 94 & PWATER & IFWO & 2.869 & RCHRES & 22 & EXTNL & IVOL & \\
\hline PERLND & 22 & PWATER & AGWO & 8.003 & RCHRES & 22 & EXTNL & IVOL & \\
\hline PERLND & 24 & PWATER & AGWO & 2.381 & RCHRES & 22 & EXTNL & IVOL & \\
\hline PERLND & 34 & PWATER & AGWO & 0.026 & RCHRES & 22 & EXTNL & IVOL & \\
\hline PERLND & 36 & PWATER & AGWO & 2.781 & RCHRES & 22 & EXTNL & IVOL & \\
\hline PERLND & 38 & PWATER & AGWO & 0.211 & RCHRES & 22 & EXTNL & IVOL & \\
\hline PERLND & 40 & PWATER & AGWO & 0.211 & RCHRES & 22 & EXTNL & IVOL & \\
\hline PERLND & 42 & PWATER & AGWO & 0.986 & RCHRES & 22 & EXTNL & IVOL & \\
\hline PERLND & 44 & PWATER & AGWO & 0.049 & RCHRES & 22 & EXTNL & IVOL & \\
\hline PERLND & 46 & PWATER & AGWO & 0.905 & RCHRES & 22 & EXTNL & IVOL & \\
\hline PERLND & 48 & PWATER & AGWO & 0.033 & RCHRES & 22 & EXTNL & IVOL & \\
\hline PERLND & 52 & PWATER & AGWO & 0.826 & RCHRES & 22 & EXTNL & IVOL & \\
\hline PERLND & 54 & PWATER & AGWO & 0.026 & RCHRES & 22 & EXTNL & IVOL & \\
\hline PERLND & 94 & PWATER & AGWO & 1.434 & RCHRES & 22 & EXTNL & IVOL & \\
\hline PERLND & 22 & PWATER & AGWO & 8.003 & RCHRES & 24 & EXTNL & IVOL & \\
\hline PERLND & 24 & PWATER & AGWO & 2.381 & RCHRES & 24 & EXTNL & IVOL & \\
\hline PERLND & 34 & PWATER & AGWO & 0.026 & RCHRES & 24 & EXTNL & IVOL & \\
\hline PERLND & 36 & PWATER & AGWO & 2.781 & RCHRES & 24 & EXTNL & IVOL & \\
\hline PERLND & 38 & PWATER & AGWO & 0.211 & RCHRES & 24 & EXTNL & IVOL & \\
\hline PERLND & 40 & PWATER & AGWO & 0.211 & RCHRES & 24 & EXTNL & IVOL & \\
\hline PERLND & 42 & PWATER & AGWO & 0.986 & RCHRES & 24 & EXTNL & IVOL & \\
\hline PERLND & 44 & PWATER & AGWO & 0.049 & RCHRES & 24 & EXTNL & IVOL & \\
\hline PERLND & 46 & PWATER & AGWO & 0.905 & RCHRES & 24 & EXTNL & IVOL & \\
\hline PERLND & 48 & PWATER & AGWO & 0.033 & RCHRES & 24 & EXTNL & IVOL & \\
\hline PERLND & 52 & PWATER & AGWO & 0.826 & RCHRES & 24 & EXTNL & IVOL & \\
\hline PERLND & 54 & PWATER & AGWO & 0.026 & RCHRES & 24 & EXTNL & IVOL & \\
\hline PERLND & 94 & PWATER & AGWO & 1.435 & RCHRES & 24 & EXTNL & IVOL & \\
\hline $\begin{array}{l}\text { IMPLND } \\
\star \star \star\end{array}$ & 96 & IWATER & SURO & 1.930 & RCHRES & 22 & EXTNL & IVOL & \\
\hline & \multicolumn{8}{|c|}{$\star \star \star$ SUB-BASIN WL22A $\star \star \star \star ~$} & $\star \star \star$ \\
\hline$\star \star \star$ & EIA & A DRAIN & S TO ADJACENT & PERLND & (ACCOUNTED F & POR IN PE & ERLND ARE & EAS ) & $\star \star \star$ \\
\hline PERLND & 46 & PWATER & AGWO & 2.140 & RECHARGES & INACTIVE & GROUND & WATER & $\star \star \star$ \\
\hline PERLND & 52 & PWATER & AGWO & 1.108 & RECHARGES & INACTIVE & GROUND & WATER & $\star \star \star$ \\
\hline IMPLND & 96 & IWATER & SURO & 0.260 & $\begin{array}{l}\text { DRAINS TO } \\
\text { RECHARG }\end{array}$ & $\begin{array}{l}\text { ADJACENT } \\
\text { GES INACT }\end{array}$ & $\begin{array}{l}\text { PERLND } \\
\text { IVE GROU }\end{array}$ & $\begin{array}{l}\text { AND THEN } \\
\text { UND WATER }\end{array}$ & $\begin{array}{l}\star \star \star \\
\star \star \star\end{array}$ \\
\hline
\end{tabular}


Table 19.--Input sequence of the Woodland Creek model used to run Hydrological Simulation Program-FORTRAN (HSPF)--Continued

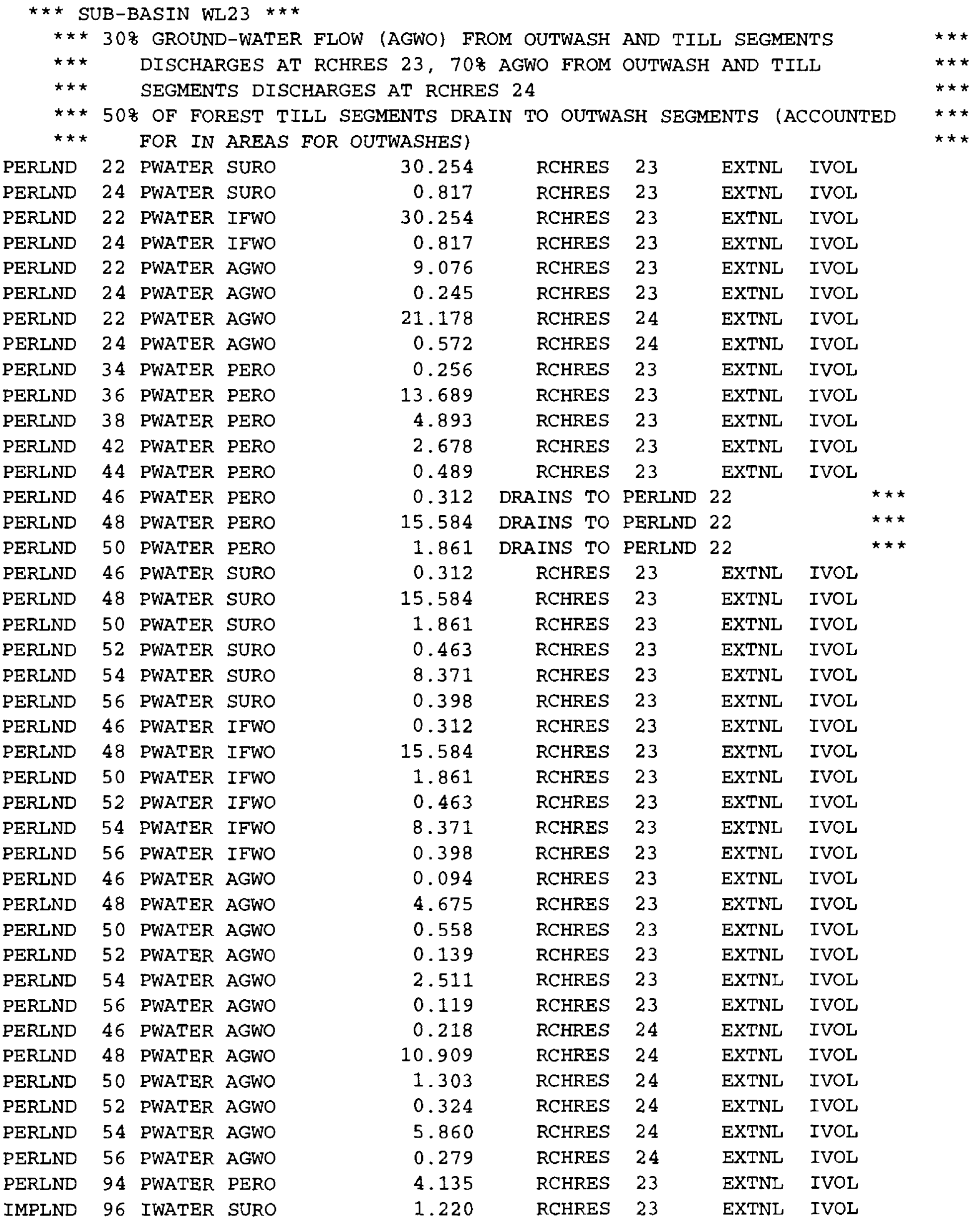


Table 19.--Input sequence of the Woodland creek model used to run Hydrological Simulation Program-FORTRAN (HSPF)--Continued

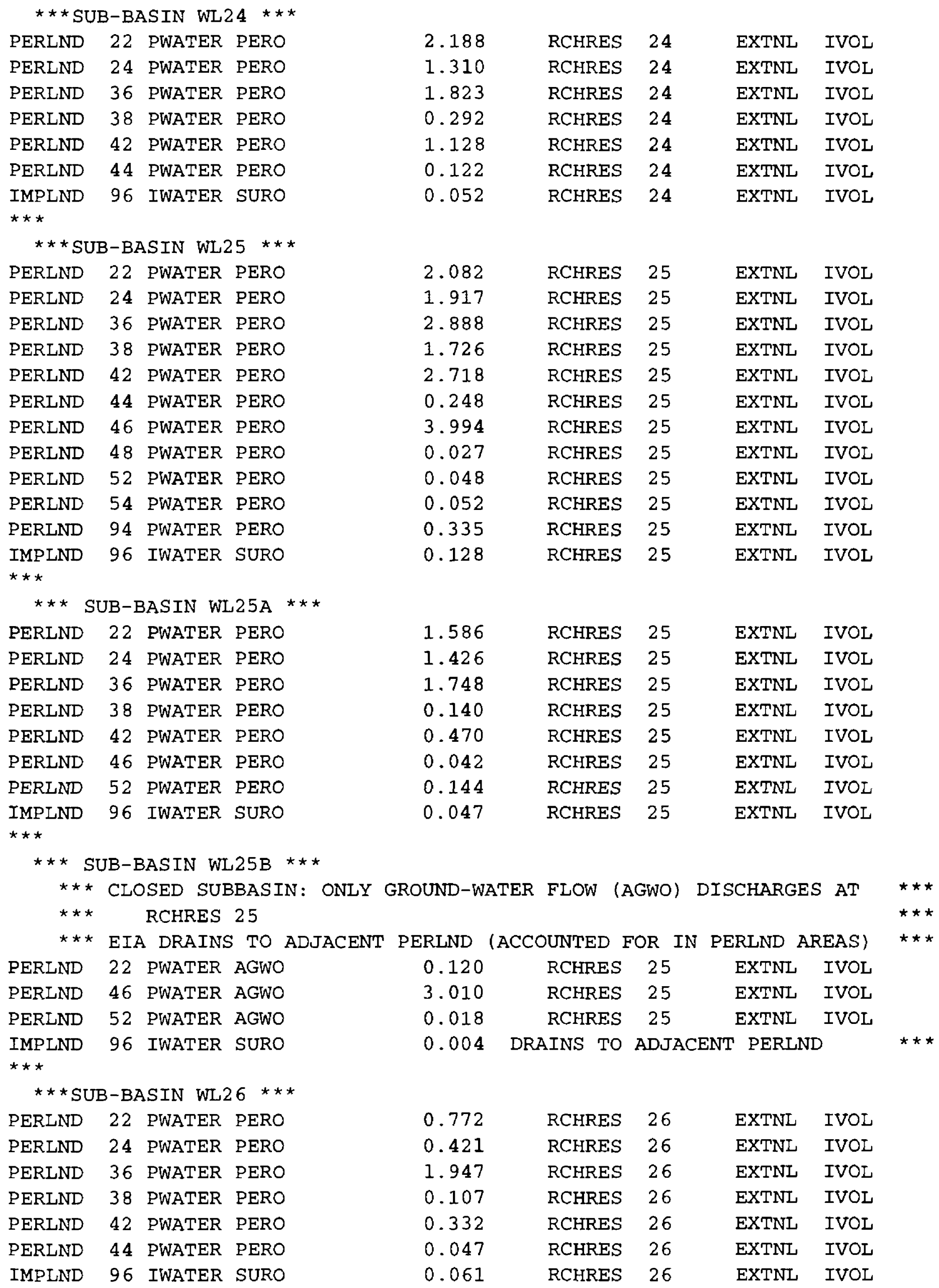


Table 19.--Input sequence of the woodland Creek model used to run Hydrological Simulation Program-FORTRAN (HSPF)--Continued

\begin{tabular}{lrlrllll}
\multicolumn{2}{c}{$*$ SUB-BASIN WL27 *** } & & & & & \\
PERLND & 22 & PWATER PERO & 3.158 & RCHRES & 27 & EXTNL & IVOL \\
PERLND & 24 & PWATER PERO & 6.994 & RCHRES & 27 & EXTNL & IVOL \\
PERLND & 34 & PWATER PERO & 0.453 & RCHRES & 27 & EXTNL & IVOL \\
PERLND & 36 & PWATER PERO & 17.274 & RCHRES & 27 & EXTNL & IVOL \\
PERLND & 38 & PWATER PERO & 7.886 & RCHRES & 27 & EXTNL & IVOL \\
PERLND & 40 & PWATER PERO & 0.451 & RCHRES & 27 & EXTNL & IVOL \\
PERLND & 42 & PWATER PERO & 21.480 & RCHRES & 27 & EXTNL & IVOL \\
PERLND & 44 & PWATER PERO & 1.040 & RCHRES & 27 & EXTNL & IVOL \\
PERLND & 46 & PWATER PERO & 9.001 & RCHRES & 27 & EXTNL & IVOL \\
PERLND & 48 & PWATER PERO & 8.805 & RCHRES & 27 & EXTNL IVOL \\
PERLND & 50 & PWATER PERO & 1.408 & RCHRES & 27 & EXTNL IVOL \\
PERLND & 52 & PWATER PERO & 1.008 & RCHRES & 27 & EXTNL IVOL \\
PERLND & 54 & PWATER PERO & 6.205 & RCHRES & 27 & EXTNL IVOL \\
PERLND & 56 & PWATER PERO & 0.922 & RCHRES & 27 & EXTNL & IVOL \\
PERLND & 94 & PWATER PERO & 6.515 & RCHRES & 27 & EXTNL & IVOL \\
IMPLND & 96 & IWATER SURO & 1.874 & RCHRES & 27 & EXTNL & IVOL
\end{tabular}

$\begin{array}{lrll}\text { RCHRES } & 4 & \text { EXTNL } & \text { IVOL } \\ \text { RCHRES } & 5 & \text { EXTNL } & \text { IVOL } \\ \text { RCHRES } & 6 & \text { EXTNL } & \text { IVOL } \\ \text { RCHRES } & 6 & \text { EXTNL } & \text { IVOL } \\ \text { RCHRES } & 8 & \text { EXTNL } & \text { IVOL } \\ \text { RCHRES } & 10 & \text { EXTNL } & \text { IVOL } \\ \text { RCHRES } & 10 & \text { EXTNL } & \text { IVOL } \\ \text { RCHRES } & 17 & \text { EXTNL } & \text { IVOL } \\ \text { RCHRES } & 17 & \text { EXTNL } & \text { IVOL } \\ \text { RCHRES } & 15 & \text { EXTNL } & \text { IVOL } \\ \text { RCHRES } & 15 & \text { EXTNL } & \text { IVOL } \\ \text { RCHRES } & 17 & \text { EXTNL } & \text { IVOL } \\ \text { RCHRES } & 18 & \text { EXTNL } & \text { IVOL } \\ \text { RCHRES } & 24 & \text { EXTNL } & \text { IVOL } \\ \text { RCHRES } & 21 & \text { EXTNL } & \text { IVOL } \\ \text { RCHRES } & 21 & \text { EXTNL } & \text { IVOL } \\ \text { RCHRES } & 24 & \text { EXTNL } & \text { IVOL } \\ \text { RCHRES } & 24 & \text { EXTNL } & \text { IVOL } \\ \text { RCHRES } & 24 & \text { EXTNL } & \text { IVOL } \\ \text { RCHRES } & 26 & \text { EXTNL } & \text { IVOL } \\ \text { RCHRES } & 27 & \text { EXTNL } & \text { IVOL } \\ \text { RCHRES } & 27 & \text { EXTNL } & \text { IVOL }\end{array}$


Table 19.--Input sequence of the woodland Creek model used to run Hydrologic $\overline{1}$ Simulation Program-FORTRAN (HSPF)--Continued

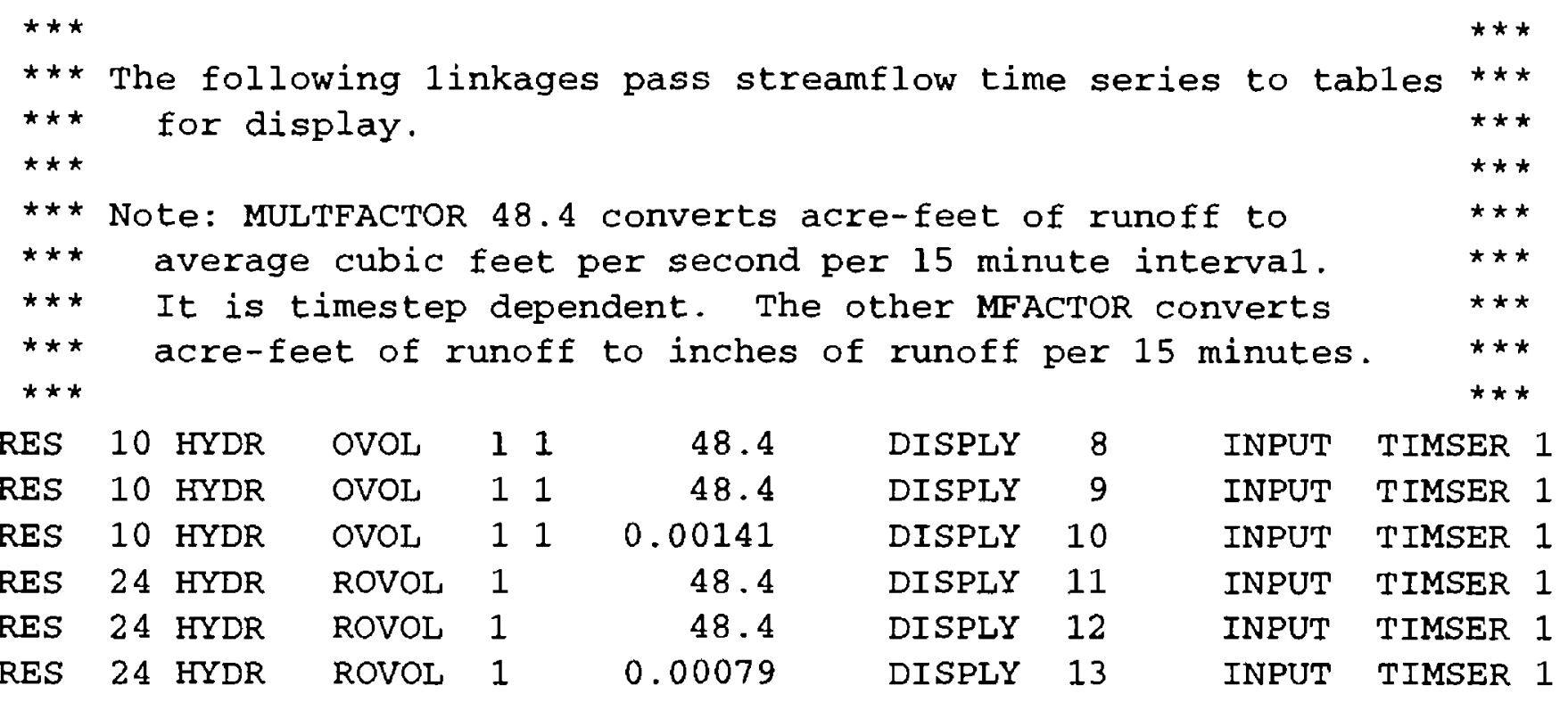

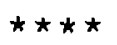

END NETWORK

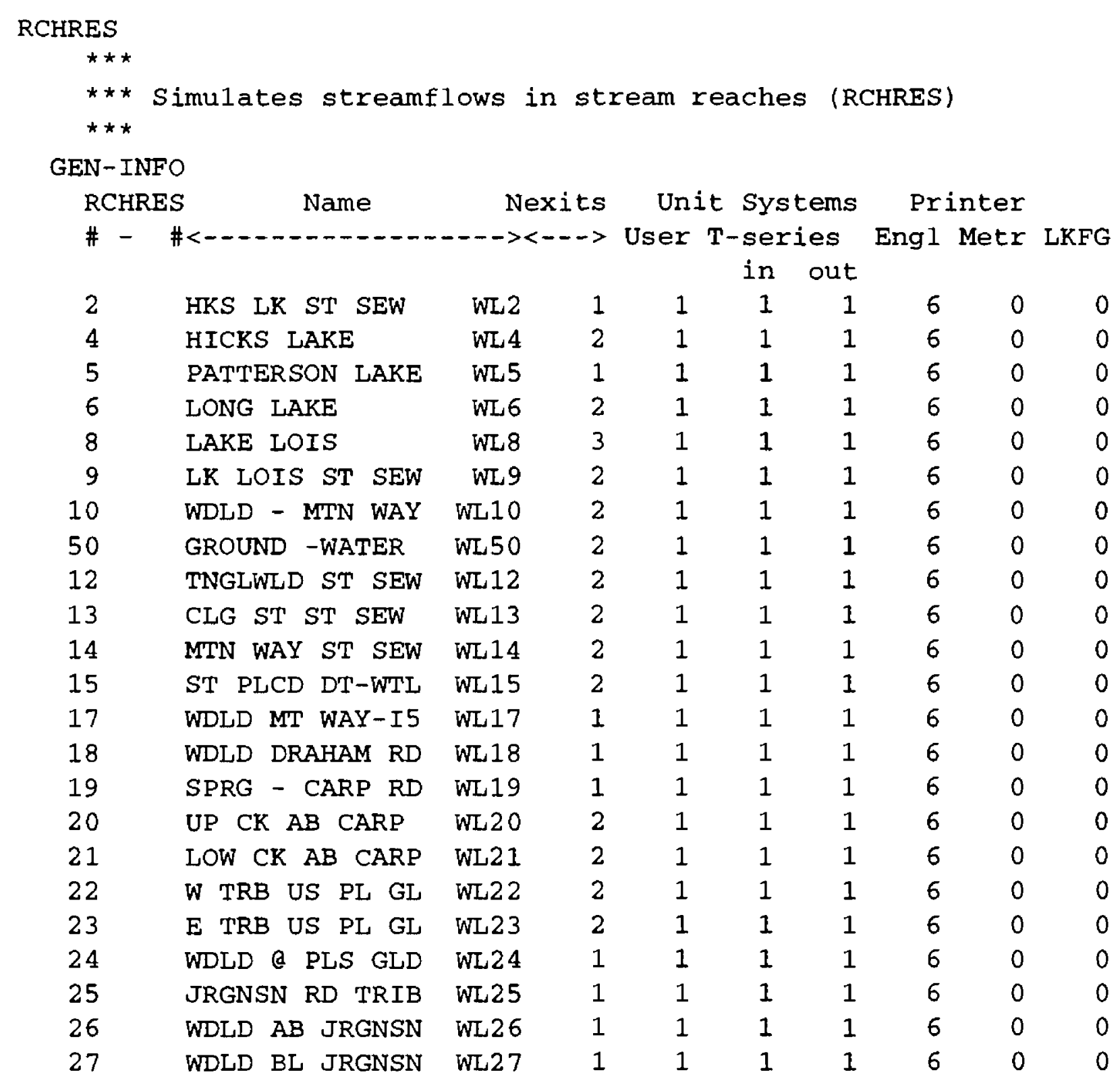


Table 19.--Input sequence of the Woodland Creek model used to run Hydrological Simulation Program-FORTRAN (HSPF)--Continued

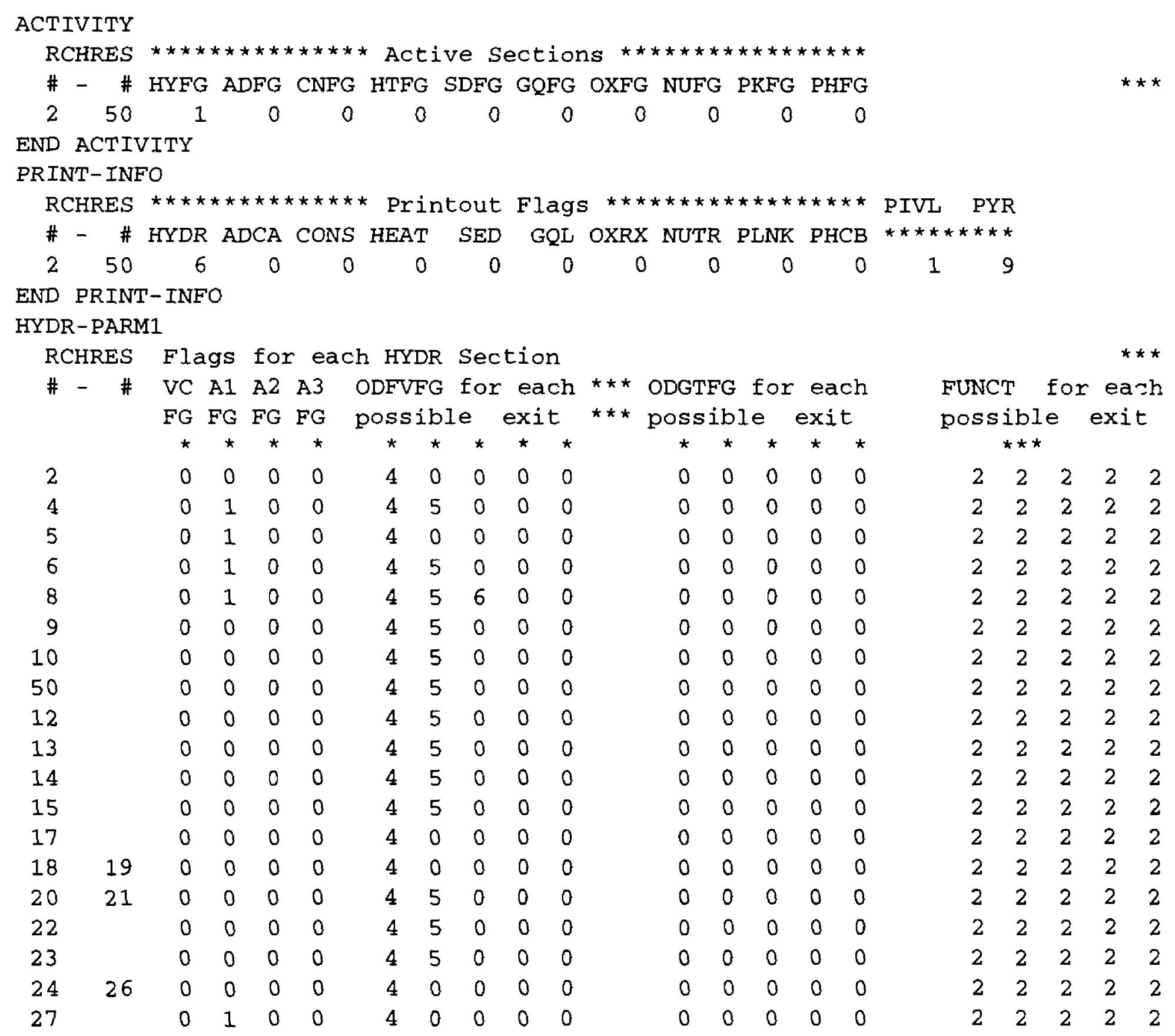

END HYDR-PARM1 
Table 19.--Input sequence of the woodland Creek model used to run Hydrological Simulation Program-FORTRAN (HSPF)--Continued

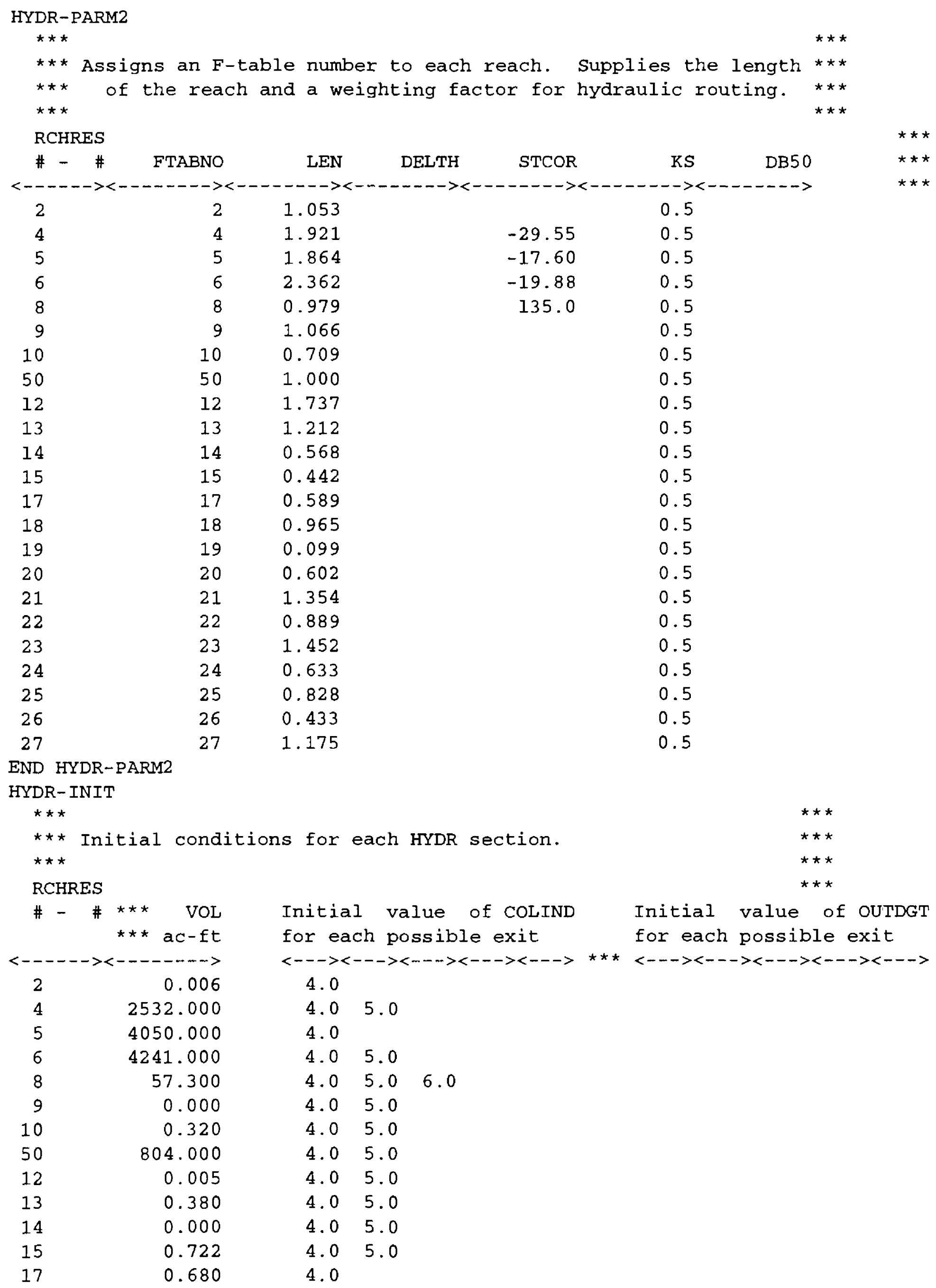


Table 19.--Input sequence of the woodland Creek model used to run Hydrological Simulation Program-FORTRAN (HSPF)--Continued

$\begin{array}{llll}18 & 0.890 & 4.0 & \\ 19 & 0.010 & 4.0 & \\ 20 & 0.100 & 4.0 & 5.0 \\ 21 & 0.150 & 4.0 & 5.0 \\ 22 & 1.000 & 4.0 & 5.0 \\ 23 & 1.500 & 4.0 & 5.0 \\ 24 & 0.920 & 4.0 & \\ 25 & 0.070 & 4.0 & \\ 26 & 0.584 & 4.0 & \\ 27 & 1.810 & 4.0 & \end{array}$

END HYDR-INIT

END RCHRES

FTABLES

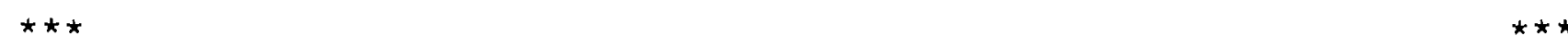

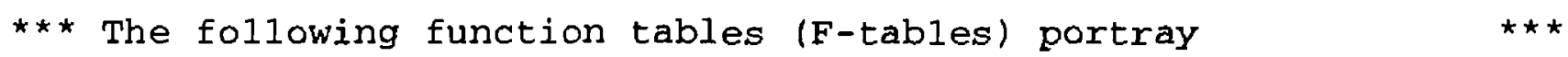

$\star \star \star$ relationships between volume and outflow, and in some $\star * \star$

$\star \star \star$ cases area (for lakes) for the defined channel reaches. $* \star \star$

$\star \star \star$ The columns for volume and outflow are used for routing $\star \star \star$

$\star * *$ streamflow from reach to reach. For reaches that $* * *$

$\star \star \star$ represent streams, only the volume-outflow $\quad * \star *$

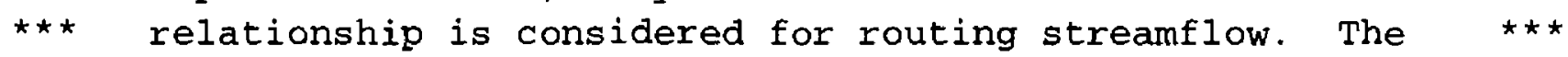

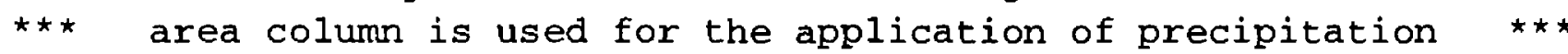

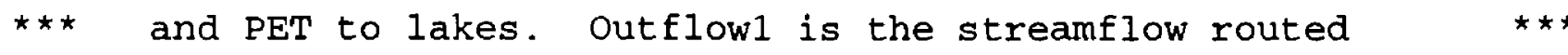

$\star \star \star$ from one reach to another reach, and other outflows $* \star \star$

$\star \star \star$ represent either channel losses from seepage or flow that $\star * \star$

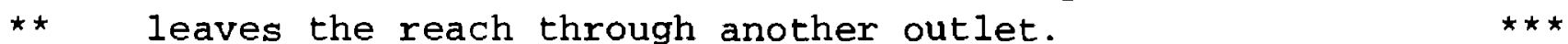

$\star \star \star$

FTABLE 2

$\star \star \star$ Drains subbasin WL2. Reach consists of storm sewer and $\star \star \star$

$\star \star \star$ a smal1 channel system within WL2.

Rows Cols

94

Depth

(ft)

$\begin{array}{rrr}\text { Area } & \text { Volume } & \text { Outflowl } \\ \text { (acres) } & \text { (acre-ft) } & \text { (cfs) }\end{array}$

$0.0 \quad 0.0 \quad 0.0 \quad 0.0$

$\begin{array}{llll}0.2 & 0.0 & 0.05 & 0.88\end{array}$

$\begin{array}{llll}0.6 & 0.0 & 0.20 & 7.59\end{array}$

$\begin{array}{llll}1.0 & 0.0 & 0.37 & 16.56\end{array}$

$\begin{array}{llll}1.4 & 0.0 & 0.57 & 30.48\end{array}$

$\begin{array}{llll}2.0 & 0.0 & 0.77 & 42.58\end{array}$

$\begin{array}{llll}2.5 & 0.0 & 2.12 & 55.56\end{array}$

$\begin{array}{llll}3.0 & 0.0 & 5.12 & 56.0\end{array}$

$\begin{array}{llll}4.0 & 0.0 & 12.0 & 56.1\end{array}$

END FTABLE 2 
Table 19.--Input sequence of the Woodland Creek model used to run Hydrologicâl Simulation Program-FORTRAN (HSPF)--Continued

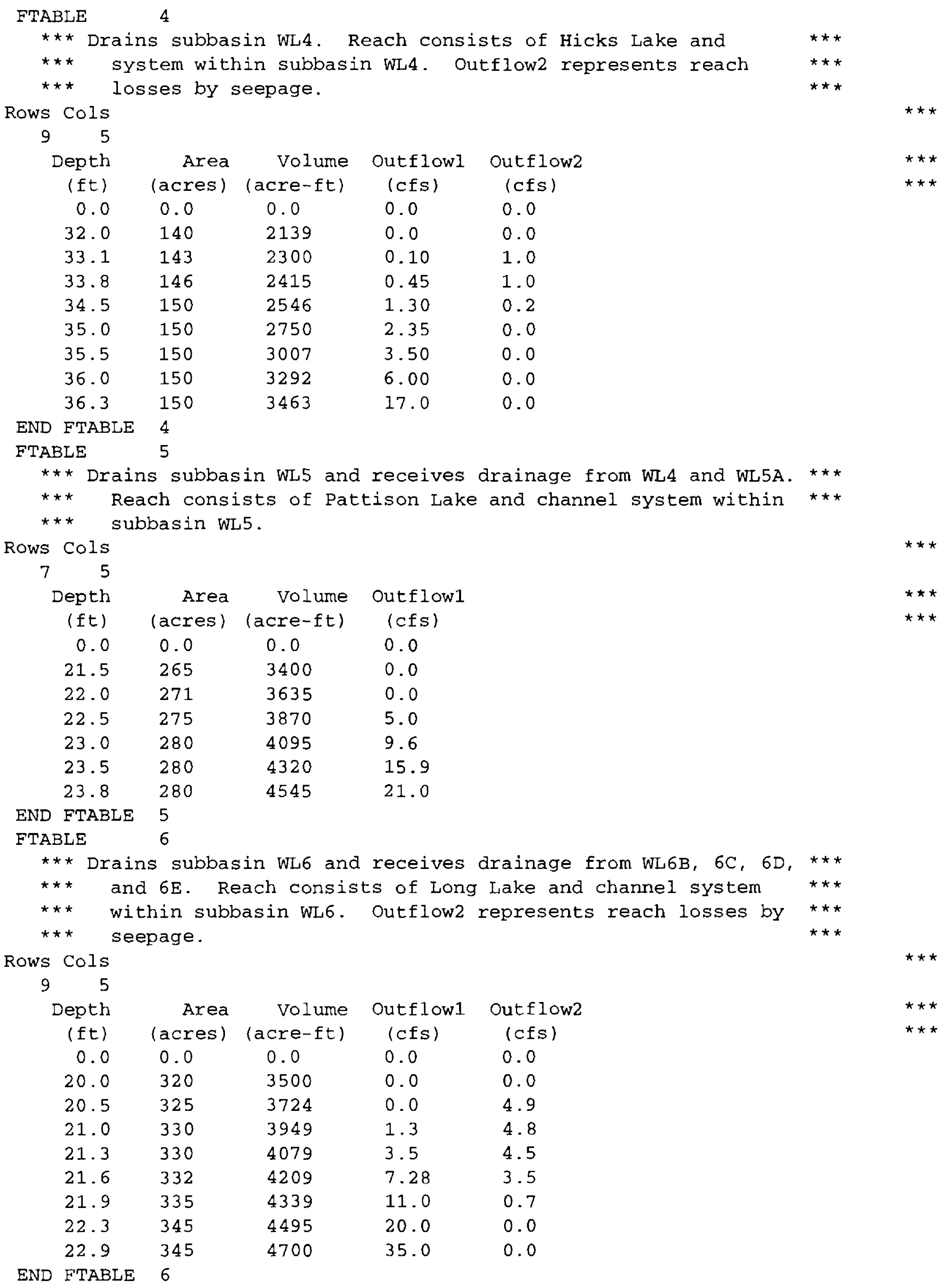


Table 19.-- Input sequence of the Woodland Creek model used to run Hydrological Simulation Program-FORTRAN (HSPF)--Continued

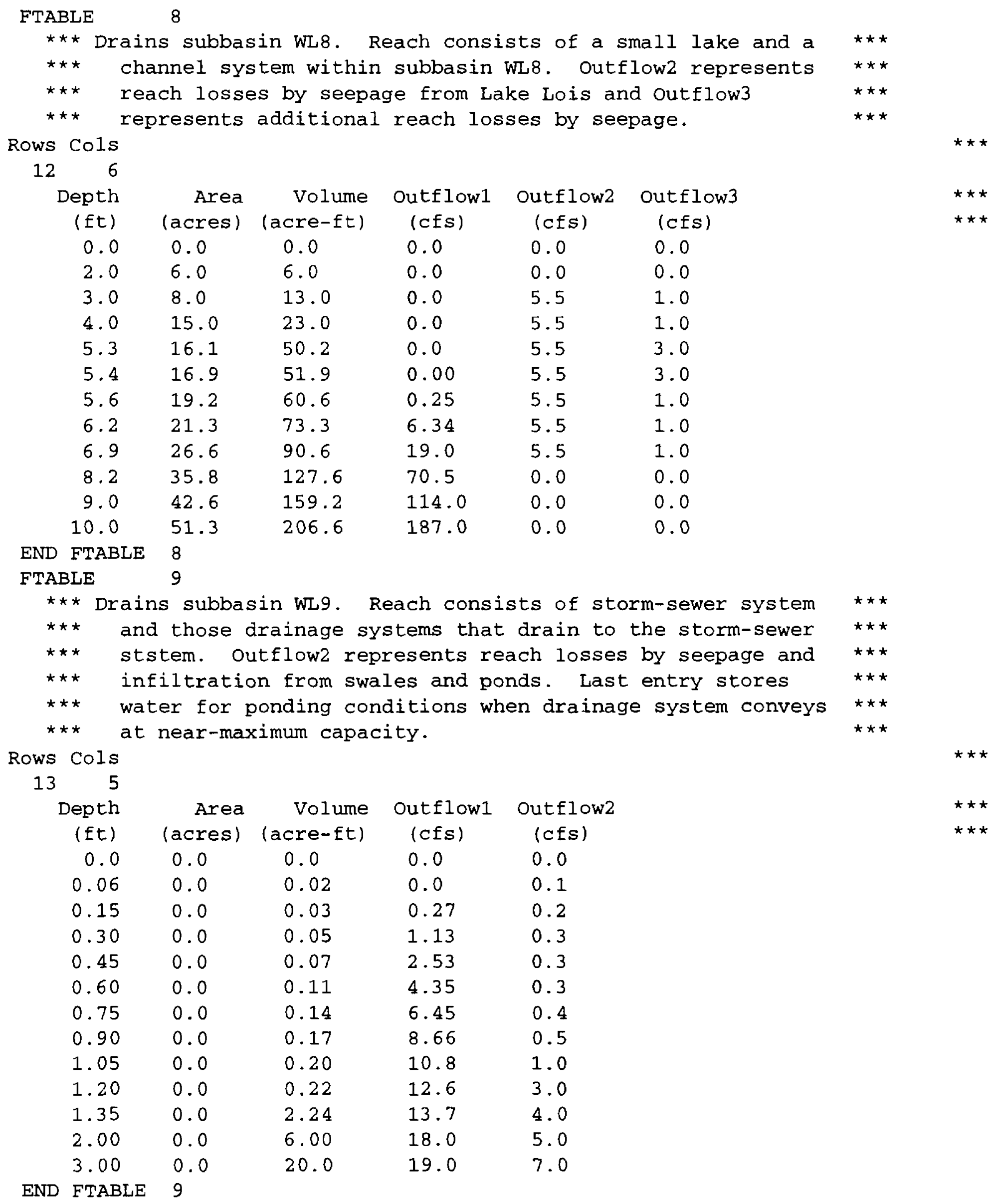


Table 19.--Input sequence of the Woodland Creek model used to run Hydrological Simulation Program-FORTRAN (HSPF)--Continued

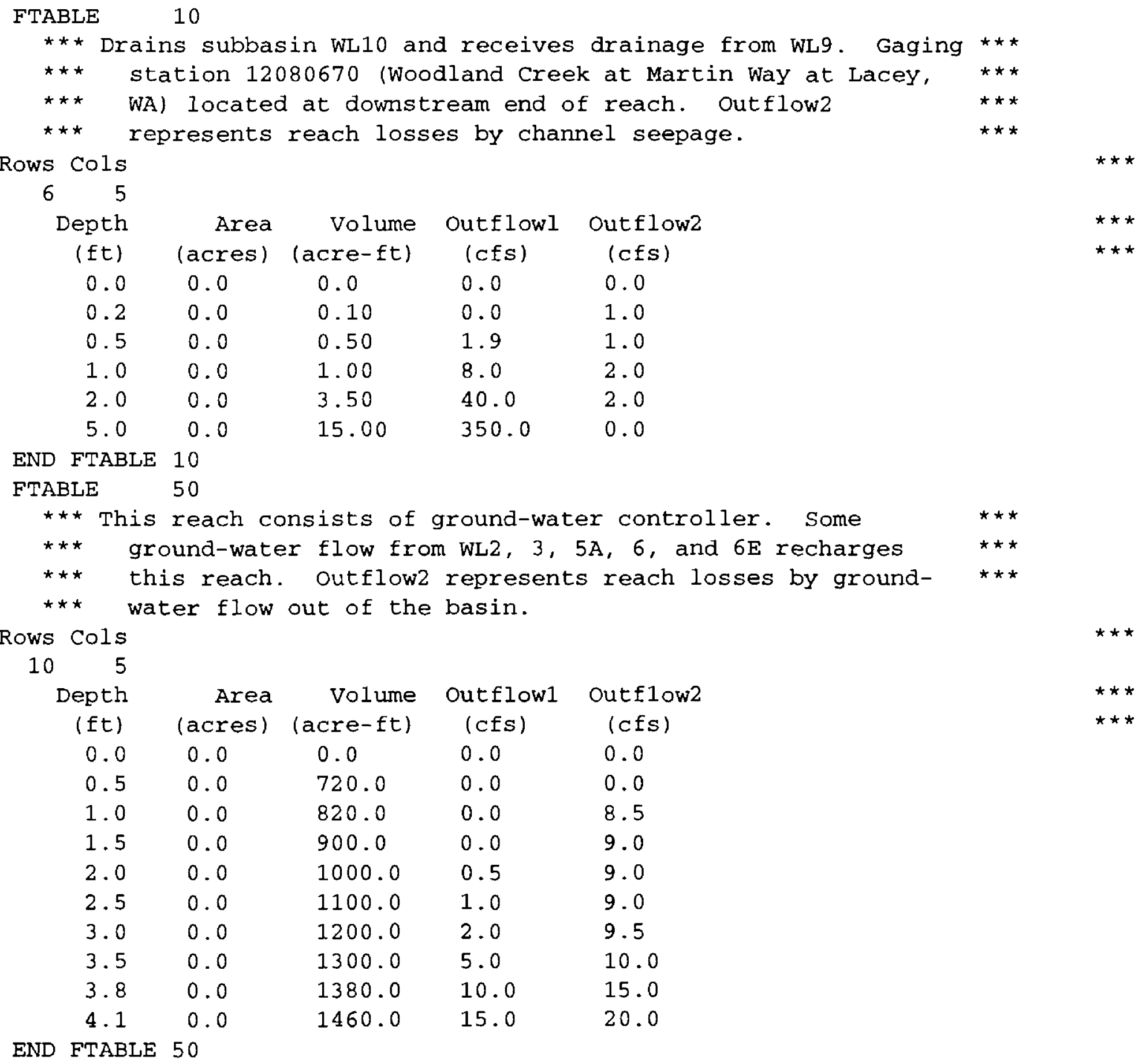


Table 19.--Input sequence of the woodland Creek model used to run Hydrological Simulation Program-FORTRAN (HSPF)--Continued

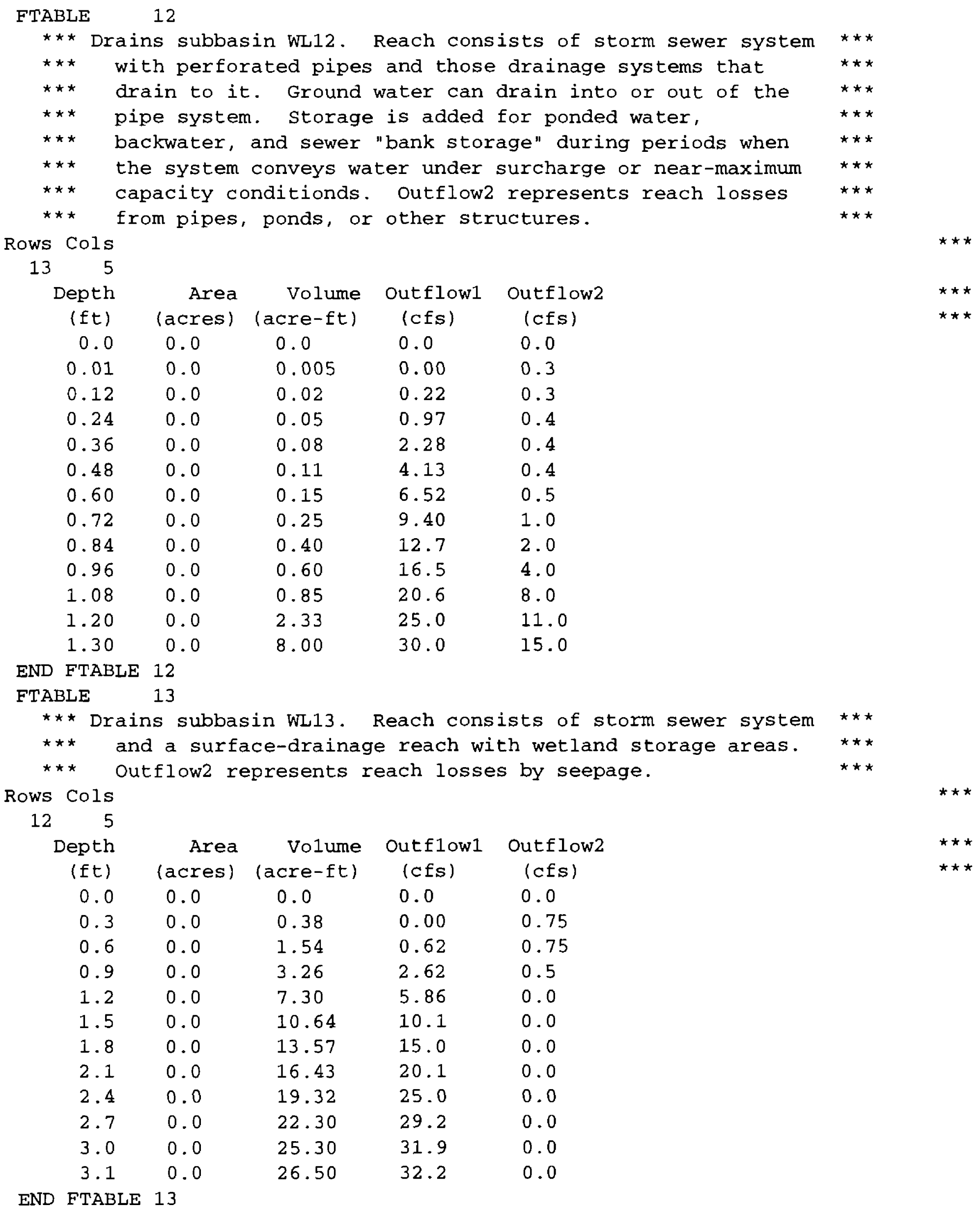


Table 19.--Input sequence of the woodland creek model used to run Hydrological Simulation Program-FORTRAN (HSPF)--Continued

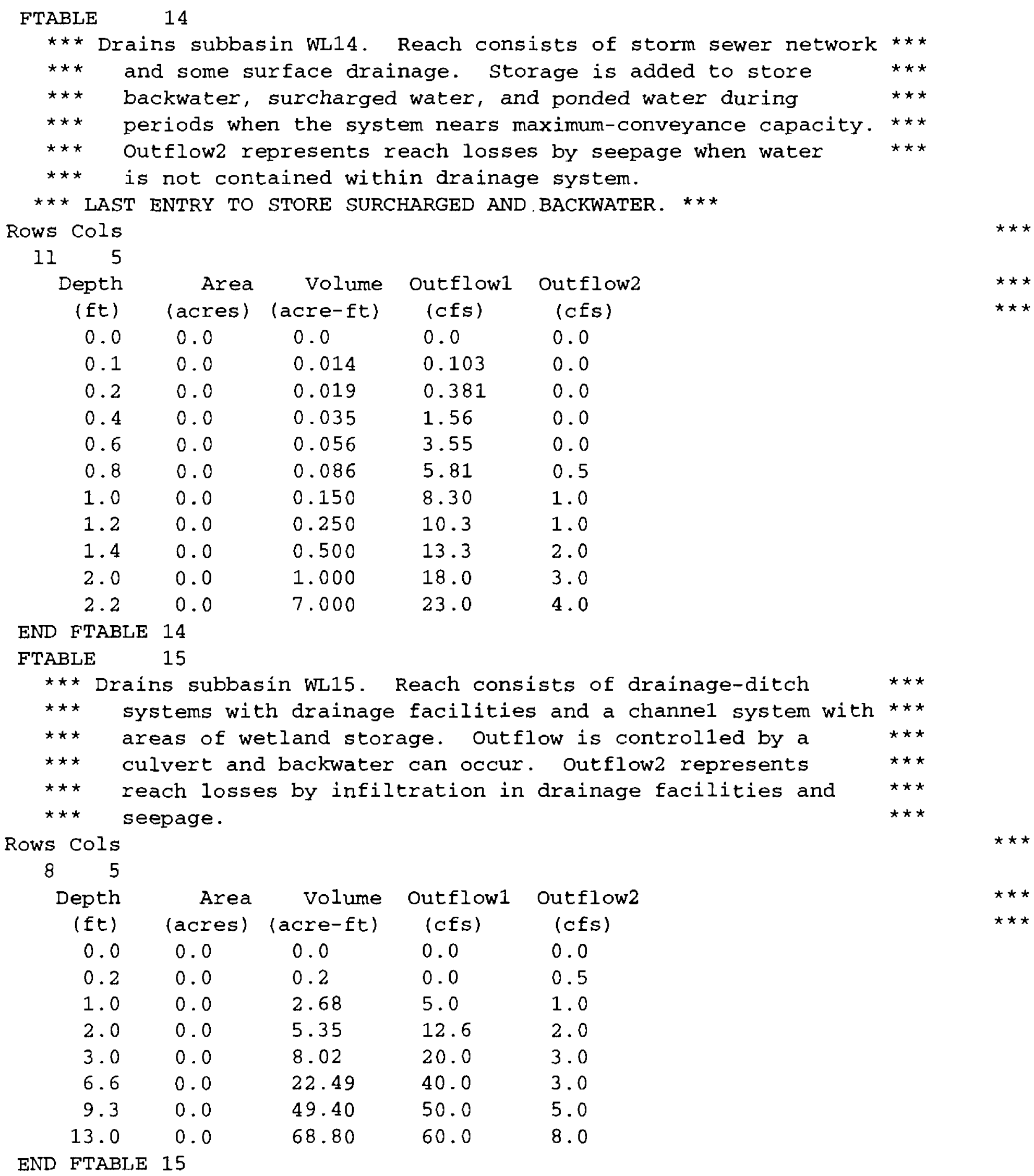


Table 19.--Input sequence of the Woodland Creek model used to run Hydrological Simulation Program-FORTRAN (HSPF)--Continued

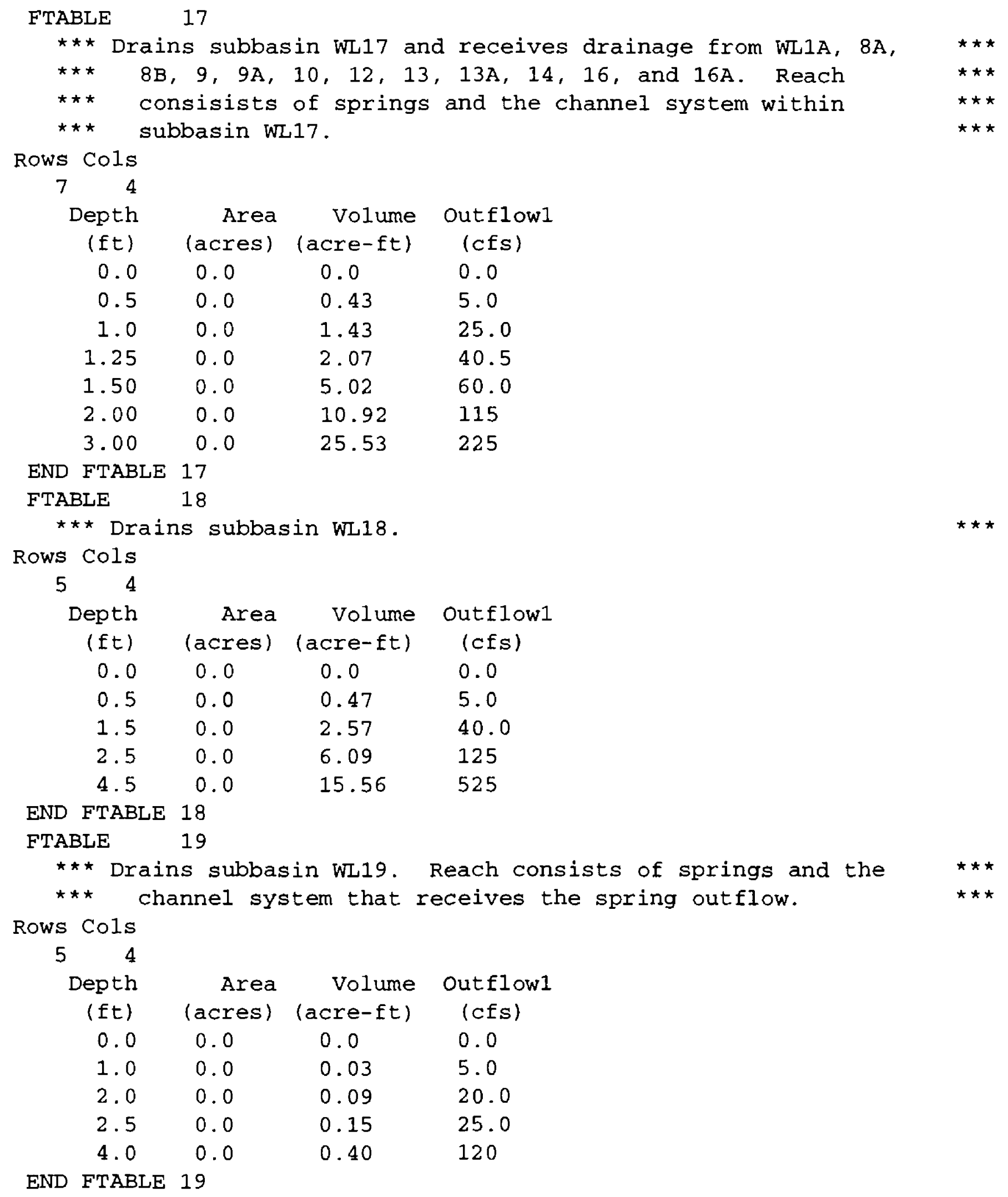


Table 19.--Input sequence of the woodland Creek model used to run Hydrological Simulation Program-FORTRAN (HSPF)--Continued

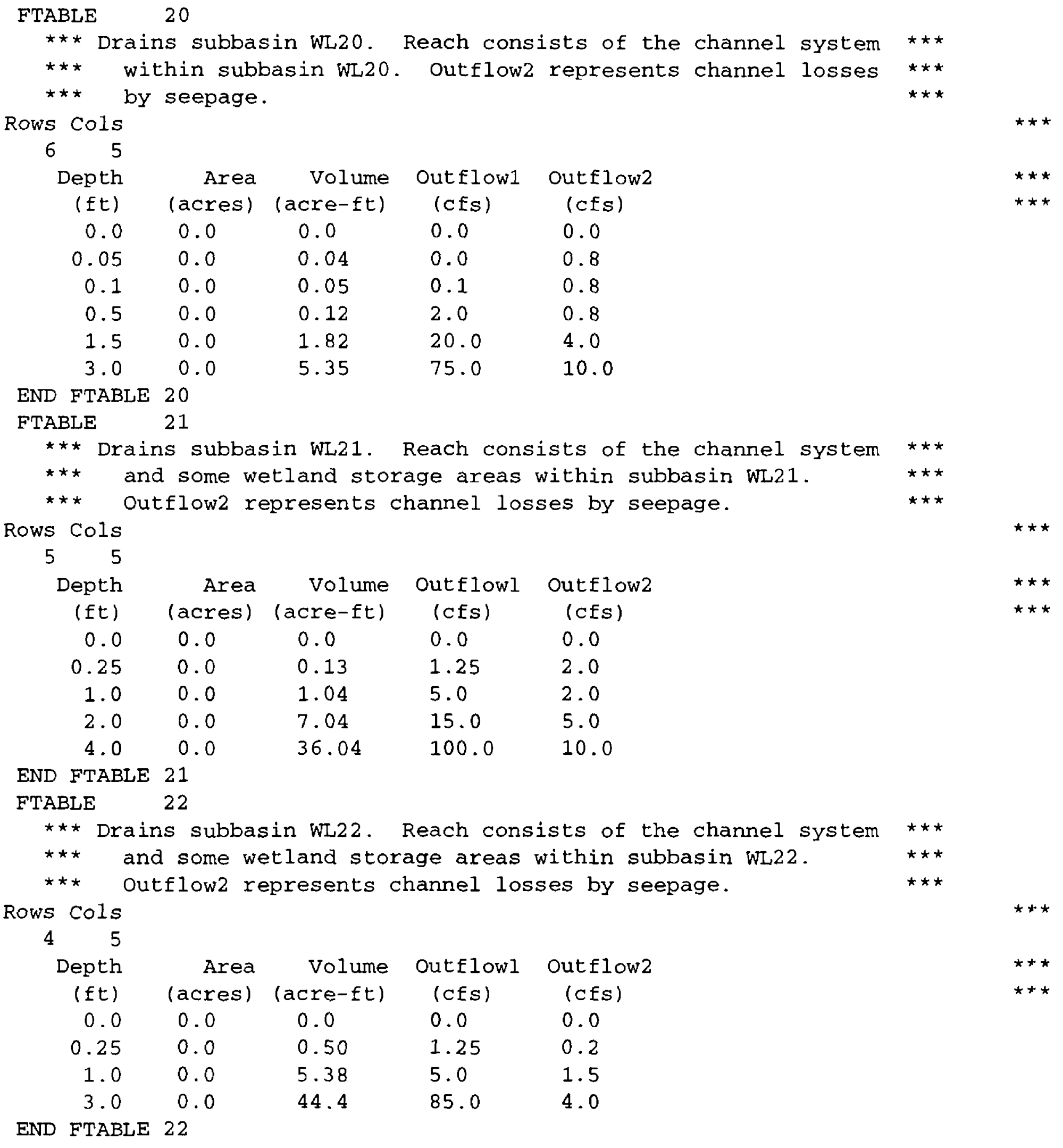


Table 19.--Input sequence of the Woodland Creek model used to run Hydrological Simulation Program-FORTRAN (HSPF)--Continued

\begin{tabular}{|c|c|c|c|c|}
\hline \multicolumn{5}{|l|}{ FTA } \\
\hline $\begin{array}{ll}\star \star \star & \text { Dr } \\
\star \star \star & \\
\star \star \star & \end{array}$ & $\begin{array}{l}\text { ains subba } \\
\text { and some w } \\
\text { outflow2 r }\end{array}$ & $\begin{array}{l}\text { in wL } 23 . \\
\text { tland sto } \\
\text { oresents }\end{array}$ & $\begin{array}{l}\text { each cons } \\
\text { ge areas } \\
\text { lannel los }\end{array}$ & $\begin{array}{l}\text { ists of } \\
\text { within } s \\
\text { ses by } s\end{array}$ \\
\hline \multicolumn{5}{|l|}{ Rows Cols } \\
\hline 5 & & & & \\
\hline $\begin{array}{l}\text { Depth } \\
\text { (ft) }\end{array}$ & $\begin{array}{r}\text { Area } \\
\text { (acres) }\end{array}$ & $\begin{array}{r}\text { Volume } \\
\text { (acre-ft) }\end{array}$ & $\begin{array}{l}\text { Outflow1 } \\
\text { (cfs) }\end{array}$ & $\begin{array}{c}\text { Outflow2 } \\
\text { (cfs) }\end{array}$ \\
\hline 0.0 & 0.0 & 0.0 & 0.0 & 0.0 \\
\hline 1.0 & 0.0 & 0.25 & 0.0 & 0.0 \\
\hline 1.25 & 0.0 & 0.41 & 0.25 & 0.5 \\
\hline 1.5 & 0.0 & 0.63 & 0.60 & 0.7 \\
\hline 2.0 & 0.0 & 1.38 & 2.00 & 1.0 \\
\hline 3.0 & 0.0 & 5.38 & 15.0 & 2.0 \\
\hline 3.5 & 0.0 & 8.88 & 38.0 & 4.0 \\
\hline 4.0 & 0.0 & 14.1 & 60.0 & 8.0 \\
\hline 5.0 & 0.0 & 39.1 & 90.0 & 16.0 \\
\hline
\end{tabular}

END FTABLE 23

FTABLE 24

*** Drains subbasin WL24 and receives drainage from WL21, 22, ***

$* \star *$ and 23. Gaging station 12081000 (Woodland Creek near $* \star *$

$\star * *$ Olympia, WA located at downstream end of the reach.

Rows Cols

54

Depth Area Volume outflow1

(ft) (acres) (acre-ft) (cfs)

$0.0 \quad 0.0 \quad 0.0 \quad 0.0$

$\begin{array}{llll}1.0 & 0.0 & 1.23 & 20.0\end{array}$

$\begin{array}{llll}3.0 & 0.0 & 4.99 & 120\end{array}$

$\begin{array}{llll}3.1 & 0.0 & 5.30 & 125\end{array}$

$\begin{array}{llll}6.0 & 0.0 & 15.1 & 350\end{array}$

END FTABLE 24

FTABLE 25

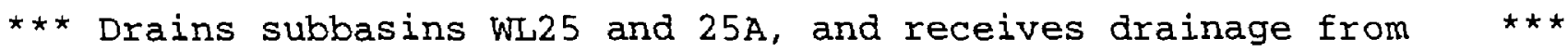

$* * *$ subbasin WL25B. Crest-stage gage 12081010 (Woodland Creek $* * *$

*** Tributary at Jorgenson Road near Olympia, WA) is located ***

$\star \star *$ at the lower end of the reach.

Rows Cols

44

Depth Area Volume Outflow1

(ft) (acres) (acre-ft) (cfs)

$\begin{array}{llll}0.0 & 0.0 & 0.0 & 0.0\end{array}$

$\begin{array}{llll}0.5 & 0.0 & 0.20 & 2.0\end{array}$

$\begin{array}{llll}1.5 & 0.0 & 0.80 & 10.0\end{array}$

$\begin{array}{llll}4.5 & 0.0 & 5.12 & 80.0\end{array}$

END FTABLE 25 
